Florida International University FIU Digital Commons

$11-7-2012$

\title{
Ecosystem structure in disturbed and restored subtropical seagrass meadows
}

Amanda Bourque

Florida International University, amandasbourque@gmail.com

DOI: $10.25148 /$ etd.FI12120601

Follow this and additional works at: https://digitalcommons.fiu.edu/etd

\section{Recommended Citation}

Bourque, Amanda, "Ecosystem structure in disturbed and restored subtropical seagrass meadows" (2012). FIU Electronic Theses and Dissertations. 792.

https://digitalcommons.fiu.edu/etd/792 


\title{
FLORIDA INTERNATIONAL UNIVERSITY
}

Miami, Florida

\section{ECOSYSTEM STRUCTURE IN DISTURBED AND RESTORED SUBTROPICAL SEAGRASS MEADOWS}

\author{
A dissertation submitted in partial fulfillment of the \\ requirements for the degree of \\ DOCTOR OF PHILOSOPHY \\ in \\ BIOLOGY \\ by
}

Amanda Sarah Bourque

2012 
To: Dean Kenneth G. Furton

College of Arts and Sciences

This dissertation, written by Amanda Sarah Bourque, and entitled Ecosystem Structure in Disturbed and Restored Subtropical Seagrass Meadows, having been approved in respect to style and intellectual content, is referred to you for judgment.

We have read this dissertation and recommend that it be approved.

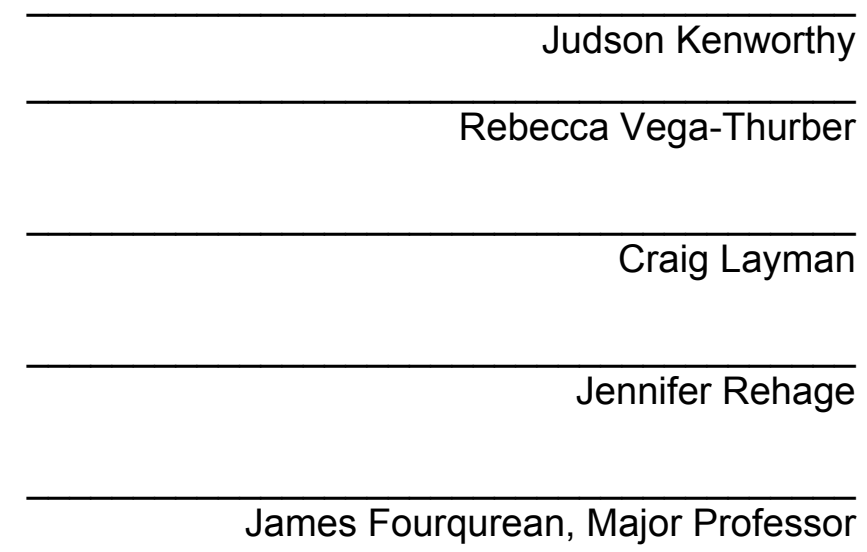

Date of Defense: November 7, 2012

The dissertation of Amanda Sarah Bourque is approved.

Dean Kenneth G. Furton

College of Arts and Sciences

Dean Lakshmi N. Reddi

University Graduate School

Florida International University, 2012 


\section{ACKNOWLEDGMENTS}

I would like to acknowledge my academic committee members for their support. I thank my major advisor, Dr. James Fourqurean, who agreed to take me on as a nontraditional student, and who has provided me with steady guidance and direction that has greatly contributed to the development of my subject matter knowledge, analytical proficiency, and effective communication skills. Dr. Judson Kenworthy shared his career-long accumulation of knowledge on seagrass ecology and restoration, as well as the shared perspective of an agency scientist who also pursued a mid-career doctoral degree. Dr. Craig Layman helped me apply ecological theory to my work in restoration, and provided practical advice on navigating the degree process. Dr. Rebecca VegaThurber enabled me to develop my fledgling interest in molecular ecology by supporting the study of microbial communities at my project sites. Dr. Jennifer Rehage helped me to define and focus my ideas, and provided encouraged me to achieve ambitious goals. In addition to my committee members, I thank Dr. DeEtta Mills, a great mentor and role model. I am also grateful to the National Park Service, Biscayne National Park, for allowing me the flexibility to pursue my coursework and for logistical support.

Funding assistance was received from the National Park Service Albright-Wirth Grant and by the Kelly Foundation Tropical Botany Scholarship.

Several people were instrumental in helping me complete this project:

From the National Park Service: M. Tongue, E. McGrath, C. Johnson, A. Palmer, K. Slattery, D. Crossett, and J. Martens assisted with fieldwork and sample processing. From Florida International University: P. Parker, J. Drake, A. Perez, G. Puig-Santana, R. Decker, E. Lacey, J. Sweatman, S. Halun, S. Rosales, A. Simoes-Correa, M. Cuvelier, and R. Welsh were helpful in providing laboratory support and advice. 


\section{DEDICATION}

For my mother, Jean. 


\title{
ABSTRACT OF THE DISSERTATION
}

\section{ECOSYSTEM STRUCTURE IN DISTURBED AND RESTORED SUBTROPICAL SEAGRASS MEADOWS}

by

\author{
Amanda Sarah Bourque \\ Florida International University, 2012 \\ Miami, Florida \\ Professor James Fourqurean, Major Professor
}

Shallow seagrass ecosystems frequently experience physical disturbance from vessel groundings. Specific restoration methods that modify physical, chemical, and biological aspects of disturbances are used to accelerate recovery. This study evaluated loss and recovery of ecosystem structure in disturbed seagrass meadows through plant and soil properties used as proxies for primary and secondary production, habitat quality, benthic metabolism, remineralization, and nutrient storage and exchange. The efficacy of common seagrass restoration techniques in accelerating recovery was also assessed.

Beyond removal of macrophyte biomass, disturbance to seagrass sediments resulted in loss of organic matter and stored nutrients, and altered microbial and infaunal communities. Evidence of the effectiveness of restoration actions was variable. Fill placement prevented additional erosion, but the resulting sediment matrix had different physical properties, low organic matter content and nutrient pools, reduced benthic metabolism, and less primary and secondary production relative to the undisturbed ecosystem. Fertilization was effective in increasing nitrogen and phosphorus availability in the sediments, but concurrent enhancement of seagrass production was not detected. Seagrass herbivores removed substantial seagrass biomass via direct grazing, 
suggesting that leaf loss to seagrass herbivores is a spatially variable but critically important determinant of seagrass transplanting success.

Convergence of plant and sediment response variables with levels in undisturbed seagrass meadows was not detected via natural recovery of disturbed sites, or through filling and fertilizing restoration sites. However, several indicators of ecosystem development related to primary production and nutrient accumulation suggest that early stages of ecosystem development have begun at these sites. This research suggests that vessel grounding disturbances in seagrass ecosystems create more complex and persistent resource losses than previously understood by resource managers. While the mechanics of implementing common seagrass restoration actions have been successfully developed by the restoration community, expectations of consistent or rapid recovery trajectories following restoration remain elusive. 
CHAPTER II: Plant communities and sediment structure following disturbance and

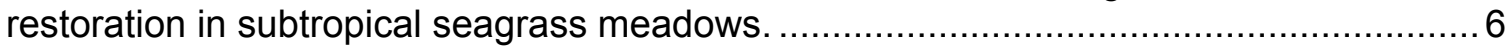

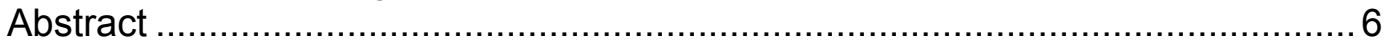

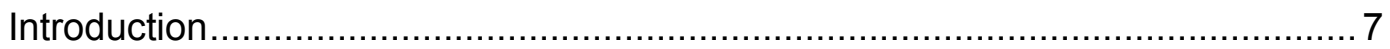

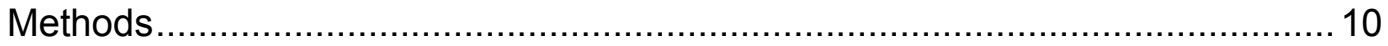

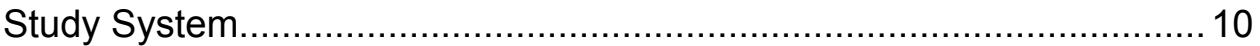

Experimental Design.................................................................. 11

Seagrass Community Characterization ........................................... 12

Sediment Core Collection and Processing ....................................... 12

Data Analysis................................................................................ 14

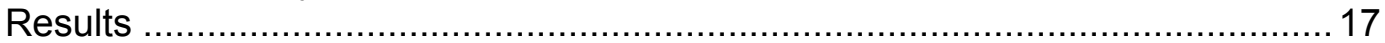

Vessel Grounding Impacts on Macrophytes and Sediment Properties ... 17

Discussion Effects of Restoration on Macrophytes and Sediment Properties ........... 19

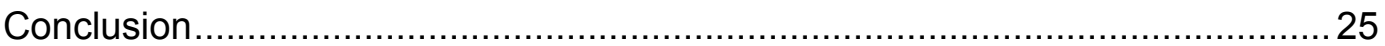

CHAPTER III: Short term effects of restoration on seagrass communities and sediment structure in subtropical seagrass meadows .............................................. 42

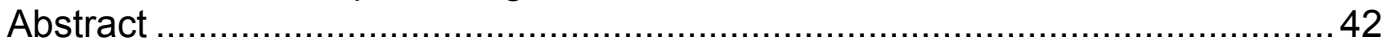

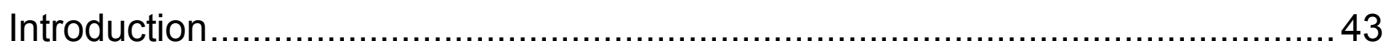

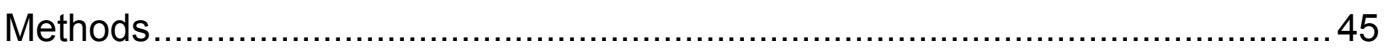

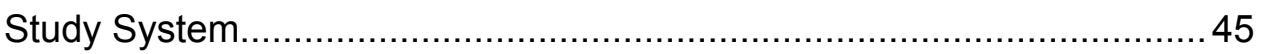

Experimental Design.......................................................... 45

Seagrass Community Characterization ........................................ 46

Sediment Core Collection and Processing ....................................46 46

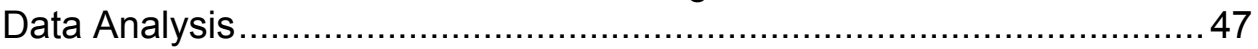

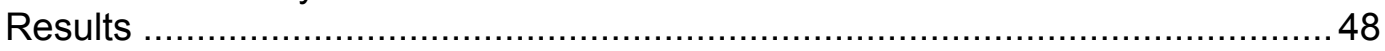

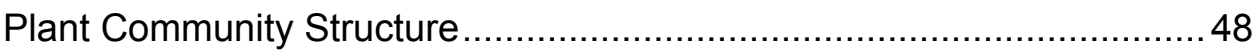

Chlorophyll a Content ................................................................. 49

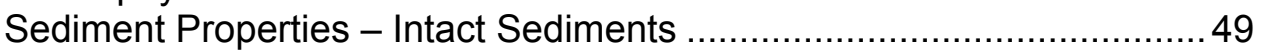

Particle Size Composition ........................................................... 50

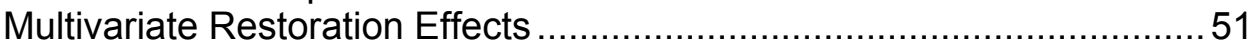

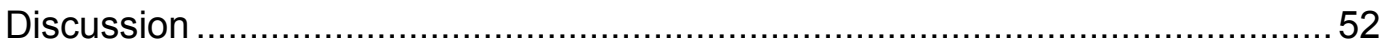

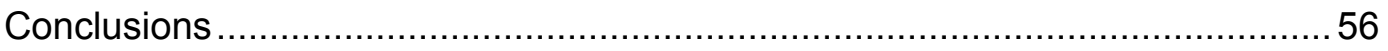

CHAPTER IV: Effects of restoration on microbial community composition in

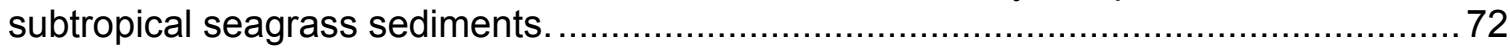

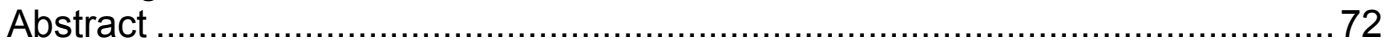

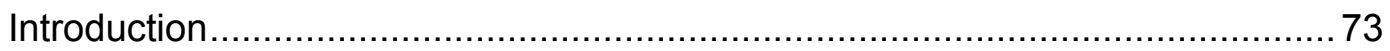

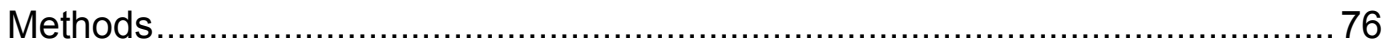

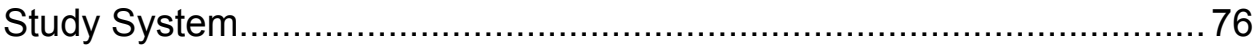

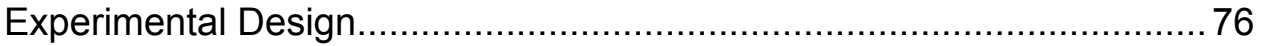

Sediment Core Collection and Processing .......................................... 77

Microbial Community Profiling .......................................................... 77 


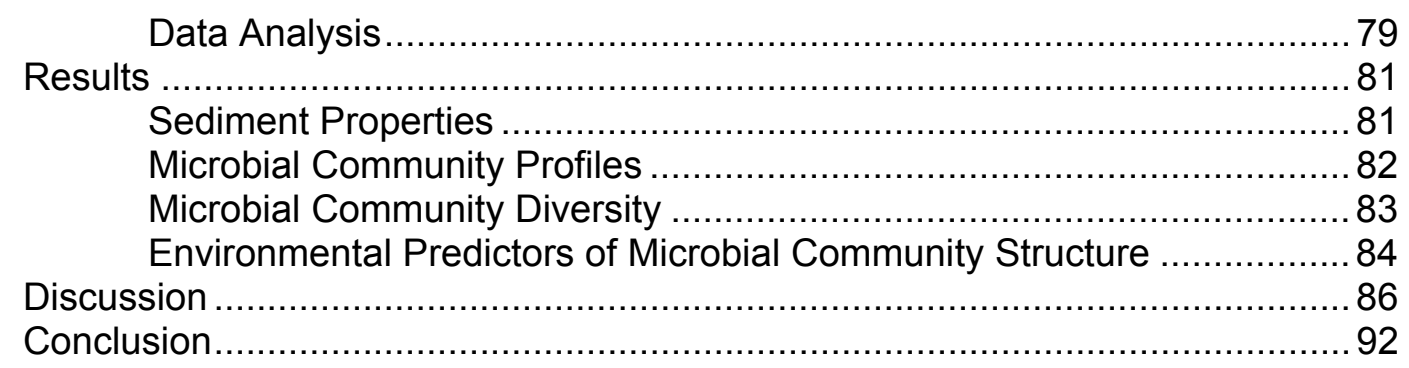

CHAPTER V: Disturbance and restoration effects on macroinvertebrate infaunal community structure in subtropical seagrass sediments........................................103

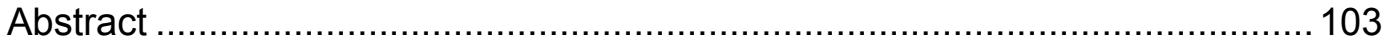

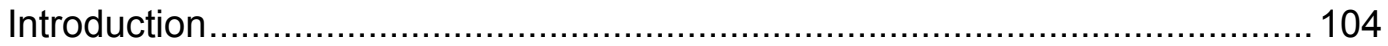

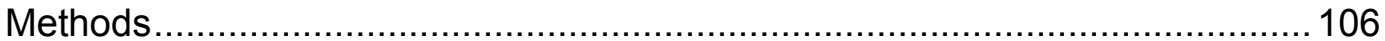

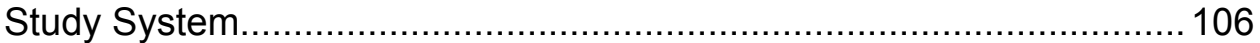

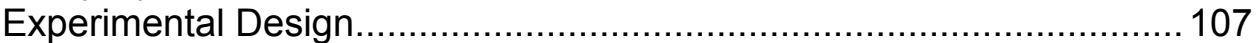

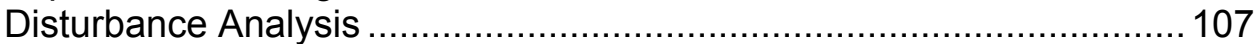

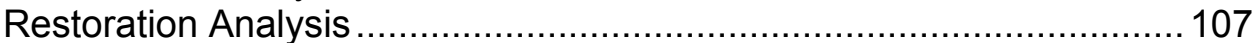

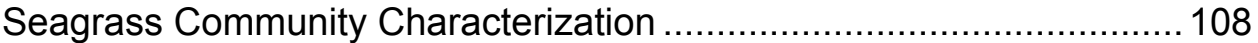

Sediment Core Collection and Processing ………………………...... 108

Infauna Core Collection and Processing ………………………........ 109

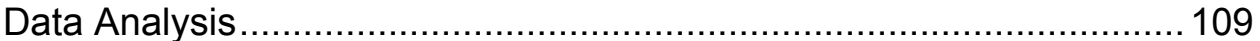

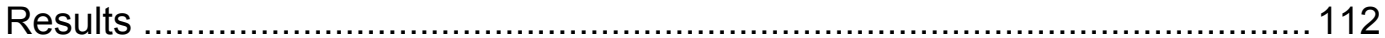

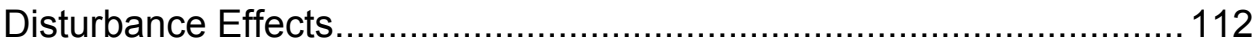

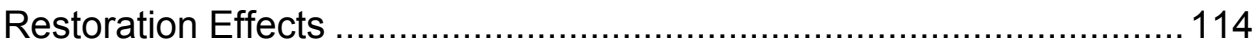

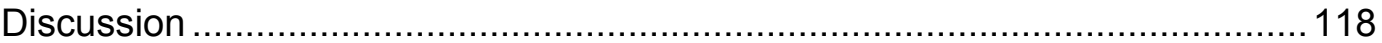

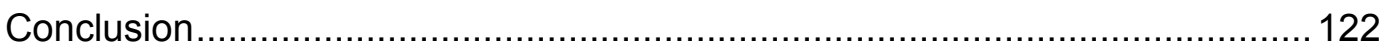

CHAPTER VI: Herbivory in subtropical seagrass ecosystems varies with time,

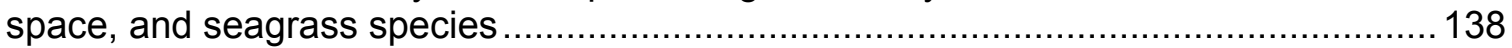

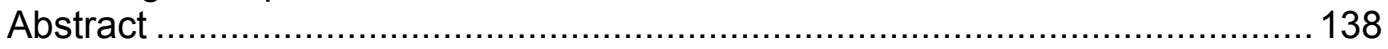

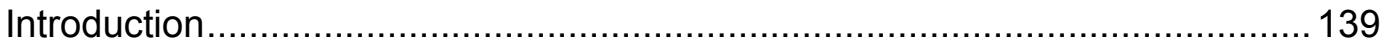

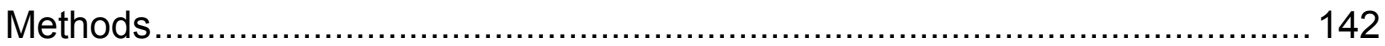

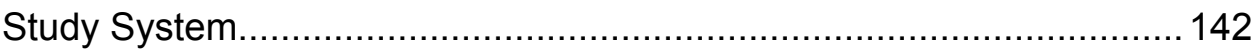

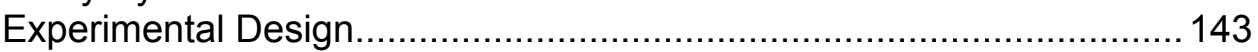

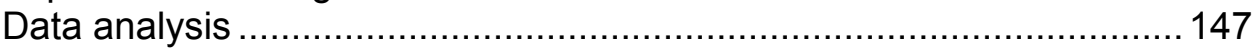

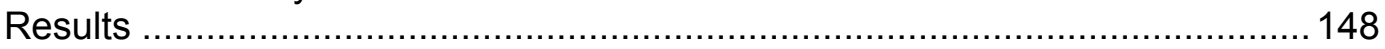

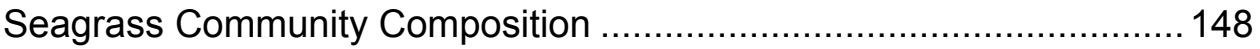

Fish Community Composition …………………………………..... 149

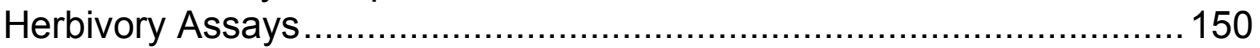

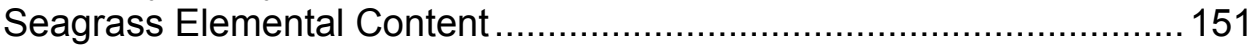

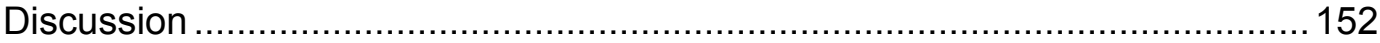

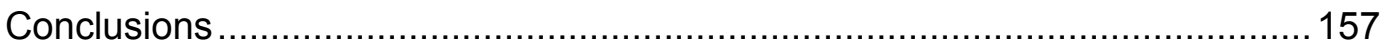

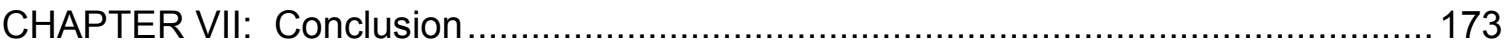

REFERENCES

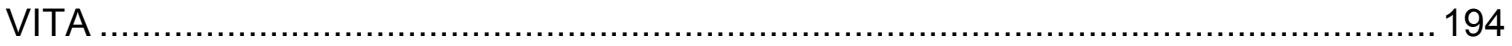




\section{LIST OF TABLES}

TABLE

PAGE

\section{CHAPTER II}

Table 1. Principal components analysis (PCA) eigenvectors for PC axes with eigenvalues $>1.0$ extracted from multivariate data sets of sediment and porewater variables sampled from $7.6 \times 40 \mathrm{~cm}$ cores collected from Grounding sites or from Restoration sites. Restoration treatments included Grounding + Stake, Fill, and Fill +

Stake.

Table 2. Results of PERMANOVA tests of site Status (injury vs. reference) and Time, and pairwise tests of the Disturbance term, on multivariate sediment properties and Principal Component scores representing the sediment organic component (PC1) and porewater inorganic nutrient pools (PC2). Refer to Methods for sediment variables included in analysis.

Table 3. Results of PERMANOVA tests of site Status (restoration vs. reference) and Time, and pairwise tests of significant Status $x$ Time terms, on Principal Component (PC) scores representing sediment organic content (PC1) and porewater inorganic nutrient pools (PC2). Restoration treatments included Grounding + Stake, Fill, and Fill + Stake. Refer to Methods for sediment variables included in analysis.

\section{CHAPTER III}

Table 1. Results of PERMANOVA test of Restoration, Fertilization, and Time, and pairwise tests of the Restoration term, on sediment chlorophyll a concentrations.

Table 2. Results of PERMANOVA test of Restoration, Fertilization, and Time, on sediment particle size classes (percent clay, silt, sand and gravel). Sediment depth as a covariate was not significant and was excluded from the model.

Table 3. Principal components analysis (PCA) eigenvectors for PC axes with eigenvalues $>1.0$ extracted from multivariate data set of sediment and porewater variables sampled from $7.6 \times 40 \mathrm{~cm}$ cores collected from study sites. Treatments included Grounding, Grounding + Stake, Fill, Fill + Stake, Intact + Stake, and Intact sites. See Figure 7 for corresponding PC ordination.

Table 4. Results of PERMANOVA tests of the short-term effects of restoration status (Grounding, Fill, Intact), fertilization (+, -), and time (0 yr, $0.25 \mathrm{yr}, 0.5 \mathrm{yr}, 0.75 \mathrm{yr}, 1 \mathrm{yr}$ ) on multivariate sediment properties and on principal component scores extracted from a Principal Component Analysis of multivariate sediment properties. PC1 is interpreted as sediment OM, and PC2 is interpreted as inorganic porewater nutrients. Pairwise tests were conducted on the Restoration x Fertilization interactions. Refer 
to Methods for sediment variables included in analyses. Sediment Depth was included as a covariate.

\section{CHAPTER IV}

Table 1. Results of PERMANOVA analysis of the effects of restoration treatment and time on multivariate microbial community diversity, with sediment depth as a covariate. Results are also included for PERMANOVA pairwise tests on the Treatment $x$ Time interaction, for levels of the Treatment factor within each time step (middle panel) and of the Time factor within each Treatment (bottom panel). $\mathrm{P}$ values in bold text indicate statistical significance at $\alpha<0.05$.

Table 2. Results of PERMANOVA analysis of the effects of restoration treatment and time on microbial community richness, evenness, diversity, and dominance at the 0 - and $1-y r$ sampling events, with sediment depth as a covariate. $P$ values in bold text indicate statistical significance at $\alpha<0.05$.

Table 3. SIMPER analysis of microbial TRF similarity across restoration treatments....95

Table 4. Multiple partial correlations between dbRDA coordinate axes and environmental variables

Table 5. Pearson correlations between log-transformed diversity metrics calculated from T-RFLP abundance data and environmental variables, sampled at 0-yr and 1-yr post-restoration. Correlations in bold text with one and two asterisks indicate that the correlation is significant at the 0.05 and 0.01 level, respectively.

\section{CHAPTER V}

Table 1. Phylogenetic list of invertebrate taxa and observed frequencies for the disturbance and restoration analyses.

Table 2. Pearson correlations $(r>0.2)$ between invertebrate taxa and principle coordinates analysis (PCO) axes from the PCO ordination (see Figure 2) of samples from vessel grounding sites and intact seagrass sites.

Table 3. Results of PERMANOVA analysis (Disturbance $x$ Age) of the effects of vessel grounding disturbance and time on multivariate infaunal community structure. 126

Table 4. SIMPER analysis results of taxonomic similarity for injury and reference sites in the disturbance analysis and for restoration treatments in the restoration analysis.

Table 5. Pearson correlations $(r>0.2)$ between invertebrate taxa and PCO axes from the PCO ordination (see Figure 4 ) of samples from restoration analysis. 
Table 6. Results of PERMANOVA analyses restoration treatment, fertilization, and age effects on multivariate infauna community structure and univariate diversity metrics. Restoration treatments include Grounding (G), Fill (F), and Intact (I) sites. $P$ values in bold text indicate significance of main effects and interactions at $\alpha=0.05$. Superscript letters indicate significance between levels of factors at $\alpha=0.016$.

Table 7. Multiple partial correlations between the first three dbRDA coordinate axes and environmental variables (see Figure 6) of the best-fit DistLM model. The percent of variation in the DistLM model (fitted) and in the total data set variation is given for each axis.

\section{CHAPTER VI}

Table 1. Median, range, and sample size (number of quadrats) of Braun-Blanquet scores of the undisturbed seagrass community at each herbivory assay site. Species codes: TT $=$ Thalassia testudinum, SF $=\mathrm{S}$. filiforme, $\mathrm{HW}=$ Halodule wrightii. Scale interpretation: $0=$ not present in quadrat, $0.1=$ single occurrence, $0.5=$ few occurrences, $1=<5 \%$ cover, $2=5-25 \%$ cover, $3=25-50 \%$ cover, $4=50$ $75 \%$ cover, $5=75-100 \%$ cover (Fourqurean et al. 2001)

Table 2. Results from Kruskal-Wallis tests of differences in planting unit biomass loss among three seagrass species within site-time pairs. Biomass loss data from the full cage treatment are excluded and data from open and partial cage treatments are pooled.

Table 3. Results from two-way ANOVA and Bonferroni tests $(\alpha=0.05)$ of Time and Species on carbon:nitrogen (C:N, rank-transformed) and carbon:phosphorus (C:P, untransformed) molar ratios in seagrasses from Pelican Shoal, the donor site for herbivory assays.

Table S1. Summary of fish community abundance at the four study sites:

$\mathrm{BC}=$ Biscayne Channel, NN=No Name Shoal, EF=East Featherbed Bank, $\mathrm{CB}=\mathrm{Cutter}$ Bank.

Table S2. Results of independent t-tests of carbon:nitrogen (C:N) and carbon:phosphorus (C:P) molar ratios in seagrass leaves from the donor site (Pelican Shoal) vs. each herbivory assay site (BC = Biscayne Channel, $\mathrm{CB}=$ Cutter Bank, EF = East Featherbed Bank, NN = No Name Shoal) for each species/time pair. 


\section{LIST OF FIGURES}

FIGURE

PAGE

CHAPTER II

Figure 1. Location of study sites in southern Biscayne Bay, Florida, USA, within the boundary of Biscayne National Park.

Figure 2. Mean \pm se seagrass (top) and macroalgae (center) percent cover and chlorophyll a content (bottom) at unrestored grounding sites (dark bars) vs. reference (light bars) sites of five known ages. Asterisks indicate where injury values were significantly lower than reference values for the age group.

Figure 3. Mean \pm se depth profiles for bulk density, $\mathrm{pH}$, Eh, and organic matter content from $7.6 \times 40 \mathrm{~cm}$ cores collected from unrestored grounding sites of known ages (filled symbols) and from adjacent undisturbed reference sites (open symbols).... 34

Figure 4. Mean \pm se depth profiles for sediment nitrogen and phosphorus content and porewater $\mathrm{NH}_{4}{ }^{+}$and SRP concentrations from $7.6 \times 40 \mathrm{~cm}$ cores collected from unrestored grounding sites of known ages (filled symbols) and from adjacent undisturbed reference sites (open symbols)

Figure 5. Mean \pm se organic matter, nitrogen, and phosphorus content in sediments from recent vessel grounding sites and adjacent intact reference sites. Data are from $7.6 \times 40 \mathrm{~cm}$ cores collected from the bottom of injuries that averaged approximately $40 \mathrm{~cm}$ deep (injury cores, closed symbols), or from the top $40 \mathrm{~cm}$ of the reference seagrass bed (reference cores, open symbols). Reference cores superimposed over injury cores enable $80 \mathrm{~cm}$ deep sediment profiles. Notations quantify organic carbon, nitrogen, and phosphorus stocks in the top meter of sediments, and loss of buried resources per unit area in vessel grounding injuries that excavate the top meter of sediment.....

Figure 6. Mean \pm se depth profiles for Principal Component (PC) scores extracted from a multivariate data set of sediment and porewater variables sampled from $7.6 \mathrm{x}$ $40 \mathrm{~cm}$ cores collected from Grounding sites of known ages (filled symbols) and from adjacent undisturbed reference sites (open symbols). PC1 is interpreted as the sediment organic component, and PC2 is interpreted to represent porewater nutrient pools.

Figure 7. Mean \pm se seagrass (left) and macroalgae (right) percent cover through time at restoration sites (filled symbols) and reference sites (open symbols) for chronosequence restoration sites.

Figure 8. Mean \pm se depth profiles for Principal Component (PC) scores extracted from a multivariate data set of sediment and porewater variables at restoration sites 
of known age groups. Data are from restoration treatments (filled symbols) including Grounding + Stake (left), Fill (center), and Fill + Stake (right) sites and from adjacent undisturbed reference sites (open symbols). PC1 is interpreted as the sediment organic component, and PC2 is interpreted to represent porewater nutrient pools. 3 yr old Fill sites were not available for inclusion in the study design

Figure S1. Mean \pm se depth profiles for bulk density and organic matter, nitrogen, and phosphorus content from $7.6 \times 40-\mathrm{cm}$ cores collected from restoration sites of known ages (filled symbols) and from adjacent undisturbed reference sites (open symbols). Restoration treatments included Grounding + Stake (GS), Fill (F), and Fill + Stake (FS). 3 yr old Fill sites were not available for inclusion in the study design. ..... 40

Figure S2. Mean \pm se depth profiles for $\mathrm{pH}$, Eh, and concentrations of $\mathrm{NH}_{4}{ }^{+}$and SRP from $7.6 \times 40-\mathrm{cm}$ cores collected from restoration sites of known ages (filled symbols) and from adjacent undisturbed reference sites (open symbols).

Restoration treatments included Grounding + Stake (GS), Fill (F), and Fill + Stake (FS). $3 \mathrm{yr}$ old Fill sites were not available for inclusion in the study design.

CHAPTER III

Figure 1. Location of study sites (polygons, lower inset) at Cutter Bank, in southern Biscayne Bay, Florida, USA, within the boundary of Biscayne National Park.

Figure 2. Mean \pm se seagrass percent cover in the first year post-restoration at restoration and reference sites. Notations are Spearman correlations and significance of relationships between seagrass percent cover and time within each restoration treatment.

Figure 3. Mean \pm se seagrass macroalgae percent cover in the first year postrestoration at restoration and reference sites. Notations are Spearman correlations and significance of relationships between macroalgae percent cover and time within each restoration treatment

Figure 4. Mean \pm se sediment chlorophyll a concentrations in $7.6 \times 2 \mathrm{~cm}$ cores collected from study sites sampled repeatedly over one year $(0 \mathrm{yr}, 0.25 \mathrm{yr}, 0.5 \mathrm{yr}$, $0.75 \mathrm{yr}, 1 \mathrm{yr}$ ). Treatments included unrestored grounding sites, filled sites, and intact seagrass sites ( $n=6$ sites per treatment). Letters indicate statistical significance $(\alpha=0.05)$ among sampling events within each treatment determined through PERMANOVA pairwise tests of time steps

Figure 5. Sediment physical properties (water content, bulk density, pH, Eh, and organic matter content) from $7.6 \times 40 \mathrm{~cm}$ cores collected from study sites. Treatments included Grounding, Grounding + Stake, Fill, Fill + Stake, Intact + Stake, and Intact sites. Sites were sampled repeatedly over one year $(0 \mathrm{yr}, 0.25 \mathrm{yr}, 0.5 \mathrm{yr}$, 
$0.75 \mathrm{yr}, 1 \mathrm{yr})$. Data are mean \pm se values at each of six depth horizons $(0-2 \mathrm{~cm}, 2-6$ $\mathrm{cm}, 6-10 \mathrm{~cm}, 10-20 \mathrm{~cm}, 20-30 \mathrm{~cm}, 30-40 \mathrm{~cm})$.

Figure 6. Sediment and porewater nutrient pools (\% nitrogen, $\%$ phosphorus, ammonium, soluble reactive phosphorus, dissolved sulfide) from $7.6 \times 40 \mathrm{~cm}$ cores collected from study sites. Treatments included Grounding, Grounding + Stake, Fill, Fill + Stake, Intact + Stake, and Intact sites. Sites were sampled repeatedly over one year $(0 \mathrm{yr}, 0.25 \mathrm{yr}, 0.5 \mathrm{yr}, 0.75 \mathrm{yr}, 1 \mathrm{yr})$. Data are mean \pm se values at each of six depth horizons $(0-2 \mathrm{~cm}, 2-6 \mathrm{~cm}, 6-10 \mathrm{~cm}, 10-20 \mathrm{~cm}, 20-30 \mathrm{~cm}, 30-40 \mathrm{~cm})$.

Figure 7. Sediment size class (clay, silt, sand, gravel) contribution in sediment cores collected from study sites. Treatments included Grounding (G), Grounding + Stake (GS), Fill (F), Fill + Stake (FS), Intact + Stake (IS), and Intact seagrass sediments (I). Data are from $7.6 \times 40 \mathrm{~cm}$ cores collected from study sites sampled twice over one year (0yr, 1yr). Data in bars are pooled over depth and time within each treatment. Letters indicate statistical significance $(\alpha=0.05)$ among treatments determined through PERMANOVA pairwise tests between treatments

Figure 8. Principal components analysis (PCA) ordination with PCA eigenvector overlay of multivariate sediment data, visualized for the Restoration $x$ Fertilization factor (G = Grounding, GS = Grounding + Stake, F = Fill, FS = Fill + Stake, IS = Intact + Stake, I = Intact). Refer to Methods for sediment variables included in the PCA.

Figure 9. Depth profiles for mean \pm se Principal Component $(P C)$ scores extracted from the multivariate data set of sediment variables sampled from study sites.

Treatments included Grounding, Grounding + Stake, Fill, Fill + Stake, Intact + Stake, and Intact seagrass sediments. PC1 is interpreted as a sediment OM and PC2 represents dissolved inorganic nutrients in the porewaters.

\section{CHAPTER IV}

Figure 1. Location of study sites at Cutter Bank, in southern Biscayne Bay, Florida, USA, within the boundary of Biscayne National Park. Polygons in lower inset are grounding/restoration sites.

Figure 2. Sediment environmental variables at grounding (top row), stake (second row), fill (third row), and intact sites (bottom row), at 0yr (circles) and 1yr (triangles) post-restoration. Values are mean \pm se at three depth horizons: $0-2 \mathrm{~cm}, 2-6 \mathrm{~cm}$, and $6-10 \mathrm{~cm}$. Abbreviations: phi $=$ sediment particle size; $\mathrm{Eh}=$ redox potential; SRP $=$ soluble reactive phosphate.

Figure 3. Sediment size class (clay, silt, sand, gravel) contribution in sediment cores collected from restoration treatments. Data in bars are pooled over three depth horizons $(0-2 \mathrm{~cm}, 2-6 \mathrm{~cm}, 6-10 \mathrm{~cm})$ and two sampling events $(0 \mathrm{yr}, 1 \mathrm{yr})$ within each 
treatment. Letters indicate statistical significance $(\alpha=0.008)$ among treatments determined through PERMANOVA pairwise tests of multivariate sediment structure between treatments.

Figure 4. Principal coordinates analysis ordinations of TRFLP profiles from sediment samples at Grounding, Stake, Fill, and Intact sites.

Figure 5. TRF richness (S, Chao 2), evenness (Pielou's J'), and diversity (ShannonWeaver H', Simpson's 1- $\lambda$ ), by restoration treatment and sampling event (0yr, dark bars and 1yr, light bars) calculated from TRFLP abundance data. Values are mean \pm se for $H^{\prime}, 1-\lambda$, and J') and mean \pm sd for Chao 2 . Where the Treatment main effect was significant, significance of pairwise tests of the Treatment levels $(\alpha=0.008)$ is indicated by letters at the base of each Treatment bar group. Significance of a Time difference within each treatment is indicated by an asterisk $(\alpha=0.05)$

Figure 6. dbRDA ordination microbial community data (binomial deviance resemblance matrix calculated from log transformed relative abundance data) fitted to environmental variables. Data are from $0 \mathrm{yr}$ and $1 \mathrm{yr}$ sampling events. Ordination is based on best-fit DistLM model with three variables $\left(\log (\mathrm{BD}), \log \left(\mathrm{NH}_{4}{ }^{+}\right)\right.$, and $\log (\mathrm{OM}))$

\section{CHAPTER V}

Figure 1. Location of study sites in southern Biscayne Bay, Florida, USA, within the boundary of Biscayne National Park.

Figure 2. Principle coordinates analysis ordination of multivariate infaunal community samples from vessel grounding sites (closed symbols) and intact seagrass sites (open symbols). Grounding sites were of multiple known ages: 0,1 , 3,4 , or 5 years old.

Figure 3. Infaunal community diversity metrics from vessel grounding sites of different ages (dark bars) and undisturbed reference sites (light bars). Values are means \pm se. An asterisk indicates a statistical difference between disturbed and reference sites within an age group ( $t$ test, $\alpha=0.05$ ).

Figure 4. Principle coordinates analysis ordination of multivariate infaunal community samples at Cutter Bank. Data are visualized by sampling event $(0.25 \mathrm{yr}$, $0.5 \mathrm{yr}, 1 \mathrm{yr}$ ) within each restoration treatment. Treatments include Grounding (G), Fill (F), and Intact (I) seagrass sites. Data from fertilization treatments are pooled with restoration treatments.

Figure 5. Mean \pm se infaunal community diversity metrics from study sites in the restoration analysis, sampled at $0 \mathrm{yr}$ (dark bars) and $1 \mathrm{yr}$ (light bars) year postrestoration. Restoration treatments included: $\mathrm{G}=$ grounding, $\mathrm{F}=$ fill, and $\mathrm{I}=$ intact. 
Data for I sites are from $0.25 \mathrm{yr}$ and $1 \mathrm{yr}$ sampling events. Asterisks indicate significance at $\alpha=0.05$ between time steps within treatments

Figure 6. dbRDA ordination of the best fit DistLM model of infaunal community data (binomial deviance resemblance matrix calculated from log transformed relative abundance data) versus log transformed environmental variables. Data are from $0.25,0.5$, and $1 \mathrm{yr}$ sampling events.

\section{CHAPTER VI}

Figure 1. Location of study sites in southern Biscayne Bay, Biscayne National Park, Florida, USA.

Figure 2. Main effects of (a) time, (b) seagrass species, (c) exclusion treatment, and (d) site on mean ( \pm se) percent seagrass biomass loss in herbivory assays. All main effects were significant $(p<0.001)$ in a 4-way ANOVA on rank-transformed biomass loss data. For (c) lower case letters indicate Bonferroni-corrected significance at $p<$ 0.017. Species codes: TT=Thalassia testudinum, SF=Syringodium filiforme, $\mathrm{HW}=$ Halodule wrightii. Site codes: $\mathrm{BC}=$ Biscayne Channel, NN=No Name Shoal, $\mathrm{EF}=$ East Featherbed Bank, $\mathrm{CB}=$ Cutter Bank.

Figure 3. Mean ( \pm se) percent seagrass biomass loss through time by species within each assay site. Seagrass biomass data from the uncaged and partial herbivore exclusion treatments are pooled. Lowercase letters indicate statistical significance among species within each site:time pair (see Table 2). Species codes:

TT=Thalassia testudinum, SF=Syringodium filiforme, HW=Halodule wrightii 168

Figure 4. Mean ( \pm se) carbon:nitrogen $(\mathrm{C}: \mathrm{N})$ and carbon:phosphorus $(\mathrm{C}: \mathrm{P})$ molar ratios in seagrass leaves from the donor site, Pelican Shoal, by species and time. Lowercase letters indicate statistical significance among times within each species at $p<0.05$ as determined through 2-way ANOVAS followed by bonferroni pairwise comparisons. Species codes: HW=Halodule wrightii, SF=Syringodium filiforme, TT=Thalassia testudinum.

Figure 5. Mean ( \pm se) carbon:nitrogen $(\mathrm{C}: \mathrm{N}$, top row) and carbon:phosphorus (C:P, bottom row) molar ratios in seagrass leaves through time by site within species. Absence of a bar in a site/time group indicates that that species was not present for collection. Asterisks indicate differences from donor site values at $p<0.05$. Site codes: $P S=$ Pelican Shoal, $B C=B i s c a y n e ~ C h a n n e l, ~ N N=$ No Name Shoal, EF=East Featherbed Bank, $\mathrm{CB}=$ Cutter Bank.

Figure 6. Mean ( \pm se) percent seagrass biomass loss vs. mean ( \pm se) carbon:nitrogen ( $\mathrm{C}: \mathrm{N}$, left column) and mean $( \pm \mathrm{se})$ carbon:phosphorus $(\mathrm{C}: \mathrm{P}$, right column) molar ratios in donor site seagrass leaves, displayed by time for each seagrass species. Error bars are displayed to show variance in the observations, but 
regression analyses assumed that mean values for each point were the independent units of observation. No regressions were significant (all $p>0.11)$. Seagrass biomass data from the uncaged and partial herbivore exclusion treatments are pooled.

Figure 7. Fish abundance (left axes) and biomass loss (mean \pm se, right axes) at the assay sites in Fall 2009 (left panel) and Winter 2010 (right panel). The stacked bars divide abundance into two feeding guilds: herbivorous fish (grey bars) vs. other fish (white bars). Percent biomass loss data from the uncaged and partial cage treatments are pooled, and presented by seagrass species (Thalassia testudinum, squares; Syringodium filiforme, triangles; Halodule wrightii, circles). Site codes: $\mathrm{BC}=$ Biscayne Channel, NN=No Name Shoal, EF=East Featherbed Bank, CB=Cutter Bank. 
CHAPTER I: Introduction

Seagrasses are important plants with the capability to modify physical, chemical, and biological aspects of their environments. The presence of seagrass biomass, structure and function in the surrounding sediments are important in such ecosystem processes as primary and secondary production, nutrient cycling, and benthic metabolism. When compared to unvegetated sediments, seagrass-vegetated sediments have greater oxygen penetration and potential to reduce chemical species (Enríquez et al. 2001; Marbà \& Duarte 2001), higher organic matter content (Pedersen et al. 1997), enhanced benthic metabolism including sulfate reduction (Isaksen \& Finster 1996; Holmer \& Duarte 2003) and nitrogen fixation (Patriquin \& Knowles 1972; Capone \& Taylor 1980), higher microalgae abundance (Bucolo et al. 2008), and more abundant and diverse macrofaunal (Stoner 1980; Virnstein et al. 1983) and microbial communities (Moriarty \& Boon 1985).

Seagrasses are globally threatened by multiple anthropogenic stressors, including physical disturbance (Orth et al. 2006). Shallow seagrass habitats near population centers frequently experience physical disturbance as a result of vessel groundings. These incidents create specific types of injuries, including blowholes, propeller scars, and berms that can excavate sediment, destroy above- and belowground seagrass biomass, and/or bury seagrasses. Natural recovery of seagrass communities from severe disturbance such vessel grounding blowholes is a slow process, and recovery of deep excavations may take several years to over a decade (Zieman 1976; Durako et al. 1992; Dawes et al. 1997; Kenworthy et al. 2002; Hammerstrom et al. 2007; Di Carlo \& Kenworthy 2008).

An accepted definition of ecological restoration is "intentional activity that initiates or accelerates the recovery of an ecosystem with respect to its health, integrity and 
sustainability" (SER 2004). It follows, then, that restoration actions should be developed and evaluated in the context of established ecological concepts (Young et al. 2005). In the field of seagrass restoration, resource managers and restoration practitioners attempt to accelerate recovery of disturbed seagrass communities by implementing specific restoration methods that modify the physical, chemical, and biological aspects of the disturbances.

For example, placing sediment fill into excavations is intended to stabilize sites from erosion and recreate the physical matrix that supports seagrasses and ecosystem functioning (Hammerstrom et al. 2007). Because seagrasses ecosystems are often nutrient-limited (Short 1987; Fourqurean et al. 1992a), applying fertilizer serves to reestablish or augment pools of vital nutrients that may be limiting to seagrass growth (Kenworthy et al. 2000). Bird roosting stakes have been shown to provide nitrogen and phosphorus to sediments (Powell et al 1989, Fourqurean et al 1995), which can have dramatic and long-lasting effects on phosphorous concentrations and seagrass biomass (Herbert \& Fourqurean 2008). Seagrasses are transplanted to more quickly replace lost plant structure and associated functions than would otherwise be accomplished through natural secondary succession following disturbance (Lewis 1987).

Following physical disturbance, seagrasses are generally thought to follow a facilitation model of succession (Connell \& Slayter 1977; Williams 1990). Early colonizers including macroalgae and fast-growing seagrass species help stabilize disturbed sediments and build nutrient pools and in turn provide for colonization by later climax species. Following seagrass restoration actions, recovery of the plant community is expected to follow this model. As such, rapid assessments of plant communities are typically used to monitor recovery at seagrass restoration sites. Few studies (e.g., Di Carlo \& Kenworthy 2008) have monitored natural or assisted recovery of grounding 
injuries in any other aspect than the above-ground plant communities (Fonseca et al. 1996a; Dawes et al. 1997; Kenworthy et al. 2002; Whitfield et al. 2004; Hammerstrom et al. 2007) or associated nekton (Fonseca et al. 1996b; Bell et al. 2001; Uhrin \& Holmquist 2003). Thus, the adequacy of current monitoring practices at accurately representing the loss of ecosystem structure resulting from vessel grounding injuries, and recovery of lost structure via both natural recovery and active restoration is of interest.

My dissertation research evaluated the loss and recovery of ecosystem structure in disturbed seagrass meadows, as well as the efficacy of common seagrass restoration techniques in accelerating recovery. To better understand the effects of physical disturbance on seagrass ecosystem structure, I studied primary producers and sediment structure at a chronosequence of vessel grounding disturbances (Chapter 2). The chronosequence approach allowed me to evaluate the impacts of recent disturbances, as well as how altered ecosystem structure changed with time in older disturbances. I also conducted a similar analysis of seagrass restoration sites of different ages, to determine if restoration accelerates the recovery of lost ecosystem structure in primary producers and sediments (Chapter 2). Because the restoration chronosequence sites studied in Chapter 2 involved varying locations, restoration methods, and sample sizes, a more intensive analysis of the effects of restoration and fertilization on primary producers and sediment structure was conducted on a group of co-located sites during the first year following restoration implementation (Chapter 3).

Microorganisms and infaunal invertebrates in seagrass sediments facilitate many key ecosystem processes. Yet current knowledge of microbial and infaunal community structure in the context of physical disturbance and active restoration in seagrass ecosystems is not well understood. Using the molecular fingerprinting technique of terminal restriction fragment length polymorphism, I studied short-term responses of 
sediment microbial communities to restoration of vessel grounding injuries during the first year post restoration (Chapter 4). In addition, I analyzed the effects of disturbance and restoration on infaunal community structure and diversity (Chapter 5).

As previously mentioned, seagrass transplanting is a common restoration technique, and transplanting projects in the western Atlantic have been designed according to the principle of modified "compressed succession" (Durako \& Moffler 1984). In these projects, fast-growing Halodule wrightii and/or Syringodium filiforme are transplanted as early colonizers, to facilitate the eventual reestablishment of Thalassia testudinum. Survival and persistence of transplanted seagrasses is highly variable, potentially limiting the hypothetical jump-start provided through modified compressed succession. One potential reason for reduced transplant success is direct grazing by herbivorous fish. I evaluated direct herbivory pressure on experimental planting units assembled from leaves of the seagrasses Thalassia testudinum, Syringodium filiforme, and Halodule wrightii (Chapter 6). I also compared seagrass biomass loss to herbivory with elemental composition of donor and ambient seagrass leaves, and with fish communities at the assay sites.

My study system was southern Biscayne Bay, a shallow $(<3 m)$ subtropical estuary located at the southeastern tip of the Florida peninsula. Much of southern Biscayne Bay is encompassed within the boundary of Biscayne National Park, a unit of the United States Department of the Interior's National Park Service. Seagrass meadows dominated by turtle grass (Thalassia testudinum) are an important habitat type in the Park, and are heavily impacted by vessel groundings in several areas.

As the manager of the Park's Damage Recovery Program since 2003, my professional responsibilities primarily include building Natural Resource Damage Assessment (Kopp \& Smith 1993) cases from vessel grounding incidents, and 
conducting habitat restoration activities at vessel grounding sites. The Park provided an excellent study system in which to explore my hypotheses. Successful settlement of numerous vessel grounding cases funded the restoration and monitoring of multiple injuries, and over fifty sites have been restored using a combination of methods since 2003. This scenario enabled hypothesis testing and the application of experimental designs incorporating replication using actual restoration sites. In contrast, much of the work conducted to date on recovery following disturbance and restoration in seagrass ecosystems has been based on experimental, small-scale disturbances (e.g. Williams 1990; Kenworthy et al. 2002; Hammerstrom et al. 2007).

From an ecological perspective, my dissertation research is important in better understanding the effects of physical disturbance on seagrass ecosystem structure. From an applied perspective, the work provides key information on injury severity, as determined by functional loss, and what can be expected in terms of natural recovery and recovery of restoration sites. This type of information is critical to scaling compensatory restoration in Natural Resource Damage Assessment cases involving seagrass resources, including vessel grounding cases. The work also enables recommendations on the efficacy of seagrass restoration methods that may be subject to site-specific conditions. 
CHAPTER II: Plant communities and sediment structure following disturbance and restoration in subtropical seagrass meadows.

Abstract

Physical disturbance to seagrass ecosystems removes plant biomass, but impacts to habitat quality and nutrient storage and cycling are not well understood. Seagrass restoration actions provide a management tool intended to accelerate the recovery of lost ecosystem structure and function following disturbance. We studied the plant community and sediment structure at vessel grounding disturbances in seagrass ecosystems to better understand the nature of such impacts, and how structure changed with time. We conducted a similar analysis of seagrass restoration sites of different ages, to determine if restoration accelerates the recovery of lost ecosystem structure in the plants and sediments. Disturbance to seagrass sediments resulted in loss of seagrass community structure and diminished sediment and porewater nutrient pools. These impacts persisted in our study sites that were up to five years in age since impact. Another effect of physical disturbance is the loss of nutrients stored in the sediments. Restoration sites that received fill were characterized after 3 to 3.5 years by low macrophyte cover and by sediments with greater bulk density and redox potential, and low sediment and porewater nutrient pools. We did not detect substantial convergence of seagrass and sediment structure with the intact seagrass ecosystem in either the disturbed or the restoration sites we studied. However, our study sites were still in a recent period of recovery following disturbance or restoration. Longer time frames will be needed to identify ecosystem recovery trajectories following disturbance and restoration in this system. 
Introduction

Seagrasses are ecosystem engineers with the capability to modify physical, chemical, and biological aspects of their environments (Orth et al. 2006). Nutrient cycling and benthic metabolism are important functions of seagrass ecosystems (Hemminga \& Duarte 2000; Marba et al. 2006b) that occur in seagrass sediments. For example, when compared to unvegetated sediments, seagrass sediments have larger sediment nutrient pools (Fourqurean et al. 1992; Duarte et al. 2005), higher organic matter content (Kenworthy 1981; Pedersen et al. 1997), more sulfate reduction activity (Isaksen \& Finster 1996; Holmer \& Duarte 2003), greater nitrogen fixation (Patriquin \& Knowles 1972; Capone \& Taylor 1980), higher benthic microalgae content, and more abundant and diverse macrofaunal (Stoner 1980; Virnstein et al. 1983) and microbial communities (Moriarty \& Boon 1985). Thus, sediment structure is an important determinant of nutrient processing rates and storage capacity, affecting plant productivity and community structure.

Seagrass ecosystem structure and function provide numerous goods and services to human populations including shoreline protection, sediment stabilization, water purification, commercial and artisanal fisheries, and nutrient cycling (Spalding et al. 2001). These goods and services have been valued at $\$ 19,000 \mathrm{ha}^{-1} \mathrm{yr}^{-1}$ (Costanza et al. 1997). Recent studies have revealed that seagrass ecosystems sequester large quantities of organic carbon, nitrogen, and phosphorus in their sediments (Duarte et al. 2010; Fourqurean et al. 2012a). Stored organic carbon can be oxidized and released into the atmosphere as $\mathrm{CO}_{2}$ when sediments are disturbed, which is problematic in the face of climate change fueled by greenhouse gas emissions. The economic incentives of protecting seagrass ecosystems from degradation are being explored in the context of developing carbon credit mitigation programs. Stored organic carbon, or "blue carbon" 
stocks in seagrass sediments can be considered a valuable ecosystem service that has recently been assigned a carbon credit revenue potential of $\$ 7,000$ ha $^{-1}$ (Murray et al. 2011).

Loss of seagrass resources in coastal ecosystems is accelerating (Waycott et al. 2009), and physical disturbance from storm events, dredging, development, and fishing gear impacts, is a contributor to this decline (Short \& Wyllie-Echeverria 1996; Orth et al. 2006; Grech et al. 2012). In root-based plant communities, disturbances to belowground components of the ecosystem can have more severe consequences than disturbances to above-ground components (Pickett \& White 1985), and below-ground impacts are slow to recover (Di Carlo \& Kenworthy 2008). Physical disturbances to seagrass meadows that disrupt the rhizosphere, such as from mussel dragging (Neckles et al. 2005) or from vessels that run aground and excavate plants and sediment (Hammerstrom et al. 2007; Di Carlo \& Kenworthy 2008), lead to persistent changes in ecosystem function, including primary production, nutrient cycling, and habitat provision for seagrass-associated organisms. Seagrass ecosystems near population centers are subject to frequent and severe physical disturbance when vessels run aground (Sargent et al. 1995; Dunton \& Schonberg 2002; SFNRC 2008).

Increased protection for seagrasses by government agencies is often accompanied by mandates to restore seagrass injuries or otherwise mitigate for seagrass impacts (Kirsch et al. 2005). Accordingly, interest in seagrass restoration has increased in recent decades (Treat \& Lewis 2006; Paling et al. 2009; Fonseca 2011). Resource managers and restoration practitioners attempt to accelerate recovery of disturbed seagrass communities by implementing specific restoration methods. Filling grounding excavations, providing a fertilizer source, and transplanting seagrasses are commonly-used seagrass restoration techniques (Fonseca et al. 1998; Kirsch et al. 
2005; McNeese et al. 2006; Farrer 2010; Hall et al. 2012b). Placing sediment fill into excavations is intended to stop erosion and to recreate the physical matrix that supports seagrasses and ecosystem functioning (Kirsch et al. 2005; Hammerstrom et al. 2007; Farrer 2010). Seagrasses are transplanted to more quickly replace lost plant structure and associated functions than would otherwise be accomplished through natural secondary succession following disturbance (Lewis 1987). Because seagrass ecosystems are often nutrient limited (Short 1987; Fourqurean \& Zieman 1992), applying fertilizer via bird roosting stakes, whereby the defecation of perching seabirds falls to the sea floor below the stakes, aims to reestablish or augment pools of vital nutrients that may be limiting to seagrass growth (Kenworthy et al. 2000; Farrer 2010).

For restoration to be successful, ecological attributes of the system such as structure, composition, and function must be reestablished (Fonseca et al. 1996a; Hobbs \& Norton 1996; Higgs 1997), but a preliminary understanding both of the effects of the disturbance and of natural recovery trajectories is required to understand the postrestoration recovery process. Recovery of subtropical seagrass communities following sediment disturbance is variable, and may take several years to over a decade (Zieman 1976; Durako \& Moffler 1985; Dawes et al. 1997; Kenworthy et al. 2002; Hammerstrom et al. 2007; Uhrin et al. 2011; Hall et al. 2012b). However, seagrass ecosystem functions extend beyond primary production and habitat provided by the plants themselves. Little is actually known about disturbance effects to and recovery of sediment structure following disturbance in seagrass ecosystems (but see Williams 1990; Di Carlo \& Kenworthy 2008). Similar knowledge gaps exist with regard to recovery of sediment structure following seagrass restoration. Once restoration has been implemented, rapid assessments of plant communities are typically used to monitor restoration success (Fonseca et al. 1998; Kirsch et al. 2005; Farrer 2010; Hall et 
al. 2012b). Few studies have assessed ecosystem structure following seagrass restoration for any aspects other than above-ground plant communities (Fonseca et al. 1996a; McNeese et al. 2006; Hammerstrom et al. 2007; Hall et al. 2012b) or associated fauna (Fonseca et al. 1996b).

Our study aimed to fill information gaps that exist regarding the impacts that physical disturbances initially have on ecosystem structure in seagrass sediments. We also sought to understand the effects of common restoration actions on seagrass ecosystem structure following restoration. We focused on structural attributes essential to habitat quality, nutrient storage, and ecosystem metabolism in the vegetation and the soil. We hypothesized that a) vessel groundings alter seagrass ecosystem structure, specifically in primary producer community and sediments, b) altered structure changes with time following disturbance through succession and ecosystem development, and c) seagrass restoration actions such as fill placement and bird stake installation accelerate the recovery of lost structure.

Methods

Study System

Southern Biscayne Bay is a shallow $(<3 \mathrm{~m})$ subtropical estuary located at the southeastern tip of the Florida peninsula (Figure 1). Seagrass communities in southern Biscayne Bay are dominated by dense Thalassia testudinum meadows. Syringodium filiforme and Halodule wrightii are also found throughout this area in lower abundance and patchy distributions. There is a strong dissolved inorganic nitrogen gradient decreasing from west to east, influenced by freshwater input from canals along the western shoreline, and the predominantly carbonate based sediments contribute to phosphorus limitation in the bay (Caccia \& Boyer 2005). Most shallow seagrass shoals 
$(<1 \mathrm{~m})$ in this area are heavily impacted by vessel grounding injuries, where seagrass has been removed and sediment excavated in discrete areas. Our study evaluated seagrass ecosystem structure on multiple seagrass shoals: Cutter Bank, Arsenicker Bank, East Featherbed Bank, and Biscayne Channel (Figure 1).

\section{Experimental Design}

Our study sites included multiple vessel grounding injuries, vessel grounding restoration sites, and adjacent undisturbed seagrass meadows on these shoals. We used a chronosequence approach to examine the effects of vessel grounding disturbance and seagrass restoration practices on plant community structure and soil properties. Twenty seven vessel grounding sites of known age (i.e., time since disturbance or restoration) were identified. Site age was rounded to the nearest sixmonth increment.

To evaluate the effects of vessel groundings on ecosystem structure, and the recovery of lost structure through time, we assessed primary producer communities and sediment structure in unrestored Grounding $(G)$ sites and in undisturbed reference seagrass meadows. Grounding sites included vessel grounding injuries that were 0, 1, 2,4 , or 5 years old, where sediments were excavated to a mean depth of $0.4 \mathrm{~m}$, but for which no restoration has taken place. Most sites were documented upon occurrence and were relocated from original assessment maps. Three sites were not documented upon occurrence, but were known from aerial photography to be at least five years old.

To assess whether or not seagrass restoration actions accelerate recovery of lost ecosystem structure in vessel groundings, we evaluated primary producer communities and sediment structure in restoration sites and in undisturbed seagrass meadows. Restoration sites had received one of three restoration treatments during multiple 
restoration projects conducted by the National Park Service during the period 2007 2010. Restoration For the Grounding + Stake (GS) treatment, bird roosting stakes were placed into injuries on 2-m centers to provide a fertilizer source to encourage natural recruitment of surrounding vegetation. Grounding + Stake sites were 0, 1, 3, or 3.5 year years old. Injuries that were filled back to the grade of the surrounding bay bottom using quarried sand comprised the Fill $(F)$ treatment. Fill sites were 0,1 , or 3.5 years old. In

the Fill + Stake (FS) treatment, sites were returned to grade with sand fill, and provided with bird roosting stakes on 2-m centers for fertilizer. Fill + Stake sites were $0,1,3$, or 3.5 years old.

In each disturbance and restoration treatment (i.e., G, GS, F, FS), there were two to four sites per treatment per age group. Sites were sampled once in February - March 2011. Undisturbed seagrass meadows adjacent to (within $2 \mathrm{~m}$ of) each grounding or restoration site were sampled as a reference sites.

\section{Seagrass Community Characterization}

To evaluate natural recovery of macrophyte (i.e., macroalgae and seagrass) communities in vessel grounding disturbances, seagrass community composition was documented at each site. Seagrass and macroalgae (i.e. calcareous green algae) abundances were estimated within randomly placed $0.25 \mathrm{~m}^{2} \mathrm{PVC}$ quadrats using a modified Braun-Blanquet (BB) cover-abundance scale (Fourqurean et al. 2001). Ten percent of each site area was sampled, with an equivalent number of quadrats sampled in the reference area for a given site.

\section{Sediment Core Collection and Processing}

We sampled a suite of soil properties that are important indicators of structure and function in seagrass ecosystems, including benthic microalgae growing on surface 
of sediments (primary production, habitat quality); redox potential, organic matter content, and porewater sulfide (benthic metabolism and remineralization); water content and bulk density (nutrient exchange); and nitrogen and phosphorus in sediment and porewater (nutrient storage). Sediments were sampled by haphazardly collecting one $7.3 \mathrm{~cm} \times 40 \mathrm{~cm}$ sediment core each from each injury or restoration site, and from the undisturbed reference seagrass bed adjacent to (within $2 \mathrm{~m}$ of) each site. Core tubes were immediately plugged at both ends following collection, and temporarily stored in the dark in a vertical position in ambient seawater until processed. Cores were extruded and sectioned into six depth horizons $(0-2 \mathrm{~cm}, 2-6 \mathrm{~cm}, 6-10 \mathrm{~cm}, 10-20 \mathrm{~cm}, 20-30$ $\mathrm{cm}$, and $30-40 \mathrm{~cm}$ in a nitrogen-filled glovebox. The redox potential $\left(\mathrm{E}_{h}\right)$ of sediments from each homogenized depth horizon were measured in the glovebox. Depth horizons were then subsampled for analysis of benthic microalgal biomass (as chlorophyll a), soil properties (bulk density, water content, organic matter content, total nitrogen, total phosphorus), and porewater constituents (ammonium $\left(\mathrm{NH}_{4}{ }^{+}\right)$, soluble reactive phosphorus (SRP), and dissolved sulfide (DS)). Sediments for porewater extraction were placed into $50 \mathrm{~mL}$ centrifuge tubes and capped inside the glove box, centrifuged for five minutes at $3000 \mathrm{rpm}$, and returned to the glovebox. Extracted porewater was filtered through GF-C $(1.2 \mu \mathrm{m})$ in-line syringe filters and subsampled into two aliquots for analysis of $\mathrm{NH}_{4}^{+} / \mathrm{SRP}(20 \mathrm{ml})$ and DS $(5 \mathrm{ml})$, respectively. Samples for DS were fixed with $1 \mathrm{M} Z \mathrm{nAc}$ in a 1:10 dilution (Holmer et al. 2001) and stored at room temperature; all other sediment and porewater samples were frozen at $-20^{\circ} \mathrm{C}$ until further analysis.

Benthic microalgal biomass was determined for the $0-2 \mathrm{~cm}$ horizon only. Sediments were freeze-dried and pigments extracted with $90 \%$ acetone for 72 hours at $20^{\circ} \mathrm{C}$, and chloropyll a content $\left(\mu \mathrm{g} \mathrm{g}^{-1}\right)$ was measured flourometrically (Strickland \& Parsons 1972) on a Shimadzu RF 5301PC spectrofluorophotometer (excitation $=435$ 
$\mathrm{nm}$, emission $=667 \mathrm{~nm}$ ). Bulk density was measured as dry mass per unit volume. Water content (WC) was determined as proportional mass loss after drying sediments at $75^{\circ} \mathrm{C}$ for 48 hours. Organic matter content was measured as loss on ignition (LOI), or proportional mass loss of dry sediments following combustion at $500^{\circ} \mathrm{C}$ for four hours (Gross 1971). Sediment total nitrogen (N) were determined using a CHN elemental analyzer (Fisons NA1500). Total P (P) was determined through a dry-oxidation, acid hydrolysis extraction followed by colorimetric analysis of phosphate concentration in the extract (Fourqurean et al. 1992a). Elemental content was calculated on a dry weight basis as (mass of element/dry weight of sample) $\times 100 \%$. Elemental ratios were calculated as molar ratios.

Porewater samples for $\mathrm{NH}_{4}{ }^{+}$and SRP were acidified to a pH of 2 with $6 \mathrm{~N} \mathrm{HCl}$ and sparged with nitrogen gas to drive off hydrogen sulfide prior to analysis. Porewater $\mathrm{NH}_{4}{ }^{+}$concentrations were measured colorimetrically with the indo-phenol blue method (Koroleff 1969, Parsons et al. 1984) and soluble reactive phosphorus (SRP) concentrations were measured colorimetrically using the ascorbate method (Parsons et al. 1984). Porewater sulfide concentrations were determined spectrophotometrically following the methods of Cline (1969).

Data Analysis

Loss of ecosystem structure in new groundings was first evaluated by comparing primary producer (seagrass, macroalgae, microphytobenthos) abundances between injury and reference sites within each age group. Seagrass and macroalgae BB scores from the seagrass community surveys were converted to percent cover data using the midpoint of the percent cover range corresponding to each BB score, and averaged by disturbance status (injury, reference) for each age group. Seagrass and macroalgae 
percent cover and chlorophyll a content between injury and reference sites at each age group were compared using Mann-Whitney U-tests (seagrass, macroalgae) or t tests (chlorophyll a) using the software SPSS 20.0 (IBM).

Vessel grounding impacts were also evaluated with reference and injury cores to develop nutrient storage estimates for sediments, which were then used to quantify nutrient loss resulting from sediment disturbance. The injury cores $(40 \mathrm{~cm}$ long, $\mathrm{n}=4)$ were collected from the bottom of recent injuries that ranged from 40 to $80 \mathrm{~cm}$ deep, with an average depth of $40 \mathrm{~cm}$. Reference cores $(40 \mathrm{~cm}$ long, $\mathrm{n}=4)$ were collected adjacent to these injuries. Superimposing reference core values over injury core provides estimates of pre-impact conditions in the top $80 \mathrm{~cm}$ of sediments. Loss of nutrients stored in the sediments (i.e., OM, N, P) resulting from grounding injuries was calculated using the volume, bulk density, and nutrient content for each core slice. Sediment OM content has been shown to be a good predictor of sediment organic carbon $\left(\mathrm{C}_{\text {org }}\right)$ in subtropical seagrass meadows with relatively high $\mathrm{C}_{\text {org }}$ content (Fourqurean et al. 2012b), so OM values were used as proxies for $\mathrm{C}_{\text {org }}$ content, using a ratio of $\mathrm{C}_{\text {org }}=$ ca. $0.38 * \mathrm{OM}$. We extrapolated mass loss to a depth of one meter, making the assumption that bulk density and elemental content for the $80-100 \mathrm{~cm}$ range did not differ from the deepest $10-\mathrm{cm}$ slice of the injury cores. We felt this was a reasonable assumption, given that for nearby Florida Bay seagrass sediments, Fourqurean et al. (2012b) documented little change $C_{\text {org }}$ content in the $80-100 \mathrm{~cm}$ horizon. We then calculated the nutrient storage in the top $1 \mathrm{~m}$ of reference sediments, and developed estimates of elemental loss for the injuries studied.

Analysis of the status of disturbance and restoration sites relative to their respective reference sites through time was conducted in two parallel approaches. The first analysis focused on disturbed sites, and the second focused on restoration sites, 
including three restoration treatments (i.e. GS, F, FS). Prior to analysis, sediment variable data were log-transformed to reduce skewness and normalized to place variables on comparable and dimensionless scales.

Principal components analysis (PCA) was used to reduce data complexity and extract composite variables that explained maximum variability in the sediment properties. Seven sediment variables were included in the PCAs: BD, Eh, OM, N, P, $\mathrm{NH}_{4}{ }^{+}$, and SRP. The PCA ordinations helped visualize multivariate differences between injury or restoration sites and reference sites. Within each analysis, we attributed ecological relevance to those PC axes with eigenvalues $>1$ and we interpreted them on the basis of soil property variables that were strongly correlated with each PC axis.

We then used Permutational Multivariate Analysis of Variance (PERMANOVA, Anderson et al. 2008) to test the effects of site Status and Time on ecosystem structure. The PERMANOVA routine enables testing of the response of one or more variables to one or more factors, one the basis of any resemblance measure, by partitioning sources of variation. A primary advantage of PERMANOVA is that statistical significance of the pseudo- $F$ statistic is determined through permutations of randomized real data, avoiding normality and homogeneity of variance assumptions (Anderson et al. 2008). Specifically, we used PERMANOVA to test for the effects of Status and Age on a) multivariate soil properties at disturbance sites, and b) univariate ecological roles represented by PC scores for individual axes for disturbance and restoration sites. Because we were more interested in the status of the restoration sites relative to reference seagrass meadows, as opposed to other restoration sites, we conducted PERMANOVA analyses on the PC scores for each individual restoration treatment.

The PERMANOVA analyses were conducted on Euclidean distance resemblance matrices, and significance values were based on 999 permutations of 
residuals under reduced models. Where data variables were available for multiple depth horizons, sediment depth was used as a covariate requiring the use of Type I sums of squares; otherwise, Type III sums of squares were used in the PERMANOVA routine. Pairwise permutational tests were conducted for significant factors and interactions. The PCA and PERMANOVA analyses were conducted with the software PERMANOVA+ for PRIMER (Primer-e, Plymouth, UK).

Results

Vessel Grounding Impacts on Macrophytes and Sediment Properties Primary Producer Abundance

Seagrass and macroalgae cover, but not benthic microphytobenthos abundance, were reduced at recent vessel grounding injuries. Mean seagrass percent cover within the injuries $(6.2 \pm 1.5 \%)$ was more than $80 \%$ lower than in the reference seagrass community $(44.4 \pm 4.5 \%)$. Seagrass cover remained lower in injuries in every age group $(0,1,3,4,5 y r)$ of unrestored grounding sites documented ( $U$ tests, $p<0.001$; Figure 2). Macroalgae cover in recent groundings $(4.4 \pm 1.1 \%)$ was approximately half of the cover in the reference seagrass community ( $U$ test, $p=0.012$; Figure 2$)$, but this reduction did not persist in sites that were $1,3,4$, or 5 yrs old ( $U$ test, $p>0.069)$. Chl a content of surficial sediments in grounding site sediments ranged from $4.1 \pm 1.1$ to $14.2 \pm 1.1 \mu \mathrm{g} / \mathrm{g}$, and was significantly lower than in reference sediments only for the $3 \mathrm{yr}$ old sites ( $\mathrm{t}$ test, $\mathrm{t}$ $=-3.3, \mathrm{df}=4, \mathrm{p}=0.029 ;$ Figure 2).

\section{Sediment Properties}

We found little difference in sediments from recent grounding vs. reference sites for the variables BD (median 0.8 vs. $0.9 \mathrm{~g} \mathrm{ml}^{-1}$ ), Eh (median -273 vs. $-220 \mathrm{mV}$ ), OM 
(median 6.1 vs. $4.9 \%$ ), $\mathrm{N}$ (median 0.14 vs. $0.11 \%$ ), or P (median 0.0084 vs. $0.0082 \%$;

Figures 3-4). Porewater nutrient concentrations $\left(\mathrm{NH}_{4}{ }^{+}\right.$and $\left.\mathrm{SRP}\right)$ in the top $10 \mathrm{~cm}$ of disturbed sediments (Figures 3,4) were reduced by half relative to reference sediments $\left(\mathrm{NH}_{4}{ }^{+}\right.$median 192.1 vs. $289.8 \mu \mathrm{M}$, SRP median 1.3 vs. $\left.3.1 \mu \mathrm{M}\right)$. Grounding impacts to sediment properties showed variable patterns for different site age groups. For example, $\mathrm{BD}, \mathrm{OM}$, and $\mathrm{N}$ were reduced in the $1 \mathrm{yr}$ old injuries, but greater than reference sediments in the $5 \mathrm{yr}$ old injures. SRP concentrations were up to five times lower in the $3 \mathrm{yr}$ old groundings than in reference sediments, but similar to reference values for the $1 \mathrm{yr}$ and $4 \mathrm{yr}$ old sites (Figure 4).

Sediment Elemental Stocks

Organic carbon $\left(\mathrm{C}_{\text {org }}\right)$ storage in the top meter of sediments at recent grounding sites contained an average of $15.0 \pm 2.0 \mathrm{~kg} \mathrm{~m}^{-3}$, or $150.0 \pm 19.7 \mathrm{t} \mathrm{ha}^{-1}$ in the top meter of sediments. Sediment nitrogen content was $0.9 \pm 0.0 \mathrm{~kg} \mathrm{~m}^{-3}$, or $9.0 \pm 0.3 \mathrm{t} \mathrm{ha}^{-1}$. Phosphorus content was $0.072 \pm 0.003 \mathrm{~kg} \mathrm{~m}^{-3}$, or $0.72 \pm 0.03 \mathrm{t} \mathrm{ha}^{-1}$. The total volume of sediment excavated from the four recent grounding sites was approximately $32.6 \mathrm{~m}^{3}$, and resulted in a loss of approximately $489 \mathrm{~kg}$ of buried soil $\mathrm{C}_{\text {org }}$ (not including $\mathrm{C}_{\text {org }}$ contained in lost seagrass biomass), $29.3 \mathrm{~kg}$ of $\mathrm{N}$, and $2.3 \mathrm{~kg}$ of $\mathrm{P}$, respectively (Figure $5)$.

Impacts to Multivariate Sediment Properties

Sediment properties differed between unrestored vessel grounding and reference sites of different age groups. OM and $\mathrm{N}$ were negatively correlated and $\mathrm{BD}$ was positively correlated with PC1 (Table 1). We interpreted PC1 as a proxy for organic matter accumulation in seagrass sediments, characterized by high $\mathrm{N}$ content and low BD. Ammonium and SRP were positively correlated with PC2 (Table 1). We interpreted 
PC2 to represent the availability of dissolved inorganic nutrients. Redox potential and P were not strongly correlated with either PC.

Disturbance status (i.e., injury vs. reference) and Time were significant factors in our analyses of the impacts of groundings on multivariate sediment variables, as was the Disturbance $x$ Time interaction (PERMANOVA, $p<0.005$; Table 2). Depth was significant as a covariate (PERMANOVA, $p<0.001$; Table 2). Multivariate injury data differed significantly from reference data in samples from recent groundings and from each subsequent age group (PERMANOVA pairwise tests, $p<0.048$; Table 2). Sediment organic composition, as represented by PC1 scores, was lower in injury samples than in reference samples at $1 \mathrm{yr}$ old and $5 \mathrm{yr}$ old sites (PERMANOVA, $\mathrm{p}<$ 0.002; Table 2; Figure 6), but not for the other age groups. Porewater nutrient concentrations, as represented by PC2 scores, were higher in injury samples than in reference samples from $0 \mathrm{yr}, 3 \mathrm{yr}$, and $4 \mathrm{yr}$ old sites (PERMANOVA, $\mathrm{p}<0.039$; Table 2; Figure 6). Depth was a significant covariate (PERMANOVA, $p<0.002$, Table 2) for porewater nutrients, indicating elevated concentrations with increasing depth (Figure 6).

Effects of Restoration on Macrophytes and Sediment Properties

Primary Producer Abundance

Seagrass percent cover in each of the restoration treatments remained low relative to reference sites for all age groups (Figure 7). At 4 yr old sites, seagrass percent cover was $11 \%, 31 \%$, and $26 \%$ of reference values for GS, F, and FS sites, respectively. In contrast, macroalgae percent cover at restoration sites increase more rapidly and exceeded reference values in each restoration treatment during the same period (Figure 7). Macroalgae cover increased over fifteen fold in four years in both F and FS sites (Figure 7). 


\section{Sediment Properties}

Sediments at restoration sites differed relative to reference sediments for several measured variables, and differences were most notable at the $F$ and FS sites. At $F$ and

FS sites, bulk density (median 1.3 vs. $0.3 \mathrm{~g} \mathrm{ml}^{-1}$ ) and Eh (median 155 vs. $-323 \mathrm{mV}$ ) were higher in restoration sites (Figure S1). Sediment nutrient content was extremely low at F and FS sites (OM median 1.9\% vs. 16.3\%; N median 0.05 vs. $0.60 \%$; Figures S1, S2). Phosphorus content was on average double in F and FS sites (median 0.34 vs. $0.14 \%$; Figure S2). Ammonium concentrations were generally elevated in restoration sites (Figure S2).

\section{Multivariate Sediment Effects}

In the PCA of sediment variables from the three restoration treatments (GS, F, FS), OM and $\mathrm{N}$ were positively correlated with $\mathrm{PC} 1$, and $\mathrm{BD}$ was negatively correlated by PC1 (Table 1). Negative correlations were found between $\mathrm{PC} 2$ and $\mathrm{P}, \mathrm{NH}_{4}{ }^{+}$, and SRP (Table 1). Redox potential was not strongly associated with either PC. As in the disturbance analysis, we associated sediment organic matter accumulation with PC1, and inorganic porewater nutrient availability with PC2 in the PCA analyses of restoration treatments.

Sediment organic content, as represented by PC1 scores, was lower in all three restoration treatments than in reference meadows (PERMANOVA, $p<0.001$; Table 3; Figure 8). Porewater nutrient concentrations (i.e., PC2 scores) were lower in the GS and FS treatments than in reference meadows (PERMANOVA, $p<0.006$; Table 3; Figure 8), but not in the $\mathrm{F}$ treatments (PERMANOVA, $p=0.408$; Table 3; Figure 8). Organic content and porewater nutrients increased with depth in all analyses (PERMANOVA, $p<0.044$; Table 3; Figure 8). One exception was observed in the F 
analysis, where porewater nutrients did not vary with depth (PERMANOVA, $p=0.102$; Table 3; Figure 8).

Time was a significant factor in explaining variation in both organic content and porewater nutrients, for each restoration treatment (PERMANOVA, $\mathrm{p}<0.001$; Table 3). However, we employed a chronosequence approach, sampling sites from several locations in southern Biscayne Bay (Figure 1). Further, because reference values exhibit variation among the different age groups, this result likely indicates spatial variability in the organic matter and porewater nutrients found in our samples.

\section{Discussion}

We documented that vessel groundings in seagrass ecosystems affected macrophyte abundance and some soil properties, and recovery of response variables to reference levels during the time frame of our study differed among variables. Initial effects on primary producers included loss of soil, seagrass and macroalgae cover. Abundance of benthic microalgae, and calcareous green macroalgae, with rapid growth rates, returned to reference levels within a year of disturbance in grounding injuries. In contrast, differences in seagrass cover and multivariate sediment structure existed between injury and reference samples for all injury age groups that we studied (0 - 5 yrs). Though these differences appeared to vary depending on the age of the injuries, differences in sediment structure seem to be linked to altered sediment and porewater nutrients in the disturbance sites. Our results suggest that seagrass ecosystem structure in vessel grounding disturbances involving sediment excavation did not return to levels in the undisturbed ecosystem in a five year period.

We found that substantial quantities of $C_{\text {org }}$, nitrogen and phosphorus are buried in the seagrass sediments of southern Biscayne Bay. Organic carbon storage is similar 
in magnitude to stocks of two other subtropical seagrass ecosystems (Florida Bay, USA and Shark Bay, Australia) for which $\mathrm{C}_{\text {org }}$ stocks have been quantified (Fourqurean et al. 2012b). The observed nutrient stocks stored in seagrass sediments translate to substantial loss of organic carbon, nitrogen, and phosphorus from the system when seagrass sediments are mechanically disturbed by excavation. Seagrass sediments in southern Biscayne Bay are heavily impacted by vessel groundings in many areas, as are seagrass shoals in many other areas in south Florida (Sargent et al. 1995; Kirsch et al. 2005; SFNRC 2008; Uhrin et al. 2011). Awareness of the magnitude and potential economic value of blue carbon resources is relatively recent (Duarte et al. 2010; Murray et al. 2011; Fourqurean et al. 2012a). The loss of blue carbon due to vessel groundings and other disturbances is a resource impact that resource managers and regulators may not be including in considerations of impact severity, nor in the economics of damage assessment and restoration.

The release of these nutrients may have complex ramifications. For example, it has been proposed that continued global decline of seagrass resources could result in substantial $\mathrm{CO}_{2}$ releases to the atmosphere (Fourqurean et al. 2012a). In this strongly $\mathrm{P}$ limited system, release of even small quantities of $P$ could locally stimulate benthic algae or phytoplankton blooms, or be exported to adjacent ecosystems (Fourqurean et al. $2012 b)$.

Seagrass communities and sediment structure at our restoration chronosequences return to the status of the undisturbed ecosystem in the time frame of this study. Restoration that involves the filling of excavations creates an immediate and lasting disturbance through the introduction of quarried sediments characterized by low $\mathrm{OM}$, and high $\mathrm{BD}$, Eh, and $\mathrm{P}$ content. Filled restoration sites had different grain size characteristics, and in the time frame of our study, lower habitat quality and nutrient 
storage capacity. Higher Eh was recorded for F and FS sites, which had little to no vegetative cover during out study period. In contrast, reference seagrass sediments were strongly reduced. We suggest that the differences in Eh we observed between Fill and reference sites can be explained by the high OM content in the reference sediments, and the near absence of OM in sites that received fill. With little organic material to act as a substrate for microbial remineralization processes in fill sites, Eh was higher in these sites.

Continued monitoring will be necessary to reveal if ecosystem structure in restoration sites recovers to the conditions in the reference seagrass meadows. Regardless of the recovery rate and uncertainty of longer-term function in these sites, filling excavations remains a critical step in stabilizing sites and minimizing the potential for erosion of excavation banks due to currents or storms (Whitfield et al. 2002; McNeese et al. 2006; Uhrin et al. 2011; Hall et al. 2012b). Further, filling excavations provides substrate for eventual recolonization by the seagrass community. Gap closure in seagrass meadows occurs primarily through clonal extension (Rasheed 1999; Kenworthy et al. 2002), and seagrass and rhizophytic algae may not be able to extend down abrupt steep slopes such as typically exist in grounding injuries (Kenworthy et al. 2002; Whitfield et al. 2002). Should plant material fall into the excavation or recruit from seed, the sediments available to them in the bottom of the excavations, as represented by our injury cores, may be qualitatively different from the surrounding seagrass beds, with lower organic matter content and porewater SRP. Drift algae, sponges, and seagrass detritus often accumulates in the bottom of excavations and may cause light limitation and increase sediment sulfides (Kenworthy et al 2002, Lamote et al 2006, but see Irlandi et al. 2004). Further, the potential for reaccumulation of sequestered resources can only be realized with the reestablishment of the seagrass community. For 
these reasons, restoration of excavations to grade is considered a critical step in the recovery process, especially for larger excavations (Uhrin et al. 2011). Planting fast growing seagrass species may also accelerate site recovery in some areas, though seagrass herbivory can have detrimental effects on transplanting projects (see Chapter $\mathrm{VI}$ of this thesis).

In the P-limited seagrass ecosystems of south Florida (Powell et al. 1989; Fourqurean et al. 1992a; Chapter VI of this thesis), resource managers conducting restoration have included a fertilizer source (usually via bird feces delivered by installing bird stakes) into restoration project design (Kenworthy et al. 2000; Kirsch et al. 2005; Farrer 2010; Hall et al. 2012b). The P contributed by bird stakes can cause a lasting enrichment effect. At sites where bird stakes were deployed for 28 months and then removed over 20 years ago, elevated sediment $\mathrm{P}$ concentrations persist (Herbert \& Fourqurean 2008). In our study, we expected to see elevated P content at our 3 and 3.5 yr old GS sites. Bird stakes installed in Florida Bay were shown to provide nitrogen (N) and phosphorus $(P)$ at loading rates of approximately $19 \mathrm{~g} \mathrm{~m}^{-2} \mathrm{y}^{-1}$ and $3.29 \mathrm{~g} \mathrm{~m}^{-2} \mathrm{y}^{-1}$, respectively (Powell et al. 1989; Fourqurean et al. 1995). The effects of this nutrient source in naturally occurring subtropical carbonate sediments can include elevated seagrass biomass and sediment $\mathrm{P}$ concentrations on decadal time scales (Herbert \& Fourqurean 2008). However, we saw no obvious effect of the bird stakes at our GS sites. Bird stakes were left in place at our older GS and FS sites for a period of 18 months. We did not document bird usage of the roosting stakes, and it is possible that the stakes were not used frequently enough to provide their intended function.

We saw elevated $\mathrm{P}$ content at our $3.5 \mathrm{yr}$ old FS sites, and also at F sites (that did not have bird stakes) in the same age groups. We attribute $\mathrm{P}$ content in the FS sites to the enriched fill material, rather than to the presence of bird stakes. The elevated $\mathrm{P}$ 
content recorded for sediments from both fill treatments was unexpected. Fill material used for restoration is sourced from multiple lake mines located throughout Miami-Dade County, Florida. It seems likely that this material was mined from phosphorus belts that underlie parts of south Florida (Marquez et al. 2008). This attribute of the fill material was not intentionally sought, and may have unforeseen consequences. Adding Penriched fill into this P-limited system could have implications for the macrophyte community structure. The $\mathrm{P}$ in this material is likely tightly adsorbed to carbonate particles, but can be released in the presence of respiration in the sediments, such as from microbial remineralization of organic matter (Erftemeijer \& Middelburg 1993; Jensen et al. 1998) or sulfate reduction (Ruiz-Halpern et al. 2008). OM content is expected to accumulate in the sediments with development of the seagrass community, and should result in increased availability of $P$ in the fill sites, above what would normally be expected. If this occurs in sites that are also fertilized via bird roosting stakes, localized "hotspots" of $\mathrm{P}$ enrichment may result, with potential implications for macrophyte communities. For example, chronic $P$ enrichment has been shown to alter seagrass community structure by favoring rapidly growing species (Fourqurean et al. 1995; Herbert \& Fourqurean 2008). Further work is needed on the nature of the material used for fill in seagrass restoration sites, to include reviewing locations of quarries in relation to know bedrock $\mathrm{P}$ deposits. We recommend that fill be analyzed for $\mathrm{P}$ content prior to use in restoration projects, and that caution be exercised when deciding to use bird stakes in conjunction with fill of unknown origin and $\mathrm{P}$ content.

Conclusion

Seagrass communities and sediment structure at our disturbance and restoration chronosequence sites remained distinct from reference seagrass meadow over the time 
frame of the study. Restoration actions involving coarse grained fill resulted in sites with different characteristics than the surrounding reference meadows. We acknowledge our study focused on relatively recent disturbances and restoration projects. It will be important to continue to document ecosystem development in these types of restoration sites to substantiate the assumption that these sites will indeed regain lost structure and function through time, and to calibrate expectations of restoration outcomes. The goal of ecosystem replacement may be questionable for sites that are highly modified sites (Zedler \& Callaway 1999). With unpredictable restoration outcomes and recovery potentially occurring in decadal time frames, we suggest that current seagrass damage assessment practices underestimate the severity of vessel groundings and other humaninduced seagrass disturbances. The potential impacts of releasing nutrients and organic carbon buried in seagrass sediments further contribute to the growing list of arguments in favor of increased protection of seagrass ecosystems. Promising avenues for future work include continuing to monitor these or a subset of sediment structural attributes at these sites over longer time frames; conducting similar studies at other seagrass restoration sites for comparison of recovery rates; and establishing links between structural attributes and ecosystem function for these systems. 
Table 1. Principal components analysis (PCA) eigenvectors for PC axes with eigenvalues $>1.0$ extracted from multivariate data sets of sediment and porewater variables sampled from 7.6 x $40 \mathrm{~cm}$ cores collected from Grounding sites or from Restoration sites. Restoration treatments included Grounding + Stake, Fill, and Fill + Stake.

\begin{tabular}{lcccc}
\hline & \multicolumn{2}{c}{ Grounding } & \multicolumn{2}{c}{ Restoration } \\
\hline & PC1 & PC2 & PC1 & PC2 \\
Variable & $(49.0 \%)$ & $(20.0 \%)$ & $(53.1 \%)$ & $(14.7 \%)$ \\
\hline BD & -0.47 & -0.07 & -0.49 & 0.07 \\
Eh & -0.30 & 0.26 & -0.35 & 0.40 \\
OM & 0.48 & -0.05 & 0.51 & 0.00 \\
$\mathrm{~N}$ & 0.47 & -0.09 & 0.49 & -0.05 \\
$\mathrm{P}$ & 0.36 & 0.35 & -0.21 & -0.57 \\
$\mathrm{NH}_{4}{ }^{+}$ & -0.02 & 0.60 & -0.17 & -0.62 \\
SRP & -0.16 & 0.58 & -0.02 & -0.33 \\
\hline
\end{tabular}


Table 2. Results of PERMANOVA tests of site Status (injury vs. reference) and Time, and pairwise tests of the Disturbance term, on multivariate sediment properties and Principal Component scores representing the sediment organic component (PC1) and porewater inorganic nutrient pools (PC2). Refer to Methods for sediment variables included in analysis.

\begin{tabular}{|c|c|c|c|c|c|c|c|c|c|c|c|c|}
\hline \multirow[b]{2}{*}{ Source } & \multicolumn{4}{|c|}{ Multivariate sediment variables } & \multicolumn{4}{|c|}{ PC1: Sediment organic component } & \multicolumn{4}{|c|}{ PC2: Porewater inorganic nutrients } \\
\hline & $\mathrm{df}$ & MS & Pseudo-F & $\mathrm{P}$ & df & MS & Pseudo-F & $\mathrm{P}$ & df & MS & Pseudo-F & $\mathrm{P}$ \\
\hline Depth & 1 & 59.7 & 14.7 & 0.001 & 1 & 0.4 & 0.5 & 0.498 & 1 & 53.8 & 65.2 & 0.001 \\
\hline Status & 1 & 13.5 & 3.3 & 0.003 & 1 & 1.2 & 1.3 & 0.258 & 1 & 9.9 & 11.9 & 0.002 \\
\hline Time & 4 & 136.5 & 33.7 & 0.001 & 4 & 114.2 & 121.5 & 0.001 & 4 & 15.2 & 18.4 & 0.001 \\
\hline St $\times \mathrm{Ti}$ & 4 & 20.2 & 5.0 & 0.001 & 4 & 12.4 & 13.2 & 0.001 & 4 & 3.1 & 3.8 & 0.008 \\
\hline Residual & 157 & 4.1 & & & 157 & 0.9 & & & 157 & 0.8 & & \\
\hline \multirow{7}{*}{\multicolumn{2}{|c|}{ Pairwise tests on Status }} & Age & $\mathrm{t}$ & $\mathrm{P}$ & & Age & $\mathrm{t}$ & $\mathrm{P}$ & & Age & $\mathrm{t}$ & $\mathrm{P}$ \\
\hline & & Oyr & 1.5 & 0.040 & & Oyr & 0.6 & 0.564 & & Oyr & 3.2 & 0.004 \\
\hline & & $1 \mathrm{yr}$ & 3.1 & 0.002 & & $1 \mathrm{yr}$ & 4.2 & 0.002 & & $1 \mathrm{yr}$ & 1.6 & 0.135 \\
\hline & & $3 y r$ & 1.9 & 0.015 & & $3 y r$ & 1.8 & 0.090 & & $3 y r$ & 2.9 & 0.009 \\
\hline & & 3.5 & - & - & & 3.5 & - & - & & 3.5 & - & - \\
\hline & & $4 y r$ & 1.7 & 0.021 & & $4 y r$ & 1.9 & 0.056 & & $4 y r$ & 2.3 & 0.039 \\
\hline & & $5+y r$ & 3 & 0.002 & & $5+y r$ & 5.9 & 0.001 & & $5+y r$ & 0.7 & 0.510 \\
\hline
\end{tabular}


Table 3. Results of PERMANOVA tests of site Status (restoration vs. reference) and Time, and pairwise tests of significant Status $x$ Time terms, on Principal Component (PC) scores representing sediment organic content (PC1) and porewater inorganic nutrient pools (PC2). Restoration treatments included Grounding + Stake, Fill, and Fill + Stake. Refer to Methods for sediment variables included in analysis.

\begin{tabular}{|c|c|c|c|c|c|c|c|c|c|}
\hline & \multirow[b]{2}{*}{ Source } & \multicolumn{4}{|c|}{ PC1 Sediment organic component } & \multicolumn{4}{|c|}{$\begin{array}{c}\text { PC2 Porewater inorganic } \\
\text { nutrients }\end{array}$} \\
\hline & & $\mathrm{df}$ & MS & Pseudo-F & $P$ & $\mathrm{df}$ & MS & Pseudo-F & $P$ \\
\hline Grounding & Depth & 1 & 7.9 & 18.2 & 0.001 & 1 & 3.6 & 5.2 & 0.026 \\
\hline+ & Status & 1 & 4.9 & 11.2 & 0.003 & 1 & 6 & 8.8 & 0.006 \\
\hline \multirow[t]{3}{*}{ Stake } & Time & 3 & 28.9 & 66.6 & 0.001 & 3 & 17.3 & 25.4 & 0.001 \\
\hline & St $\times \mathrm{Ti}$ & 1 & 1.7 & 3.8 & 0.052 & 1 & 0.6 & 0.9 & 0.316 \\
\hline & Residual & 113 & 0.4 & & & 113 & 0.7 & & \\
\hline \multirow[t]{12}{*}{ Fill } & Depth & 1 & 18.5 & 18.4 & 0.001 & 1 & 2.3 & 3.1 & 0.102 \\
\hline & Status & 1 & 373.2 & 380.2 & 0.001 & 1 & 0.5 & 0.7 & 0.408 \\
\hline & Time & 2 & 40.8 & 41.6 & 0.001 & 2 & 20.8 & 28.6 & 0.001 \\
\hline & St $\times \mathrm{Ti}$ & 2 & 37.3 & 38 & 0.001 & 2 & 2.1 & 2.8 & 0.069 \\
\hline & Residual & 89 & 1 & & & 89 & 0.7 & & \\
\hline & Pairwise tests & & Age & $\underline{\mathrm{t}}$ & $\underline{P}$ & & & & \\
\hline & on Status & & Oyr & 15.7 & 0.001 & & & & \\
\hline & & & $1 \mathrm{yr}$ & 13.6 & 0.001 & & & & \\
\hline & & & $3 y r$ & - & - & & & & \\
\hline & & & 3.5 & 2.6 & 0.017 & & & & \\
\hline & & & $4 y r$ & & & & & & \\
\hline & & & $5+y r$ & & & & & & \\
\hline Fill & Depth & 1 & 45 & 32.8 & 0.001 & 1 & 3.8 & 4.3 & 0.044 \\
\hline+ & Status & 1 & 485.5 & 353.3 & 0.001 & 1 & 7.7 & 8.7 & 0.005 \\
\hline \multirow[t]{8}{*}{ Stake } & Time & 3 & 8.6 & 6.3 & 0.001 & 3 & 7.7 & 8.8 & 0.001 \\
\hline & St $\times \mathrm{Ti}$ & 3 & 40.1 & 29.2 & 0.001 & 3 & 6.4 & 7.3 & 0.001 \\
\hline & Residual & 147 & 1.4 & & & 147 & 0.9 & & \\
\hline & Pairwise tests & & Age & $\underline{t}$ & $\underline{P}$ & & Age & $\underline{\mathrm{t}}$ & $\underline{p}$ \\
\hline & on Status & & Oyr & 16.5 & 0.001 & & Oyr & 1.6 & 0.142 \\
\hline & & & $1 \mathrm{yr}$ & 17.9 & 0.001 & & $1 \mathrm{yr}$ & 1.6 & 0.148 \\
\hline & & & $3 y r$ & 9.3 & 0.001 & & $3 y r$ & 4.8 & 0.001 \\
\hline & & & 3.5 & 1.8 & 0.093 & & 3.5 & 0.2 & 0.833 \\
\hline
\end{tabular}


Figure 1. Location of study sites in southern Biscayne Bay, Florida, USA, within the boundary of Biscayne National Park.

Figure 2. Mean \pm se seagrass (top) and macroalgae (center) percent cover and chlorophyll a content (bottom) at unrestored grounding sites (dark bars) vs. reference (light bars) sites of five known ages. Asterisks indicate where injury values were significantly lower than reference values for the age group.

Figure 3. Mean \pm se depth profiles for bulk density, $\mathrm{pH}$, Eh, and organic matter content from 7.6 x $40 \mathrm{~cm}$ cores collected from unrestored grounding sites of known ages (filled symbols) and from adjacent undisturbed reference sites (open symbols).

Figure 4. Mean \pm se depth profiles for sediment nitrogen and phosphorus content and porewater $\mathrm{NH}_{4}{ }^{+}$and SRP concentrations from $7.6 \times 40 \mathrm{~cm}$ cores collected from unrestored grounding sites of known ages (filled symbols) and from adjacent undisturbed reference sites (open symbols).

Figure 5. Mean \pm se organic matter, nitrogen, and phosphorus content in sediments from recent vessel grounding sites and adjacent intact reference sites. Data are from $7.6 \times 40 \mathrm{~cm}$ cores collected from the bottom of injuries that averaged approximately $40 \mathrm{~cm}$ deep (injury cores, closed symbols), or from the top $40 \mathrm{~cm}$ of the reference seagrass bed (reference cores, open symbols). Reference cores superimposed over injury cores enable $80 \mathrm{~cm}$ deep sediment profiles. Notations quantify organic carbon, nitrogen, and phosphorus stocks in the top meter of sediments, and loss of buried resources per unit area in vessel grounding injuries that excavate the top meter of sediment.

Figure 6. Mean \pm se depth profiles for Principal Component (PC) scores extracted from a multivariate data set of sediment and porewater variables sampled from $7.6 \times 40 \mathrm{~cm}$ cores collected from Grounding sites of known ages (filled symbols) and from adjacent 
undisturbed reference sites (open symbols). PC1 is interpreted as the sediment organic component, and PC2 is interpreted to represent porewater nutrient pools.

Figure 7. Mean \pm se seagrass (left) and macroalgae (right) percent cover through time at restoration sites (filled symbols) and reference sites (open symbols) for chronosequence restoration sites.

Figure 8. Mean \pm se depth profiles for Principal Component (PC) scores extracted from a multivariate data set of sediment and porewater variables at restoration sites of known age groups. Data are from restoration treatments (filled symbols) including Grounding + Stake (left), Fill (center), and Fill + Stake (right) sites and from adjacent undisturbed reference sites (open symbols). PC1 is interpreted as the sediment organic component, and PC2 is interpreted to represent porewater nutrient pools. $3 \mathrm{yr}$ old Fill sites were not available for inclusion in the study design.

Figure $\mathbf{S 1}$. Mean \pm se depth profiles for bulk density and organic matter, nitrogen, and phosphorus content from $7.6 \times 40 \mathrm{~cm}$ cores collected from restoration sites of known ages (filled symbols) and from adjacent undisturbed reference sites (open symbols). Restoration treatments included Grounding + Stake (GS), Fill (F), and Fill + Stake (FS). $3 \mathrm{yr}$ old Fill sites were not available for inclusion in the study design.

Figure S2. Mean \pm se depth profiles for $\mathrm{pH}$, Eh, and concentrations of $\mathrm{NH}_{4}{ }^{+}$and SRP from 7.6 x $40 \mathrm{~cm}$ cores collected from restoration sites of known ages (filled symbols) and from adjacent undisturbed reference sites (open symbols). Restoration treatments included Grounding + Stake (GS), Fill (F), and Fill + Stake (FS). 3 yr old Fill sites were not available for inclusion in the study design. 


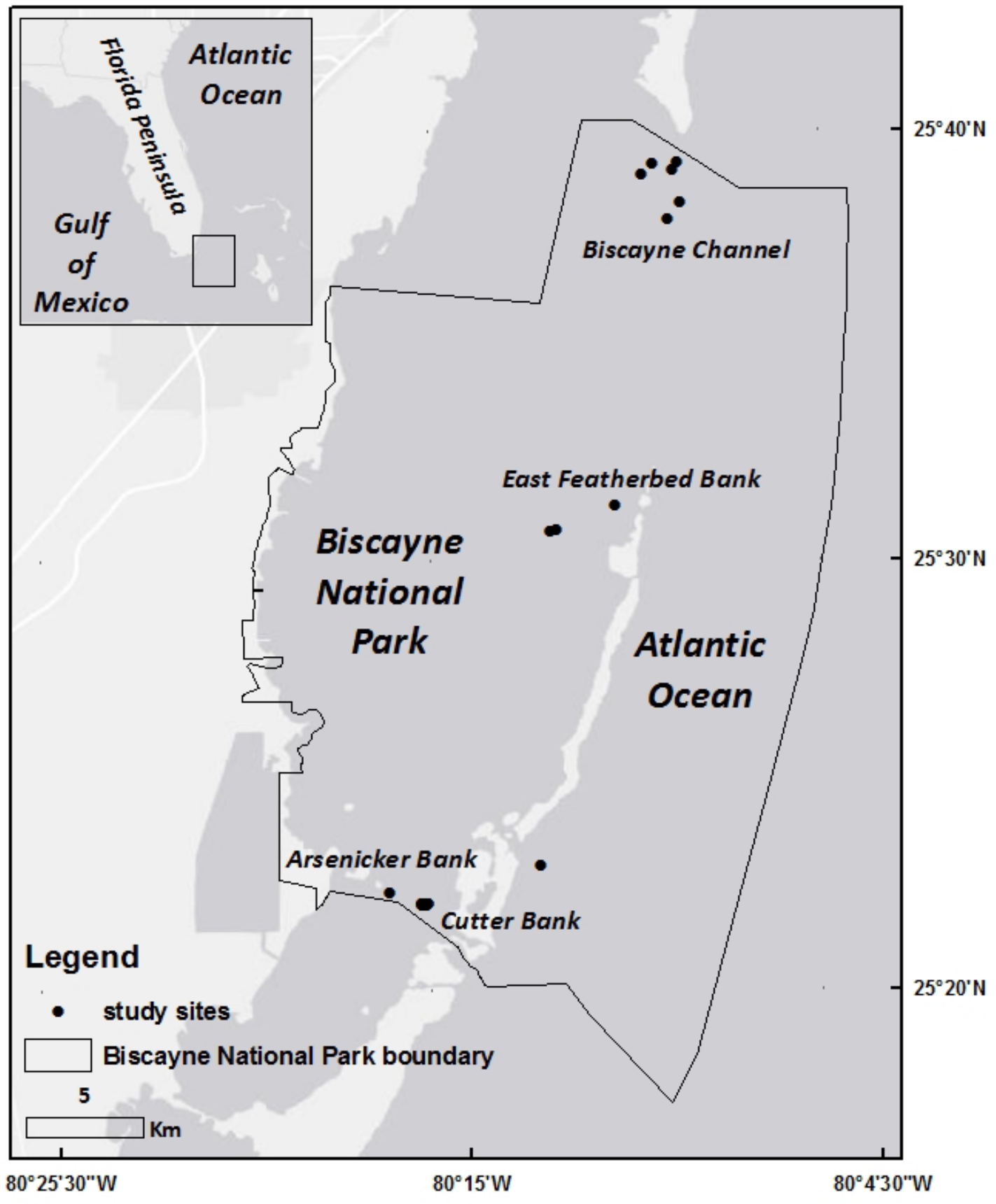



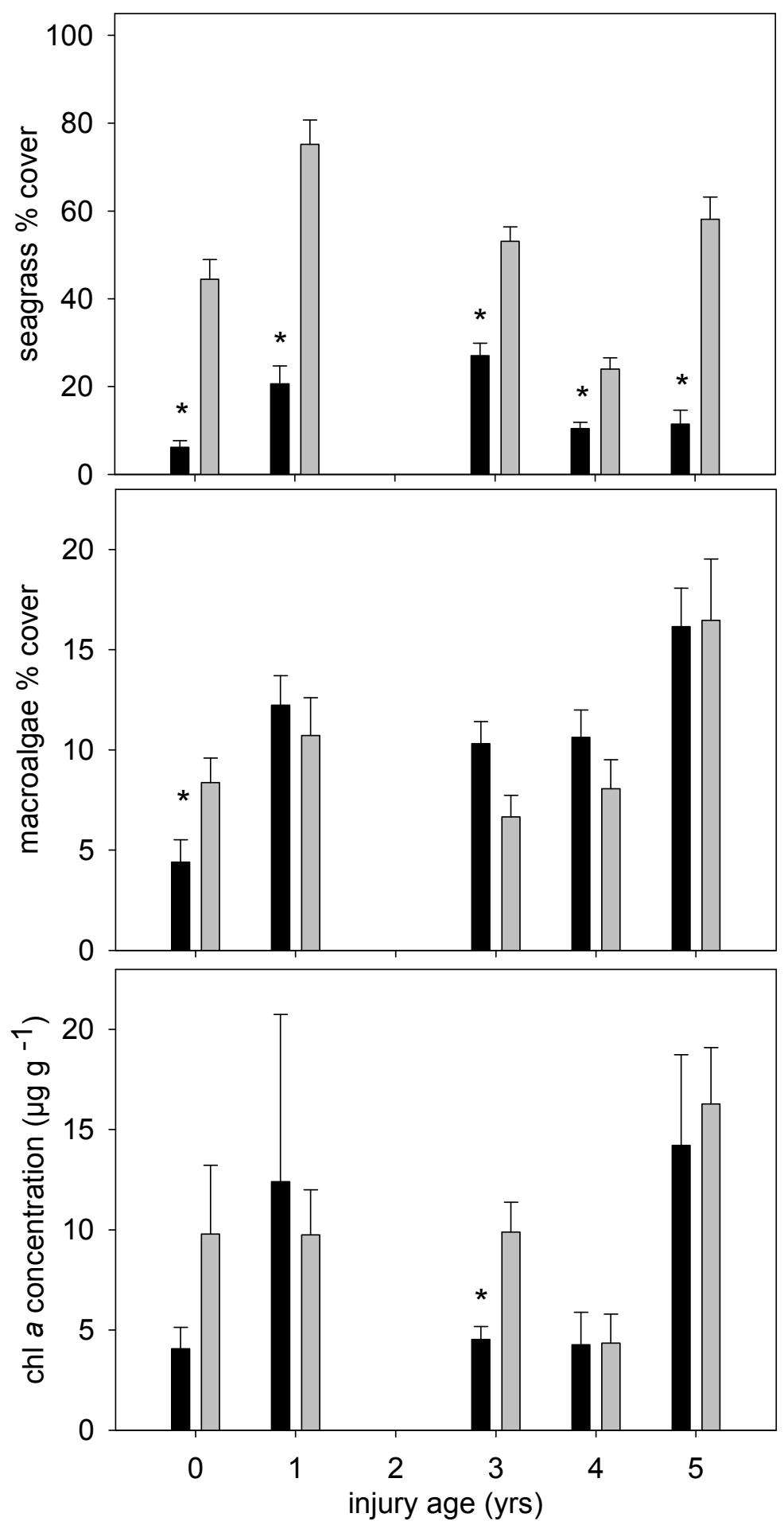


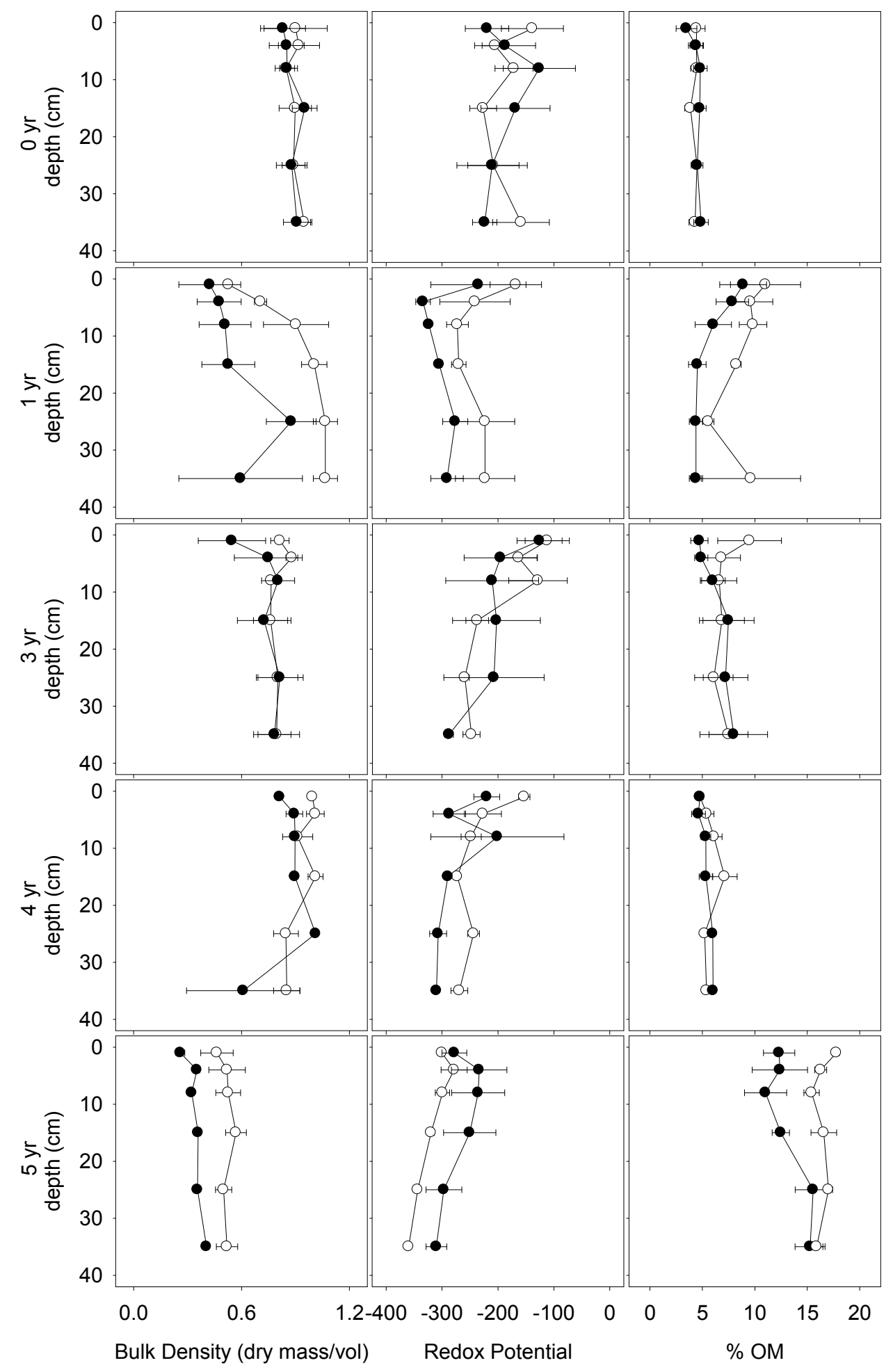




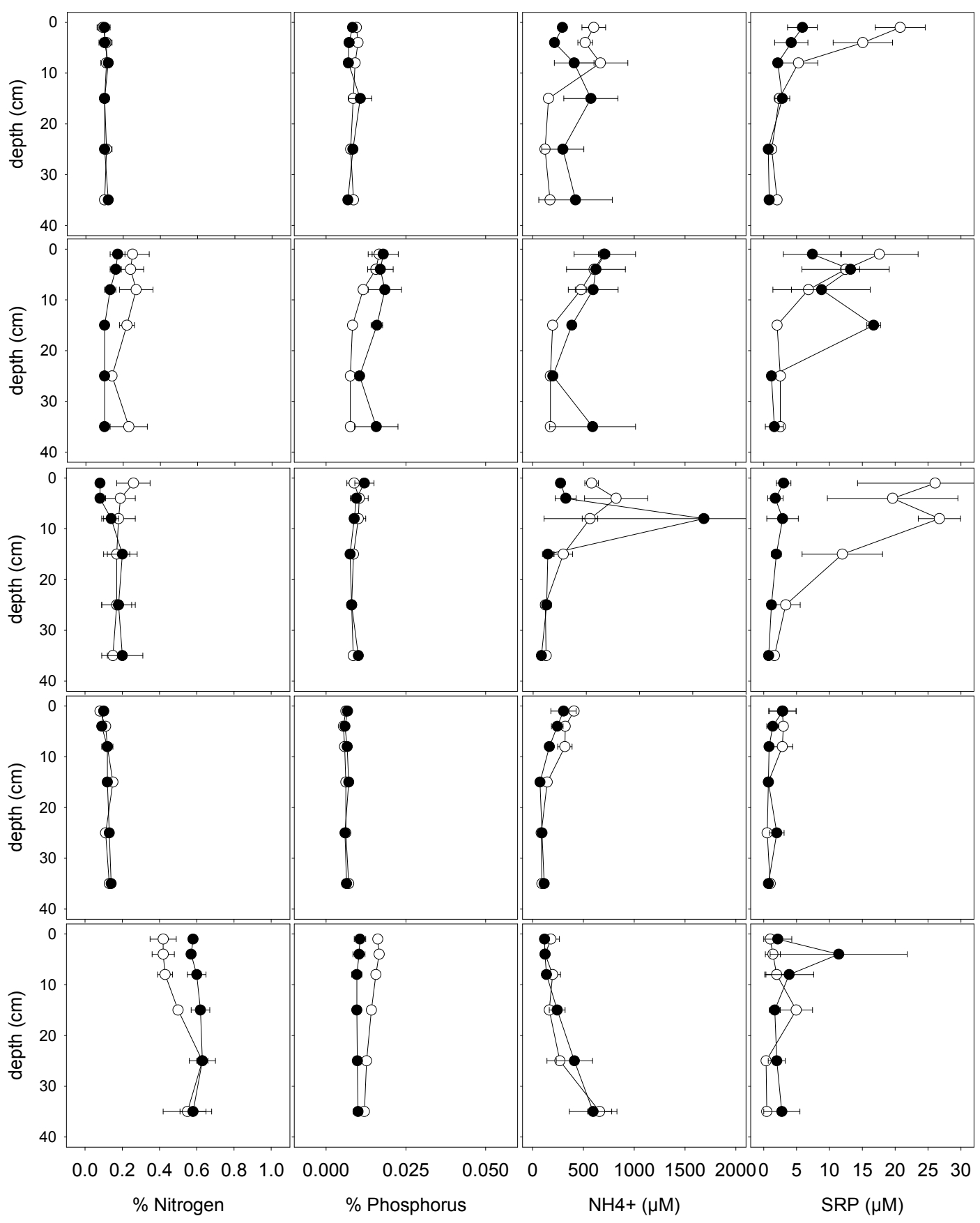




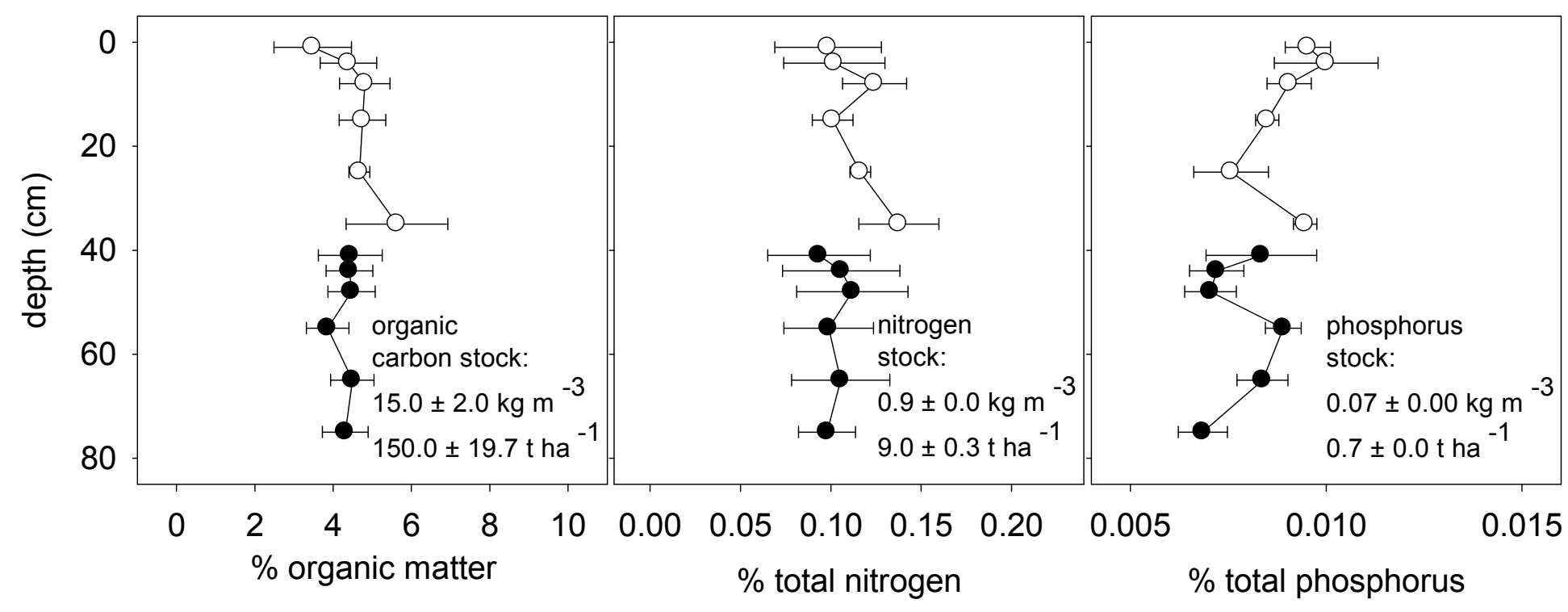




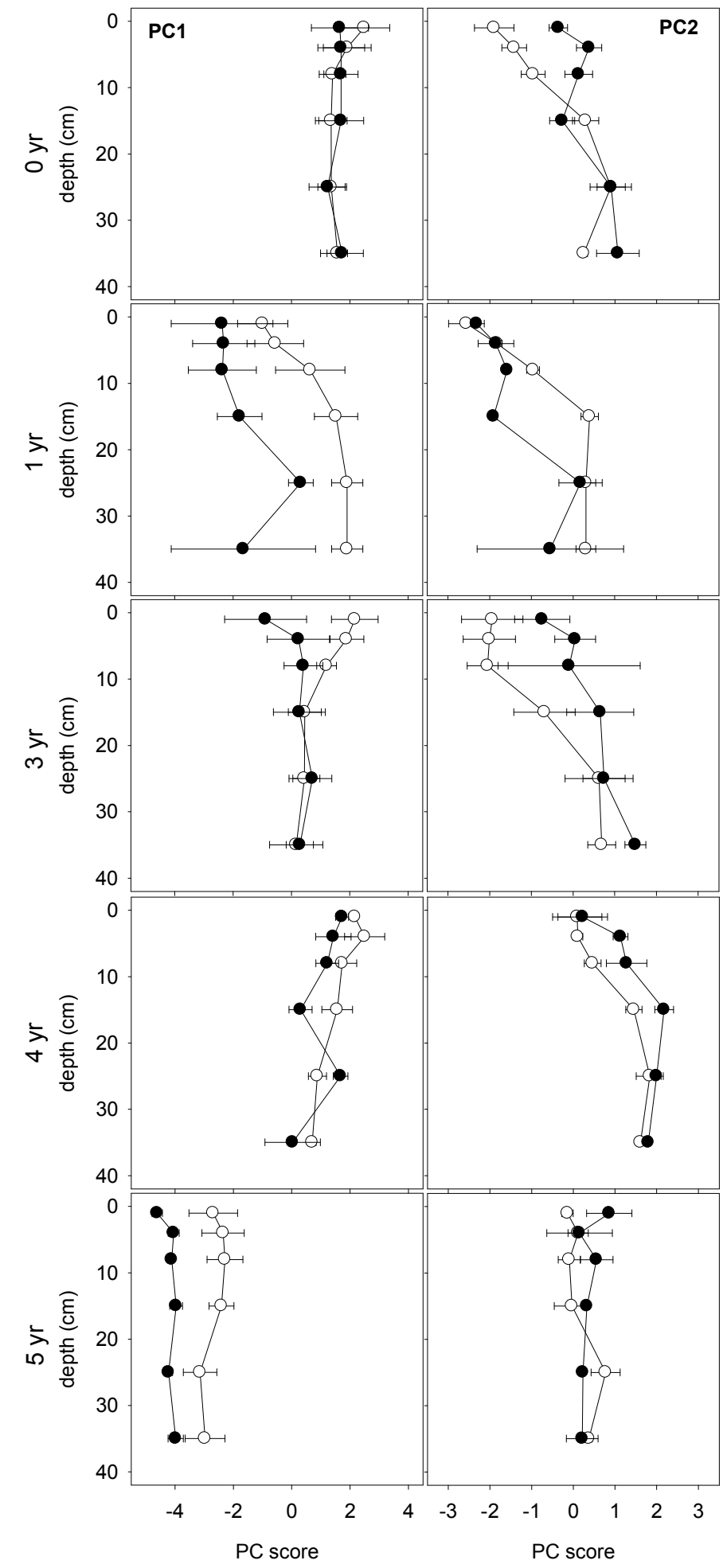


Seagrass
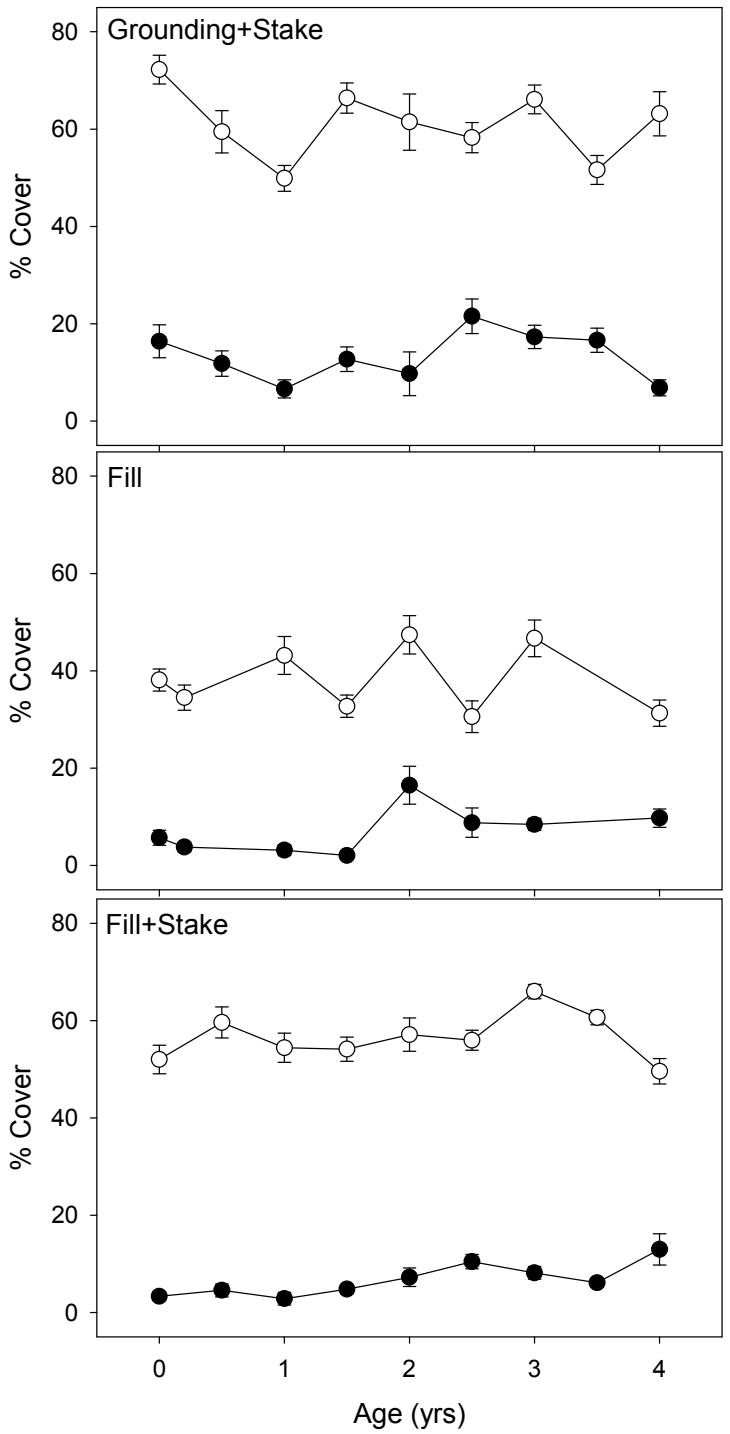

Macroalgae
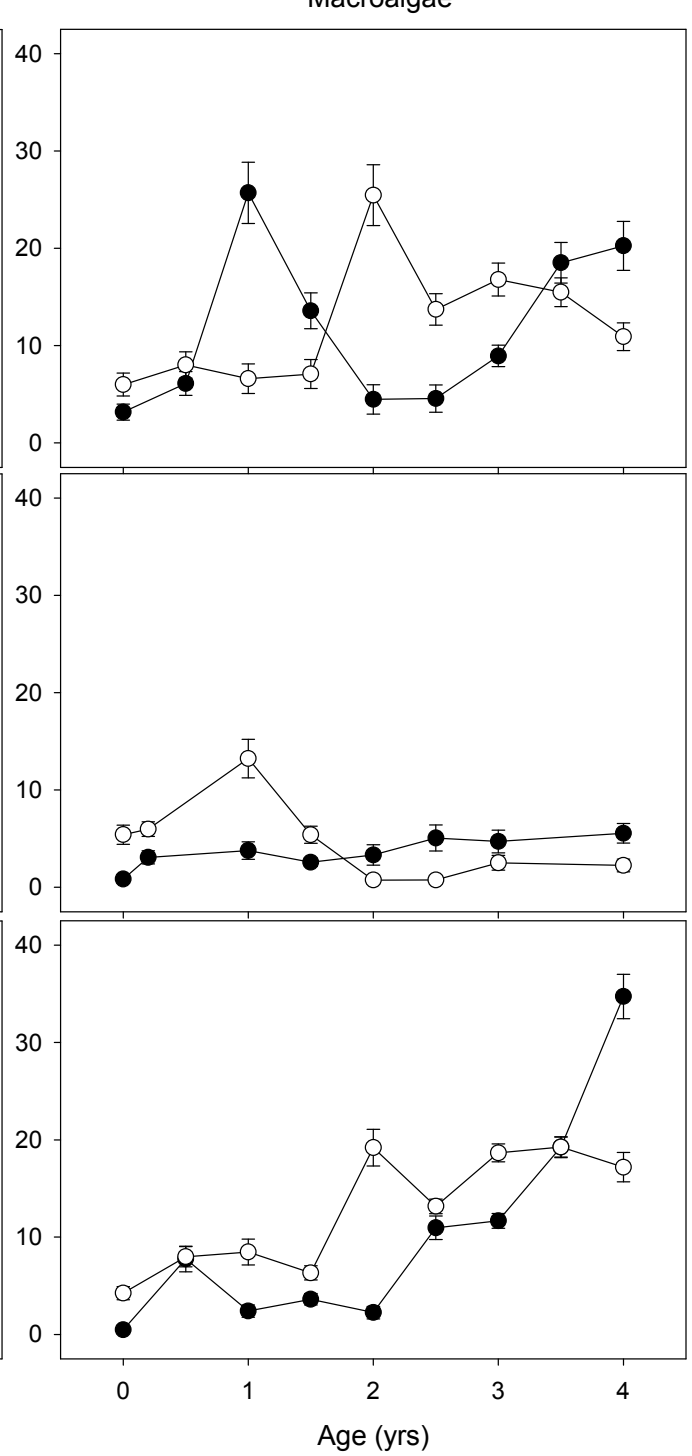


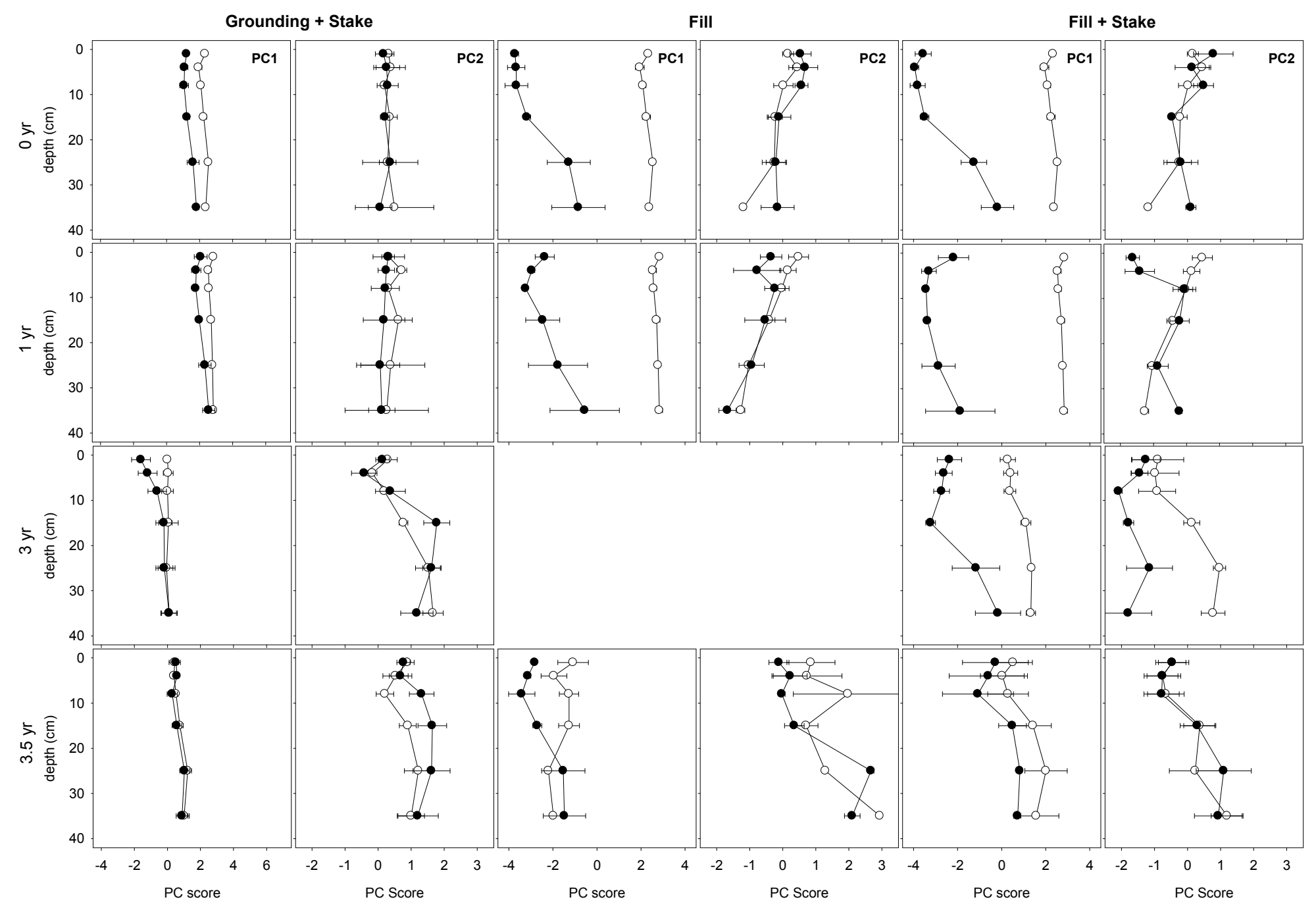



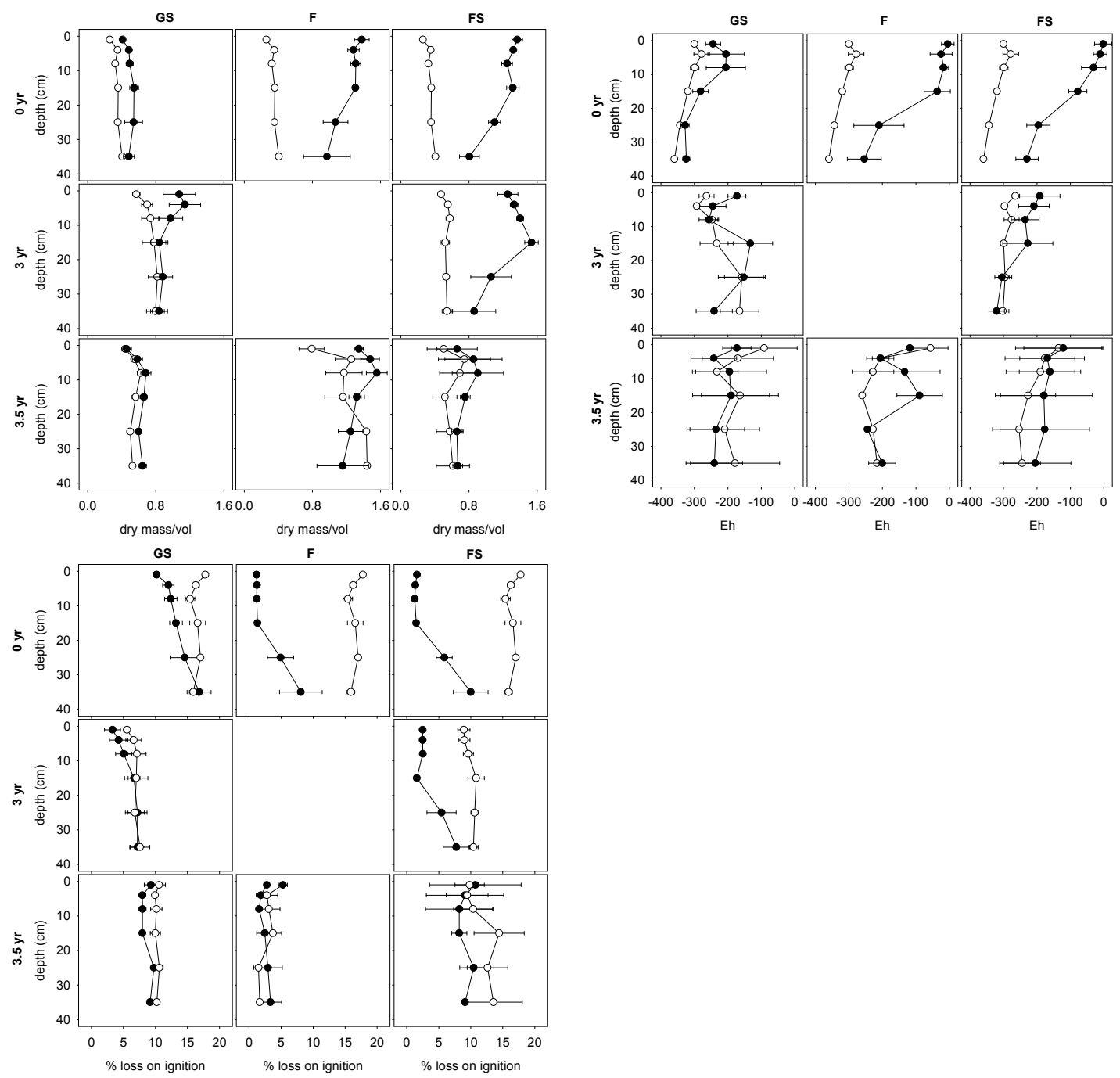

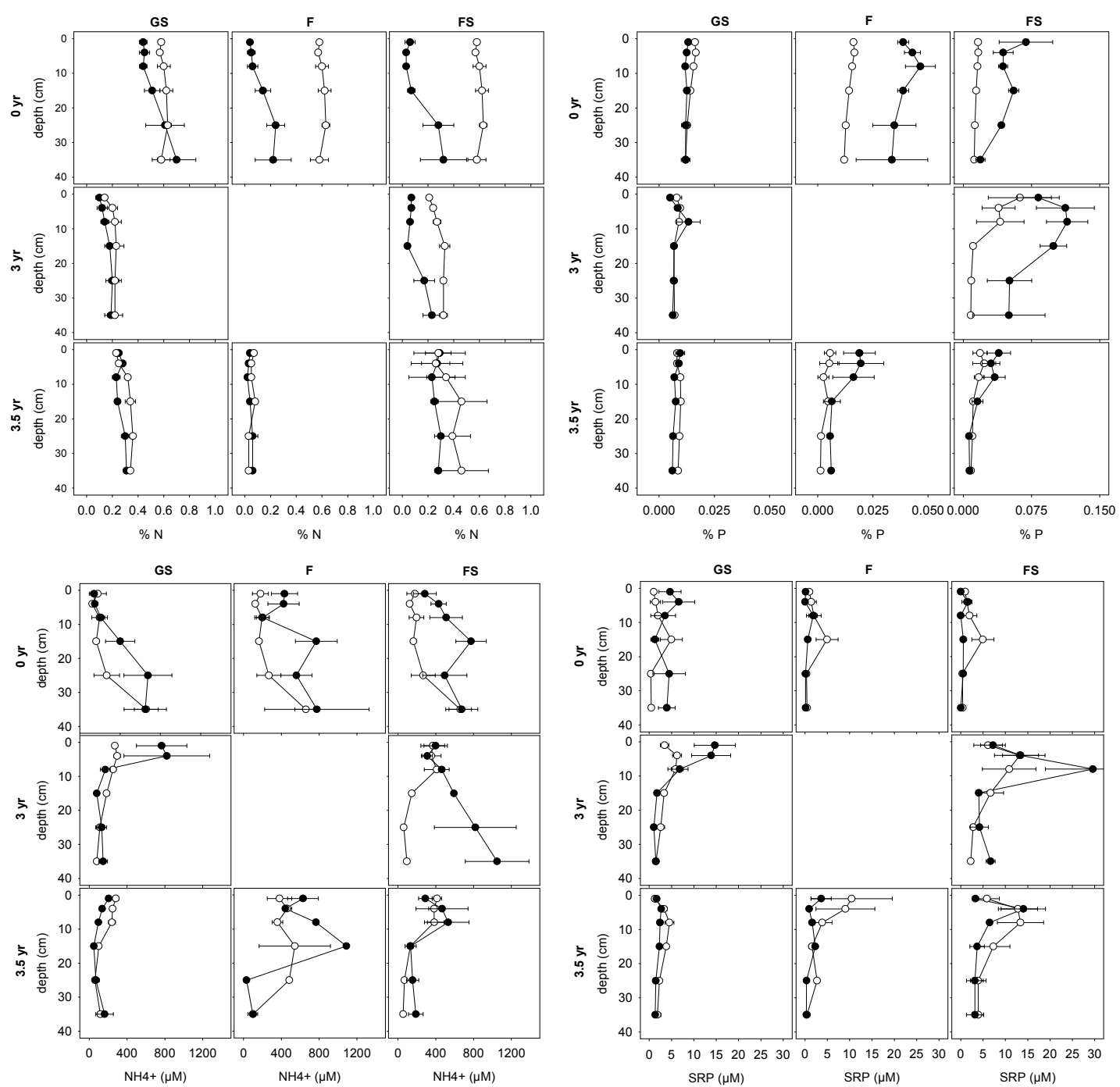
CHAPTER III: Short term effects of restoration on seagrass communities and sediment structure in subtropical seagrass meadows

Abstract

Common seagrass restoration methods following physical disturbance in seagrass meadows include stabilizing excavations through fill placement and providing a fertilizer source to encourage recruitment of nutrient-limited macrophytes into restoration sites. We sampled macrophyte and sediment structure at a group of unrestored and restored vessel grounding disturbances in seagrass meadows over the course of a year in order to better under understand the effects of filling and fertilizing on seagrass ecosystem structure and rate of recovery of the disturbed sites. We hypothesized that a) restoration actions including fill placement and fertilizer delivery via bird roosting stakes alter seagrass ecosystem structure, b) altered structure changes with time following disturbance through succession and ecosystem development, and c) sites that had been restored either though filling or fertilization more rapidly converged on pre-disturbance conditions than did unrestored sites. Fill placement was effective in stabilizing sites and preventing erosion, but ecosystem structure at filled sites was altered relative to both unrestored disturbances and to the undisturbed seagrass ecosystem. Filling vessel grounding injuries initially altered seagrass ecosystem structure by creating a sediment matrix with different physical properties, low organic matter content and nutrient pools, and less primary production relative to the undisturbed ecosystem. Adding a fertilizer source via bird roosting stakes increased porewater nutrient pools at grounding injuries and in undisturbed seagrass, but not at filled sites. As was expected, filling and fertilizing did not result in convergence of our plant and sediment response variables between restoration and intact sites in the first year post-restoration. However, we did 
detect several indicators of ecosystem development in these restoration sites, related to primary production and nutrient accumulation. These results suggest that early stages of ecosystem development have begun at these sites.

Introduction

Loss of seagrass resources in coastal ecosystems is accelerating (Waycott et al. 2009), and physical disturbance from storm events, dredging, development, and fishing gear impacts, contributes to this decline (Short \& Wyllie-Echeverria 1996; Orth et al. 2006; Grech et al. 2012). Seagrass sediments are critical in supporting key ecosystem functions such as nutrient cycling and benthic remineralization processes (Hemminga \& Duarte 2000; Marba et al. 2006b). Physical disturbance to seagrass meadows that disrupts the rhizosphere leads to persistent changes in ecosystem function, including primary production, nutrient cycling, and habitat provision for seagrass-associated organisms (Neckles et al. 2005; Hammerstrom et al. 2007; Di Carlo \& Kenworthy 2008). Seagrass ecosystems in locations where boating is popular are subject to frequent and severe physical disturbance when vessels run aground (Sargent et al. 1995; Dunton \& Schonberg 2002; Kirsch et al. 2005; SFNRC 2008). Vessel grounding disturbances also results in alterations to sediment structure including loss of organic matter and stored nutrients (Kenworthy et al. 2002; Chapter II of this thesis). Accordingly, interest in seagrass restoration has increased in recent decades (Treat \& Lewis 2006; Paling et al. 2009; Fonseca 2011).

Resource managers attempt to accelerate recovery of disturbed seagrass communities by implementing specific restoration methods. Filling grounding excavations, providing a fertilizer source, and transplanting seagrasses are commonlyused seagrass restoration techniques (Fonseca et al. 1998; Kirsch et al. 2005; McNeese 
et al. 2006; Farrer 2010). Placing sediment fill into excavations is intended to prevent erosion and recreate the physical matrix that supports seagrasses and ecosystem functioning (Kirsch et al. 2005; Hammerstrom et al. 2007; Farrer 2010; Hall et al. 2012b). Seagrasses also may be transplanted to more quickly replace lost plant structure and associated functions than would otherwise be accomplished through natural secondary succession following disturbance (Lewis 1987). Because seagrass ecosystems are often nutrient limited (Short 1987; Fourqurean \& Zieman 1992), applying fertilizer via bird roosting stakes at restoration sites aims to reestablish or augment pools of limiting nutrients (Fourqurean et al. 1995; Kenworthy et al. 2000; Farrer 2010).

For restoration to be successful, ecological attributes of the system such as structure, composition, and function must be reestablished (Fonseca et al. 1996a; Hobbs \& Norton 1996; Higgs 1997). Once restoration has been implemented, rapid assessments of plant communities are typically used to monitor restoration success (Fonseca et al. 1998; Kirsch et al. 2005; Farrer 2010). Few studies have assessed ecosystem structure following seagrass restoration for any aspects other than aboveground plant communities (Fonseca et al. 1996a; McNeese et al. 2006; Hammerstrom et al. 2007; Hall et al. 2012b) or associated fauna (Fonseca et al. 1996b, but see Evans \& Short 2005, Di Carlo \& Kenworthy 2008).

Recent work has shown that sediment structure is substantially altered by some restoration practices, especially placing coarse-grained fill into fine-grained seagrass ecosystems (McNeese et al. 2006; Chapter II of this thesis). Filling excavations achieves the objective of stabilizing sites prone to erosion and providing the physical matrix needed to support macrophyte recolonization, but seagrasses and nutrient pools in the sediments and porewater can be slow to recover (Chapter II of this thesis). 
We sampled macrophyte and sediment structure at seagrass restoration sites over the first year following restoration, in order to better under understand the effects of common restoration actions on seagrass ecosystem structure. We hypothesized that a) restoration actions including fill placement and fertilizer delivery via bird stakes alter seagrass ecosystem structure, and specifically, primary producer abundance and sediment properties; b) altered structure changes with time following disturbance through succession and ecosystem development; and c) sites that had been restored either though filling or fertilization more rapidly converged on pre-disturbance conditions than did unrestored sites. Our response variables included structural attributes essential to habitat quality, nutrient storage, and ecosystem metabolism in the vegetation and the sediments.

Methods

\section{Study System}

This study was conducted in southern Biscayne Bay, described in Chapter II of this thesis. Specifically, we evaluated seagrass ecosystem structure at multiple vessel grounding injuries, restoration sites, and adjacent undisturbed seagrass meadows on Cutter Bank (Figure 1).

\section{Experimental Design}

We examined the effects of vessel grounding disturbance and seagrass restoration practices on plant soil properties at eighteen individual sites at Cutter Bank sampled following implementation of a restoration project in January-February 2010. A factorial design was employed, with Restoration, Fertilization, and Time as factors. Restoration treatments included unrestored vessel grounding injuries ( $G=$ grounding), 
injuries that were returned to grade with sediment fill $(\mathrm{F}=$ fill), and intact undisturbed seagrass sites (I=intact). The Restoration factor was crossed with a Fertilization factor by installing bird roosting stakes into a subset of sites within each three Restoration treatments (GS = grounding+stake, FS = fill+stake, IS = intact+stake). Sites were an average of $34 \mathrm{~m}^{2}$ in size, and Restoration and Fertilization treatments were randomly assigned to sites. Note the $\mathrm{G}$ sites were not recent injuries, but rather were known to be a minimum of five years old based on unpublished NPS data on injury features at Cutter Bank. Intact $(n=3)$ and Intact + Stake $(n=3)$ plots were established by delineating $32 \mathrm{~m}^{2}$ circular plots around randomly selected points across in the seagrass meadow on the shoal that showed no signs of recent vessel grounding injury. Three sites were included in each Restoration x Fertilization treatments (i.e., G, GS, F, FS, I, IS). The eighteen sites were sampled within one month of restoration implementation and at three, six, nine, and twelve months following restoration (February, May, August, November 2010 and February 2011).

Seagrass Community Characterization

To evaluate the status of the macrophyte community, seagrass and macroalgae (i.e. calcareous green algae) abundance was estimated according to methods described in Chapter II of this thesis.

\section{Sediment Core Collection and Processing}

We used cores of the surface sediments to define the soil environment as a function of restoration and fertilization treatments. We sampled a suite of eleven soil properties that are indicators of structure and function in seagrass ecosystems, including benthic microalgae (primary production, habitat quality); $\mathrm{pH}$, redox potential, organic matter content, and porewater sulfide (benthic metabolism and remineralization); bulk 
density, water content, and particle size (nutrient exchange); and nitrogen and phosphorus in sediment and porewater (nutrient storage). Detailed descriptions of coring and environmental analyses are provided in Chapter II of this thesis. Grain size contributions were determined through sieve analysis (Ingram 1971; Folk 1974) at Terra Environmental (St. Petersburg FL).

\section{Data Analysis}

We used Spearman correlations to detect changes in seagrass and macroalgae percent cover at Restoration and Fertilization treatments through time. We explored sediment structure among restoration treatments using principal components analysis (PCA) with the software Primer-e (Clarke \& Gorley 2006). The PCA allowed us to reduce data complexity and extract composite variables that explained maximum variability in the sediment properties. Nine sediment variables were included in the PCA: $\mathrm{BD}, \mathrm{pH}, \mathrm{Eh}, \mathrm{OM}, \mathrm{N}, \mathrm{P}, \mathrm{NH}_{4}{ }^{+}, \mathrm{SRP}$, and DS. The PCA ordinations helped visualize multivariate differences among treatments. We then described an ecological role for the composite variables, on the basis of sediment variables that were strongly correlated with PC axes that had eigenvalues $>1$.

We tested our hypotheses that restoration alters ecosystem structure and that structure changes through time using Permutational Multivariate Analysis of Variance (PERMANOVA, Anderson et al. 2008). The PERMANOVA routine enables testing of the response of one or more variables to one or more factors, based on any resemblance measure, by partitioning sources of variation. A primary advantage of PERMANOVA is that statistical significance of the pseudo- $F$ statistic is determined through permutations of randomized real data, avoiding normality and homogeneity of variance assumptions (Anderson et al. 2008). Specifically, we used PERMANOVA to test for the effects of 
Restoration, Fertilization, and Time on a) chlorophyll a content, b) sediment particle size class composition, c) multivariate soil properties, and d) each composite variable extracted from the PCA.

All PERMANOVA analyses were conducted on Euclidean distance resemblance matrices calculated from normalized, log-transformed data. Significance values were based on 999 permutations of residuals under reduced models. Where data variables were available for multiple depth horizons, sediment depth was used as a covariate requiring the use of Type I sums of squares. Otherwise, Type III sums of squares were used in PERMANOVA.

Results

Plant Community Structure

The intact seagrass community at Cutter Bank is characterized by dense Thalassia testudinum (median percent cover 62.5\%) mixed with sparse calcareous green macroalgae (median percent cover 2.5\%). Over the course of the first year postrestoration, seagrass cover remained below $10 \%$ of reference values for the F and FS sites, and at around $20 \%$ for G and GS sites (Figure 2). Seagrass cover remained unchanged over time for G, FS, and F treatments ( $p>0.05$; Figure 2), and declined in the GS treatment $(\rho=-0.18, p=0.038$; Figure 2). In contrast, macroalgae cover in restoration sites ranged from $30 \%(F)$ to $161 \%(G S)$ of reference values after a year (Figure 3). Within restoration sites, macroalgae cover increased four to twelve times over the course of the study and was significantly correlated with time in each treatment $(p<0.041$; Figure 3). 


\section{Chlorophyll a Content}

Restoration status during the first year post-restoration at the Cutter Bank sites affected sediment microphytobenthos abundance. Chlorophyll a content across all samples ranged from $10.6 \pm 1.7$ to $16.4 \pm 1.9 \mu g^{-1}$ (Figure 4). Chlorophyll a content varied among restoration treatments and time (PERMANOVA, $p<0.001$; Table 1), but not with fertilization $(p=0.263)$, so results are presented for the main restoration treatments (i.e. G, F, I). Chlorophyll a content was highest at the I sites (PERMANOVA pairwise tests, $p<0.002$; Table 1; Figure 4), and there was some variation among sampling events. Chlorophyll a content was lower in G sites, ranging from $10.6 \pm 1.7$ to $11.6 \pm 2.8 \mu \mathrm{g} \mathrm{g}^{-1}$, and values did not vary significantly with time (PERMANOVA pairwise tests, $p<0.05$; Figure 4). The F sites had the lowest overall chlorophyll a content (PERMANOVA pairwise tests, $p<0.002$; Table 1), ranging from $0.2 \pm 0.1$ to $5.4 \pm 1.3 \mu \mathrm{g}$ $\mathrm{g}^{-1}$. Chlorophyll a content at F sites increased steadily with each time step (PERMANOVA pairwise tests, $p<0.05$; Figure 4), but remained lower than $G$ or I sites at the $1 \mathrm{yr}$ mark.

Sediment Properties - Intact Sediments

Water content ranged from $64 \pm 5.4 \%$ to $81.0 \pm 0.7 \%$ in intact sediments and did not vary with depth below the top $2 \mathrm{~cm}$ of sediment (Figure 5). Bulk density ranged from $0.18 \pm 0.01 \mathrm{~g} \mathrm{ml}^{-1}$ to $0.41 \pm 0.10 \mathrm{~g} \mathrm{ml}^{-1}$, and was lower in the top $2 \mathrm{~cm}$ of sediments than in the deeper horizons (Figure 5). Sediment $\mathrm{pH}$ ranged from $6.56 \pm 0.02$ to $7.38 \pm 0.02$ generally decreased with depth below $30 \mathrm{~cm}$. Sediments were strongly reduced, and redox potential decreased with depth over the all depth horizons, ranging from $-278.3 \pm$ $23.3 \mathrm{mv}$ to $-359.6 \pm 0.9 \mathrm{mv}$ (Figure 5$)$. Organic matter content $(13.8 \pm 1.2 \%$ to $18.3 \pm$ $0.5 \%$; Figure 6) increased with depths below $6 \mathrm{~cm}$. Nitrogen content was fairly constant, 
ranging from $0.52 \pm 0.01 \%$ to $0.67 \pm 0.01 \%$, and did not vary with depth (Figure 6). Total phosphorus content was very low $(0.011 \pm 0.001 \%$ to $0.019 \pm 0.002 \%$, Figure 6$)$ and decreased with depth. Ammonium $(83.0 \pm 6.4 \mu \mathrm{m}$ to $842.9 \pm 108.9 \mu \mathrm{m}), \operatorname{SRP}(0.09 \pm$ $0.02 \mu \mathrm{m}$ to $18.8 \pm 4.5 \mu \mathrm{m})$, and DS $(76.4 \pm 9.0 \mu \mathrm{m}$ to $3157.5 \pm 241.7 \mu \mathrm{m})$ concentrations all ranged widely (Figure 6). Ammonium and DS increased with depth, while SRP showed no trends with depth. Porewater profiles showed some anomalies that contribute to the wide-ranging values. Specifically, $\mathrm{NH}_{4}{ }^{+}$and SRP profiles for the $0.5 \mathrm{yr}$ sampling event were elevated in the top $20 \mathrm{~cm}$ of sediments relative to profiles from the other four sampling events (Figure 6). Dissolved sulfide profiles increased substantially with sediment depth for the $1 \mathrm{yr}$ profile relative to the previous sampling events (Figure $6)$.

\section{Particle Size Composition}

At Cutter Bank, intact sediments were dominated by silt $(59.8 \pm 3.4 \%)$ and clay $(29.3 \pm 3.0 \%)$, with small sand $(8.6 \pm 1.5 \%)$ and gravel $(2.3 \pm 0.9 \%)$ fractions (Figure 7$)$. Multivariate sediment profiles (\% clay, silt, sand, gravel) differed among Restoration treatments (PERMANOVA, $p<0.001$; Table 2), but not with Fertilization or Time $(p>$ 0.236). G sites had similar composition as intact sediments, but $F$ sites were much coarser, consisting predominately of sand $(50.3 \pm 1.8 \%)$ and gravel $(47.3 \pm 1.9 \%)$. The Restoration x Fertilization term was significant (PERMANOVA, $p<0.001$; Table 2), suggesting that fertilization affected the grain size distribution in restoration treatments in different ways. Specifically, only IS differed from its non-fertilized pair (PERMANOVA pairwise tests, $p<0.008$; Figure 7). 


\section{Multivariate Restoration Effects}

The effects of restoration status on multivariate sediment properties during the first year post-restoration at the Cutter Bank sites were evident in the PCA ordination visualized for the Restoration x Fertilization factor (Figure 8). PC1 had positive OM and $\mathrm{N}$ loadings and negative $\mathrm{BD}, \mathrm{pH}, \mathrm{Eh}$, and $\mathrm{P}$ loadings, and explained $57 \%$ of variation in the data set (Table 3). We interpreted PC1 to represent sediment OM. Ammonium and SRP loaded positively onto PC2 (18.3\% of variance explained; Table 3$)$, and we described PC2 as representing dissolved inorganic nutrients. Dissolved sulfide was not strongly correlated with either axis. Fill sediments from F and FS samples were characterized by high $\mathrm{BD}, \mathrm{P}, \mathrm{pH}$, and $\mathrm{Eh}$, and clearly separated from $\mathrm{G}, \mathrm{GS}$, IS, and I samples (Figure 8). There was considerable overlap among G, GS, IS, and I samples, characterized by high $\mathrm{OM}$ and $\mathrm{N}$ content, in the right portion of the plot. Samples from I sites had higher sediment organic content than G, GS, and IS samples. There was little difference among any treatments for porewater nutrient concentrations.

Multivariate sediment structure at the Cutter Bank sites varied by Restoration, Fertilization, and Time (PERMANOVA, $p<0.001$; Table 4). Pairwise tests on the Restoration factor show significant differences in multivariate data among the three treatments (PERMANOVA pairwise tests, $p<0.001$ ), confirming the structure evident in the PCA ordination (Figure 8).

Our composite variables were also affected by restoration status (PERMANOVA, $p<0.001$; Table 4, Figure 9). Each restoration treatment $(G, F, I)$ differed from the others for both composite variables (PERMANOVA pairwise tests, $p<0.001$; Table 4; Figure 9). Organic matter content was highest in I sites, lower content in G sites, and nearly absent in F sites (Figure 9). Noticeable trends of porewater nutrient patterns among Restoration $x$ Fertilization treatments were lacking, though concentrations in $\mathrm{F}$ 
and FS treatments were more variable than in the other treatments. Concentrations were highest in the 6 month samples (from August 2010) across all Restoration $x$ Fertilization treatments.

Porewater nutrients, but not OM content, were affected by fertilization (PERMANOVA, $p<0.001$; Table 4; Figure 9). In Restoration x Fertilization pairs, porewater nutrient concentrations was elevated for the fertilized sites within the G-GS and I-IS pairs (PERMANOVA pairwise tests, $p<0.001$ ); Table 4; Figure 9), but not in the F-FS pair. Sediment depth was a significant covariate for both composite variables (PERMANOVA, $p<0.001$; Table 4). Across all Restoration x Fertilization treatments, OM and porewater nutrient pools tended to increase with depth (Figure 9).

\section{Discussion}

Filling vessel grounding injuries initially altered seagrass ecosystem structure by creating a sediment matrix with different physical properties, low organic matter content and nutrient pools, and lower macrophyte cover and microalgal abundance relative to the undisturbed ecosystem. Adding a fertilizer source via bird roosting stakes increased porewater nutrient pools at GS and IS sites, but not at FS sites.

Seagrass cover did not increase in any of the restoration treatments during the first year post-restoration. In contrast, calcareous green macroalgae did increase during this period in all restoration treatments, though greater increases were seen for $G$ and GS sites than in F and FS sites. These findings are consistent with observed patterns of early succession in tropical seagrass ecosystems. The first colonizers following disturbance are turf and calcareous green macroalgae, followed by rapidly growing seagrass species, and culminating with a monospecific climax community dominated by slower-growing species, or a mixed community of climax and successional species 
(Zieman 1982; Williams 1990; Rollon et al. 1999; Kenworthy et al. 2002; Whitfield et al. 2002). It has been proposed (Williams 1990) that these patterns indicate a facilitation (sensu Connell \& Slayter 1977) model of succession. Early colonizers stabilize sediments and help build nutrient pools that eventually provide for colonization by climax species, consistent with the resource-ratio hypothesis of community development (Tilman 1985). We interpret the observed trend of macroalgae colonization as a positive early indicator of recovery.

Benthic microalgae perform important functions in shallow coastal sediments by fixing carbon, oxygenating surficial sediments, and providing food sources to meio- and macrofauna (Moncreiff et al. 1992; Pollard \& Kogure 1993). Nutrient limitation in coastal ecosystems extends to other primary producers in the ecosystem, including benthic microalgae (e.g., Granéli \& Sundbäck 1985; Howarth 1988; Posey et al. 2002; Allgeier et al. 2010). In our study, benthic microalgae did not respond to fertilizer input via defecation by wild birds using the bird roosting stakes, suggesting that the microalgae are not nutrient limited at this location. Microalgal response to nutrient addition in seagrass sediments can be variable and may reflect complex interactions between biotic and abiotic factors (Armitage et al. 2005, 2006). We saw a clear pattern of development of benthic microalgal abundance in the filled sites over the course of the study. Recovery of benthic microalgae following disturbance occurs relatively quickly due to rapid rates of growth and reproduction (Larson \& Sundback 2008; Montserrat \& Colen 2008) and the motility of some benthic diatom taxa (Admirall 1984) may enable rapid colonization of new substrate. Though chlorophyll a content did not yet reach levels of the surrounding seagrass meadow, the observed increase is nonetheless an early indicator of returning structure and function. 
Excavation of sediments by vessel groundings removes the vital substrate needed by seagrasses and rhizophytic macroalgae to thrive. Replacing that physical matrix by placing fill into injuries is an important restoration action for two primary reasons. Filling excavations stabilizes the site and helps to prevent further site damage through erosion caused by currents or severe storms (e.g., Whitfield et al. 2002; Uhrin et al. 2011). Gap closure in seagrass meadows occurs primarily through clonal extension (Rasheed 1999; Kenworthy et al. 2002), and seagrass and rhizophytic algae may be not be able to extend down abrupt steep slopes such as typically exist in grounding injuries (Kenworthy et al. 2002; Whitfield et al. 2002). Thus, filling excavations is expected to encourage greater recovery of the plant community that would be expected in unfilled excavations. For these reasons, filling excavations to grade is considered a critical step in the recovery process, especially for larger and deeper injuries (Uhrin et al. 2011).

We found very low soil organic content at sites filled with quarried sand, and organic content did not increase in the short term. In seagrass meadows redeveloping from an unvegetated state, OM can accumulate in the sediments during the recolonization process (Pedersen et al. 1997; Cebrián \& Pedersen 2000; Barrón et al. 2004; McGlathery et al. 2012). Sources of OM include dead roots and rhizomes; root exudates; organic particles and litter buried by sedimentation and bioturbation; and benthic microalgal exudates (Pedersen et al. 1997; Holmer et al. 2001). Organic matter content in filled sites is expected to remain low until these sites support dense monospecific or mixed seagrass communities.

Another key difference between filled sites and the undisturbed ecosystem was particle size composition. In seagrass ecosystems, sediment grain size and porosity affects exchange of sediment pore water with overlying waters (Koch et al. 2001). Grain size is correlated with pore water exchange (Fourqurean et al. 1992), and thus nutrients 
and also toxic compounds such as sulfide may accumulate faster and at higher concentrations in fine-grained sediments relative to coarse sediments. To avoid erosion, sediments used in seagrass restoration projects are typically far coarser than ambient sediments (e.g., McNeese et al. 2006; Hall et al. 2012b) , as was the case with our fill treatments. Turbidity created during fill placement can be difficult to control with fine sediments, and there also is concern that fine sediments may wash away from the site with tides and wave energy. The silt/clay fraction of fill material used in this restoration project ranged from $1 \%$ to $6 \%$, within the range of sediments that $T$. testudinum is known to grow in (Koch et al. 2001), but far lower than ambient sediments at Cutter Bank. Seagrass blades attenuate water movement and trap suspended particles, and fine sediments accumulate in seagrass meadows through sedimentation and percolation (Terrados \& Duarte 2000). Fine sediments are expected to increase in the fill sites as the seagrass community develops with time and seagrass blades entrain particles from the water column, but these sites will likely always remain coarser than the surrounding sediments.

The sand used to fill grounding excavations had elevated $\mathrm{P}$ content compared to sediments found in the reference areas around the injuries, and may have been quarried from bedrock containing phosphorus deposits (Marquez et al. 2008). Using fertilizer to aid restoration is desirable in P-limited seagrass ecosystems (Kenworthy et al. 2000), hence the use of bird roosting stakes to deliver phosphorus (Fourqurean et al. 1995). However, even small P inputs can have long lasting effects in this system. For example, following the experimental use of bird roosting stakes, with a P loading rate of $3.29 \mathrm{~g} \mathrm{~m}^{-2}$ $\mathrm{y}^{-1}$ (Powell et al. 1989), elevated $\mathrm{P}$ content in sediments was detected over twenty years later (Herbert \& Fourqurean 2008). 
Carbonate dissolution is one mechanism by which P tightly sorbed to carbonate particles is released into the rhizosphere and becomes available for uptake by seagrasses (Erftemeijer \& Middelburg 1993; Jensen et al. 1998). In carbonate systems, $\mathrm{pH}$ values lower than 8.2 have been correlated with carbonate dissolution (Burdige \& Zimmerman 2002). The range of $\mathrm{pH}$ values recorded in our study was surprisingly low (median $\mathrm{pH}$ 7.0) in grounding and intact sediments. This may reflect intense benthic metabolism associated with remineralization of elevated OM content or with sulfide oxidation (Jensen et al. 1998). These $\mathrm{pH}$ values are within the range at which carbonate dissolution should occur. The median $\mathrm{pH}$ for fill sites was 7.7. If $\mathrm{pH}$ drops through time in sites with P-enriched fill, the release of ecologically significant quantities of $\mathrm{P}$ could result. Ramifications could include localized eutrophic effects (e.g. changes in seagrass community structure, water column phytoplankton blooms), or export to and enrichment of adjacent ecosystems including coral reefs. Of further concern is that bird stakes are often placed in restoration sites receiving fill material. If the fill is P-enriched, additional nutrient input via bird stakes could compound these effects. Further work is needed on the nature of the material used for fill in seagrass restoration sites, to include reviewing locations of quarries in relation to know bedrock $P$ deposits. We recommend that fill be analyzed for $\mathrm{P}$ content prior to use in restoration projects, and that caution be exercised when deciding to use bird stakes in conjunction with fill of unknown origin and $\mathrm{P}$ content.

\section{Conclusions}

Ecosystem structure was altered at restoration sites relative to both unrestored grounding disturbances and the undisturbed seagrass ecosystem. Filling and fertilizing did not result in convergence of seagrass, microalgae, or sediment response variables between restoration and intact sites in the first year post-restoration. We did, however, 
observe several indicators of ecosystem development in the restoration sites, including increased macroalgae cover at fill sites and increased porewater nutrients at some fertilized sites. This study provides greater perspective on the impacts to sediment structure of filling excavations in seagrass ecosystems, and on the early changes in primary producers and sediment structure that occur during the post-restoration recovery process. 
Table 1. Results of PERMANOVA test of Restoration, Fertilization, and Time, and pairwise tests of the Restoration term, on sediment chlorophyll a concentrations.

\begin{tabular}{|c|c|c|c|c|}
\hline Source & df & MS & Pseudo-F & $\mathrm{P}$ \\
\hline Restoration & 2 & 21.36 & 415.82 & 0.001 \\
\hline Fertilization & 1 & 0.07 & 1.40 & 0.263 \\
\hline Time & 4 & 1.11 & 21.53 & 0.001 \\
\hline $\mathrm{Re} \times \mathrm{Fe}$ & 2 & 0.05 & 1.02 & 0.378 \\
\hline $\operatorname{Re} \times \mathrm{Ti}$ & 8 & 0.74 & 14.39 & 0.001 \\
\hline $\mathrm{Fe} \times \mathrm{Ti}$ & 4 & 0.04 & 0.86 & 0.500 \\
\hline $\mathrm{Re} \times \mathrm{Fe} \times \mathrm{Ti}$ & 8 & 0.10 & 1.89 & 0.091 \\
\hline Residual & 60 & 0.05 & & \\
\hline \multicolumn{3}{|c|}{ Pairwise test on Restoration } & $\mathrm{t}$ & $P$ \\
\hline & & $G, F$ & 21.61 & 0.001 \\
\hline & & G, I & 3.67 & 0.002 \\
\hline & & $\mathrm{F}, \mathrm{I}$ & 30.94 & 0.001 \\
\hline
\end{tabular}

Table 2. Results of PERMANOVA test of Restoration, Fertilization, and Time, on sediment particle size classes (percent clay, silt, sand and gravel). Sediment depth as a covariate was not significant and was excluded from the model.

\begin{tabular}{lrrrr}
\hline Source & df & MS & Pseudo-F & $P$ \\
\hline Restoration & 2 & 398.75 & 365.22 & 0.001 \\
Fertilization & 1 & 0.84 & 0.77 & 0.539 \\
Time & 1 & 1.53 & 1.41 & 0.236 \\
Re $x$ Fe & 2 & 5.56 & 5.09 & 0.001 \\
Re $\times \mathrm{Ti}$ & 2 & 1.47 & 1.34 & 0.233 \\
Fe $\times \mathrm{Ti}$ & 1 & 2.85 & 2.61 & 0.040 \\
Re x Fe x Ti & 2 & 1.65 & 1.51 & 0.147 \\
Residual & 92 & 100.45 & 1.09 & \\
\hline
\end{tabular}


Table 3. Principal components analysis (PCA) eigenvectors for PC axes with eigenvalues $>1.0$ extracted from multivariate data set of sediment and porewater variables sampled from $7.6 \times 40 \mathrm{~cm}$ cores collected from study sites. Treatments included Grounding, Grounding + Stake, Fill, Fill + Stake, Intact + Stake, and Intact sites. See Figure 7 for corresponding PC ordination.

\begin{tabular}{lrr}
\hline Variable & PC1 $(57.0 \%)$ & PC2 $(18.3 \%)$ \\
\hline $\mathrm{BD}$ & 0.40 & 0.15 \\
$\mathrm{pH}$ & 0.39 & -0.12 \\
$\mathrm{Eh}$ & 0.37 & -0.21 \\
$\mathrm{OM}$ & -0.42 & -0.10 \\
$\mathrm{~N}$ & -0.41 & -0.09 \\
$\mathrm{P}$ & 0.37 & 0.13 \\
$\mathrm{NH}_{4}{ }^{+}$ & 0.05 & 0.65 \\
$\mathrm{SRP}$ & -0.01 & 0.61 \\
$\mathrm{DS}$ & -0.28 & 0.31 \\
\hline
\end{tabular}


Table 4. Results of PERMANOVA tests of the short-term effects of restoration status (Grounding, Fill, Intact), fertilization (+, -), and time $(0 \mathrm{yr}, 0.25 \mathrm{yr}, 0.5 \mathrm{yr}, 0.75 \mathrm{yr}, 1 \mathrm{yr})$ on multivariate sediment properties and on principal component scores extracted from a Principal Component Analysis of multivariate sediment properties. PC1 is interpreted as sediment OM, and PC2 is interpreted as inorganic porewater nutrients. Pairwise tests were conducted on the Restoration x Fertilization interactions. Refer to Methods for sediment variables included in analyses. Sediment Depth was included as a covariate.

\begin{tabular}{|c|c|c|c|c|c|c|c|c|c|c|c|c|}
\hline \multirow[b]{2}{*}{ Source } & \multicolumn{4}{|c|}{ Multivariate Tests } & \multicolumn{4}{|c|}{ Tests of PC1 Scores } & \multicolumn{4}{|c|}{ Tests of PC2 Scores } \\
\hline & df & MS & Pseudo-F & $P$ & $\mathrm{df}$ & MS & Pseudo-F & $P$ & $\mathrm{df}$ & MS & Pseudo-F & $P$ \\
\hline Depth & 1 & 397.6 & 129.7 & 0.001 & 1 & 219.5 & 301.3 & 0.001 & 1 & 388.1 & 152.3 & 0.001 \\
\hline Restoration & 2 & 1090 & 355.5 & 0.001 & 2 & 1034.4 & 1419.6 & 0.001 & 2 & 1086.9 & 426.7 & 0.001 \\
\hline Fertilization & 1 & 15.5 & 5.1 & 0.001 & 1 & 1.0 & 1.4 & 0.232 & 1 & 13.5 & 5.3 & 0.002 \\
\hline Time & 4 & 103.6 & 33.8 & 0.001 & 4 & 10.3 & 14.1 & 0.001 & 4 & 93.2 & 36.6 & 0.001 \\
\hline $\mathrm{Re} \times \mathrm{Fe}$ & 2 & 13.2 & 4.3 & 0.001 & 2 & 3.0 & 4.2 & 0.022 & 2 & 11.6 & 4.6 & 0.001 \\
\hline $\operatorname{Re} \times \mathrm{Ti}$ & 8 & 25.9 & 8.4 & 0.001 & 8 & 5.9 & 8.1 & 0.001 & 8 & 23.6 & 9.3 & 0.001 \\
\hline $\mathrm{Fe} \times \mathrm{Ti}$ & 4 & 5 & 1.6 & 0.035 & 4 & 1.3 & 1.8 & 0.136 & 4 & 3.5 & 1.4 & 0.149 \\
\hline $\operatorname{Re} \times \mathrm{Fe} \times \mathrm{Ti}$ & 8 & 3.6 & 1.9 & 0.190 & 8 & 0.6 & 0.8 & 0.603 & 8 & 2.8 & 1.1 & 0.309 \\
\hline Residual & 509 & 3.1 & & & 509 & 0.7 & & & 509 & 2.5 & & \\
\hline \multicolumn{3}{|c|}{ Pairwise tests on Rest $x$ Fert } & $\mathrm{t}$ & $P$ & & & $\mathrm{t}$ & $P$ & & & $\mathrm{t}$ & $P$ \\
\hline \multicolumn{3}{|l|}{ G vs. G+ } & 2.7 & 0.001 & & & 0.1 & 0.137 & & & 2.7 & 0.001 \\
\hline \multicolumn{3}{|l|}{ F vs. F+ } & 1.4 & 0.109 & & & 2.2 & 0.023 & & & 1.5 & 0.094 \\
\hline \multicolumn{3}{|l|}{ | vs. I+ } & 2.7 & 0.001 & & & 0.7 & 0.497 & & & 2.9 & 0.001 \\
\hline
\end{tabular}


Figure 1. Location of study sites (polygons, lower inset) at Cutter Bank, in southern Biscayne Bay, Florida, USA, within the boundary of Biscayne National Park.

Figure 2. Mean \pm se seagrass percent cover in the first year post-restoration at restoration and reference sites. Notations are Spearman correlations and significance of relationships between seagrass percent cover and time within each restoration treatment.

Figure 3. Mean \pm se seagrass macroalgae percent cover in the first year postrestoration at restoration and reference sites. Notations are Spearman correlations and significance of relationships between macroalgae percent cover and time within each restoration treatment.

Figure 4. Mean \pm se sediment chlorophyll a concentrations in $7.6 \times 2 \mathrm{~cm}$ cores collected from study sites sampled repeatedly over one year ( $0 \mathrm{yr}, 0.25 \mathrm{yr}, 0.5 \mathrm{yr}, 0.75 \mathrm{yr}, 1 \mathrm{yr})$. Treatments included unrestored grounding sites, filled sites, and intact seagrass sites (n $=6$ sites per treatment). Letters indicate statistical significance $(\alpha=0.05)$ among sampling events within each treatment determined through PERMANOVA pairwise tests of time steps.

Figure 5. Sediment physical properties (water content, bulk density, $\mathrm{pH}$, Eh, and organic matter content) from $7.6 \times 40 \mathrm{~cm}$ cores collected from study sites. Treatments included Grounding, Grounding + Stake, Fill, Fill + Stake, Intact + Stake, and Intact sites. Sites were sampled repeatedly over one year $(0 \mathrm{yr}, 0.25 \mathrm{yr}, 0.5 \mathrm{yr}, 0.75 \mathrm{yr}, 1 \mathrm{yr})$. Data are mean \pm se values at each of six depth horizons $(0-2 \mathrm{~cm}, 2-6 \mathrm{~cm}, 6-10 \mathrm{~cm}, 10-20 \mathrm{~cm}, 20-$ $30 \mathrm{~cm}, 30-40 \mathrm{~cm})$.

Figure 6. Sediment and porewater nutrient pools (\% nitrogen, $\%$ phosphorus, ammonium, soluble reactive phosphorus, dissolved sulfide) from $7.6 \times 40 \mathrm{~cm}$ cores collected from study sites. Treatments included Grounding, Grounding + Stake, Fill, Fill 
+ Stake, Intact + Stake, and Intact sites. Sites were sampled repeatedly over one year $(0 \mathrm{yr}, 0.25 \mathrm{yr}, 0.5 \mathrm{yr}, 0.75 \mathrm{yr}, 1 \mathrm{yr})$. Data are mean \pm se values at each of six depth horizons $(0-2 \mathrm{~cm}, 2-6 \mathrm{~cm}, 6-10 \mathrm{~cm}, 10-20 \mathrm{~cm}, 20-30 \mathrm{~cm}, 30-40 \mathrm{~cm})$.

Figure 7. Sediment size class (clay, silt, sand, gravel) contribution in sediment cores collected from study sites. Treatments included Grounding (G), Grounding + Stake (GS), Fill (F), Fill + Stake (FS), Intact + Stake (IS), and Intact seagrass sediments (I). Data are from $7.6 \times 40 \mathrm{~cm}$ cores collected from study sites sampled twice over one year (Oyr, 1yr). Data in bars are pooled over depth and time within each treatment. Letters indicate statistical significance $(\alpha=0.05)$ among treatments determined through PERMANOVA pairwise tests between treatments.

Figure 8. Principal components analysis (PCA) ordination with PCA eigenvector overlay of multivariate sediment data, visualized for the Restoration $\times$ Fertilization factor ( $G=$ Grounding, GS = Grounding + Stake, F = Fill, FS = Fill + Stake, IS = Intact + Stake, I = Intact). Refer to Methods for sediment variables included in the PCA.

Figure 9. Depth profiles for mean \pm se Principal Component $(P C)$ scores extracted from the multivariate data set of sediment variables sampled from study sites. Treatments included Grounding, Grounding + Stake, Fill, Fill + Stake, Intact + Stake, and Intact seagrass sediments. PC1 is interpreted as a sediment OM and PC2 represents dissolved inorganic nutrients in the porewaters. 


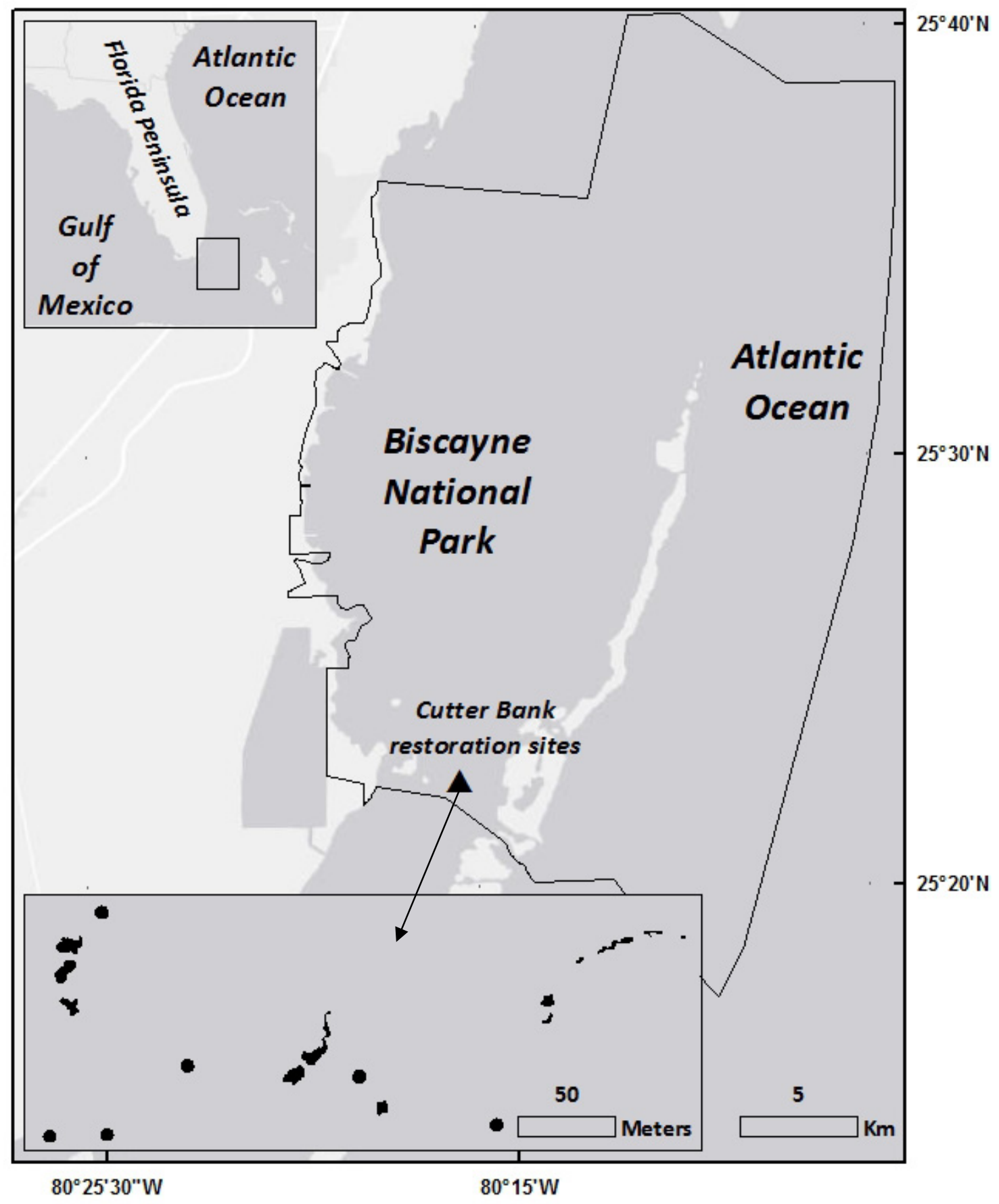




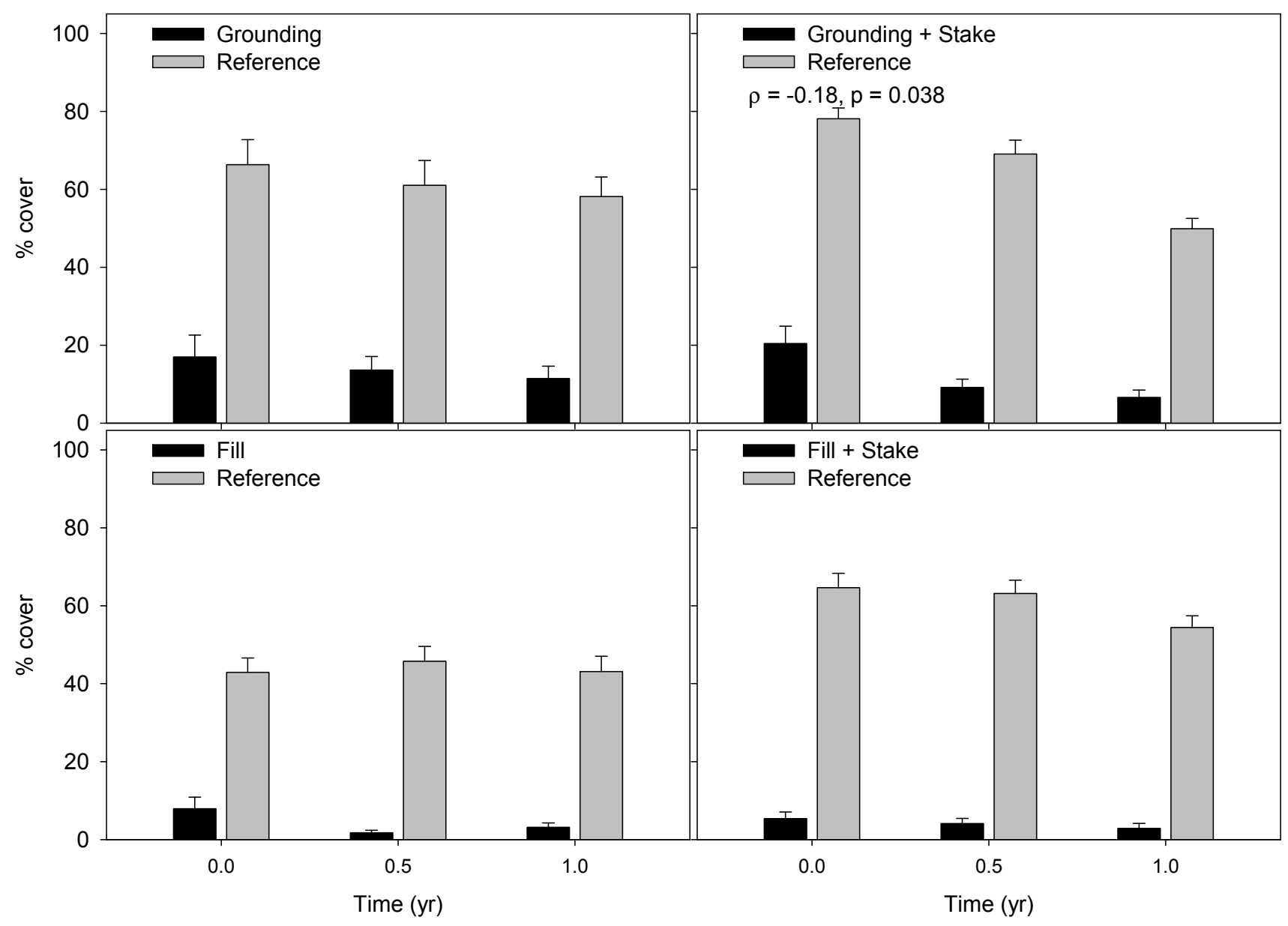




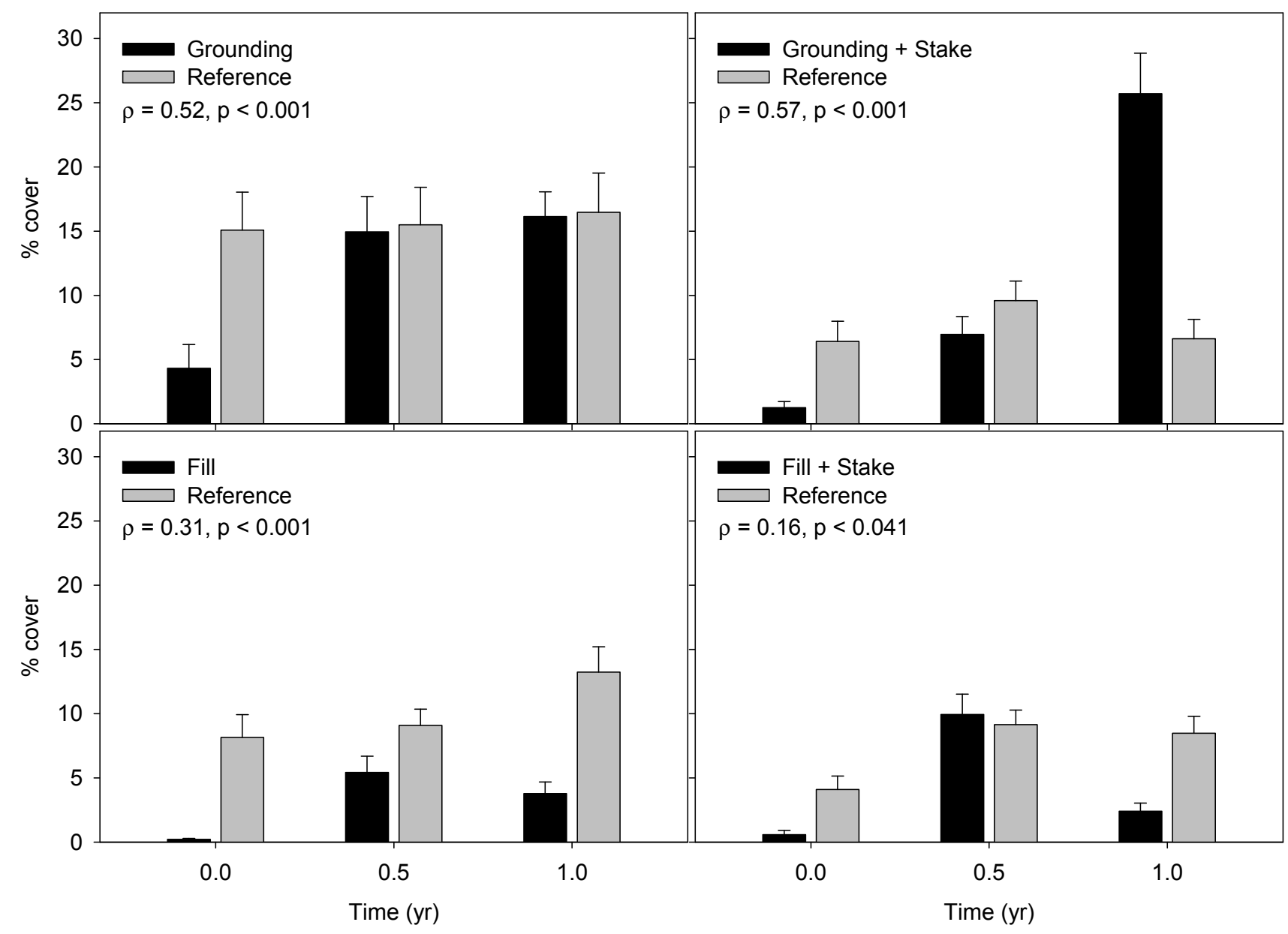




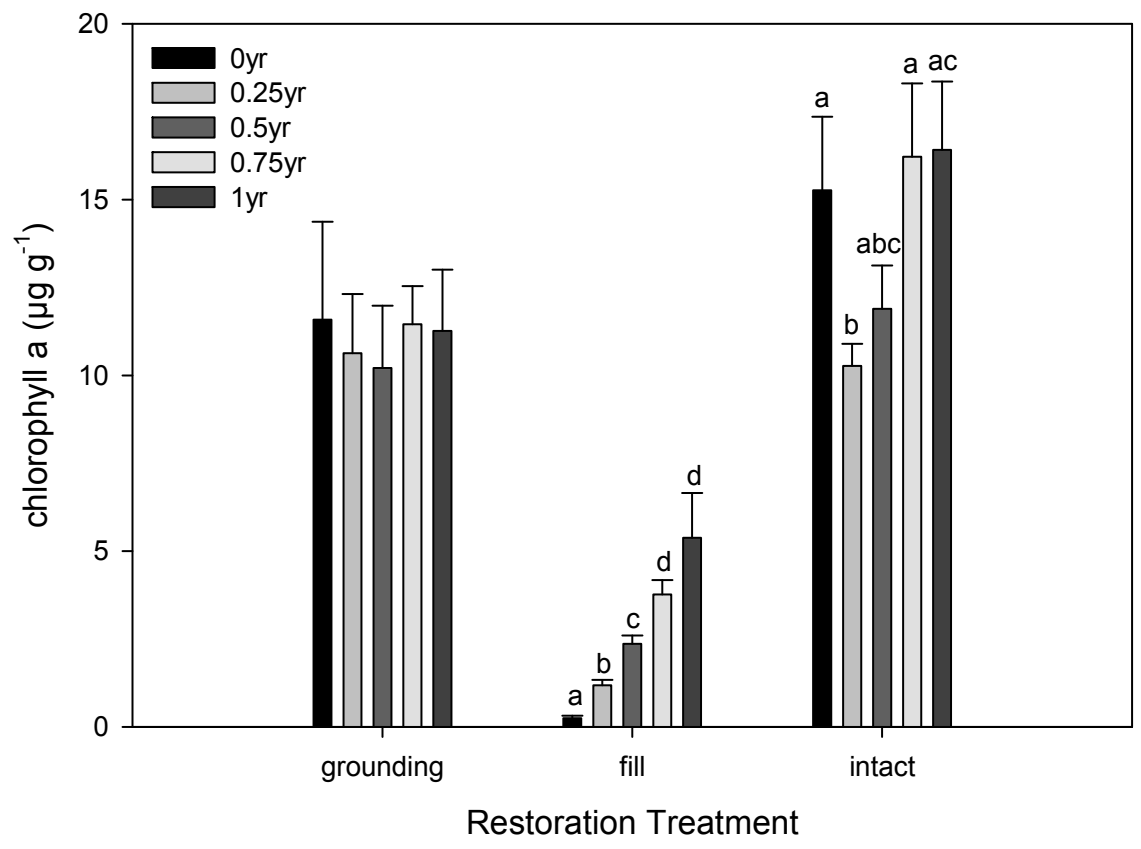




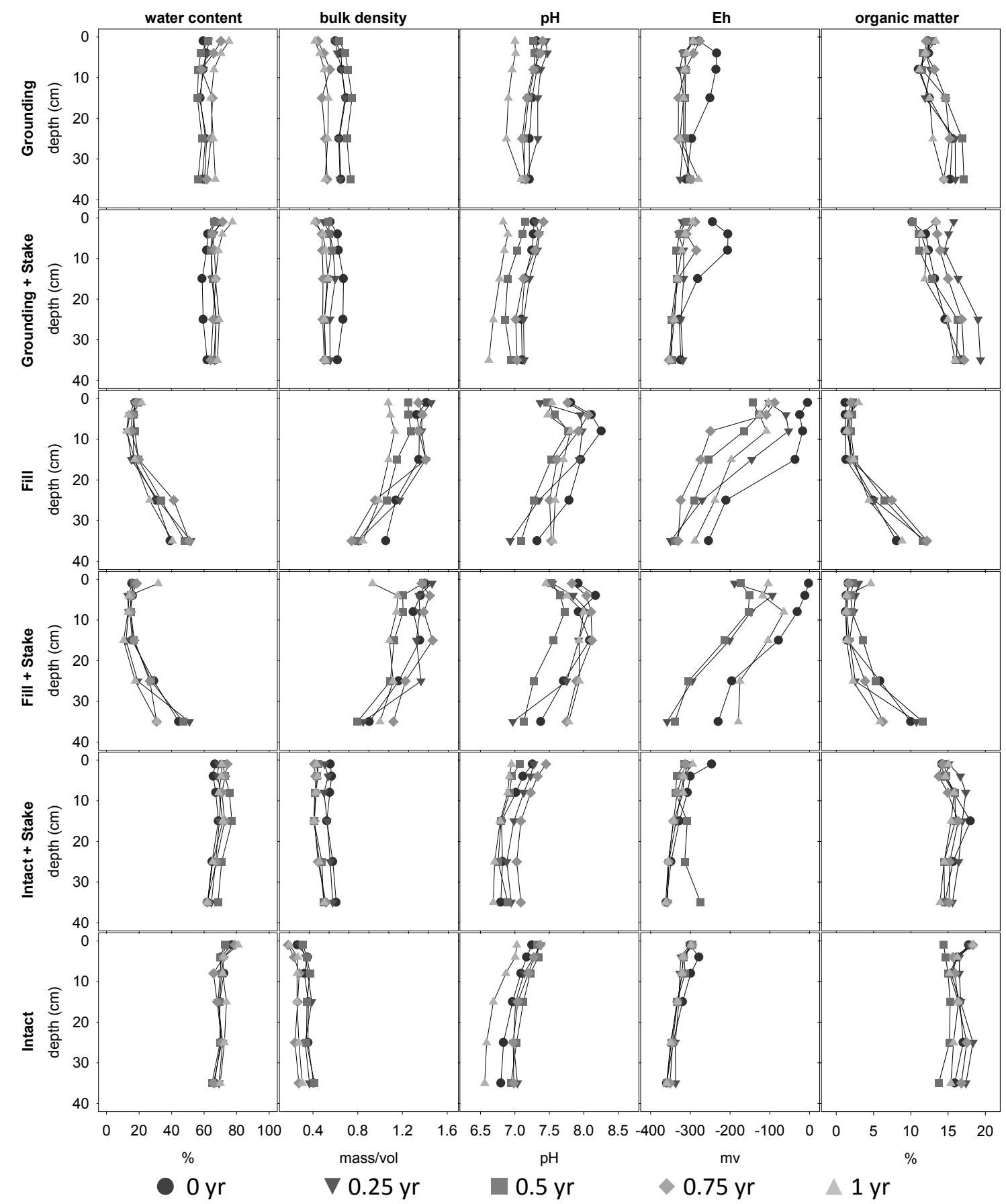




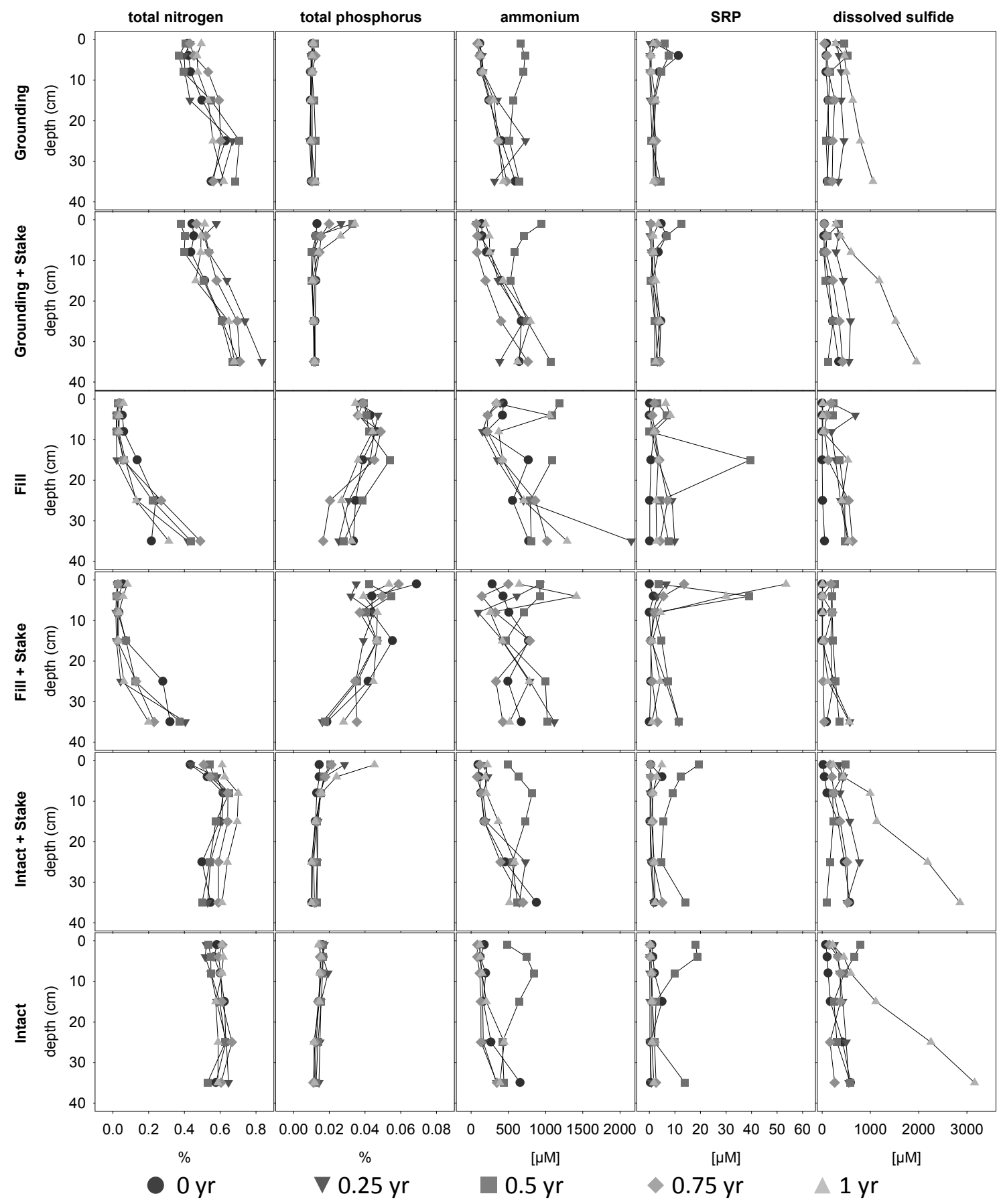




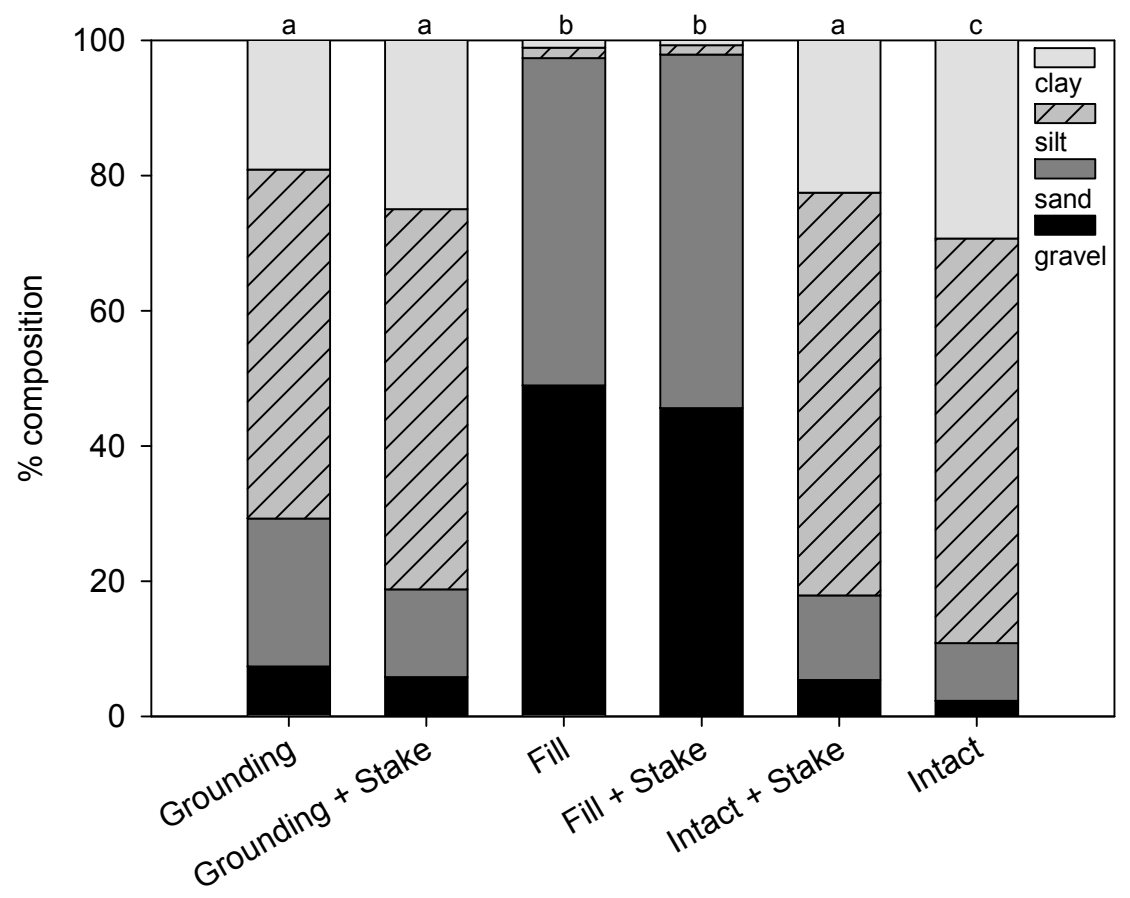

Restoration x Fertilization Treatment 

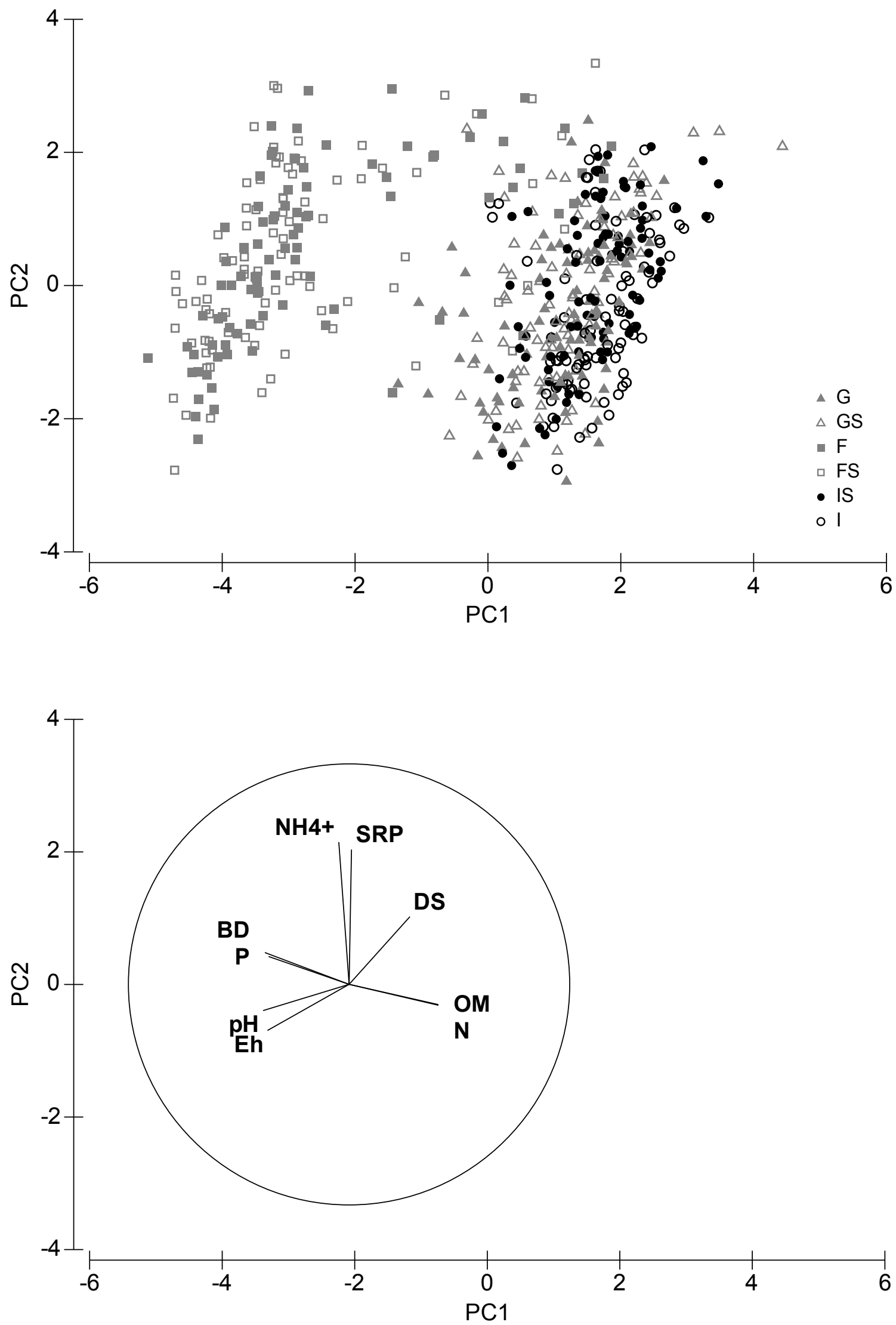


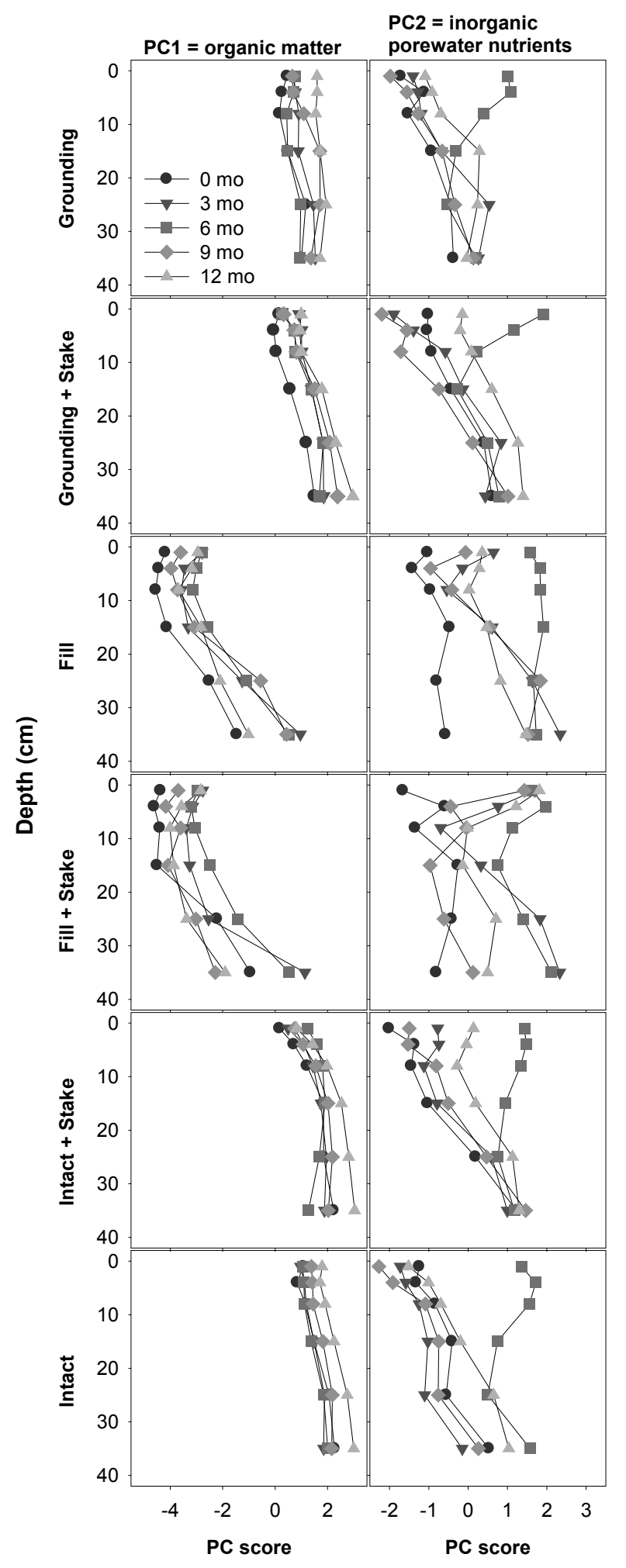


CHAPTER IV: Effects of restoration on microbial community composition in subtropical seagrass sediments.

\section{Abstract}

Microorganisms in seagrass sediments facilitate many key ecosystem processes, yet current knowledge of microbial facilitation of seagrass community recovery following disturbance or restoration is limited. Using Terminal Restriction Fragment Length Polymorphism, we studied microbial community responses to restoration of vessel grounding injuries in a subtropical seagrass ecosystem in south Florida, USA.

Restoration methods included installation of bird roosting stakes as a means to provide a nutrient source, and placement of sediment fill into excavations. Microbial community structure in our study sites provided insight on the status of restoration sites relative to the intact ecosystem. Unrestored grounding sites and restoration sites had less complex microbial community structure than intact seagrass sediments. Microbial community structure differed little between unrestored sites and fertilized sites, but was distinct among treatments in fill sites. Sediment bulk density, organic matter content, and porewater ammonium concentration were important environmental predictors of microbial community structure across the restoration treatments. In our study of microbial community structure and diversity in seagrass sediments following different restoration scenarios, we were able to show that community structure and diversity varied with sediment depth, among restoration treatments, and through time. 
Introduction

Microbes mediate the remineralization of organic matter in marine sediments, increasing the availability of nutrients required for seagrass meadow development. At the water-sediment interface, and in the rhizosphere of seagrasses, oxygen is available to support aerobic metabolism, while in deeper sediments, nitrate, iron, and sulfate become electron acceptors for anaerobic metabolism (Canfield et al. 1993). In tropical sediments, iron and nitrate concentrations are low (Kristensen et al. 2000), and sulfate reduction plays an important role in remineralization and nutrient availability (Holmer et al. 2001). These varying metabolic processes suggest that seagrass sediments support complex microbial communities, and that microbial community structure and function are subject to disruption when seagrass sediments are disturbed.

Advances in molecular microbial ecology are providing insight into the roles of soil microorganisms in ecosystem processes (Zak et al. 2006; Hall et al. 2011). For example, soil structure (Sessitsch et al. 2001; Girvan et al. 2003; Chau et al. 2011), nutrient content (Ramirez et al. 2010), pH (Fierer \& Jackson 2006; Tripathi et al. 2012), biogeographical factors (Blum et al. 2004; Hartman et al. 2008), sediment organic matter content (Blum et al. 2004), and the presence and composition of vegetation (Nacke et al. 2011) have all been shown to be important in structuring microbial communities in terrestrial ecosystems. In aquatic systems, changes in microbial abundance and diversity are correlated with redox potential and $\mathrm{pH}$ differentials associated with soil depth (Sørensen et al. 2007; Hartman et al. 2008). In seagrass ecosystems, structuring factors of microbial communities include the presence vs. absence of seagrass, proximity to seagrass rhizomes, sediment depth, and temperature (Danovaro \& Fabiano 1995; James et al. 2006; Jensen et al. 2007), all factors related to benthic metabolic capacity. 
Loss of seagrass resources along the world's coastlines is accelerating (Waycott et al. 2009), and physical disturbance is a key contributor to the global decline of seagrasses (Short \& Wyllie-Echeverria 1996; Orth et al. 2006; Grech et al. 2012). Disturbance to the rhizosphere leads to persistent injuries. The loss of plant structure alters ecosystem function, and in particular, primary production and habitat provision for seagrass-associated organisms (Neckles et al. 2005; Hammerstrom et al. 2007; Di Carlo \& Kenworthy 2008). Shallow seagrass ecosystems near population centers frequently experience physical disturbance as a consequence of vessel groundings. Seagrass colonization of injuries involving deeper excavations is variable, and may take several years to over a decade (Zieman 1976; Durako \& Moffler 1985; Dawes et al. 1997; Kenworthy et al. 2002; Hammerstrom et al. 2007; Di Carlo \& Kenworthy 2008). The effects of such disturbance on aspects of ecosystem structure other than the plant community are not well understood.

In the face of global seagrass decline, increased protection for seagrasses by governmental agencies is often accompanied by mandates to restore seagrass injuries or otherwise mitigate seagrass impacts. Resource managers and restoration practitioners attempt to accelerate recovery of disturbed seagrass communities by implementing specific restoration methods with specific objectives. Filling grounding excavations, applying fertilizer, and transplanting seagrasses are commonly-used seagrass restoration techniques (Fonseca et al. 1998; Kirsch et al. 2005; Farrer 2010). Placing sediment fill into excavations is intended to recreate the physical matrix that supports seagrasses and ecosystem functioning (Hammerstrom et al. 2007; Hall et al. 2012b). Because seagrass ecosystems are often nutrient limited (Short 1987; Fourqurean \& Zieman 1992), applying fertilizer (via bird roosting stakes, where the feces of roosting seabirds fertilizes the sea floor below) aims to reestablish or augment pools 
of vital nutrients that may be limiting to seagrass growth (Kenworthy et al. 2000). Seagrasses also may be transplanted to more quickly replace lost plant structure and associated functions than would otherwise be accomplished through natural secondary succession following disturbance (Lewis 1987). Even after restoration has taken place, the seagrass community may take several years to develop, and may differ from the reference community during recovery. For example, patterns of early succession in seagrass ecosystems indicate that the first colonizers are turf and calcareous green macroalgae, followed by rapidly growing seagrass species (e.g., Halodule wrightii or Syringodium filiforme in the Caribbean), and culminating with a monospecific climax community of slower-growing seagrasses (e.g., Thalassia testudinum in the Caribbean) or a mixed community of climax and successional species (Zieman 1982; Williams 1990; Rollon et al. 1999; Kenworthy et al. 2002; Whitfield et al. 2002).

Ecological restoration practices should be based upon and evaluated in the context of established ecological concepts (Palmer et al. 1997; Young et al. 2005). Knowledge of the soil microbial community (e.g., mass, composition, and activity) may be useful in assessing ecosystem status, particularly of disturbed, degraded or recovering systems (Harris 2003), and should be considered in the context of energy flow and material cycling when conducting ecological restoration (Heneghan et al. 2008).

We used microbial community composition and simple measures of the soil environment to evaluate ecosystem status and sediment quality following seagrass restoration at vessel grounding sites in south Florida, USA. Two specific seagrass restoration methods were evaluated: addition of nutrients via installation of bird roosting stakes and placement of sediment fill. By examining differences among grounding and restoration sites and undisturbed reference sediments, we evaluated whether or not linkages between biotic and abiotic elements of ecosystem structure were being 
reestablished in these restoration sites (Harris 2003). We hypothesized that microbial community structure, and implicitly the microbially-mediated biogeochemical processes in the sediment, would vary among restoration treatments due to differences in organic matter available for remineralization in the oxidation-reduction conditions in the sediments. We also hypothesized that microbial communities would vary with sediment depth, and with time, as ecosystem function developed in the restoration sites.

Methods

Study System

This study was conducted in southern Biscayne Bay, described in Chapter II of this thesis. Microbial communities in seagrass sediments have not been studied in this area. Study sites included multiple vessel grounding injuries, vessel grounding restoration sites, and adjacent undisturbed seagrass meadows on Cutter Bank (Figure 1).

\section{Experimental Design}

The short-term effects of restoration on seagrass ecosystem structure were evaluated at twelve individual sites at Cutter Bank following implementation of a restoration project in January-February 2010. A factorial design was employed, with Restoration Treatment and Time as fixed factors. Restoration Treatments included unrestored vessel grounding injuries ( $G=$ grounding), injuries that were provided a nutrient source via bird roosting stakes (GS = grounding + stake), injuries that were returned to grade with quarried limestone sand used as fill $(F=$ fill), and intact undisturbed seagrass sites $(I=$ intact $)$. Sites selected for inclusion in the study $(n=3$ per Treatment) were an average of $36 \mathrm{~m}^{2}$ in size. Grounding and Grounding + Stake 
sites were an average of $0.5 \mathrm{~m}$ deep, and Fill sites were filled to the grade of the surrounding sea floor with quarried sand during the restoration project. Intact sites were established by delineating $32 \mathrm{~m}^{2}$ circular plots around randomly selected points across the shoal. The twelve sites were sampled within one month of restoration implementation, and at three, six, nine, and twelve months following restoration (February, May, August, November 2010 and February 2011).

\section{Sediment Core Collection and Processing}

To identify environmental predictors of microbial community structure in our treatments, we sampled a suite of sediment properties that are indicators of microbiallymediated processes in seagrass ecosystems. These variables included sediment particle size and bulk density (microhabitat quality, nutrient exchange); $\mathrm{pH}$, redox potential, organic matter content, and porewater sulfide (benthic metabolism and remineralization); and nitrogen and phosphorus content in sediment and porewater (nutrient storage). Detailed descriptions of coring and environmental analyses are provided in Chapters II and III of this thesis.

\section{Microbial Community Profiling}

Terminal Restriction Length Fragment Polymorphism (TRFLP, Liu et al. 1997) was used to profile microbial community diversity in seagrass sediments. TRFLP is one of several polymerase chain reaction (PCR)-based finger-printing techniques that can be used to study changes in community structure. We selected TRFLP as our analysis method because it is a high throughput technique with short run times (Schütte et al. 2008). However, resulting estimates of total diversity, as determined by the number of observed ribotypes are conservative because multiple taxa can share the position of a given restriction site. Therefore the frequency of identical terminal restriction fragments 
(TRF) sizes can increase, especially at higher levels of diversity (Engebretson \& Moyer 2003). To address this we used multiple restriction enzymes to increase the specificity and confidence of our resulting data interpretation (Nocker et al. 2007). While TRFLP cannot provide phylogenetic inference into the specific taxa altered or variation in the functional composition of those different taxa directly (Torsvik \& Øvreås 2002), it is valuable as a comparative tool, capable of detecting microbial community changes across large numbers of samples and treatments.

We selected the 16S rRNA gene as our gene of interest because it is highly conserved in bacteria and archaea (Leloup et al. 2009). Because TRFs can represent both bacterial and archaeal sequences, we describe our results in terms of microbial communities. DNA was extracted from $1.5 \mathrm{~g}$ sediment samples using the PowerSoil DNA Isolation Kit (MO BIO Laboratories, Inc., Carlsbad CA). DNA was amplified using the primer sets FAM-Univ 9F and Univ 1509R (Integrated DNA Technologies, Inc., Coralville IA) in $50 \mu \mathrm{I}$ PCR reactions (GoTaq Flexi DNA Polymerase kit (Promega, Madison WI) containing $10 \mu \mathrm{l}$ of $5 \mathrm{x}$ buffer, $2.4 \mu \mathrm{M}$ of $\mathrm{MgCl}, 0.2 \mu \mathrm{M}$ of each primer, $2.5 \mathrm{U}$ of Taq polymerase, and $0.2 \mathrm{mM}$ of each dNTP. PCR reactions used the following touchdown thermo-cycler program: $95^{\circ} \mathrm{C} 2 \mathrm{~min}, 34$ cycles of $95^{\circ} \mathrm{C} 1 \mathrm{~min}, 55.6^{\circ} \mathrm{C} 1 \mathrm{~min}(-$ $0.3^{\circ} \mathrm{C}$ ), and $72^{\circ} \mathrm{C} 1 \mathrm{~min}$, and a final extension of $72^{\circ} \mathrm{C} 5 \mathrm{~min}$ step. Amplifications were checked for efficiency on 1.2\% agarose gels and cleaned using the Wizard SV 96 PCR Clean-Up System (Promega Corporation, Madison WI). 256 ng of DNA were digested in separate $20 \mu \mathrm{l}$ reactions using the restriction enzymes Mspl (Promega Corporation, Madison WI) and BstUI (New England Biolabs Inc., Ipswich MA). Fragments were analyzed at Laragen, Inc. (Culver City CA) on an ABI 3730 sequencer (Applied Biosystems, Carlsbad CA), with $9.5 \mu \mathrm{Hi}-\mathrm{Di}$ formamide and $0.5 \mu \mathrm{I} 1200 \mathrm{LIZ}$ size standard (Applied Biosystems, Carlsbad CA) added to $0.5 \mu$ l of each PCR reaction. 
Sizes of TRFs were determined using the Local Southern size-calling algorithm of Peak Scanner Software v1.0 (Applied Biosystems, Carlsbad CA). The peak amplitude threshold was set at 100 florescent units. The TRFLP datasets were combined and further processed using the T-REX software (Culman et al. 2009). Peak height was used as a metric of microbial abundance. Peaks were retained if height exceeded the standard deviation (assuming zero mean) computed over all peaks (Abdo et al. 2006) and aligned using a clustering threshold of 0.5 base pairs (Smith et al. 2005). The TRFs outside the size range of $40-1160$ base pairs were omitted to ensure fragments did not exceed the dynamic range of the LIZ-1200 size standard. The TRF's that occurred in less than $1 \%$ of samples were omitted. Prior to analysis, TRF heights were standardized within samples to provide relative abundance data, removing some of the effect of differential PCR amplification (Fierer \& Jackson 2006).

Using the restriction enzymes Mspl ( $n=462$ samples) and BstUI ( $n=463$ samples), we obtained a total of 925 TRFLP profiles that passed quality checks. These profiles represented $86 \%$ of our analyzed sediment samples. Following averaging of site replicates, data analysis was conducted on 169 averaged profiles, representing $94 \%$ of our total potential averaged profiles.

Data Analysis

The TRF data were log-transformed to reduce the influence of highly abundant TRFs on the data set. Principal coordinates analysis (PCO) was used to visualize differences in the microbial community on the basis of restoration treatments. An unconstrained ordination method, PCO projects samples onto axes and minimizes residual variation in the space of the chosen dissimilarity measure (Anderson et al. 2008). 
Permutational Multivariate Analysis of Variance (PERMANOVA, Anderson et al. 2008) was used to test the hypotheses that a) multivariate microbial community diversity varies with sediment depth, b) restoration affects multivariate microbial community diversity, and c) restoration affects univariate community characteristics including TRF richness (S, Chao 2), evenness (Pielou's J'), and diversity (Shannon-Weaver, $H^{\prime}$ and Simpson's 1- $\lambda$ ). PERMANOVA enables testing of the response of one or more variables to one or more factors, based on any resemblance measure, by partitioning sources of variation. A primary advantage of PERMANOVA is that statistical significance of the pseudo- $F$ statistic is determined through permutations of randomized real data, thus avoiding normality and homogeneity of variance assumptions (Anderson et al. 2008).

The PERMANOVA analysis of multivariate microbial community data was derived from the binomial deviance dissimilarity measure (Anderson \& Millar 2004), and analyses of univariate diversity metrics were based on Euclidean distance resemblances. Significance values for PERMANOVA tests were built on 999 permutations of residuals under reduced models. Where data variables were available for multiple depth horizons (e.g., 0-2 cm, 2-6 cm, 6-10 cm), sediment depth was used as a covariate requiring the use of Type I sums of squares in the PERMANOVA analyses. Otherwise, Type III sums of squares were used. Pairwise permutational tests with Bonferroni corrections were conducted on significant main effects and interactions in the PERMANOVA analyses. The SIMPER procedure (Clarke et al 2006) was used to determine TRF similarity within restoration groups, and to identify the contribution of the most abundant TRFs to within-group similarity.

Distance-based linear modeling (DistLM) and distance-based redundancy analyses (dbRDA) (Legendre \& Anderson 1999; McArdle \& Anderson 2001; Anderson et al. 2008) were used to explore relationships between microbial community relative 
abundance data and multivariate data on sediment properties. The dbRDA ordination visualizes the PCO axes constrained by linear combinations of the environmental variables calculated by the DistLM routine that maximally explain biotic variation (Anderson et al. 2008). Parameters for the DistLM routine, which is analogous to linear multiple regression, included the Best selection procedure and the Akaike Information Criteria corrected for small sample sizes (AICc; Akaike 1973; Burnham \& Anderson 2002) selection criteria; the procedure was run with 9999 permutations. Environmental data were log-transformed prior to analysis to reduce skewness. Pearson correlations between individual log-transformed environmental variables and diversity metrics were calculated from log-transformed microbial relative abundance data and analyzed for significance in SPSS 20.0 (IBM).

PCO, PERMANOVA, SIMPER, DistLM, and dbRDA analyses were conducted with the software PERMANOVA+ for PRIMER (Clarke \& Gorley 2006; Anderson et al. 2008).

Results

Sediment Properties

Sediments in Intact plots at Cutter Bank were fine (6.8 $\pm 0.2 \phi$, Figure 2), and dominated by silt and clay fractions (Figure 3). These sediments were strongly reduced (-302.6 $\pm 9.1 \mathrm{mv}$ Eh) with high organic matter content (16.5 $\pm 0.5 \%$ loss on ignition). Nutrient concentrations were low $\left(0.015 \% \pm 0.001 \% \mathrm{P}\right.$ content; $148.3 \pm 41.5 \mu \mathrm{M} \mathrm{NH}_{4}{ }^{+}$; $1.0 \pm 0.6 \mu \mathrm{M}$ SRP). Sediments from Grounding and Grounding + Stake sites had similar properties (Figure 2) and particle size composition (PERMANOVA pairwise test, $\alpha=$ $0.008, p>0.039$; Figure 3 ) as the Intact sites. A notable exception is that $P$ content and porewater $\mathrm{NH}_{4}{ }^{+}$concentration increased by $99 \%$ and $67 \%$, respectively, in the 
Grounding + Stake sites over the year-long course of the study as a consequence of the deposition of bird feces.

Sediment properties and microbial community structure from Fill sites differed sharply from Intact sites for all variables examined. Fill sites had lower organic matter and dissolved sulfide concentrations, and higher bulk density, $\mathrm{pH}$, Eh, $\mathrm{P}$ content, and $\mathrm{NH}_{4}{ }^{+}$and SRP concentrations, than the Intact sites (Figure 2). Fill site sediments were heavily dominated by gravel and sand, and were substantially coarser than Intact sediments (PERMANOVA pairwise test, $\alpha=0.008, \mathrm{p}<0.004$; Figure 3 ).

Microbial Community Profiles

Microbial communities were structured across restoration treatments (Figure 4). Profiles from Fill sites clustered tightly and were separated from other treatments along PCO1, which explained $36.2 \%$ of variation in the data matrix. Intact profiles also clustered tightly, and were partially overlapped by Grounding profiles, and to a lesser extent, by Grounding + Stake profiles. Grounding + Stake profiles showed the least structure, and varied along both PCO axes. PCO2, explaining $22.6 \%$ of variation in the data matrix, separated the profiles from Grounding and Intact sites from Fill and Grounding + Stake profiles, respectively.

Sediment depth had a significant effect on microbial community structure across all samples (PERMANOVA, $d f=2$, pseudo-F = 9.0, $p<0.001$ ), and community abundance differed with each depth horizon (PERMANOVA pairwise tests, $p<0.005$ ). Community abundance differed across the four restoration treatments (PERMANOVA, $p$ $<0.001$; Table 1), with distinct profiles for each treatment $(p<0.001)$. Community profiles also changed with time over the year-long course of the study (PERMANOVA, $p$ $<0.001$; Table 1), and overall, differed with each sampling event (PERMANOVA 
pairwise tests, $p<0.001)$. There was a significant Time $x$ Treatment interaction in the community analysis. Grounding and Grounding + Stake sites had similar community profiles for all time steps (PERMANOVA pairwise tests, $p>0.064$; Table 1) except at the $0 \mathrm{yr}$ sampling event. Fill site profiles were different from the Intact profiles and from the Grounding and Grounding + Stake profiles at every time step (PERMANOVA pairwise tests, $p<0.002$; Table 1) except at the $0 \mathrm{yr}$ sampling event, when profiles between Fill and Intact sites were similar. Within restoration treatments, community profiles at the 1 yr sampling event differed from the 0 yr sampling event for the Grounding, Grounding + Stake, and Fill treatments (PERMANOVA pairwise tests, $p<0.002$; Table 1), but not for the Intact treatment.

Microbial Community Diversity

In total, 122 and 95 TRFs were detected with the Mspl and BstUI digests, respectively, and 166 unique TRFs were common to the combined dataset. Maximum TRF richness across restoration treatments was 122 TRFs, with an average of $59.6 \pm$ 1.8 TRFs per sample. For clarity of presentation, microbial community diversity results are included for the $0 \mathrm{yr}$ and $1 \mathrm{yr}$ sampling events. TRF richness (Figure 5) pooled over all time steps for each treatment was highest for the Grounding + Stake treatment $(71.1$ \pm 5.4 TRF) and lowest for the Fill treatment $(48.0 \pm 8.5 \mathrm{TRF})$. TRF richness in Grounding and Grounding + Stake treatments was nearly a third greater than in Intact treatment. Chao 2 estimates (Figure 5) were highest for the Grounding treatment (165.7 \pm 13.7 sd TRF), and lowest for the Intact treatment (118.3 \pm 13.3 sd TRF).

With samples pooled across time steps, microbial community richness, evenness, and diversity $\left(H^{\prime}\right.$ and $\left.1-\lambda\right)$ varied among restoration treatments (PERMANOVA, $\mathrm{P}<0.008$; Table 2; Figure 5), though with complex patterns among 
metrics. Values for all four diversity metrics were similar in samples from Grounding and Grounding + Stake treatments (Figure 5). Diversity $\left(H^{\prime}\right)$ was lower in Intact sites than in Grounding and Grounding + Stake sites (PERMANOVA pairwise tests, $p<0.013$; Figure 5). Fill sites had similar richness, evenness, and diversity ( $H^{\prime}$ and $\left.1-\lambda\right)$ as Intact sites (Figure 5).

Time was a significant factor for microbial richness and diversity $\left(H^{\prime}\right.$; PERMANOVA, $\mathrm{P}<0.007$; Table 2; Figure 5). Values for both metrics were lower at $1 \mathrm{y}$ than at 0 yr following restoration for the Grounding and Grounding + Stake treatments. No temporal changes were observed for richness and diversity $\left(H^{\prime}\right)$ in Fill or Intact treatments, or for evenness or diversity $(1-\lambda)$ in any treatment (Figure 5).

Within treatments, Intact sites had the most similar microbial communities (68.3\%), while the least similar communities (46.4\%) were found in Fill sites (SIMPER, Table 3). The most abundant TRF in each treatment was shared between the Grounding and Grounding + Stake communities (106 bp), and also between the Fill and Intact communities (504 bp; SIMPER, Table 3). Dissimilarity between communities in treatment pairs was lowest between the Grounding and Intact treatments (35.0\%). Among all treatment pairs, Fill site communities shared the highest dissimilarity percentages (> 50\%) with each of the other three treatments (SIMPER, Table 3).

\section{Environmental Predictors of Microbial Community Structure and Diversity}

Total nitrogen, mean phi size, and water content were excluded from the DistLM analysis due to high correlation $(|r|>0.95)$ with organic matter content and bulk density. When constrained by environmental variables, microbial community structure among restoration treatments became even more pronounced, as seen the in the dbRDA ordination (Figure 6). 
Microbial community profiles from Fill sites separated from the other restoration treatment profiles distinctly along dbRDA1. Intact site profiles clustered tightly, sharing little space with Grounding and Grounding + Stake profiles, which overlapped somewhat with each other (Figure 6). The first two dbRDA axes explain $94.5 \%$ of the fitted variation, and $27.3 \%$ of the variation in the resemblance matrix (Figure 6), and are likely capturing substantial information about the microbial community structure at these sites as influenced by important environmental predictors.

There were strong negative correlations between organic matter content and dbRDA1 (DistLM, $r=-0.998 ;$ Table 4), between bulk density and dbRDA2 ( $r=-0.804$; Table 4), and between $\mathrm{NH}_{4}{ }^{+}$concentration and dbRDA3 ( $r=-0.802$; Table 4; not plotted in Figure 6). We interpret these correlations to indicate that high organic matter content in Intact, Grounding, and Grounding + Stake sediments, high $\mathrm{NH}_{4}{ }^{+}$concentration in Grounding + Stake sediments, and high bulk density in Fill sediments are important drivers of the microbial community structure across the restoration treatments.

The DistLM marginal tests that fit each environmental variable individually to the microbial community data showed that every variable except SRP concentration had a significant relationship with microbial community abundance (DistLM marginal tests, $p<$ 0.001). DistLM selected bulk density, organic matter content, and $\mathrm{NH}_{4}{ }^{+}$concentration for inclusion in the best multivariate predictor model explaining microbial community structure across the restoration treatments (DistLM, $r^{2}=0.29$ ). However, the solutions for the ten best models all had AICc values within two units of each other, so all may be considered viable (Burnham \& Anderson 2002). The ten best models included between three and six variables, and all included bulk density, organic matter content, and $\mathrm{NH}_{4}{ }^{+}$ concentration. None of the best models included $\mathrm{pH}$ as a predictor variable. 
Univariate measures of microbial community diversity and evenness showed slightly different relationships with environmental predictor variables. TRF richness and diversity $\left(H^{\prime}, 1-\lambda\right)$ were correlated with particle size and with organic matter and phosphorus content (Pearson correlations, $p<0.05$; Table 5). Diversity $(1-\lambda)$ was correlated with bulk density and redox potential $\left(\mathrm{p}<0.05\right.$; Table 5). However, $\mathrm{pH}, \mathrm{NH}_{4}{ }^{+}$, SRP, and dissolved sulfide concentrations were not correlated with microbial community diversity or evenness. No significant correlations were found between microbial community evenness and any of the measured environmental variables.

\section{Discussion}

By exploring microbial community structure and diversity in seagrass sediments that were intact, disturbed, or restored using different methods, we were able to show that community structure varied with sediment depth, among restoration treatments, and through time. We also identified environmental variables important to sediment structure, ecosystem metabolism, and nutrient storage that are predictors of microbial community structure.

Sediment depth was a significant factor in our analyses of relative microbial community structure, but not for community diversity metrics. Electron acceptors available for microbial use in mineralization vary with depth and the presence of belowground plant biomass. At the water-sediment interface, and in the rhizosphere of seagrasses, oxygen is available to support aerobic metabolism (Pedersen et al. 1998; Kristensen et al. 2000). In deeper sediments, nitrate, iron, and sulfate become electron acceptors for anaerobic metabolism (Canfield et al. 1993). In marine sediments, sulfate reduction plays an important role in remineralization and nutrient availability because of the high concentrations of sulfate in seawater (Holmer et al. 2001; Holmer \& Duarte 
2003). It follows that microbial communities will differ with depth, reflecting the different metabolic processes taking place throughout the seagrass rhizosphere. For example, microbial community differences have been detected between oxidized and reduced sediments in seagrass ecosystems, and in the presence of root zone sediments (Jensen et al. 2007; Sørensen et al. 2007), though community differences with depth are not detected (James et al. 2006; García-Martínez et al. 2008).

The similarity in diversity values between Fill and Intact sites may suggest microbial communities that are of similar complexity, but not necessarily of similar identity. The most distinct differences in total microbial community structure across our restoration treatments were seen when comparing Fill sites to other treatments. Fill sites were characterized by a near absence of organic matter in the top $10 \mathrm{~cm}$, which is not surprising given that the fill material was created from mined limestone. Organic matter content is an important determinant of microbial community structure in terrestrial systems (Sessitsch et al. 2001; Girvan et al. 2003; Blum et al. 2004), and our results support this relationship for seagrass ecosystems. Microbes mediate the remineralization of organic matter in marine sediments. Organic matter supplying benthic remineralization processes is provided by dead roots and rhizomes; root exudates; organic particles and litter buried by sedimentation and bioturbation; and benthic microalgal exudates (Pedersen et al. 1997; Holmer et al. 2001).

Because organic matter content in developing seagrass meadows is driven by the accumulation of plant biomass, and is a slow process (Pedersen et al. 1997; Di Carlo \& Kenworthy 2008; McGlathery et al. 2012), organic matter content in Fill sites is expected to remain low until these sites support dense, climax seagrass communities. In the initial stages of seagrass community development, a lack of organic matter in the 
sediments as substrate for microbial remineralization may lead to persistently low nutrient pools available to support seagrass and macroalgae colonization.

The fill material used for restoration was locally sourced from lake mines in south Florida. Any microbial community present in the fill material prior to placement was likely strongly reduced following inundation by sea water. The status of the microbial community may be an important consideration for seagrass restoration efforts. For example, disrupted microbial community diversity in seagrass sediments has been linked to high mortality in seagrass transplants (Milbrandt et al. 2008). Organic matter content at all of our study sites also was measured at deeper sediment horizons, down to $40 \mathrm{~cm}$ (data not shown). In the deeper horizons, organic matter content increases and particle size decreases (see Chapter III of this thesis), presumably due to mixing between the fill layer and underlying sediments. It is possible that the microbial community in this mixing layer can stimulate remineralization using the organic matter present as a substrate. However, in sites where the fill layer is thicker, or if organic matter is not available as a substrate, this may not be possible.

Nutrient addition can stimulate microbial remineralization of organic matter (Lopez et al. 1998), and we expected to see evidence and products of metabolism in the Grounding + Stake treatment. We predicted that bird stakes would provide nutrient input that would affect diversity as the microbial community responded to $\mathrm{N}$ and $\mathrm{P}$ inputs in this nutrient-limited system (Danovaro \& Fabiano 1995). Phosphorus content was elevated at the Grounding + Stake sites after a year, and the microbial community did change in the Grounding + Stake treatment over the course of the study, though the Grounding + Stake sites differed from the Grounding sites only at the initial sampling event. Redox potential was lower and DS was elevated in Grounding + Stake sites after 
one year compared to the start of our study, though this pattern was also seen in the Grounding and Intact sites.

Particle size composition is important in shaping microbial communities. In agricultural systems, underlying soil type affects microbial communities, and microbial diversity is negatively correlated with particle size (Sessitsch et al. 2001; Girvan et al. 2003). Different particle size fractions are thought to act as microhabitats with different organic matter content and redox conditions, that accordingly support different microbial communities (Miller \& Dick 1995; Zhang et al. 2007). We too found that microbial diversity was negatively correlated with particle size. Grounding, Grounding + Stake, and Intact sites generally had more complex communities than Fill sites, and bulk density and particle size were important predictors of variability in microbial community relative abundance.

In seagrass ecosystems, the importance of sediment grain size and porosity in seagrass bed sediments is linked to exchange of sediment pore water with overlying waters (Koch et al. 2001). Grain size is correlated with pore water exchange (Fourqurean et al. 1992), and thus nutrients and also toxic compounds such as sulfide may accumulate in fine-grained sediments. We did see elevated $\mathrm{NH}_{4}{ }^{+}, \mathrm{SRP}$, and DS in the porewaters from the fines-dominated Grounding, Grounding + Stake, and Intact treatments, when compared to the Fill treatments. However, we attribute those differences to lower benthic metabolism in the newly-placed fill material, rather than differences in porewater constituent retention related to sediment particle size.

Sediments used in seagrass restoration projects are typically far coarser than ambient sediments, and this was certainly the case with our Fill treatment. Turbidity created during fill placement can be difficult to control with fine sediments, and there also is concern that fine sediments may wash away from the site with tides and wave energy. 
The silt/clay fraction of fill material used in this restoration project ranged from $1 \%$ to $6 \%$, within the range of sediments that $T$. testudinum is known to grow in (Koch et al. 2001), but far lower than ambient sediments at Cutter Bank. Despite dramatic differences in particle size distributions, TRF richness was similar in Fill and Intact sites. However, TRFs of similar sizes may be derived from different microbial taxa, and thus richness alone is not a good indicator of community similarity with the TRFLP method (Engebretson \& Moyer 2003). Seagrass blades attenuate water movement and trap suspended particles, and fines sediments accumulate in seagrass meadows through sedimentation and percolation (Terrados \& Duarte 2000). Fine sediments are expected to increase in the fill sites as the seagrass community develops with time and seagrass blades entrain particles from the water column, but these sites will likely always remain coarser than the surrounding sediments. Fill sites, then, may continue to support a distinct microbial community on the basis of sediment structure.

Seagrass blades attenuate water movement and trap suspended particles, and fines accumulate in seagrass sediments through sedimentation and percolation (Terrados \& Duarte 2000). Fine sediments are expected to increase in the fill sites as the seagrass community develops with time and seagrass blades entrain particles from the water column, but these sites will likely always remain coarser than the surrounding sediments.

In our study, TRF richness and diversity were negatively correlated with sediment Eh. Relatively higher Eh values were recorded for Fill sites, which had little to no vegetative cover during out study period, whereas Intact seagrass sediments were strongly reduced. Microbial community diversity in seagrass beds has been shown to differ in the presence vs. absence of seagrass (James et al. 2006) and between the root zone and bulk sediments (Jensen et al. 2007). Seagrasses can modifying redox 
conditions in the rhizosphere (Marbà \& Duarte 2001; Enríquez et al. 2001). This capability, linked to photosynthetic activity and release of $\mathrm{O}_{2}$ from seagrass roots (Pedersen et al. 1997; Connell et al. 1999; Jensen et al. 2007;Terrados et al. 1999), may also influence microbial activity in the rhizosphere. Oxygen intrusion supports aerobic metabolism and sulfide oxidation, and seagrass sediments can have higher redox potential than unvegetated sediments, where anaerobic sulfate reduction occurs. However redox potential in the surface $(<10 \mathrm{~cm})$ layer of vegetated sediments can be lower than in unvegetated sediments in the presence elevated organic matter subject to microbial metabolism (Pedersen et al. 1997), or because the photosynthetic activity of sediment microphytobenthos may be reduced by seagrass canopy shading (Enríquez et al. 2001). We suggest that the differences in redox potential we observed between Fill and Intact sites can be explained by the high organic matter content in the Intact sediments and its near absence in the Fill sites.

We found that Time was a significant factor in altering the microbial community. However, in the multivariate analysis, patterns of change through time were not clear within treatments. Further, the direction of change in the univariate metrics was unexpected, as diversity values were often lower at the $1 \mathrm{yr}$ mark within restoration treatments. A clear cause for these patterns is elusive. One potential explanation is that the $0 \mathrm{yr}$ sampling event occurred within weeks of a rare extreme cold event in south Florida during January 2010. The average water temperature in January and February at this location ranges between $20^{\circ}$ and $21^{\circ} \mathrm{C}$ (Biscayne National Park, 2010). During the cold snap, water temperatures remained below $15^{\circ} \mathrm{C}$ for the 12 -day period $4-16$ January 2010 , and reached a low of $9.2^{\circ} \mathrm{C}$ on 11 January 2010 . Water temperatures during the 0 year sampling event were between $19.2^{\circ} \mathrm{C}$ and $19.7^{\circ} \mathrm{C}$, nearly back to normal, at $19.5^{\circ} \mathrm{C}$. Temperature can affect microbial development in seagrass 
ecosystems (Danovaro \& Fabiano 1995; James et al. 2006) and it is plausible that the microbial community was impacted by the cold snap. Microbial diversity can increase following disturbance (Hall et al. 2012a), and the community may have been in a period of recovery when we sampled it.

Conclusion

Current knowledge of microbial roles facilitation of seagrass community recovery following disturbance or restoration is limited. Our study is among the first to examine sediment microbial communities in the context of seagrass restoration (see also Milbrandt et al. 2008). The quarried sand used to fill excavations provided a coarser sediment matrix to support microbial communities and functions than found in undisturbed seagrass meadows. The absence of organic matter in filled sites was an important driver of microbial community structure in filled sites. Incorporation of organic material into fill used in restoration sites may help to accelerate development and function of the microbial community, and in turn, the seagrass community. In the early stages of macrophyte community development, our comparative study of microbial community status, when evaluated in the context of relevant environmental variables, provides insight on the status restoration sites relative to the intact ecosystem. 
Table 1. Results of PERMANOVA analysis of the effects of restoration treatment and time on multivariate microbial community diversity, with sediment depth as a covariate.

Results are also included for PERMANOVA pairwise tests on the Treatment $x$ Time interaction, for levels of the Treatment factor within each time step (middle panel) and of the Time factor within each Treatment (bottom panel). $\mathrm{P}$ values in bold text indicate statistical significance at $\alpha<0.05$.

\begin{tabular}{lrrrrr}
\hline Source & df & MS & Pseudo-F & P \\
\hline Depth & & 1 & 3391.8 & 29.8 & 0.001 \\
Treatment & & 3 & 2977.5 & 26.1 & 0.001 \\
Time & 4 & 810.8 & 7.1 & 0.001 \\
Treatment x Time & & 12 & 325.5 & 2.9 & 0.001 \\
Residual & & 149 & 575.0 & & \\
\hline Treatment $(\alpha=0.008)$ & Oyr & $0.25 \mathrm{yr}$ & $0.5 \mathrm{yr}$ & $0.75 \mathrm{yr}$ & $1 \mathrm{yr}$ \\
\hline Grounding & $\mathrm{a}$ & $\mathrm{ac}$ & $\mathrm{a}$ & $\mathrm{a}$ & $\mathrm{ac}$ \\
Stake & $\mathrm{b}$ & $\mathrm{a}$ & $\mathrm{a}$ & $\mathrm{a}$ & $\mathrm{a}$ \\
Fill & $\mathrm{c}$ & $\mathrm{b}$ & $\mathrm{b}$ & $\mathrm{b}$ & $\mathrm{b}$ \\
Intact & $\mathrm{cd}$ & $\mathrm{c}$ & $\mathrm{c}$ & $\mathrm{c}$ & $\mathrm{c}$ \\
\hline Time $(\alpha=0.005)$ & $\mathrm{Grounding}$ & Stake & $\mathrm{Fill}$ & Intact \\
\hline $0 \mathrm{yr}$ & & $\mathrm{a}$ & $\mathrm{a}$ & $\mathrm{a}$ & $\mathrm{ad}$ \\
$0.25 \mathrm{yr}$ & & $\mathrm{b}$ & $\mathrm{ac}$ & $\mathrm{abcd}$ & $\mathrm{abd}$ \\
$0.5 \mathrm{yr}$ & & $\mathrm{ab}$ & $\mathrm{a}$ & $\mathrm{bd}$ & $\mathrm{b}$ \\
$0.75 \mathrm{yr}$ & & $\mathrm{b}$ & $\mathrm{b}$ & $\mathrm{cd}$ & $\mathrm{bd}$ \\
$1 \mathrm{yr}$ & & $\mathrm{b}$ & $\mathrm{bc}$ & $\mathrm{c}$ & $\mathrm{ac}$ \\
\hline
\end{tabular}


Table 2. Results of PERMANOVA analysis of the effects of restoration treatment and time on microbial community richness, evenness, diversity, and dominance at the 0 - and 1-yr sampling events, with sediment depth as a covariate. $P$ values in bold text indicate statistical significance at $\alpha<0.05$.

\begin{tabular}{|c|c|c|c|c|c|}
\hline Diversity Metric & Source & $\mathrm{df}$ & MS & Pseudo-F & $P$ \\
\hline \multirow{5}{*}{ TRF Richness } & Depth & 1 & 25 & 0.09 & 0.770 \\
\hline & Treatment & 3 & 2233.4 & 7.7 & 0.001 \\
\hline & Time & 1 & 4522 & 15.6 & 0.003 \\
\hline & $\operatorname{Tr} \times \mathrm{Ti}$ & 3 & 829.9 & 2.9 & 0.040 \\
\hline & Residual & 57 & 0.253 & & \\
\hline \multirow[t]{5}{*}{ Pielou's J' } & Depth & 1 & 0.000 & 0.034 & 0.851 \\
\hline & Treatment & 3 & 0.005 & 3.832 & 0.008 \\
\hline & Time & 1 & 0.002 & 1.964 & 0.171 \\
\hline & $\operatorname{Tr} \times \mathrm{Ti}$ & 3 & 0.004 & 2.823 & 0.037 \\
\hline & Residual & 57 & 0.001 & & \\
\hline \multirow[t]{5}{*}{ Shannon-Weaver $H^{\prime}$} & Depth & 1 & 0.035 & 0.310 & 0.577 \\
\hline & Treatment & 3 & 1.030 & 9.232 & 0.001 \\
\hline & Time & 1 & 0.892 & 8.000 & 0.007 \\
\hline & $\operatorname{Tr} \times \mathrm{Ti}$ & 3 & 0.278 & 2.489 & 0.067 \\
\hline & Residual & 57 & 0.112 & & \\
\hline \multirow[t]{5}{*}{ Simpson's 1- $\lambda$} & Depth & 1 & 0.000 & 0.502 & 0.473 \\
\hline & Treatment & 3 & 0.007 & 9.915 & 0.001 \\
\hline & Time & 1 & 0.003 & 4.016 & 0.050 \\
\hline & $\operatorname{Tr} \times \mathrm{Ti}$ & 3 & 0.001 & 1.874 & 0.151 \\
\hline & Residual & 57 & 0.001 & & \\
\hline
\end{tabular}


Table 3. SIMPER analysis of microbial TRF similarity across restoration treatments.

\begin{tabular}{lccc}
\hline \multirow{2}{*}{ Treatment } & $\begin{array}{l}\text { Within Treatment } \\
\text { Mean Similarity (\%) }\end{array}$ & \multicolumn{2}{c}{ Most Abundant TRF (bp) } \\
& Size (bp) & Contribution (\%) \\
\hline Grounding & 65.5 & 106 & 7.1 \\
Stake & 57.1 & 106 & 7.6 \\
Fill & 46.4 & 504 & 9.6 \\
Intact & \multicolumn{4}{c}{68.3} & 504 & 7.4 \\
\hline \multicolumn{4}{c}{ Among Treatment Mean Dissimilarity (\%) } \\
Stake & Grounding & Stake & Fill \\
Fill & 40.2 & & \\
Intact & 54.2 & 58.1 \\
\hline
\end{tabular}

Table 4. Multiple partial correlations between dbRDA coordinate axes and environmental variables

\begin{tabular}{lrrr}
\hline Variable & dbRDA1 & dbRDA2 & dbRDA3 \\
\hline Organic matter & -0.998 & -0.037 & -0.059 \\
Bulk density & 0.005 & -0.804 & 0.594 \\
$\mathrm{NH}_{4}{ }^{+}$concentration & -0.069 & -0.593 & -0.802 \\
\hline
\end{tabular}

Table 5. Pearson correlations between log-transformed diversity metrics calculated from T-RFLP abundance data and environmental variables, sampled at $0-y r$ and 1 -yr postrestoration. Correlations in bold text with one and two asterisks indicate that the correlation is significant at the 0.05 and 0.01 level, respectively.

\begin{tabular}{|c|c|c|c|c|c|c|c|c|c|}
\hline Diversity Metric & phi & $\mathrm{BD}$ & $\mathrm{pH}$ & Eh & OM & $P$ & $\mathrm{NH}_{4}^{+}$ & SRP & DS \\
\hline Richness S & $0.34^{* *}$ & -0.16 & -0.23 & -0.18 & $0.32^{* *}$ & $-0.51^{* *}$ & -0.16 & 0.06 & -0.01 \\
\hline Shannon-Weaver $H^{\prime}$ & $0.34^{* *}$ & -0.17 & -0.21 & -0.22 & $0.31^{*}$ & $-0.51^{* *}$ & -0.14 & -0.01 & 0.02 \\
\hline Simpson's $1-\lambda$ & $0.40^{* *}$ & $-0.30^{*}$ & -0.24 & $-0.33^{* *}$ & $0.40^{* *}$ & $-0.52^{* *}$ & -0.22 & -0.05 & 0.15 \\
\hline Pielou's J' & 0.16 & -0.06 & 0.04 & -0.13 & 0.09 & -0.23 & -0.01 & -0.19 & 0.00 \\
\hline
\end{tabular}


Figure 1. Location of study sites at Cutter Bank, in southern Biscayne Bay, Florida, USA. Polygons in lower inset are grounding/restoration sites.

Figure 2. Sediment environmental variables at grounding (top row), stake (second row), fill (third row), and intact sites (bottom row), at 0yr (circles) and 1yr (triangles) postrestoration. Values are mean \pm se at three depth horizons: $0-2 \mathrm{~cm}, 2-6 \mathrm{~cm}$, and $6-10$ cm. Abbreviations: phi $=$ sediment particle size; $\mathrm{Eh}=$ redox potential; SRP $=$ soluble reactive phosphate.

Figure 3. Sediment size class (clay, silt, sand, gravel) contribution in sediment cores collected from restoration treatments. Data in bars are pooled over three depth horizons $(0-2 \mathrm{~cm}, 2-6 \mathrm{~cm}, 6-10 \mathrm{~cm})$ and two sampling events (0yr, 1yr) within each treatment. Letters indicate statistical significance $(\alpha=0.008)$ among treatments determined through PERMANOVA pairwise tests of multivariate sediment structure between treatments. Figure 4. Principal coordinates analysis ordinations of TRFLP profiles from sediment samples at Grounding, Stake, Fill, and Intact sites.

Figure 5. TRF richness ( $S$, Chao 2), evenness (Pielou's J'), and diversity (ShannonWeaver $H^{\prime}$, Simpson's $\left.1-\lambda\right)$, by restoration treatment and sampling event $(0 \mathrm{yr}$, dark bars and $1 \mathrm{yr}$, light bars) calculated from TRFLP abundance data. Values are mean \pm se for $H^{\prime}, 1-\lambda$, and $\left.J^{\prime}\right)$ and mean \pm sd for Chao 2 . Where the Treatment main effect was significant, significance of pairwise tests of the Treatment levels $(\alpha=0.008)$ is indicated by letters at the base of each Treatment bar group. Significance of a Time difference within each treatment is indicated by an asterisk $(\alpha=0.05)$.

Figure 6. dbRDA ordination microbial community data (binomial deviance resemblance matrix calculated from log transformed relative abundance data) fitted to environmental variables. Data are from $0 \mathrm{yr}$ and $1 \mathrm{yr}$ sampling events. Ordination is based on best-fit DistLM model with three variables (log(BD), $\log \left(\mathrm{NH}_{4}{ }^{+}\right)$, and $\log (\mathrm{OM})$ ). 


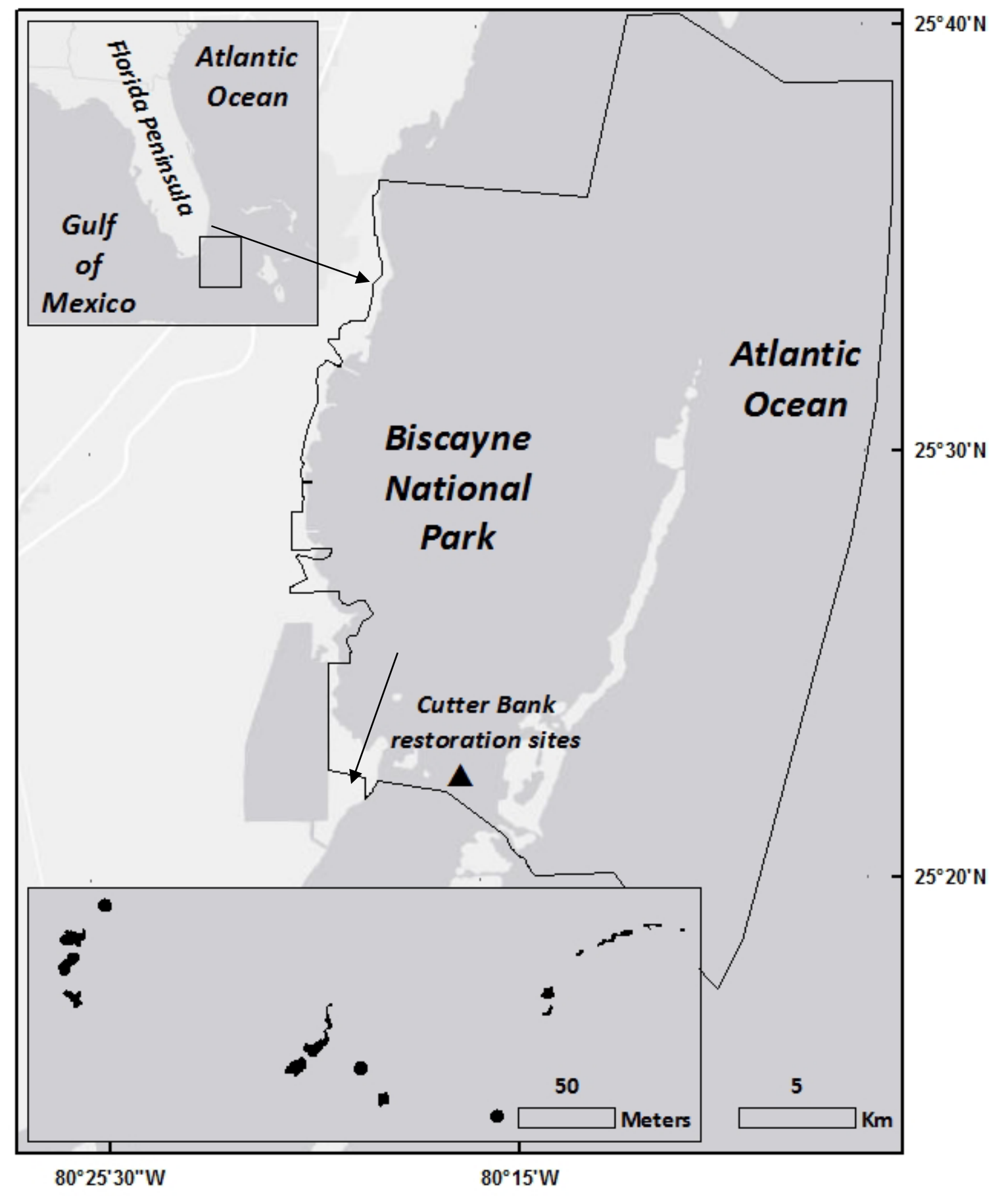




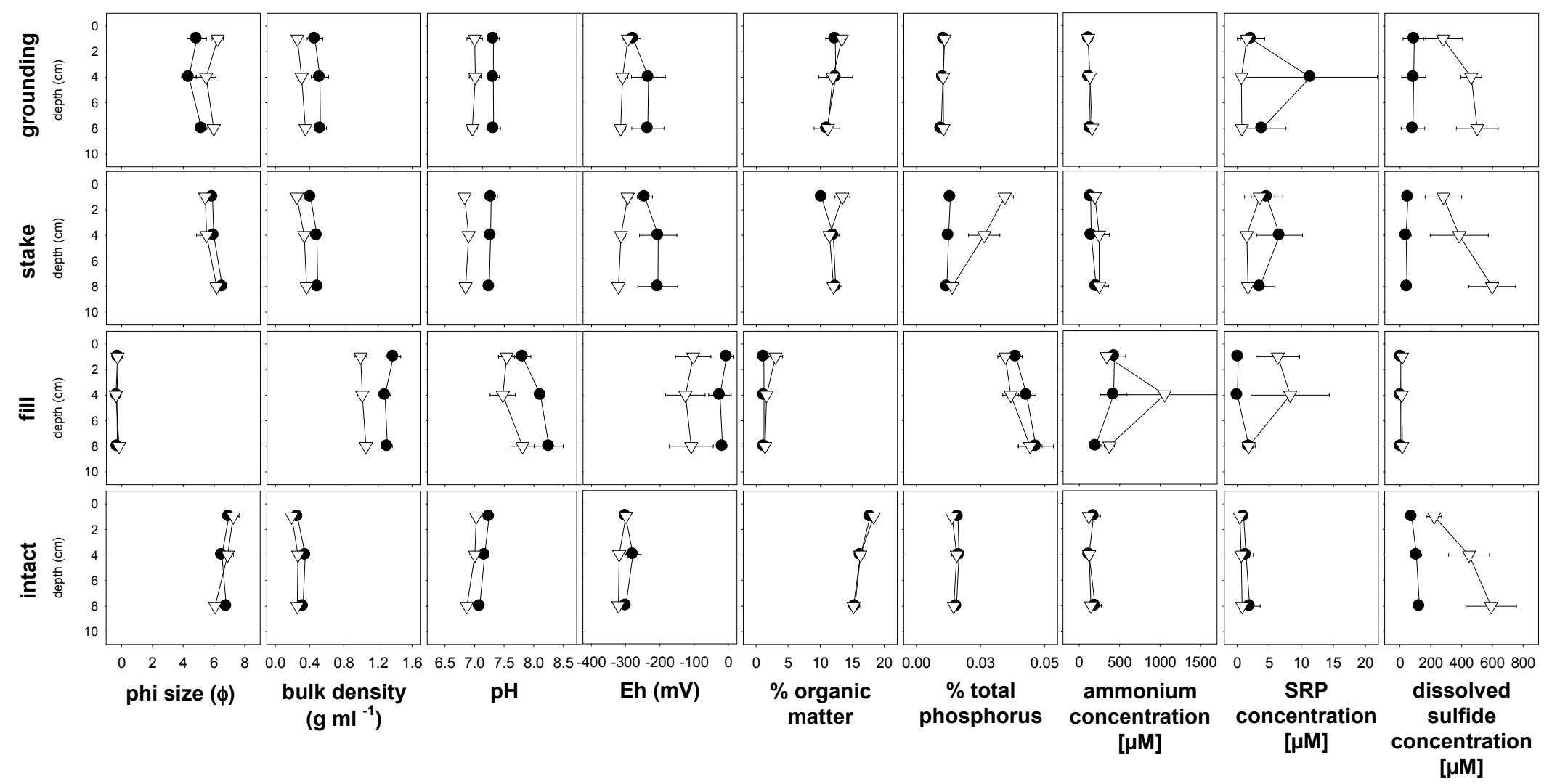




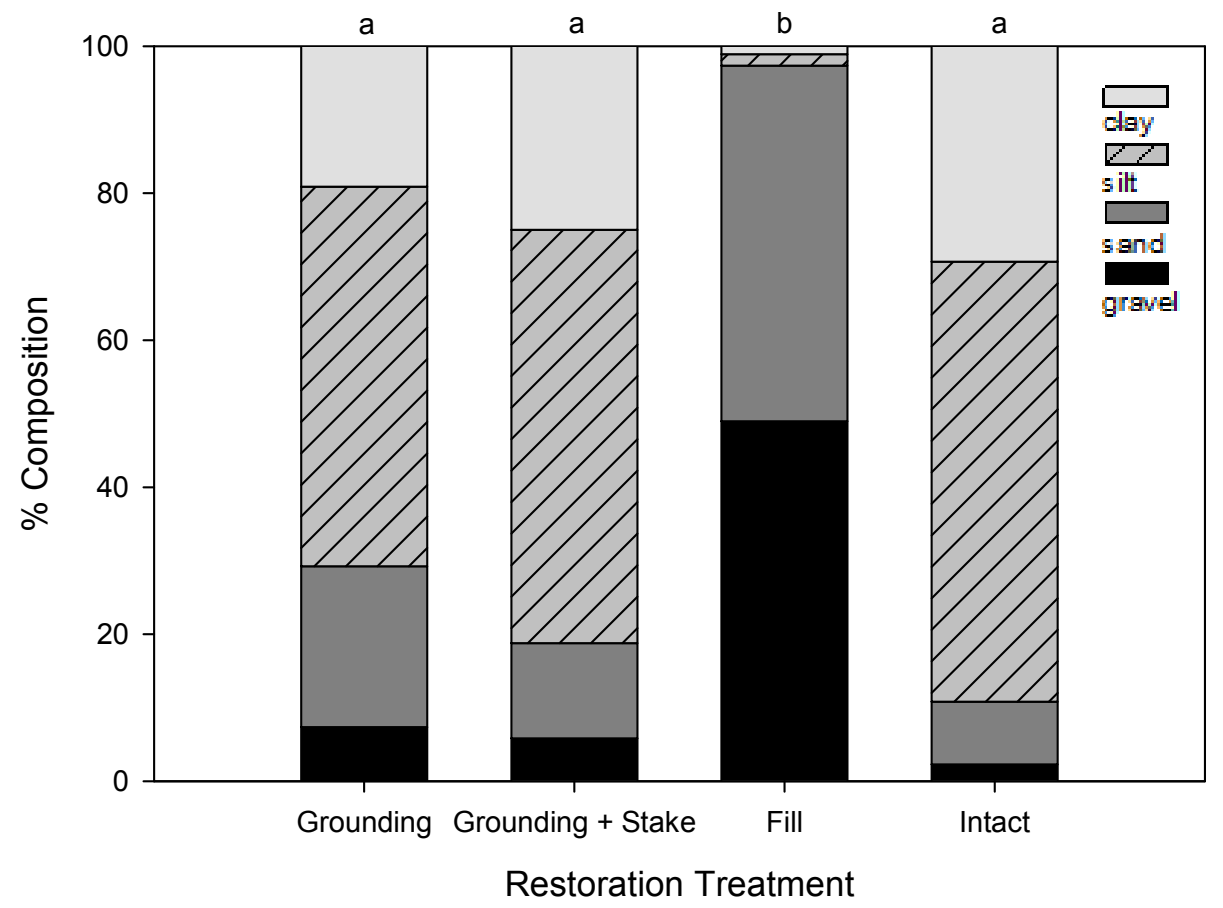




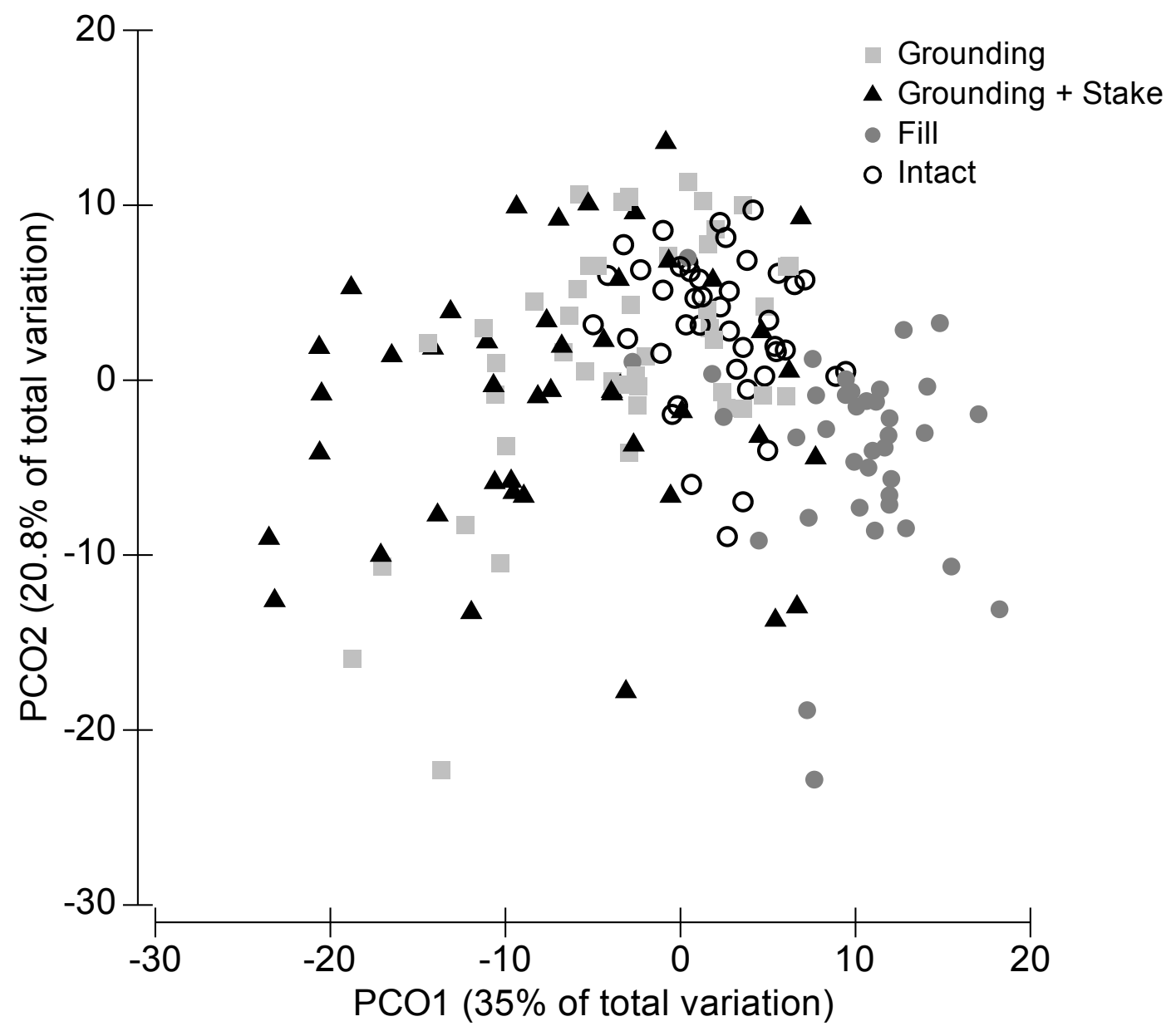



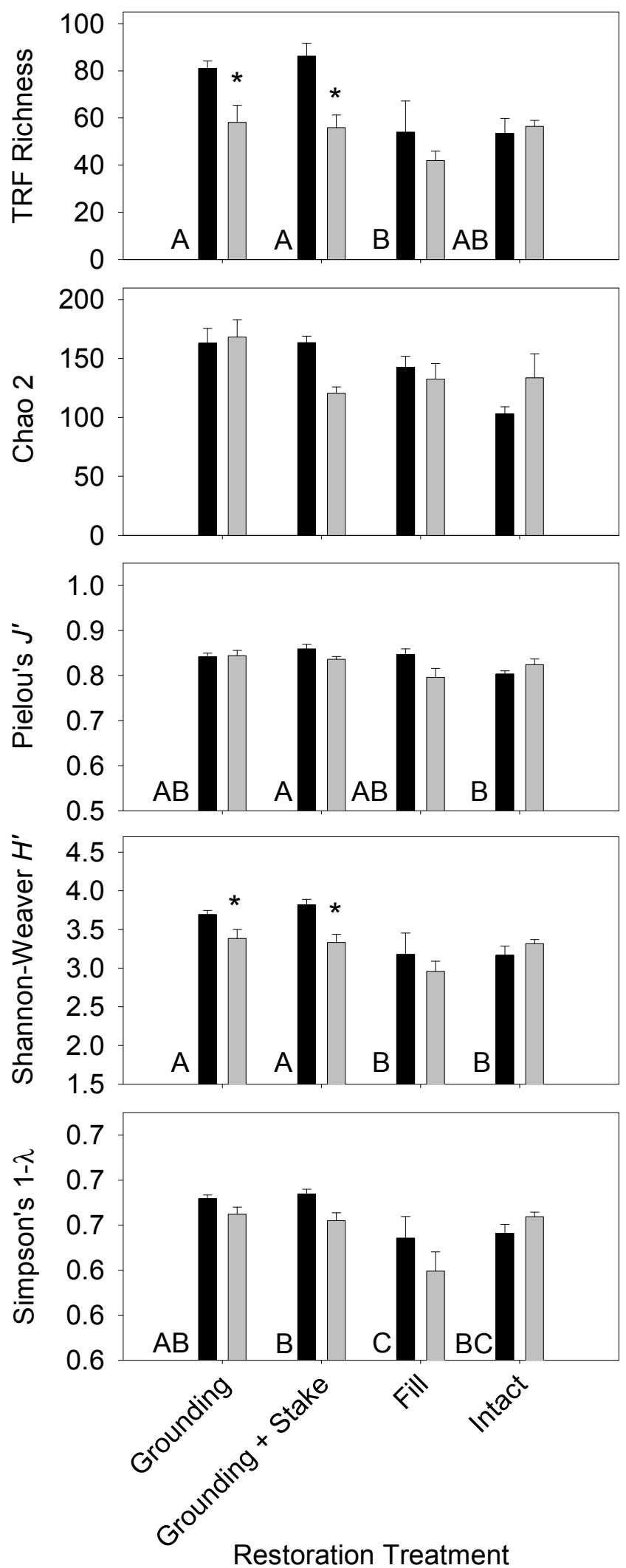


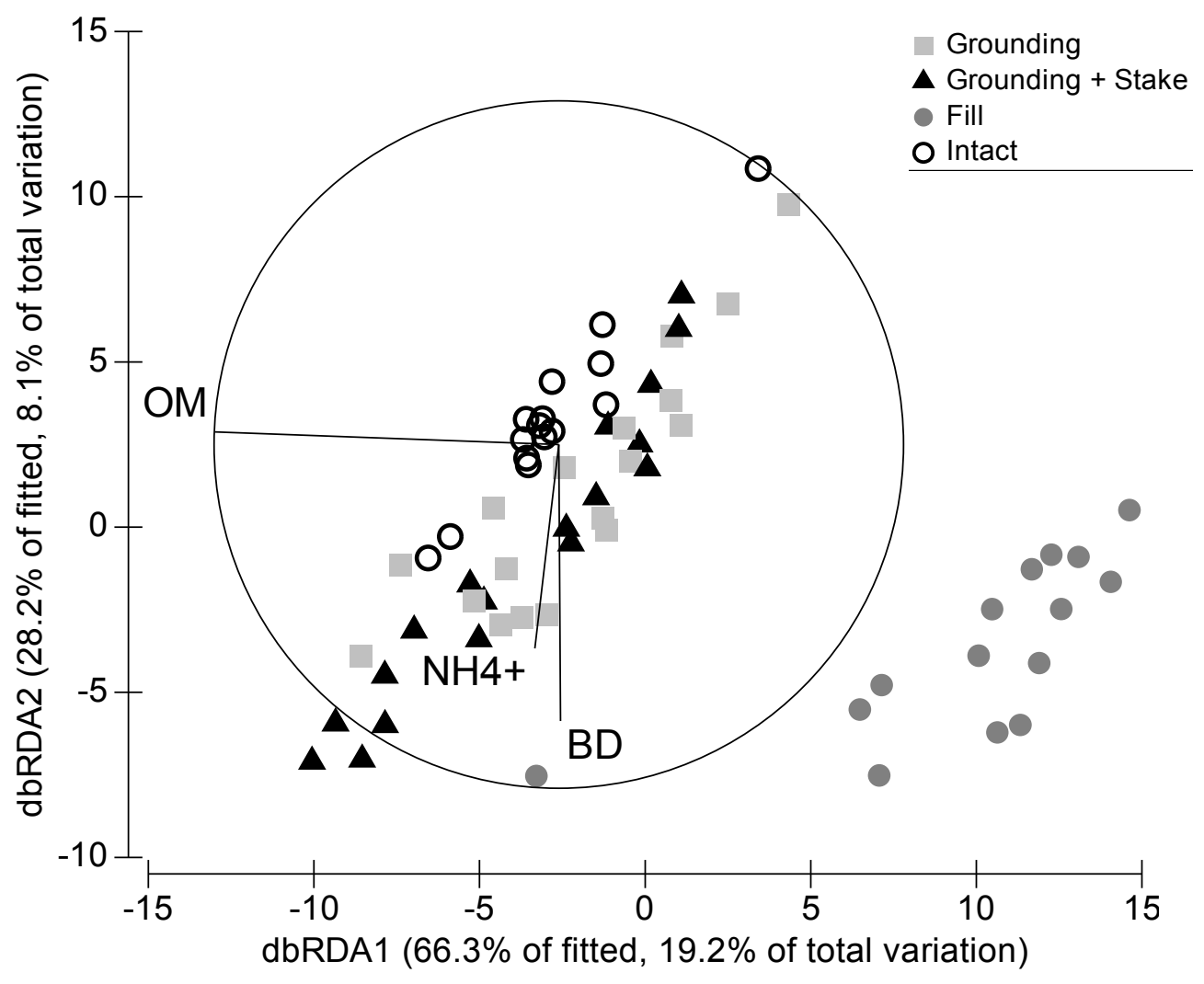


CHAPTER V: Disturbance and restoration effects on macroinvertebrate infaunal community structure in subtropical seagrass sediments.

\section{Abstract}

Infaunal invertebrates in seagrass sediments facilitate many key ecosystem processes, yet infaunal community response to and recovery from physical disturbance to seagrass sediments is not well understood. We evaluated infaunal community structure, macrophyte communities, benthic microalgae, and sediment properties in sites where vessel groundings excavated seagrass sediments, and in sites where restoration actions had been implemented. Restoration methods included installation of bird roosting stakes as a means to provide a fertilization source, and placement of sediment fill to re-grade and stabilize excavations. Infauna communities in both disturbed and filled sites had different community structure, and reduced abundance, richness, evenness, diversity, and dominance relative to the undisturbed seagrass meadow. Fertilizing seagrass sediments increased infaunal abundance, but did not affect other diversity metrics. Environmental predictors of infaunal community structure across restoration treatments included sediment bulk density, organic matter content, and porewater inorganic nutrient pools. Disturbance to seagrass sediments can cause impacts to infaunal communities that may persist for several years. Restoration actions also impact infaunal communities, and recovery of infaunal communities was not observed at restoration sites during the first year post-restoration. 
Introduction

Seagrass ecosystems provide numerous goods and services to human populations including shoreline protection, sediment stabilization, water purification, and commercial and artisanal fisheries, and (Spalding et al. 2001). These goods and services have been valued at $\$ 19,000 \mathrm{ha}^{-1} \mathrm{yr}^{-1}$ (Costanza et al. 1997). Ecosystem functions that support these goods and services include primary and secondary production, nutrient cycling, and benthic metabolism (Hemminga \& Duarte 2000; Marba et al. 2006b).

Benthic infauna play an important role in seagrass ecosystem functioning and in maintaining the ecosystem services provided by seagrasses. Infauna biomass represents secondary production, i.e. the transfer of a portion of the carbon fixed by seagrasses and benthic microalgae to higher tropic levels. Infauna are an important component in seagrass food web structure, consuming benthic microalgae and serving as prey for epibenthic predators, including several important fishery species (Summerson \& Peterson 1984). Bioturbation by infauna irrigates and oxygenates shallow sediments, and enhances benthic-pelagic fluxes and stimulates primary production (Norkko et al. 2001; Lohrer et al. 2004; Montserrat et al. 2008).

Loss of seagrass resources along the world's coastlines is accelerating (Waycott et al. 2009), and physical disturbance is a key contributor to this decline (Orth et al. 2006). Physical disturbances to seagrass meadows that disrupt the rhizosphere, such as from vessels that run aground and excavate plants and sediment (Fonseca et al. 2004; Di Carlo \& Kenworthy 2008), influence factors important in controlling infaunal communities such as benthic microalgae, macroalgae, and seagrass abundance, as well as sediment organic matter and nutrient pools (see Chapters II and III of this thesis). 
The effects of physical disturbance on infauna in seagrass sediments are not well documented (but see (Sheridan 2004a), though such impacts are well described for soft sediments in other ecosystems, primarily in the context of natural processes such as storm events (Dobbs \& Vozarik 1983; Hall 1994; Posey \& Lindberg 1996; Zajac et al. 1998) or anthropogenic activities such as trawling (Collie \& Hall 2000; Kaiser et al. 2006). In seagrass ecosystems, attention has focused on epibenthic invertebrates. For example, vessel grounding impacts to epibenthic species have been documented, and described as taxa- and scale-dependent (Bell et al. 2002; Uhrin \& Holmquist 2003). Disturbance to and subsequent recovery of seagrass meadows are expected to result in changes to infaunal communities, and these changes may in turn influence functioning in these ecosystems.

Increased protection for seagrasses by national governments is often accompanied by mandates to restore seagrass injuries or otherwise mitigate for seagrass impacts. Accordingly, interest in seagrass restoration has increased in recent decades (Fonseca 2011). Resource managers and restoration practitioners attempt to accelerate recovery of disturbed seagrass communities by implementing specific restoration methods, often to re-grade and stabilize excavations and delivery fertilizers to restoration sites (Fonseca et al. 1998; Kirsch et al. 2005). For restoration to be successful, ecological attributes of the system such as structure, composition, and function must be reestablished (Hobbs \& Norton 1996; Higgs 1997), but a preliminary understanding both of the effects of the disturbance and of natural recovery trajectories is required to understand the post-restoration recovery process.

Once seagrass restoration has been implemented, rapid assessments of plant communities are typically used to monitor restoration success (Fonseca et al. 1998; Uhrin et al. 2011). Analyses conducted to date on functional performance other than 
primary production in restored seagrass sites, have focused on infauna (Bell et al. 1993; Sheridan et al. 2003; Sheridan 2004b) or epibenthic invertebrates (Fonseca et al. 1990, 1996). These studies have been limited to restoration sites where seagrass has been transplanted. We are unaware of studies of seagrass infauna community response to vessel grounding disturbances, or to restoration activities involving methods other than seagrass transplanting, such as filling excavations or fertilizing restoration sites. Information currently lacking on infaunal recovery trajectories following seagrass restoration is needed to fully assess restoration goals.

Our study aimed to fill some information gaps that exist regarding the effects of physical disturbances on infaunal community structure in seagrass sediments. We also sought to characterize the recovery of seagrass infauna following common restoration actions (other than transplanting). We hypothesized that a) vessel groundings that excavate sediments alter infaunal community structure; b) altered community structure changes with time following disturbance through succession, and c) seagrass restoration actions such as fill placement and fertilization (via installation of bird roosting stakes) accelerate the recovery of infaunal communities.

Methods

Study System

This study was conducted in southern Biscayne Bay, described in Chapter II of this thesis. Infauna in seagrass sediments for this area have been described in the context of the development and early operation of the Florida Power and Light Turkey Point power plant (Roessler 1971; McLaughlin et al. 1983). This study evaluated infaunal communities and sediment structure on multiple seagrass shoals: Cutter Bank, Arsenicker Bank, East Featherbed Bank, and Biscayne Channel. Our study sites 
included multiple vessel grounding injuries, restoration sites, and adjacent undisturbed seagrass meadows on these shoals. (Figure 1).

\section{Experimental Design}

Disturbance Analysis

Effects of physical disturbance on infaunal community structure were evaluated at fourteen vessel grounding sites of known age on Cutter Bank, Arsenicker Bank, East Featherbed Bank, and Biscayne Channel. These grounding sites $(G)$ included vessel grounding disturbances where sediments were excavated to a mean depth of $0.4 \mathrm{~m}$, but for which no restoration has taken place. Sites were documented upon occurrence, with the exception of the $5 \mathrm{yr}$ age group, that included three sites known from aerial photography to be at least five years old. Sites were assigned to age groups rounded to the nearest six-month increment. There were two to four sites per age group (0 yr: 4 sites; 1 yr: 2 sites; 3 yr: 3 sites; 4 yr: 2 sites; and 5 yr: 3 sites). G sites were sampled once during February - March 2011. One $7.3 \mathrm{~cm}$ x $10 \mathrm{~cm}$ sediment core was haphazardly collected from each site, and one core was collected from the undisturbed reference seagrass meadow adjacent to each feature.

\section{Restoration Analysis}

Effects of seagrass restoration methods on infaunal communities were examined at eighteen vessel grounding sites on Cutter Bank, sampled quarterly following implementation of multi-site restoration project conducted in January-February 2010. A factorial design was employed, with Restoration, Fertilization, and Time as factors. Restoration treatments included unrestored vessel grounding injuries $(G)$, injuries that were returned to grade of the surrounding sea floor with quarried sand $(F)$, and intact undisturbed seagrass sites (I). The Restoration factor was crossed with a Fertilization 
factor by installing bird roosting stakes into a subset of sites within each of the three Restoration treatments (GS = grounding+stake, FS = fill+stake, IS = intact+stake). Sites included in the study were an average of $36 \mathrm{~m}^{2}$ in size. G and GS sites were an average of $0.5 \mathrm{~m}$ deep, and F and FS sites were filled to grade. Circular plots $32 \mathrm{~m}^{2}$ in size were established as I and IS sites at random points across the shoal. Three sites were included in each Restoration x Fertilization treatment (i.e. G, GS, F, FS, I, IS), and three cores were collected per site per sampling event. Sites were sampled within one month of restoration implementation and again at three, six, and twelve months following restoration (February, May, August, and February 2011).

\section{Seagrass Community Characterization}

To evaluate the status of the macrophyte community, seagrass and macroalgae (i.e. calcareous green algae) abundance was estimated according to methods described in Chapter II of this thesis.

\section{Sediment Core Collection and Processing}

We used cores of the surface sediments to define the soil environment and invertebrate communities as a function of restoration and fertilization treatments. We sampled a suite of eleven soil properties that are indicators of structure and function in seagrass ecosystems, including benthic microalgae (primary production, habitat quality); $\mathrm{pH}$, redox potential, organic matter content, and porewater sulfide (benthic metabolism and remineralization); bulk density, water content, and particle size (nutrient exchange); and nitrogen and phosphorus in sediment and porewater (nutrient storage). Detailed descriptions of coring and environmental analyses are provided in Chapters II of this thesis. 
Infauna Core Collection and Processing

$7.3 \mathrm{~cm} \times 10 \mathrm{~cm}$ cores were collected by hand for infauna analysis. At disturbance sites, one infauna core was haphazardly collected from each injury feature and from the adjacent undisturbed reference seagrass bed. At restoration sites, three infauna were randomly collected from each site/time. Data from replicate infauna and sediment cores were averaged for sediments analysis.

Core contents were sieved through $500 \mu \mathrm{m}$ mesh. Material retained on the sieve was fixed in $4 \%$ seawater-buffered formalin for several weeks, rinsed, and stored in $90 \%$ ethanol. Samples were stained with Rose Bengal and organisms were separated from sediment and detritus. Infauna were then counted and sorted at Mote Marine Laboratory (Sarasota FL) into groups determined by coarse taxonomic level, usually determined by class or order. We did not measure biomass of the organisms we sampled. Invertebrate abundance can be highly variable with regard to biomass depending on body size of individuals. Overall, the sizes of the individuals were very small, and many were damaged. In addition, organisms from the $\mathrm{G}$ and I sediments were tightly embedded in a matrix of organic particles that would have confounded biomass results. The effort involved with isolating the organisms from this matrix would have exceeded our available resources.

Data Analysis

Effects of disturbance on ecosystem structure and recovery through time were evaluated by comparing primary producer (seagrass, macroalgae, microphytobenthos) abundances, infauna abundance, and infauna diversity between vessel grounding and reference sites within each age group. Effects of restoration on ecosystem structure and recovery through time were evaluated by comparing primary producer (seagrass, 
macroalgae, microphytobenthos) abundances, infauna abundance and diversity, and between vessel grounding and reference sites within each age group.

Plant community structure at disturbance and restoration sites was assessed with seagrass and macroalgae percent cover. Seagrass and macroalgae BB scores from the seagrass community surveys were converted to percent cover data using the midpoint of the percent cover range corresponding to each BB score, and averaged by disturbance status (injury, reference) for each time step. For the disturbance analysis, seagrass and macroalgae percent cover and chlorophyll a content between injury and reference sites at each time step were compared using Mann-Whitney U-tests (seagrass, macroalgae) or t tests (chlorophyll a) in the software SPSS 20.0 (IBM). For the restoration analysis, changes in seagrass and macroalgae percent cover through time were detected with Spearman correlations (SPSS 20.0, IBM).

Principal coordinates analysis (PCO) was used to visualize differences in infauna community structure by disturbance status, and by restoration status and time. PCO is an unconstrained ordination method that projects samples onto axes and minimizes residual variation in the space of the chosen dissimilarity measure (Anderson et al. 2008).

Permutational Multivariate Analysis of Variance (PERMANOVA, Anderson et al. 2008) was used to test the hypotheses that physical disturbance to sediments and restoration actions alter infauna community structure, and that the altered communities changes through time towards convergence with reference communities. Specifically, for the disturbance and restoration analyses, we tested these hypotheses on multivariate infauna community structure and on univariate community characteristics including taxonomic richness $(S)$, evenness (Pielou's J', Simpson's $\lambda^{\prime}$ ), diversity (ShannonWeaver, $H^{\prime}$ ), and dominance (Simpson, $1-\lambda^{\prime}$ ). PERMANOVA enables testing of the 
response of one or more variables to one or more factors, based on any resemblance measure, by partitioning sources of variation. A primary advantage of PERMANOVA is that statistical significance of the pseudo- $F$ statistic is determined through permutations of randomized real data, thus avoiding normality and homogeneity of variance assumptions (Anderson et al. 2008). PERMANOVA analyses of multivariate infauna abundance data were based on the binomial deviance dissimilarity measure (Anderson \& Millar 2004), and analyses of univariate diversity metrics were based on Euclidean distance resemblances. Significance values for PERMANOVA tests were based on 999 permutations of residuals under reduced models, using Type III sums of squares. Pairwise permutational tests with Bonferroni corrections were conducted on significant main effects and interactions in the PERMANOVA analyses. Changes in diversity metrics between $0 \mathrm{yr}$ and $1 \mathrm{yr}$ samples within restoration treatments were evaluated using Mann-Whitney U-tests in SPSS 20.0 (IBM).

For the restoration analysis, the SIMPER procedure (Clarke et al 2006) was used to determine taxonomic similarity within the restoration groups. SIMPER also identified the contribution of the most abundant taxa in each analysis to within group similarity. Distance-based linear modeling (DistLM) and distance-based redundancy analyses (dbRDA) (Legendre \& Anderson 1999; McArdle \& Anderson 2001; Anderson et al. 2008) were used to determine relationships between infauna community abundance data from the restoration analysis and multivariate data on sediment properties. dbRDA visualizes the DistLM results as PCO axes constrained by linear combinations of the environmental variables that maximally explain biotic variation (Anderson et al. 2008). Parameters for the DistLM routine, which is analogous to linear multiple regression, included the Best selection procedure and the Akaike Information Criteria corrected for small sample sizes (AICc; Akaike 1973; Burnham \& Anderson 2002) selection criteria; 
the procedure was run with 9999 permutations. Sediment data from the top three depth horizons $(0-2 \mathrm{~cm}, 2-6 \mathrm{~cm}, 6-10 \mathrm{~cm})$ were weighted proportionally and combined for comparison with the infauna data, which was also collected from the top $10 \mathrm{~cm}$ of sediment. Sediment data were log-transformed prior to analysis to reduce skewness. PCO, PERMANOVA, SIMPER, DistLM and dbRDA analyses were conducted with the software PERMANOVA+ for PRIMER (Clarke 2006, Anderson et al. 2008).

\section{Results}

Disturbance Effects on Macrophytes and Infaunal Communities

\section{Primary Producer Abundance}

Seagrass and macroalgae cover, but not microphytobenthos abundance, were reduced at recent vessel grounding injuries (i.e. in the $0 \mathrm{yr}$ age group) relative to the reference seagrass meadow. Mean seagrass percent cover within the injuries (6.2 \pm $1.5 \%$ ) was approximately $15 \%$ of that in the intact seagrass community $(44.4 \pm 4.5 \%)$. This difference was evident in every age group $(0,1,3,4,5 \mathrm{yr})$ of unrestored grounding sites documented ( $U$ tests, $p<0.001$; Figure II-2). Seagrass cover did not differ between new injuries and 5yr old injuries ( $U$ test, $p=0.135$; Figure 2). Macroalgae cover in recent groundings $(4.4 \pm 1.1 \%)$ was approximately half of the cover in the intact seagrass community ( $U$ test, $p=0.012$; Figure 2$)$, but this reduction did not persist in sites that were $1,3,4$, or 5 years old ( $U$ test, $p>0.069)$. Macroalgae cover in injuries increased with site age, and was significantly higher in $5 y$ old sites $(16.2 \pm 1.9 \%)$ than in new groundings ( $U$ test, $p<0.001$; Figure 2). Chlorophyll a content of surficial sediments in grounding sites ranged from $4.1 \pm 1.1$ to $14.2 \pm 1.1 \mu \mathrm{g} / \mathrm{g}$, and was significantly lower than in reference sediments only for the 3 yr old sites $(t$ test, $t=-3.317, d f=4, p=0.029$; Figure 2). 
Infauna Community Structure and Diversity

A total of 1,806 individual organisms of 16 infauna taxa were identified from thirteen disturbances cores and fourteen reference cores (the sample vial for one disturbance core broke and was discarded). $31 \%$ of the organisms collected were from grounding sites, and $69 \%$ were from reference sites. Mean abundance per core was $42.7 \pm 1.9$ organisms for injury cores, compared with $89.4 \pm 16.6$ organisms for reference cores.

Disturbance reduced infaunal community abundance, which was different in vessel grounding sites when compared with undisturbed sites (PERMANOVA, $p=0.016$; Table 3). This difference between communities was visible in the PCO ordination, where grounding site cores separated from reference site cores along PCO1, through with some overlap between the two groups (Table 2). Tanaidacea, Nemertinea, Isopoda, Polychaeta, and Ophiuroiea abundance contributed to the differences between injury and reference cores, as indicated by strong positive correlations (> 0.7) with PCO1 (Table 2). Infaunal community abundance did not change with site age (PERMANOVA, $\mathrm{p}=0.728 ;$ Table 3; Figure 3).

Taxonomic richness was lower in injury sites than in reference areas (PERMANOVA, $p=0.0204 ;$ Table 3; Figure 3). We did not detect a disturbance effect on univariate infauna abundance, evenness, diversity, or dominance in these sites (PERMANOVA, $p>0.063 ;$ Table 3; Figure 3). Age was not a significant factor for these metrics ( $p>0.282 ;$ Table 3$)$.

SIMPER analysis revealed that polychaetes, nematodes, and oligochaetes made substantial contributions to both injury and reference samples, and in similar proportions (Table 4). Amphipods made a smaller contribution (4.2\%) to the similarity among injury samples; for reference samples, amphipods contributed $13.0 \%$ to reference similarity. 
Restoration Effects on Macrophytes, Sediment Properties, and Infaunal Communities Primary Producer Abundance

Seagrass percent cover at restoration sites relative to reference sites was $23 \%$, $15 \%$, and $6 \%$ for GS, F, and FS sites, respectively, at the 0 yr sampling event. Relative percent cover declined by half over four years in GS sites, while relative percent cover of macroalgae more than tripled in the same period (Figures III-2 and III-3). Relative seagrass cover doubled for F sites and quadrupled for FS sites over four years. Relative macroalgae cover increased over fifteen fold in four years in both F and FS sites (Figures III-2 and III-3).

Restoration status during the first year post-restoration at the Cutter Bank sites affected microphytobenthos abundance. Chlorophyll a content across all samples ranged from $10.6 \pm 1.7$ to $16.4 \pm 1.9 \mu \mathrm{g} \mathrm{g}^{-1}$ (Figure III-4). Chlorophyll a content was highest at the I sites, and there was some variation among sampling events. Chlorophyll a was lower in $\mathrm{G}$ sites, ranging from $10.6 \pm 1.7$ to $11.6 \pm 2.8 \mu \mathrm{g} \mathrm{g}^{-1}$. F sites had the lowest overall Chlorophyll a content, ranging from $0.2 \pm 0.1$ to $5.4 \pm 1.3 \mu \mathrm{g} \mathrm{g}^{-1}$.

Chlorophyll a content at F sites increased steadily with each time step (Figure III-4), but remained lower than $\mathrm{G}$ or I sites at the $1 \mathrm{yr}$ mark.

\section{Sediment Properties}

Sediments in undisturbed seagrasses $(\mathrm{I})$ at Cutter Bank were fine $(6.8 \pm 0.2 \phi)$, and dominated by silt $(59.8 \pm 3.4 \%)$ and clay $(29.3 \pm 3.0 \%)$, with small sand $(8.6 \pm 1.5 \%)$ and gravel $(2.3 \pm 0.9 \%)$ fractions (data not shown). These sediments were strongly reduced $(-302.6 \pm 9.1 \mathrm{mv}$ Eh) with high organic matter content $(16.5 \pm 0.5 \%$ loss on ignition). $\mathrm{pH}$ was neutral at $7.1 \pm 0.03$. Nutrient concentrations were low $(0.015 \% \pm$ 
$0.001 \% \mathrm{P}$ content; $\left.148.3 \pm 41.5 \mu \mathrm{M} \mathrm{NH}_{4}{ }^{+} ; 1.0 \pm 0.6 \mu \mathrm{M} \mathrm{SRP}\right)$. Sediments from G and IS sites had similar properties as I sites (Figure IV-2).

Sediment properties of $\mathrm{F}$ sites differed sharply from I sites for all variables examined. Fill sites had lower OM and DS concentrations, and higher bulk density, $\mathrm{pH}$, Eh, $\mathrm{P}$ content, and $\mathrm{NH}_{4}{ }^{+}$and SRP concentrations, than the Intact sites (Figure 2). $\mathrm{F}$ sediments were substantially coarser that I sediments (-0.3 \pm 0.2 ; Figure 3$)$, heavily dominated by gravel $(50.0 \pm 1.7 \%)$ and sand $(48.4 \pm 1.6 \%)$. OM content in F sites doubled over the course of the year, but remained low, at $3.0 \pm 1.1 \%$.

Fertilization via bird roosting stakes had varying results among restoration treatments. P content doubled in the course of the year at GS and IS sites, but did not change at FS sites (Figure IV-2). $\mathrm{NH}_{4}{ }^{+}$concentrations increased in all three fertilization treatments by $38 \%$ in GS sites, $80 \%$ in IS sites, and $90 \%$ in $\mathrm{FS}$ sites. $\mathrm{NH}_{4}^{+}$ concentrations also increased in $\mathrm{F}$ sites by $66 \%$. SRP concentration in IS sites increased by $50 \%$ and by nearly $2000 \%$ for FS sites. SRP concentrations in F sites also increased eight-fold over the year.

Infaunal Community Structure and Diversity

Infaunal community analysis was conducted on samples from the $0.25 \mathrm{yr}, 0.5 \mathrm{yr}$, and $1 \mathrm{yr}$ time steps. A total of 7,226 individual organisms of 12 infauna taxa were identified from 159 cores for the restoration analysis (three sample vials, one each from the G, GS, and I treatments, were lost). Across the three sampling events, mean abundance per core ranged from $35.1 \pm 3.9$ organisms for all $\mathrm{G}$ cores to 61.8 organisms for all IS cores. Taxonomic richness ranged from $5.5 \pm 0.5$ taxa per core for all GS cores to $7.1 \pm 0.1$ taxa per core for all IS sites.

Infauna communities were structured across restoration treatments and separation among the treatment groups was evident in the PCO ordination for the 
restoration analysis (Figure 4). Communities from $\mathrm{F}$ samples clustered separately from G and I samples along PCO2. G and I samples separated along PC1, though there was some overlap between these two groups. Within each treatment, samples also clustered by time step. There were strong negative correlations between oligochaete and nematode abundances, respectively, and PCO2 (Table 5) indicating that these taxa were important in distinguishing $\mathrm{G}$ and I samples from $\mathrm{F}$ samples. Cumaceans, amphipods, and tanaidaceans contributed to the separation of I from IS, as determined by strong correlation of those taxa $(r>0.7)$ with PCO1 (Table 5).

Infauna community abundance differed among the restoration treatments (PERMANOVA, $p=0.001 ;$ Table 5 ), and each treatment supported different communities (PERMANOVA pairwise tests, $p<0.001$ ). Across treatments, infauna communities also differed with each time step (PERMANOVA, $p=0.001$; Table 5). There was a significant Restoration $x$ Age interaction (PERMANOVA, $p=0.002$ ). Fertilization was not a significant source of variation in the infauna community data set. Restoration was also a significant factor in explaining variance in univariate metrics of infaunal abundance (PERMANOVA, $p=0.001$; Table 5; Figure 5), evenness $(p=0.003)$, diversity $(p=0.001)$, and dominance $(p=0.001)$. Abundance in $G$ samples was lower than in I samples (PERMANOVA pairwise tests, $p=0.001$ ), but $G$ and I samples did not differ on the basis of evenness, diversity, or dominance. Abundance, evenness, diversity, and dominance were all lower in $\mathrm{F}$ samples than in I samples (PERMANOVA pairwise tests, $p<0.004)$.

Age explained significant variation in infauna abundance, richness, and diversity (PERMANOVA, $p=0.001$; Table 5; Figure 5). Values for each of these metrics were higher at the $0.25 \mathrm{yr}$ sampling event than at the $0.5 \mathrm{yr}$ and $1 \mathrm{yr}$ events (PERMANOVA pairwise tests, $p<0.004)$. 
Abundance was affected by a significant interaction between Restoration and Age (PERMANOVA, $p=0.001$; Table 5), indicating that age affected infauna abundance differently among the restoration treatments. Abundance in the Intact treatment was lower at the 0.5 and $1 \mathrm{yr}$ sampling events that at the $0.25 \mathrm{yr}$ event (PEMANOVA pairwise tests, $p<0.002$; data not shown).

Infauna abundance was the only metric for which the Fertilization factor explained significant variation (PERMANOVA, $p=0.039$; Table 5). Across treatments, abundance was about $18 \%$ higher $(41.8 \pm 3.9$ organisms per core $)$ in the fertilized treatments than in unfertilized treatments $(49.4 \pm 4.0) \quad$ (PERMANOVA pairwise tests, $p$ $=0.034)$.

SIMPER analysis revealed that polychaetes and nematodes contributed strongly to similarity within samples from each restoration treatment (Table 4). Oligochaetes were abundant in $\mathrm{G}$ and I samples, but not in $\mathrm{F}$ samples. Amphipods were important contributors to F and I samples, but not to $G$ samples.

Environmental Predictors of Infauna Community Structure

Total nitrogen, mean phi size, and water content were excluded from the DistLM analysis due to high correlation $(|r|>0.95)$ with organic matter content and bulk density. The dbRDA ordination visualizes infauna community samples coded by restoration treatment constrained by environmental variables (Figure 6). Infauna samples from F sites separated from $G$ and I samples in the ordination. $G$ and I samples overlapped completely, contrary to what was observed in the unconstrained PCO ordination (Figure 4), where there was some separation between the two treatments. The first three dbRDA axes explained $94.1 \%$ of the fitted variation, and $43.1 \%$ of the variation in the resemblance matrix (Figure 6), and are likely capturing substantial information about the infauna community structure at these sites as influenced by environmental predictors. 
There was a strong negative correlation between SRP concentration and dbRDA1 (DistLM, r =-0.77; Table 6). OM content had a strong negative loading on dbRDA2 (DistLM, $r=-0.77$ ). dbRDA3 had a positive correlation with BD (DistLM, $r=$ $0.77)$ and a negative correlation with $\mathrm{NH}_{4}{ }^{+}(\mathrm{r}=-0.56) . \mathrm{P}$ and $\mathrm{pH}$ did not load clearly onto the first three axes. These correlations indicate that high OM content in the $\mathrm{G}$ and I sediments, and high $\mathrm{BD}, \mathrm{NH}_{4}{ }^{+}$, and $\mathrm{SRP}$ in the $\mathrm{F}$ sediments are important drivers of the observed infauna community structure across restoration treatments.

DistLM marginal tests that fit each environmental variable individually to the infauna community data showed that every variable except $\mathrm{NH}_{4}{ }^{+}$concentration had a significant relationship with infauna community abundance (DistLM marginal tests, $p<$ 0.020). DistLM returned a best multivariate predictor model explaining infauna community structure across restoration treatments that included $\mathrm{OM}, \mathrm{BD}, \mathrm{pH}, \mathrm{NH}_{4}{ }^{+}$, SRP, and $\mathrm{P}\left(\right.$ DistLM, $\left.\mathrm{r}^{2}=0.43\right)$. However, the solutions for the seven best models all had AICc values within two units of each other, so all may be considered viable (Burnham \& Anderson 2002). The ten best models included between three and six variables. All models included $\mathrm{NH}_{4}{ }^{+}$and $\mathrm{SRP}$, and six of the seven models included OM, and all included bulk density, organic matter content, and $\mathrm{NH}_{4}{ }^{+}$concentration. None of the best models included Eh, DS, or chlorophyll a as a predictor variable.

Discussion

We were able to confirm our hypotheses that disturbance to seagrass ecosystems that excavated sediments, and restoration that replaced lost sediments, both alter infauna communities. Disturbance to seagrass sediments changed infauna communities relative to those in undisturbed seagrass meadows by reducing infauna community abundance and taxonomic richness in vessel grounding injuries up to five 
years of age. Placing fill into excavations created localized patches with different community structure, by reducing abundance, richness, and diversity, and increasing evenness and dominance relative to the undisturbed seagrass meadow. Fertilizing sites increased abundance by nearly $20 \%$.

We found varying evidence that infauna from disturbance and restoration sites converge with reference communities in the time frame of our observations. In disturbed sites, while overall community abundance and taxonomic richness was affected, there was no difference in abundance between injury and reference sites. These results suggest that disturbance sites are supporting different infaunal communities, though numerical recovery has occurred. Infaunal communities at fill sites did not converge with reference communities during the first year post restoration, exhibiting reduced abundance, evenness, and diversity, and greater dominance than reference communities. However, both the number of individuals and taxonomic richness at the fill sites increased over the course of our study, suggesting that the infauna community has entered a recovery trajectory.

Infaunal communities can change rapidly in disturbed sediments, and may exhibit variable spatial and temporal responses to disturbance in patterns of colonization (Santos \& Simon 1980; Zajac \& Whitlatch 1982; Zajac et al. 1998; Schaffner 2010; Whomersley \& Huxham 2010) . Diversity was highest in I and G samples, perhaps indicating more developed infaunal communities than in F sites While polychaetes were the dominant taxa in all three restoration treatments, they had a third greater contribution to group similarity in the $F$ samples, than in the $G$ and I samples. Dominance values for F samples reflect this composition, and were higher than for $G$ and I sites. These results suggest that infaunal communities at the $\mathrm{G}$ and $\mathrm{F}$ sites may be at early (albeit differing) points along the successional trajectory. In our restoration analysis, the $\mathrm{G}$ sites were 
known to be at least five years old at the time of our study, and represented the status of the F sites before they were filled. The G sites were viewed as a "status quo" option, representing the ecosystem state if no restoration actions were taken. The status of the infuanal community at $\mathrm{G}$ sites indicates that they are further along this trajectory. For example taxonomic richness, evenness, diversity, and dominance did not differ between $\mathrm{G}$ and I samples. However, community and total abundance was lower in $\mathrm{G}$ than in I samples, indicating that numerical recovery has not occurred.

We propose that the altered infauna communities we observed in disturbance and restoration sites can be explained by reduced habitat quality in these sites. In seagrass ecosystems, plant community structure provides habitat complexity and more food resources, when compared to unvegetated sediments (Orth et al. 1984a; Summerson \& Peterson 1984). The slow recovery of the plant community at the $\mathrm{G}$ sites, where seagrass cover is only about $20 \%$ of that in the undisturbed meadow, may explain the differences in abundance that we observed. In transplanted seagrass sites, recovery of epibenthic infaunal communities has been shown to track development of the seagrass community (Fonseca et al. 1990), and it follows that a similar trajectory would apply to infauna.

Calcareous green macroalgae cover had returned to or exceeded reference values in grounding injury sites of all ages, with the exception of recent injuries. These observations are consistent with successional patterns in tropical seagrass ecosystems, in which the first colonizers are turf and calcareous green macroalgae. Rapidly growing seagrass species follow, and succession culminating with a monospecific climax community or a mixed community of climax and subdominant species (Zieman 1982; Williams 1990; Rollon et al. 1999; Kenworthy et al. 2002; Whitfield et al. 2002). Seagrass species have different physical characteristics that include varying ratios of 
above ground to below ground biomass (Zieman 1982; Duarte \& Chiscano 1999; Di Carlo \& Kenworthy 2008). Early successional species (e.g. Halodule wrightii and Syringodium filiforme in the Caribbean), like rhizophytic macroalgae, possess shallower and less below-ground biomass than do climax seagrass species such as Thalassia testudinum. This may also provide insight into the status of infauna communities in these sites. Infaunal abundance and diversity has shown to be reduced in seagrass meadows dominated by successional seagrass species, driven by structural characteristics of the seagrasses (Micheli et al. 2008). It may be that the less complex below-ground physical structure provided by the macroalgae community at these sites is supporting an altered infaunal community.

Our study sites were tens of square meters in size. At this scale, infaunal organisms are likely to actively migrate or be passively transported from the surrounding seagrass meadows into the restoration sites during recolonization, though larval recruitment may also occur (Savidge \& Taghon 1988). Habitat quality, including food availability, will be an important factor in the ability of these sites to support recolonization by infauna. Benthic microalgae are a primary food source for many infauna species. Occupying the surficial sediments, benthic microalgae are prone to impacts of physical disturbance of the sediments. However, recovery following disturbance occurs relatively quickly due to rapid rates of growth and reproduction (Larson \& Sundback 2008; Montserrat \& Colen 2008) and recolonization by mobile diatom taxa (Admirall 1984). Our results are consistent with this pattern. In our analysis, sediment chlorophyll a content in disturbed sites did not initially differ from that in reference sediments at the $0 \mathrm{yr}$ time step, though it was lower in the 3-yr sites. In the restoration analysis, chlorophyll a in the fill sites increased steadily over the course of the first year following restoration. While fill site chlorophyll a only reached 
approximately half of the reference levels, this rapid development is likely to be an important factor in the recovery of infauna communities following disturbance.

Infaunal communities had strong relationships to sediment properties among treatments, and in particular between F vs. G and I sites. The material used as fill in these restoration sites was much coarser in texture that the ambient sediments. It remains to be seen whether physico-chemical differences in fill sites from the surrounding seagrass meadow will affect the recovery trajectory of seagrasses and infauna. This seems possible, given the particle coarseness, lack of OM, and high $\mathrm{P}$ content that we documented in the fill sites. Documented recovery of infaunal communities typically occurs within a year following physical disturbance to soft sediments (e.g. Collie \& Hall 2000; Dernie 2003; Skilleter et al. 2006). However most studies of these recovery dynamics focus on native sediment that has been disturbed. The fill sites we studied involved terrestrially-sourced material with distinct properties relative to the surrounding area. We are unaware of studies that have examined infauna colonization dynamics in seagrass restoration sites involving fill placement, so we looked to studies of colonization in dredge spoil deposits as an analogue. Reports of infaunal community recovery time in dredge spoil deposited in seagrass habitat range from over a year (i.e. recovery not detected during the first year of monitoring) to ten years (reviewed in Sheridan 2004).

\section{Conclusion}

We documented multi-year effects on infauna communities at disturbance sites and incomplete recovery of infauna in the filled sites we studied. Despite the potential for long term differences between filled sites and undisturbed seagrass sediment, we reiterate the importance of filling excavations in seagrass ecosystems whenever 
possible. Physical disturbances also cause loss of plant biomass and stocks of organic carbon and limiting nutrients (Chapter 2, this thesis). Unrestored injuries result in reduced seagrass cover, diminished sediment and porewater nutrient pools, and altered microbial communities that can persist for several years (Chapters 3-4, this thesis). Further, because of the potential for erosion of excavated banks due to currents or storms (Whitfield et al. 2002), filling excavations to grade is considered a critical step in the recovery process, especially for larger excavations (Uhrin et al. 2011).

Recovery trajectories of infaunal communities in restoration sites involving fill placement should be established over longer time frames. This knowledge will increase understanding of ecosystem functioning in the sediments, as well as secondary production and reestablishment of trophic linkages in disturbed seagrass ecosystems. 
Table 1. Phylogenetic list of invertebrate taxa and observed frequencies for the disturbance and restoration analyses.

\begin{tabular}{|c|c|c|c|c|c|c|c|c|c|c|c|}
\hline \multirow[b]{2}{*}{ Phylum/Subphylum } & \multirow[b]{2}{*}{ Class/Subclass } & \multirow[b]{2}{*}{ Order } & \multicolumn{2}{|c|}{ Disturbance Analysis } & \multicolumn{2}{|c|}{ Restoration Analysis } & \multirow[b]{2}{*}{$\mathrm{F}$} & \multirow[b]{2}{*}{ FS } & \multirow[b]{2}{*}{ is } & \multirow[b]{2}{*}{1} & \multirow[b]{2}{*}{ Total by taxa } \\
\hline & & & Dist. & Ref. & G & GS & & & & & \\
\hline \multirow[t]{2}{*}{ Annelida } & Clitellata/Oligochaeta & & 166 & 229 & 215 & 261 & 30 & 66 & 323 & 191 & 1,481 \\
\hline & Polychaeta & & 363 & 880 & 366 & 370 & 609 & 589 & 667 & 496 & 4,340 \\
\hline \multicolumn{12}{|l|}{ Arthropoda } \\
\hline Chelicerata & Pycnogonida & & 1 & & 1 & 1 & 1 & 2 & 1 & & 7 \\
\hline Crustacea & Branchiopoda/Phyllopoda & Diplostraca & & & & & & & & 1 & 1 \\
\hline Crustacea & Cephalocarida & & 4 & 7 & & 2 & 6 & 1 & 4 & 11 & 35 \\
\hline Crustacea & Malacostraca/Eumalacostraca & Amphipoda & 80 & 262 & 41 & 53 & 159 & 232 & 177 & 156 & 1,160 \\
\hline Crustacea & Malacostraca/Eumalacostraca & Cumacea & 25 & 89 & 19 & 13 & 19 & 14 & 99 & 62 & 340 \\
\hline Crustacea & Malacostraca/Eumalacostraca & Isopoda & 22 & 37 & & 5 & 1 & 1 & 19 & 11 & 96 \\
\hline Crustacea & Malacostraca/Eumalacostraca & Mysida & 2 & 1 & 1 & 1 & & & & 1 & 6 \\
\hline Crustacea & Malacostraca/Eumalacostraca & Tanaidacea & 27 & 114 & 11 & 5 & 32 & 17 & 25 & 24 & 255 \\
\hline Crustacea & Malacostraca/Phyllocarida & Leptostraca & & & & & & & 1 & & 1 \\
\hline Crustacea & Malacostraca & Decapoda - crabs & 7 & 13 & 4 & 2 & 1 & 2 & 1 & 1 & 31 \\
\hline Crustacea & Malacostraca & Decapoda - shrimp & & 7 & 1 & & 1 & & 3 & 3 & 15 \\
\hline Crustacea & Ostracoda & & 20 & 27 & 12 & 11 & 20 & 21 & 9 & 8 & 128 \\
\hline Chordata & \multicolumn{2}{|c|}{ Amphioxiformes/ Branchiostomidae/ Branchiostoma } & & & & & & & & & \\
\hline Cephalochordata & Leptocardii & & & 1 & & & & & & & 1 \\
\hline Tunicata & Ascidiacea & & & 2 & & & & & & 1 & 3 \\
\hline \multirow{2}{*}{ Cnidaria/Medusozoa } & Hydrozoa & & 4 & 1 & & & & & 1 & & 6 \\
\hline & Anthozoa & & 1 & 4 & & 2 & 3 & 3 & & & 13 \\
\hline \multicolumn{12}{|l|}{ Echinodermata } \\
\hline Asterozoa & Ophiuroidea & & 9 & 32 & 1 & 5 & & 1 & 5 & 7 & 60 \\
\hline Echinozoa & Holothuroidea & & & 1 & & & & & & & 1 \\
\hline \multirow{5}{*}{ Mollusca } & \multicolumn{2}{|c|}{ Aplacophora /Solenogastres (Noemeniomorpha) } & & 2 & 1 & & & & & 1 & 4 \\
\hline & Bivalvia & & 20 & 26 & 10 & 10 & 7 & 10 & 9 & 9 & 101 \\
\hline & Gastropoda & & 16 & 22 & 4 & 6 & 6 & 7 & 14 & 11 & 86 \\
\hline & Gastropoda (Nudibranchia) & & & 4 & & & & & 2 & 4 & 10 \\
\hline & Polyplacophora (Amphineura) & & 4 & 15 & & & 1 & 9 & 7 & 7 & 43 \\
\hline Nematoda & & & 392 & 525 & 209 & 343 & 147 & 195 & 256 & 250 & 2,317 \\
\hline Nemertinea & & & 30 & 95 & 12 & 4 & 17 & 12 & 22 & 17 & 209 \\
\hline Phoronida & & & & 1 & & & & & & & 1 \\
\hline Platyhelminthes & & & & 2 & & & 3 & 1 & 2 & 4 & 12 \\
\hline Porifera & Hexactinellida & & 4 & & & & & & & & 4 \\
\hline \multirow[t]{2}{*}{ Sipuncula } & Sipunculidea & & $\underline{12}$ & $\underline{27}$ & $\underline{5}$ & $\underline{12}$ & 7 & $\underline{5}$ & 22 & $\underline{3}$ & 93 \\
\hline & & & 1,209 & 2,426 & 913 & 1,106 & 1,070 & 1,188 & 1,669 & 1,279 & 10,860 \\
\hline
\end{tabular}


Table 2. Pearson correlations $(r>0.2)$ between invertebrate taxa and principle coordinates analysis (PCO) axes from the PCO ordination (see Figure 2) of samples from vessel grounding sites and intact seagrass sites.

\begin{tabular}{lrr}
\hline Invertebrate Taxon & PCO1 & PCO2 \\
\hline Amphineura (Polyplacophora) & 0.49 & 0.29 \\
Amphipoda & 0.53 & 0.64 \\
Anthozoa & 0.53 & 0.16 \\
Aplacophora (Neomeniomorpha) & 0.28 & -0.04 \\
Bivalvia & 0.57 & -0.53 \\
Branchiostoma & 0.37 & -0.21 \\
Cephalocarida & -0.38 & 0.01 \\
Cumacea & 0.28 & 0.74 \\
Decapoda - Crabs & 0.35 & -0.28 \\
Decapoda - Shrimp & -0.05 & 0.57 \\
Gastropoda & 0.47 & -0.32 \\
Gastropoda (nudibranch) & 0.49 & -0.08 \\
Isopoda & 0.81 & 0.19 \\
Nematoda & 0.31 & 0.37 \\
Nemertinea & 0.83 & -0.11 \\
Oligochaeta & 0.51 & -0.24 \\
Ophiuroidea & 0.73 & -0.33 \\
Ostracoda & 0.53 & -0.38 \\
Polychaeta & 0.78 & 0.04 \\
Sipunculida & 0.29 & 0.65 \\
Tanaidacea & 0.88 & 0.15 \\
\hline
\end{tabular}


Table 3. Results of PERMANOVA analysis (Disturbance $x$ Age) of the effects of vessel grounding disturbance and time on multivariate infaunal community structure.

\begin{tabular}{|c|c|c|c|c|}
\hline Source & $\mathrm{df}$ & MS & Pseudo-F & $\mathrm{P}$ \\
\hline \multicolumn{5}{|l|}{$\begin{array}{l}\text { Multivariate Infauna Community } \\
\text { Abundance }\end{array}$} \\
\hline Disturbance status (injury, reference) & 1 & 72.5 & 4.9 & 0.016 \\
\hline Age $(0,1,3,4,5$ yrs $)$ & 4 & 10.3 & 0.7 & 0.728 \\
\hline Disturbance $\times$ Age & 4 & 27.4 & 1.8 & 0.109 \\
\hline Residual & 17 & 15.5 & & \\
\hline \multicolumn{5}{|l|}{ Abundance } \\
\hline Disturbance status (injury, reference) & 1 & 3749.8 & 1.9 & 0.201 \\
\hline Age $(0,1,3,4,5$ yrs $)$ & 4 & 2731.7 & 1.4 & 0.282 \\
\hline Disturbance $x$ Age & 4 & 5785.5 & 2.9 & 0.062 \\
\hline Residual & 17 & 2010.9 & & \\
\hline \multicolumn{5}{|l|}{ Richness } \\
\hline Disturbance status (injury, reference) & 1 & 46.9 & 5 & 0.024 \\
\hline Age $(0,1,3,4,5$ yrs $)$ & 4 & 2.7 & 0.3 & 0.881 \\
\hline Disturbance $x$ Age & 4 & 18.5 & 2 & 0.121 \\
\hline Residual & 17 & 9.3 & & \\
\hline \multicolumn{5}{|l|}{ Pielou's J' } \\
\hline Disturbance status (injury, reference) & 1 & 0.01 & 0.8 & 0.356 \\
\hline Age $(0,1,3,4,5$ yrs $)$ & 4 & 0.01 & 0.9 & 0.494 \\
\hline Disturbance $x$ Age & 4 & 0.03 & 3.4 & 0.038 \\
\hline Residual & 17 & 0.01 & & \\
\hline \multicolumn{5}{|l|}{ Shannon-Weaver $\mathrm{H}^{\prime}$} \\
\hline Disturbance status (injury, reference) & 1 & 0.57 & 4.1 & 0.063 \\
\hline Age $(0,1,3,4,5$ yrs $)$ & 4 & 0.03 & 0.3 & 0.905 \\
\hline Disturbance $x$ Age & 4 & 0.27 & 2 & 0.144 \\
\hline Residual & 17 & 0.14 & & \\
\hline \multicolumn{5}{|l|}{ Simpson's 1- $\lambda^{\prime}$} \\
\hline Disturbance status (injury, reference) & 1 & 0.05 & 2.7 & 0.109 \\
\hline Age $(0,1,3,4,5$ yrs $)$ & 4 & 0.01 & 0.8 & 0.517 \\
\hline Disturbance $x$ Age & 4 & 0.04 & 2 & 0.144 \\
\hline Residual & 17 & 0.02 & & \\
\hline
\end{tabular}


Table 4. SIMPER analysis results of taxonomic similarity for injury and reference sites in the disturbance analysis and for restoration treatments in the restoration analysis.

\begin{tabular}{|c|c|c|c|}
\hline Analysis/Groups & $\begin{array}{l}\text { Within Treatment } \\
\text { Mean Similarity (\%) }\end{array}$ & $\begin{array}{l}\text { Most abundant } \\
\text { taxa }\end{array}$ & $\begin{array}{l}\% \text { contribution to } \\
\text { group similarity }\end{array}$ \\
\hline \multicolumn{4}{|c|}{ Disturbance Analysis } \\
\hline \multirow[t]{5}{*}{ Injury } & 58.1 & Polychaeta & 38.6 \\
\hline & & Nematoda & 26.9 \\
\hline & & Oligochaeta & 17.9 \\
\hline & & Amphipoda & 4.2 \\
\hline & & Nemertinea & 3.9 \\
\hline \multirow[t]{6}{*}{ Reference } & 58.6 & Polychaeta & 32.8 \\
\hline & & Nematoda & 23.4 \\
\hline & & Amphipoda & 13.0 \\
\hline & & Oligochaeta & 12.8 \\
\hline & & Nemertinea & 4.3 \\
\hline & & Isopoda & 3.9 \\
\hline \multicolumn{4}{|c|}{ Restoration Analysis } \\
\hline \multirow[t]{5}{*}{ Grounding } & 70.2 & Polychaeta & 33.1 \\
\hline & & Nematoda & 26.4 \\
\hline & & Oligochaeta & 25.2 \\
\hline & & Amphipoda & 5.2 \\
\hline & & Cumacea & 2.2 \\
\hline \multirow[t]{6}{*}{ Fill } & 68.4 & Polychaeta & 43.3 \\
\hline & & Nematoda & 17.1 \\
\hline & & Amphipoda & 16.2 \\
\hline & & Oligochaeta & 5.6 \\
\hline & & Tanaidacea & 5.5 \\
\hline & & Ostracoda & 4.2 \\
\hline \multirow[t]{6}{*}{ Intact } & 67.4 & Polychaeta & 31.2 \\
\hline & & Oligochaeta & 22.3 \\
\hline & & Nematoda & 21.8 \\
\hline & & Amphipoda & 12.2 \\
\hline & & Nemertinea & 2.3 \\
\hline & & Cumacea & 1.8 \\
\hline
\end{tabular}


Table 5. Pearson correlations $(r>0.2)$ between invertebrate taxa and PCO axes from the PCO ordination (see Figure 4) of samples from restoration analysis.

\begin{tabular}{lrr}
\hline Invertebrate Taxa & PCO1 & PCO2 \\
\hline Amphipoda & 0.78 & 0.31 \\
Anthozoa & 0.13 & 0.43 \\
Ascidiacea & 0.42 & -0.03 \\
Bivalvia & 0.14 & -0.26 \\
Cumacea & 0.82 & -0.33 \\
Decapoda - Crabs & 0.23 & -0.14 \\
Gastropoda & 0.47 & -0.39 \\
Isopoda & 0.45 & -0.45 \\
Mysida & 0.21 & -0.15 \\
Nematoda & 0.16 & -0.59 \\
Nemertinea & 0.50 & 0.18 \\
Neomeniomorpha (Aplacophora) & 0.34 & -0.08 \\
Oligochaeta & -0.14 & -0.81 \\
Ostracoda & 0.51 & 0.23 \\
Platyhelminthes & 0.48 & 0.22 \\
Polychaeta & 0.64 & 0.05 \\
Polyplacophora (Amphineura) & 0.61 & 0.16 \\
Pycnogonida & 0.07 & 0.27 \\
Sipunculida & 0.29 & -0.26 \\
Tanaidacea & 0.76 & 0.15 \\
\hline
\end{tabular}


Table 6. Results of PERMANOVA analyses of restoration treatment, fertilization, and age on infauna community structure and diversity metrics. Restoration treatments include Grounding $(G)$, Fill $(F)$, and Intact $(I)$ sites. Bold text indicates significance of main effects and interactions at $\alpha=0.05$. Superscript letters indicate significance between levels of factors at $\alpha=0.016$.

\begin{tabular}{|c|c|c|c|c|c|c|c|c|c|}
\hline Source & $\mathrm{df}$ & MS & Pseudo-F & $\mathrm{P}$ & Source & $\mathrm{df}$ & MS & Pseudo-F & $\mathrm{P}$ \\
\hline Multivariate Abundance & & & & & Pielou's J' & & & & \\
\hline Restoration $\left(\mathrm{G}^{\mathrm{a}}, \mathrm{F}^{\mathrm{b}}, \mathrm{I}^{\mathrm{C}}\right)$ & 2 & 38.6 & 11.7 & 0.001 & Restoration $\left(\mathrm{G}^{\mathrm{a}}, \mathrm{F}^{\mathrm{b}}, \mathrm{I}^{\mathrm{a}}\right)$ & 2 & 0.056 & 8.66 & 0.003 \\
\hline Fertilization (yes, no) & 1 & 8.8 & 2.7 & 0.078 & Fertilization (yes, no) & 1 & 0.008 & 1.17 & 0.307 \\
\hline Age $\left(0.25^{\mathrm{a}}, 0.5^{\mathrm{b}}, 1^{\mathrm{c}} \mathrm{yr}\right)$ & 2 & 53.3 & 16.1 & 0.001 & Age $(0.25,0.5,1 \mathrm{yr})$ & 2 & 0.001 & 0.12 & 0.874 \\
\hline $\mathrm{Re} \times \mathrm{Fe}$ & 2 & 2.2 & 0.7 & 0.644 & $\mathrm{Re} \times \mathrm{Fe}$ & 2 & 0.002 & 0.29 & 0.738 \\
\hline $\operatorname{Re} \times \mathrm{Ag}$ & 4 & 12.3 & 3.7 & 0.002 & $\operatorname{Re} \times A g$ & 4 & 0.010 & 1.60 & 0.197 \\
\hline $\mathrm{Fe} \times \mathrm{Ag}$ & 2 & 1.8 & 0.5 & 0.719 & $\mathrm{Fe} \times \mathrm{Ag}$ & 2 & 0.009 & 1.44 & 0.277 \\
\hline $\operatorname{Re} \times \mathrm{Fe} \times \mathrm{Ag}$ & 4 & 1.6 & 0.5 & 0.833 & $\operatorname{Re} \times \mathrm{Fe} \times \mathrm{Ag}$ & 4 & 0.003 & 0.44 & 0.805 \\
\hline Residual & 36 & 3.3 & & & Residual & 36 & 0.006 & & \\
\hline Abundance & & & & & Shannon-Weaver $H^{\prime}$ & & & & \\
\hline Restoration $\left(\mathrm{G}^{\mathrm{a}}, \mathrm{F}^{\mathrm{a}}, \mathrm{I}^{\mathrm{b}}\right)$ & 2 & 1521.9 & 9.2 & 0.001 & Restoration $\left(\mathrm{G}^{\mathrm{ab}}, \mathrm{F}^{\mathrm{a}}, \mathrm{I}^{\mathrm{b}}\right)$ & 2 & 0.335 & 9.58 & 0.001 \\
\hline Fertilization (yes, no) & 1 & 779.5 & 4.7 & 0.039 & Fertilization (yes, no) & 1 & 0.000 & 0.00 & 0.964 \\
\hline Age $\left(0.25^{\mathrm{a}}, 0.5^{\mathrm{b}}, 1^{\mathrm{b}} \mathrm{yr}\right)$ & 2 & 1548.6 & 9.4 & 0.001 & Age $\left(0.25^{\mathrm{a}}, 0.5^{\mathrm{b}}, 1^{\mathrm{b}} \mathrm{yr}\right)$ & 2 & 0.307 & 8.77 & 0.001 \\
\hline $\mathrm{Re} \times \mathrm{Fe}$ & 2 & 60.3 & 0.4 & 0.679 & $\mathrm{Re} \times \mathrm{Fe}$ & 2 & 0.004 & 0.12 & 0.890 \\
\hline $\operatorname{Re} \times \mathrm{Ag}$ & 4 & 2116.9 & 12. 8 & 0.001 & $\operatorname{Re} \times A g$ & 4 & 0.078 & 2.24 & 0.086 \\
\hline $\mathrm{Fe} \times \mathrm{Ag}$ & 2 & 341.4 & 2.1 & 0.142 & $\mathrm{Fe} \times \mathrm{Ag}$ & 2 & 0.017 & 0.48 & 0.600 \\
\hline $\operatorname{Re} \times \mathrm{Fe} \times \mathrm{Ag}$ & 4 & 112.7 & 0.7 & 0.624 & $\operatorname{Re} \times \mathrm{Fe} \times \mathrm{Ag}$ & 4 & 0.061 & 1.73 & 0.169 \\
\hline Residual & 36 & 165.6 & & & Residual & 36 & 0.035 & & \\
\hline Richness & & & & & Simpson's $\lambda^{\prime}$ & & & & \\
\hline Restoration (G, F, I) & 2 & 13.9 & 3.4 & 0.053 & Restoration $\left(\mathrm{G}^{\mathrm{a}}, \mathrm{F}^{\mathrm{b}}, \mathrm{I}^{\mathrm{a}}\right)$ & 2 & 0.078 & 14.33 & 0.001 \\
\hline Fertilization (yes, no) & 1 & 1.9 & 0.5 & 0.505 & Fertilization (yes, no) & 1 & 0.000 & 0.01 & 0.945 \\
\hline Age $\left(0.25^{\mathrm{a}}, 0.5^{\mathrm{b}}, 1^{\mathrm{b}} \mathrm{yr}\right)$ & 2 & 43.9 & 10.7 & 0.001 & Age $(0.25,0.5,1 \mathrm{yr})$ & 2 & 0.002 & 0.40 & 0.648 \\
\hline $\mathrm{Re} \times \mathrm{Fe}$ & 2 & 2.0 & 0.5 & 0.633 & $\mathrm{Re} \times \mathrm{Fe}$ & 2 & 0.001 & 0.14 & 0.866 \\
\hline $\mathrm{Re} \times \mathrm{Ag}$ & 4 & 6.7 & 1.6 & 0.184 & $\operatorname{Re} \times A g$ & 4 & 0.014 & 2.56 & 0.053 \\
\hline $\mathrm{Fe} \times \mathrm{Ag}$ & 2 & 0.9 & 0.2 & 0.800 & $\mathrm{Fe} \times \mathrm{Ag}$ & 2 & 0.003 & 0.63 & 0.566 \\
\hline $\operatorname{Re} \times \mathrm{Fe} \times \mathrm{Ag}$ & 4 & 9.9 & 2.4 & 0.071 & $\mathrm{Re} \times \mathrm{Fe} \times \mathrm{Ag}$ & 4 & 0.004 & 0.78 & 0.553 \\
\hline Residual & 36 & 4.093 & & & Residual & 36 & 0.005 & & \\
\hline
\end{tabular}


Table 7. Multiple partial correlations between the first three dbRDA coordinate axes and environmental variables (see Figure 6) of the best-fit DistLM model. The percent of variation in the DistLM model (fitted) and in the total data set variation is given for each axis.

\begin{tabular}{|c|c|c|c|c|}
\hline \multicolumn{2}{|c|}{ Variable } & $\mathrm{dbRDA} 1$ & $\mathrm{dbRDA} 2$ & dbRDA3 \\
\hline & $\%$ fitted variation & 50.7 & 34.0 & 9.4 \\
\hline & $\%$ total variation & 24.6 & 14.5 & 4.0 \\
\hline OM & & 0.07 & -0.77 & 0.14 \\
\hline BD & & 0.04 & 0.23 & 0.77 \\
\hline $\mathrm{pH}$ & & 0.51 & 0.48 & 0.02 \\
\hline $\mathrm{NH}_{4}^{+}$ & & 0.17 & 0.01 & -0.56 \\
\hline SRP & & -0.82 & 0.30 & -0.11 \\
\hline$P$ & & 0.20 & 0.20 & -0.24 \\
\hline
\end{tabular}


Figure 1. Location of study sites in southern Biscayne Bay, Florida, USA, within the boundary of Biscayne National Park.

Figure 2. Principle coordinates analysis ordination of multivariate infaunal community samples from vessel grounding sites (closed symbols) and intact seagrass sites (open symbols). Grounding sites were of multiple known ages: $0,1,3,4$, or 5 years old.

Figure 3. Infaunal community diversity metrics from vessel grounding sites of different ages (dark bars) and undisturbed reference sites (light bars). Values are means \pm se. An asterisk indicates a statistical difference between disturbed and reference sites within an age group (t test, $\alpha=0.05$ ).

Figure 4. Principle coordinates analysis ordination of multivariate infaunal community samples at Cutter Bank. Data are visualized by sampling event $(0.25 \mathrm{yr}, 0.5 \mathrm{yr}, 1 \mathrm{yr})$ within each restoration treatment. Treatments include Grounding (G), Fill (F), and Intact (I) seagrass sites. Data from fertilization treatments are pooled with restoration treatments.

Figure 5. Mean \pm se infaunal community diversity metrics from study sites in the restoration analysis, sampled at $0 \mathrm{yr}$ (dark bars) and $1 \mathrm{yr}$ (light bars) year postrestoration. Restoration treatments included: $\mathrm{G}=$ grounding, $\mathrm{F}=$ fill, and $\mathrm{I}=$ Intact. Data for I sites are from $0.25 \mathrm{yr}$ and $1 \mathrm{yr}$ sampling events. Asterisks indicate significance at $\alpha=0.05$ between time steps within treatments Figure 6. dbRDA ordination of the best fit DistLM model of infaunal community data (binomial deviance resemblance matrix calculated from log transformed relative abundance data) versus log transformed environmental variables. Data are from 0.25 , 0.5 , and $1 \mathrm{yr}$ sampling events. 


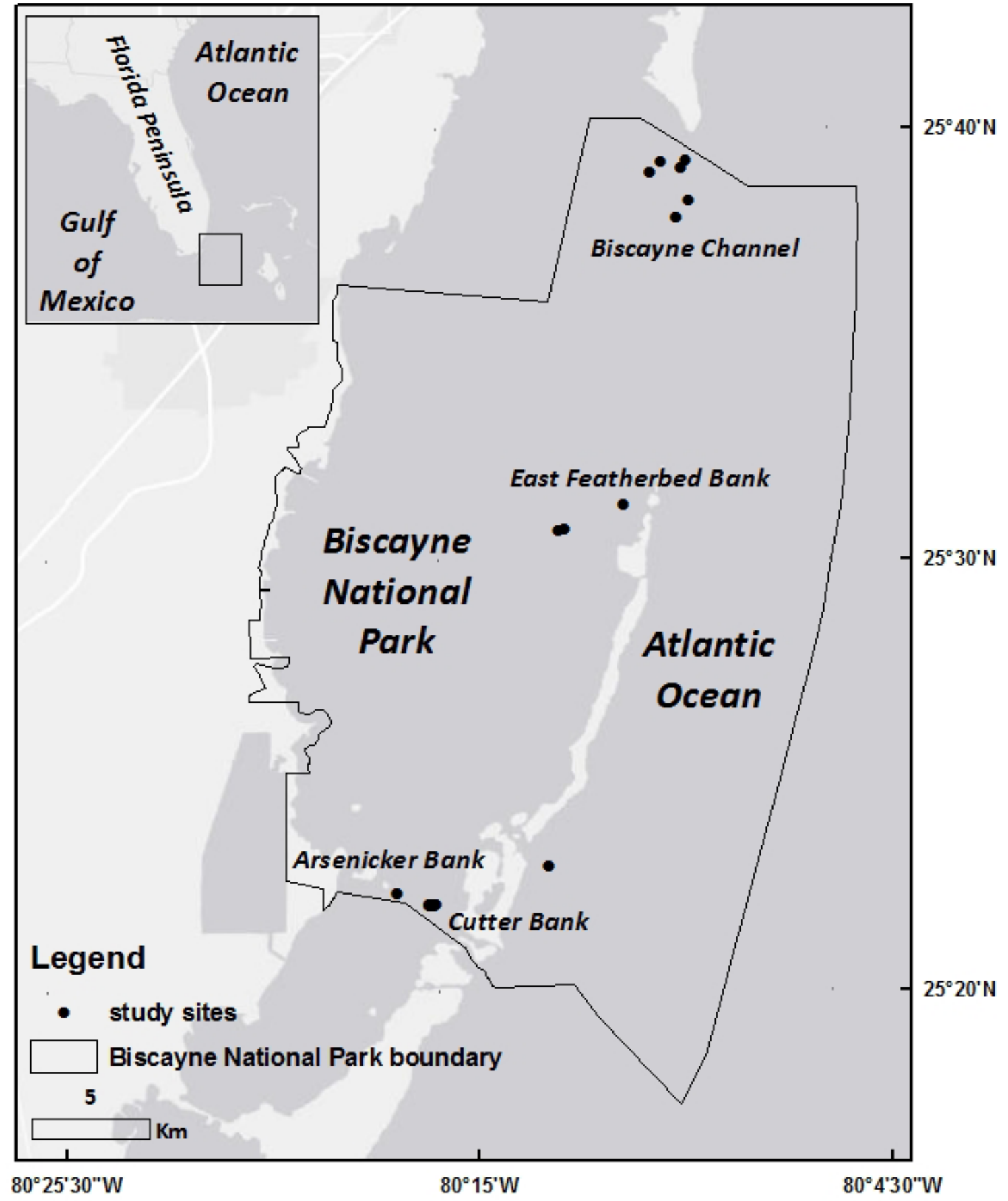




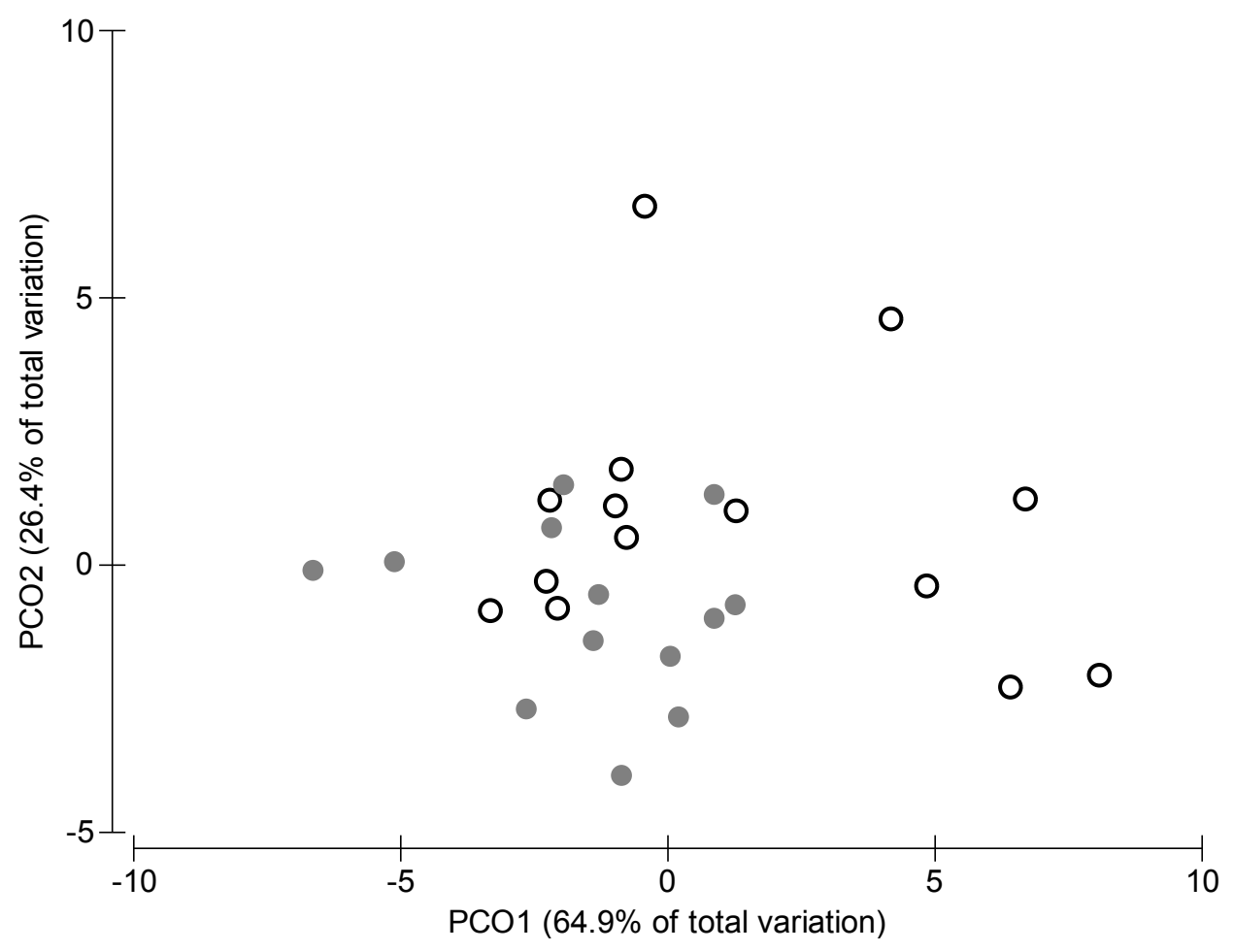



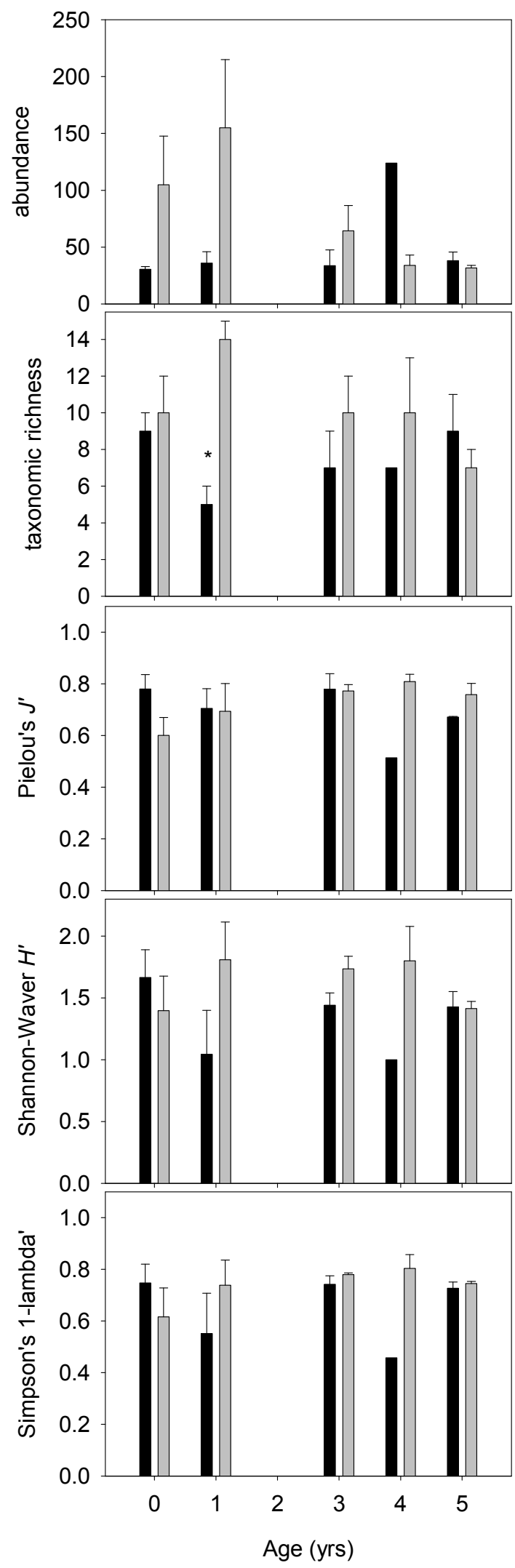


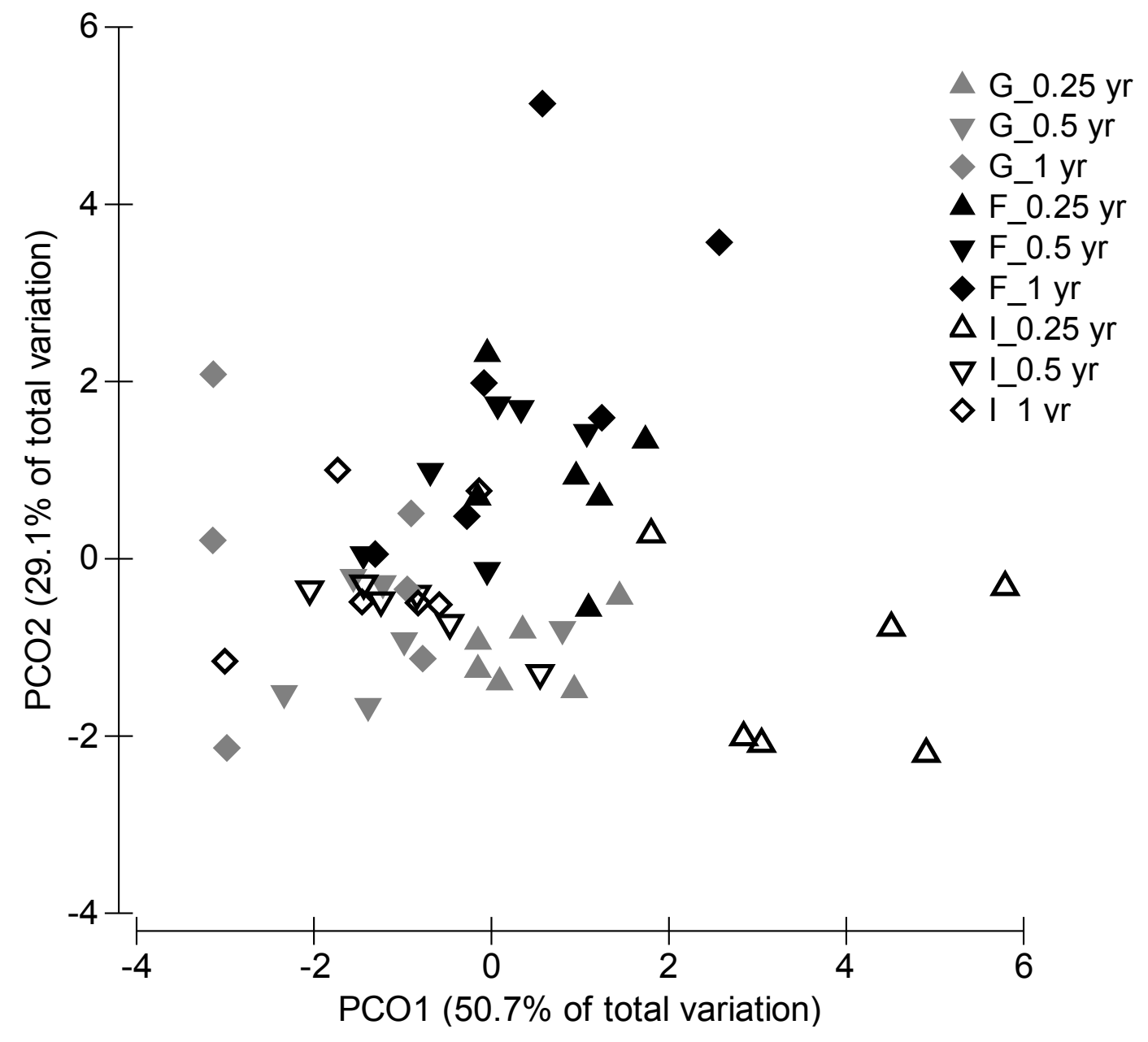



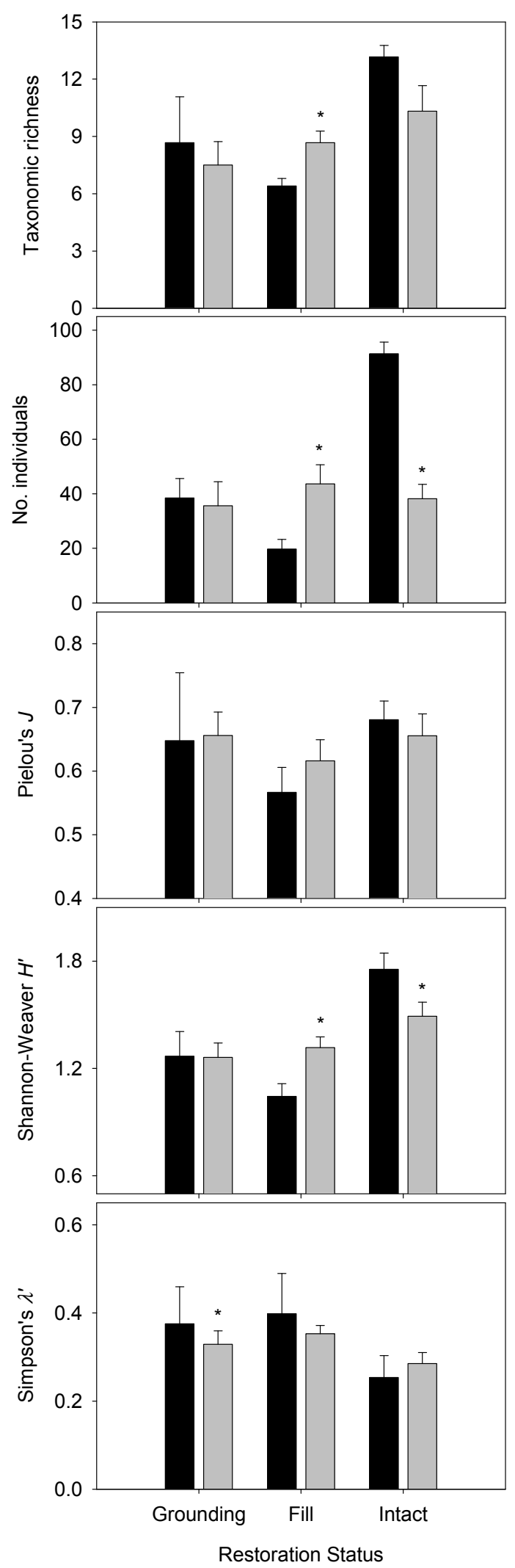


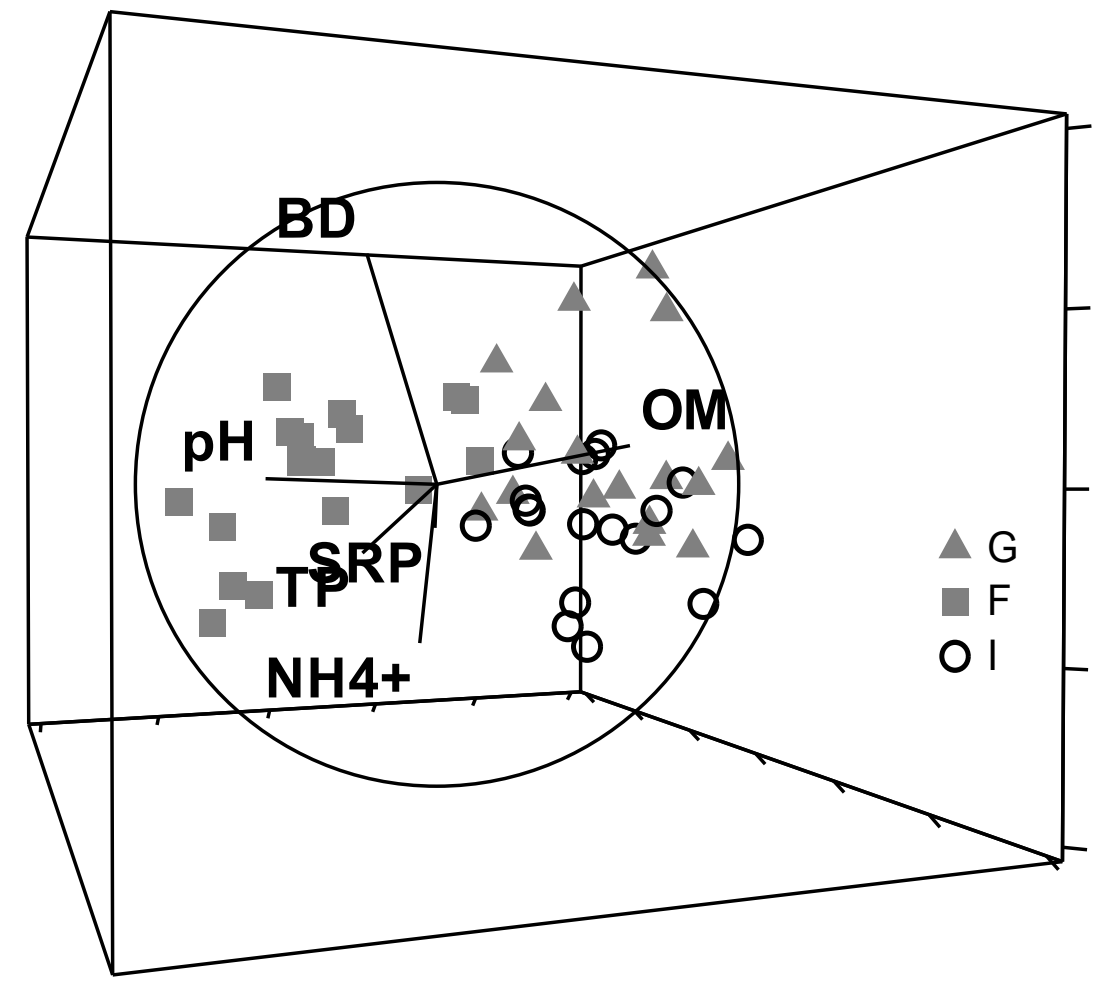


CHAPTER VI: Herbivory in subtropical seagrass ecosystems varies with time, space, and seagrass species

Abstract

Herbivory structures ecosystems in multiple and complex ways and is capable of affecting the success of ecological restoration projects that involve reestablishing plant communities. Direct herbivory on experimental planting units assembled from leaves of the seagrasses Thalassia testudinum, Syringodium filiforme, and Halodule wrightii was assayed in 2009-2010 in south Florida, USA. Seagrass biomass loss to herbivory was compared with elemental composition of donor and ambient seagrass leaves as well as with fish communities at the assay sites. Seagrass herbivores were capable of removing substantial biomass from our experimental planting units, and this varied significantly across seagrass species, location, and time. Seagrass biomass loss to herbivory ranged from $0 \%$ to $82 \%$. More biomass was lost during the spring assays than in fall and winter assays. Biomass loss was greatest in S. filiforme and $H$. wrightii, and negligent in $T$. testudinum. The assay site closest to tidal cuts leading to the coral reef tract experienced the highest average levels of herbivory. No significant relationships were detected between seagrass biomass loss and $\mathrm{C}: \mathrm{N}$ ratios, $\mathrm{C}: \mathrm{P}$ ratios, or herbivorous fish abundance. Leaf loss to seagrass herbivores appears to be a spatially variable but critically important determinant of seagrass transplanting success. We recommend that local knowledge of herbivory pressure be considered during restoration planning. In our system, a conservative approach to seagrass transplanting, limiting projects to winter months and refraining from seagrass transplanting all together in areas proximal to coral reefs, are likely to maximize the potential for success. 
Introduction

Because of the ecological importance of seagrasses and rapid rates of seagrass loss along the world's coastlines (Waycott et al. 2009), resource managers aim to both stop the loss of seagrasses and restore degraded or destroyed seagrass habitat. Disturbances to seagrass ecosystems may result in loss of or a reduction in their ability to provide key ecosystem functions. As a result, there has been increasing interest in seagrass restoration since the mid 1970's (Fonseca 2011).

Ecological restoration often attempts to reestablish plant communities that have been destroyed or degraded. For restoration to be successful, ecological attributes of the system such as structure and function must be reestablished (Hobbs \& Norton 1996; Higgs 1997). Herbivores are capable of altering ecosystem structure and function (Milchunas et al. 1988; Parker et al. 2006) through interacting effects of stress from grazing and release from competitive exclusion (Paine 1971; Grime 1973; Connell 1978). In terrestrial grasslands, the success of restoration and recovery trajectories in restoration projects that target rehabilitation of plant communities may be influenced by selective herbivory (Howe \& Lane 2004; Fraser \& Madson 2008).

In seagrass meadows, herbivory structures ecosystems in multiple and complex ways such as directly removing biomass, facilitating energy flow through food webs, controlling epiphytic growth, stimulating primary and secondary production, and altering species composition (Heck \& Valentine 2006). Epiphytic microalgae on seagrass plants and benthic microalgae are critical food sources for micrograzers (Bologna \& Heck 1999; Moncreiff \& Sullivan 2001). The seagrasses themselves are also directly consumed by certain herbivores. Megaherbivores such as green turtles and sirenians are capable of consuming a substantial amount of biomass, and can influence spatial distribution and 
standing biomass of seagrass meadows (Fourqurean et al. 2010; Lal et al. 2010). Direct herbivory on seagrasses by fish and urchins is also an important process (Cebrián \& Duarte 1994, 1998; Rose et al. 1999; Kirsch et al. 2002; Alcoverro \& Mariani 2004). Seagrasses support high levels of secondary production as a result (Mateo et al. 2006) . Fish grazing can regulate local seagrass species composition and density (Randall 1965; Tribble 1981; Valentine \& Heck 1999; Armitage \& Fourqurean 2006).

Like grazers in terrestrial environments (Mattson 1980), seagrass grazers may preferentially consume plants with higher nutrient content (Williams 1988; McGlathery 1995; Goecker et al. 2005; Heck \& Valentine 2006; Prado \& Heck 2011) or faster growing plants (Cebrián \& Duarte 1998). Nutrient content in seagrass leaves varies among species, and also spatially within species (Duarte 1990). In south Florida and the Caribbean, the dominant seagrass species include Thalassia testudinum, Syringodium filiforme, and Halodule wrightii, which occur in both monospecific and mixed beds (McMillan \& Phillips 1979; Thorhaug 1981). Nutrient content varies among and within these species over relatively small spatial scales in response to terrestrial, oceanic, groundwater, or point source inputs (Fourqurean et al. 1992a; Caccia \& Boyer 2005; Campbell \& Fourqurean 2009; Peterson et al. 2012). Thus local seagrass landscapes can exhibit substantial variation in community composition and stoichiometry, to which herbivores respond.

Herbivory is a key process that should be considered in restoration (Young et al. 2005). Seagrass transplanting is a common restoration method, used to more quickly replace lost plant structure and associated functions than would otherwise occur through a relatively slower natural recovery process (Lewis 1987; Fonseca et al. 1998). Seagrass restoration projects involving transplanting are often designed to mimic observed patterns of succession by incorporating the principle of "modified compressed 
succession" (sensu Durako \& Moffler 1985). In these projects, an early successional, faster-growing seagrass species (e.g., H. wrightii and/or S. filiforme in the subtropical western Atlantic region) is transplanted under the assumption that they will colonize more quickly than slower-growing climax species (e.g., T. testudinum), which in time, will reestablish dominance in the restoration area. Experimental evidence exists that that transplanted, early-successional seagrasses may be preferentially consumed through selective herbivory (Howe \& Lane 2004; Armitage \& Fourqurean 2006; Fraser \& Madson 2008; Prado et al. 2010). However, despite the literature record as well as cautionary notes of the potential impact of herbivory to planting unit survival (Fonseca et al. 1998), the impacts of herbivores on transplanting success in seagrass meadows remains largely unstudied.

This study aimed to evaluate herbivory pressure on transplanted seagrasses. Understanding the impacts of herbivores on seagrass transplants is necessary to maximize the success of costly restoration efforts. Herbivory is suspected as the cause of poor performance of some seagrass transplanting efforts that have been conducted to repair injuries from vessel groundings in Biscayne National Park, adjacent to the Miami metropolitan area in south Florida, USA. Qualitative observations of these transplanting efforts led us to several hypotheses as to the loss of the planted seagrasses. Because planting unit biomass was lost overnight or within days of planting at some locations, we hypothesized that loss was due to herbivory rather than transplanting shock to the transplanted clones. Planting unit success differed among restoration sites, so we hypothesized that biomass loss to herbivory varied across space. Apparent interspecific differences in rates of loss between seagrass species led us to hypothesize that biomass loss to herbivory varied with seagrass species, possibly suggesting consumer feeding preferences. Since herbivores may choose high-nutrient plants, we 
hypothesized that rates of herbivory would be related to plant nutrient content. In a landscape with patchy distribution of seagrass species with variable stoichiometry, transplantation of these species for restoration may result in the presentation of a more preferred food source in some areas. Further, since we suspected that the herbivores responsible for the observed loss of seagrass transplants were fish, we expected rates of herbivory to be related to the size and species composition of the fish community. Given that fish community abundance is correlated with water temperature, we also expected herbivory to vary throughout the year.

Methods

Study System

Southern Biscayne Bay is a shallow $(<3 \mathrm{~m})$ subtropical estuary located at the southeastern tip of the Florida peninsula (Figure 1). The extensive seagrass communities in southern Biscayne Bay are dominated by dense T. testudinum. Syringodium filiforme and $H$. wrightii are also found throughout this area in lower abundance and with patchy distributions. This study was conducted at four shoals: Biscayne Channel, No Name Shoal, East Featherbed Bank, and Cutter Bank (Figure 1). These shoals are characterized by thriving seagrass communities, but have been impacted by multiple vessel grounding injuries over the past two decades. Vessel groundings remove seagrass and excavate sediment in discrete patches on shallow seagrass shoals. Existing vessel grounding injuries selected at each shoal as study sites ranged from 40 to 60 square meters in size, and were unvegetated patches surrounded by a dense seagrass community. 


\section{Experimental Design}

Seagrass and fish community surveys, herbivory assays, and elemental analysis of seagrass leaf tissue were conducted during the Spring of 2009 through the Winter of 2010.

Seagrass community surveys

Seagrass community composition was documented in undisturbed seagrass habitat in the vicinity (within 100 meters) of each herbivory assay site. Seagrass and macroalgae abundance was estimated within randomly placed $0.25-\mathrm{m}^{2}$ PVC quadrats according to a modified Braun-Blanquet cover-abundance scale (Fourqurean et al. 2001). The number of quadrats varied per site (18-268), as did the timing and frequency of monitoring efforts. For each site, quadrat data from all available monitoring events were pooled for analysis. At No Name Shoal, data from a single monitoring event conducted in March 2011 were available (111 quadrats). At Biscayne Channel, East Featherbed Bank, and Cutter Bank, four monitoring events were conducted at each site during the 20-month period from December 2009 through July 2011, providing 71, 400, and 1070 total quadrats for analysis, respectively.

Fish community surveys

Two fish surveys were conducted at each assay site in October 2009 (Fall09) and in February-March 2010 (Win10), respectively (4 sites x 2 events x 2 surveys per site per event $=16$ fish surveys) using a modification to the roving diver technique (Schmitt and Sullivan 1996). For each survey, a snorkeler slowly and surveyed one half of a 50-diameter circle (total survey area approximately $980 \mathrm{~m}^{2}$ ), as delimited with a 25$\mathrm{m}$ transect tape attached to a central stake, for 30 minutes. The snorkeler counted fish observed within the survey area and identified them to species (when possible) or 
genus. Data from the two surveys per time and event were pooled for analysis. Water temperature and salinity were measured for each survey using a YSI Model 30 instrument. Fish taxa expected to directly consume seagrass were categorized as seagrass herbivores (Ferreira \& Floeter 2004; Floeter 2004; Valentine \& Duffy 2006). Note that while urchins are known to be important consumers of seagrass biomass, few urchins were observed at the study sites. As such their role in removing seagrass biomass was not evaluated in this study, as was suspected to be minimal.

Herbivory assays

Herbivory pressure was examined through herbivore exclusion in a year-long study conducted in 2009-2010. A full factorial design was employed, with the following factors and levels: location (Biscayne Channel, E. Featherbed, Cutter Bank, No Name Shoal); seagrass species (T. testudinum, H. wrightii, S. filiforme); time (spring, summer, fall, winter), and herbivore exclusion (no cage, partial cage, full cage).

Planting units (PUs) designed to mimic the growth form and appearance of natural seagrass (sensu Hay 1981; Kirsch, Valentine, \& Heck 2002) were used as experimental units in the herbivory assays. PUs consisted of freshly-harvested seagrass leaf material inserted into simulated short shoots (binder clips) affixed to a simulated rhizome (labeled semi-rigid 30-cm plastic strip cut from cable tie). For deployment, the "rhizome" of the PU was gently pressed into bottom sediments and held in place with a U-shaped sod staple. This approach was beneficial for three reasons. It enabled the standardization of plant leaf tissue biomass used in each PU across species. It also eliminated consideration of non-photosynthetic and belowground tissue biomass that may mask leaf tissue biomass loss. Lastly, impacts to donor beds were minimized by removing only leaf material but leaving belowground tissues intact. 
Seagrass shoots for use in constructing PUs were collected from a single donor site: Pelican Shoal (Figure 1). Collecting donor material from a single location ensured that a sufficient supply of all three seagrass species was available for all assays over the year-long study. Shoots were collected on the morning of each assay deployment. Intact green leaves were selected from the collection for PUs; age of leaf tissue was not considered. Leaf tissue for each PU was spun in a salad spinner to remove excess water, gently wiped clean of epiphytes, and patted dry. Leaf tissue biomass was standardized across the three seagrass species, and approximately $1.5 \mathrm{~g}$ of fresh seagrass leaf material was used for each PU. After weighing, the leaf tissue for each PU was carefully clipped into the set of binder clips attached to each plastic rhizome. PUs were then placed into individual zip lock bags flooded with fresh seawater, for transport to the study site in seawater-filled coolers.

Herbivore exclusion cages were constructed of $0.635-\mathrm{cm}$ black plastic aquaculture mesh. This mesh size was chosen as appropriate for excluding juvenile and adult fish of species known to directly consume seagrasses in the subtropical western Atlantic such as pinfishes, parrotfishes (Valentine \& Heck 1999). Full cages were formed of cylinders approximately $40 \mathrm{~cm}$ in height with a flat top approximately $30 \mathrm{~cm}$ in diameter. To control for possible influences of the cage structures on the PUs not related to herbivory, we also deployed partial cages as "cage controls". Partial cages had two sides and a top, and were open on two sides. The partial cages were approximately $30 \mathrm{~cm} \times 30 \mathrm{~cm} \times 30 \mathrm{~cm}$ in size. Full and partial cages had lengths of leadcore line cable-tied to the bottom edges that rested on the sediment to help keep them upright. U-shaped sod staples were inserted through mesh into the sediments to further stabilize the cages. 
Ten replicate PUs per each of the three seagrass species were randomly assigned to each of the three herbivore exclusion treatments, for a total of 90 PU's per assay deployment, per site. Each PU with its respective caging treatment was randomly placed at $0.5 \mathrm{~m}$ intervals in rows in existing grounding injury features at each location. Placing PUs in the unvegetated injuries was intended to mimic an actual transplanting scenario. The configuration (number and length of rows) of the array varied according to the injury shape.

In each assay, planting units were deployed for a period of 72 hours. Upon retrieval, the PU's were disassembled in the lab. Plant material was again spun and gently patted dry, then reweighed. Change in biomass was expressed as the percent biomass loss per planting unit, determined by calculating the proportional loss in wet weight of each planting unit following the assay.

Herbivory assays were conducted at each site four times over a one-year period in 2009-2010: in May-June 2009 (Spr09), August 2009 (Sum09), November 2009 (Fall09), and February-March 2010 (Win10). These time periods were selected in order to coincide with warm (summer), cold (winter), and intermediate (spring, fall) water temperatures in this subtropical system. During each event, water temperature and salinity were measured at each site using a YSI Model 30 instrument.

Seagrass elemental composition

Seagrass leaf tissue was collected from each study site and the donor site for elemental content (total carbon $=\mathrm{C}$, total nitrogen $=\mathrm{N}$, total phosphorus $=\mathrm{P}$ ) analyses. Leaf tissue was collected in triplicate during each of the four seasonal assays, from all seagrass species present at the study site at that time (e.g., S. filiforme and $H$. wrightii were observed at every assay). Seagrass leaves were gently scraped to remove epiphytes, dried at $80^{\circ} \mathrm{C}$, and ground to a fine powder in a ball mill grinder. Total 
phosphorus content was determined through a dry-oxidation, acid hydrolysis extraction followed by colorimetric analysis of phosphate concentration in the extract (Fourqurean et al. 1992). Total carbon and total nitrogen were determined using a $\mathrm{CHN}$ analyzer. Elemental content was calculated on a dry weight basis (mass of element/dry weight of sample) $\times 100 \%$. Elemental ratios were calculated as molar ratios.

\section{Data analyses}

Due to difficulty distinguishing sea bream (Archosargus rhomboidalis) and pinfish (Lagodon rhomboides) in the field, survey data for these two species were grouped for analysis. Differences in total herbivore abundance between the two survey times (Fall 2009, Winter 2010), and differences in site-specific herbivore abundance within each survey time and each site-time pair were evaluated using chi-square tests.

Data from herbivory assays (\% biomass loss per PU) were not normally distributed (Shapiro-Wilk test, $p>0.05$ ), so herbivory pressure was analyzed for differences among herbivore exclusion treatment, species, site, and time using a fourway analysis of variance (ANOVA) on rank-transformed biomass loss data. The potential for caging artifacts was analyzed using a Bonferroni multiple comparisons test on the exclusion treatment, with significant differences in biomass loss between control sites and partial cages as the indicator of caging artifact. To evaluate herbivory pressure across seagrass species at different times of the year at each site, herbivory assay data were analyzed by species within each site-time pair using Kruskal-Wallis tests followed by all multiple pairwise comparisons.

$\mathrm{C}: \mathrm{N}$ and $\mathrm{C}: \mathrm{P}$ ratios of seagrasses from Pelican Shoal - the donor site - were analyzed for differences among species and sampling time using two-way ANOVA on rank-transformed $\mathrm{C}: \mathrm{N}$ ratios and on log-transformed $\mathrm{C}: \mathrm{P}$ ratios. Post-hoc tests on 
species and time were conducted for significant results using Bonferroni pairwise comparisons.

Donor seagrasses from Pelican Shoal and ambient seagrasses from each assay sites were compared for potential differences in elemental composition. Pairwise comparisons were conducted on seagrass $\mathrm{C}: \mathrm{N}$ and $\mathrm{C}: \mathrm{P}$ ratios between the donor site and assay site for each site/species/time combination. For elemental variables with normal distributions (C:P - all species; $\mathrm{C}: \mathrm{N}-T$. testudinum and $H$. wrightii), independent sample $t$-tests were used. Mann-Whitney $U$-tests were used for data with non-normal distributions (C:N - S. filiforme).

Relationships between seagrass biomass loss and C:N ratios, C:P ratios, and fish abundance, respectively, were evaluated using simple linear regression.

Results

Seagrass community composition

Dense seagrass communities dominated by $T$. testudinum surrounded the assay sites (Table 1). The median Braun Blanquet score for this species was 5.0 (75-100\% cover) at each site except at No Name Shoal, with a median score of $3.0(25-50 \%$ cover). Syringodium filiforme was not present in the seagrass monitoring quadrats at Biscayne Channel or Cutter Bank, though it was sampled at Biscayne Channel during the Summer 2009 herbivory assay (see below). Sparse S. filiforme was detected at East Featherbed Bank, though it wasn't located there during any of the herbivory assays. Halodule wrightii was not present in the seagrass monitoring quadrats at Biscayne Channel or East Featherbed Bank, though it was sampled at Biscayne Channel during the Summer 2009 and Winter 2010 herbivory assays. Sparse $H$. wrightii was detected at Cutter Bank in seagrass monitoring quadrats, though it wasn't located there during 
any of the herbivory assays. Both $S$. filiforme and $H$. wrightii were found at No Name Shoal during all four herbivory assays and in the seagrass monitoring quadrats.

Fish community composition

A total of 1,439 individuals of 25 taxa were observed during the eight pooled fish surveys (Table S1). Of these, 594 individuals were classified as herbivorous (parrotfish) or omnivorous (bream/pinfish) across seven taxa. Total fish abundance ranged from 88 to 766 individuals during the Fall 2009 surveys, but dropped to less than $10 \%$ of those values during the Winter 2010 surveys. At the Cutter Bank winter survey, no fish were observed at all. Water temperatures recorded during the Fall 2009 surveys ranged from $29.5^{\circ} \mathrm{C}$ to $31.3^{\circ} \mathrm{C}$, and dropped to between $17.6^{\circ} \mathrm{C}$ to $19.5^{\circ} \mathrm{C}$ during the Winter 2010 surveys (Table S1).

The three most abundant taxa observed over all surveys were sea bream/pinfish (A. rhomboidalis/L. rhomboides), grey snapper (L. griseus), and juvenile grunt species (Haemulon spp.), respectively (Table S1). Of the 597 herbivorous fish observed during all surveys, $77 \%$ were sea bream/pinfish. Pinfish undergo an ontogenetic shift from a carnivorous to herbivorous diet at approximately $100 \mathrm{~mm}$ in length (Stoner \& Livingston 1984; Luczkovich \& Stellwa 1993). We estimate that the majority of the pinfish we observed were at least $100 \mathrm{~mm}$ in length. Herbivores represented $21 \%-46 \%$ of the fish abundance during the Fall 2009 surveys, and herbivore abundance was significantly higher in the fall (242 fish) than in the Winter 2010 surveys (68 fish) $\left(x^{2}=351.6, d f=2, p\right.$ $<0.0001$ ). During the Winter 2010 surveys, $85 \%$ of the fish observed at No Name Shoal and the single fish observed at Biscayne Channel and Cutter Bank, respectively, were pinfish/sea bream. During the fall surveys, herbivore abundance varied significantly across sites $\left(x^{2}=390.9, d f=3, p<0.0001\right)$, with the most herbivores observed at No 
Name Shoal $(n=315)$. Herbivore abundance was highest at No Name Shoal during the winter surveys as well ( $n=66$ pinfish/bream). Site differences for the winter surveys were not evaluated because at the other three sites, only two fish were observed in total (Table S1).

Herbivory assays

Seagrass biomass removal (mean \pm SEM) in our experiments was significantly influenced by time, species, exclusion treatment, and site (Table 2, Figure 2). More seagrass biomass was lost during the Spring $2009(12.7 \pm 1.7 \%)$ and Summer 2009 $(11.6 \pm 1.6 \%)$, than in Fall $2009(8.2 \pm 1.3 \%)$ and Winter $2010(-2.2 \pm 0.4 \%)$. Biomass gain was attributed to seagrass growth. Mean biomass loss was greatest in S. filiforme $(22.3 \pm 1.9 \%)$, and was $12.7 \pm 1.4 \%$ and $2.3 \pm 1.3 \%$ for $H$. wrightii and $T$. testudinum, respectively. At East Featherbed Bank, and average of $25.5 \pm 1.9 \%$ of planting unit biomass was lost. At Biscayne Channel and No Name Shoal mean biomass loss was $2.4 \pm 0.9 \%$ and $1.6 \pm 0.9 \%$, respectively. At Cutter Bank, mean biomass increased by $0.1 \pm 0.8 \%$. Among the exclusion treatments, mean biomass loss in the partial cage and uncaged treatments $(9.8 \pm 1.2 \%$ and $14.8 \pm 1.4 \%$, respectively $)$ was significantly greater than in the fully caged treatment $(3.1 \pm 0.3 \%)$ suggesting that there was no caging artifact. and significantly lower than the other two exclusion treatments. There was no significant difference between biomass loss in the partial and uncaged treatments $(p=0.618)$.

Because no caging artifact was observed, herbivory assay data from partial and open cage treatments were pooled for subsequent analyses. Patterns of herbivory pressure varied across site, time, and species (Table 2, Figure 3). At East Featherbed Bank, biomass loss was high in both $H$. wrightii and S. filiforme, ranging from $35.6 \pm$ 
$6.3 \%$ (H. wrightii, Summer 2009) to $81.9 \pm 1.3 \%$ (S. filiforme, Spring 2009). Biomass loss also was high at this site for $T$. testudinum during Spring 2009 (81.3 $\pm 1.2 \%)$, but remained low during the Summer 2009, Fall 2009, and Winter 2010 assays ( $-2.5 \pm$ $2.6 \%, 9.5 \pm 5.3 \%$, and $-5.5 \pm 0.6 \%$ respectively). In the Spring and Fall 2009 assays at Cutter Bank, loss ranged from $8.5 \pm 5.2 \%$ to $11.6 \pm 3.6 \%$ for $H$. wrightii and from $17.4 \pm$ $6.9 \%$ to $17.9 \pm 5.0 \%$ for S. filiforme. Biomass increase was documented for all four $T$. testudinum assays, and for $\mathrm{H}$. wrightii and S. filiforme in the Summer 2009 and Winter 2010 assays at Cutter Bank. At Biscayne Channel only four of the twelve assays resulted in biomass loss, specifically in the Summer and Fall 2009 assays with $H$. wrightii ( $12.8 \pm 3.8 \%$ and $8.6 \pm 2.6 \%$, respectively) and S. filiforme (42.7 \pm 7.7 and $18.4 \pm$ 5.2, respectively). The other eight assays, including all $T$. testudinum assays, resulted in biomass increase. At No Name Shoal, the only two assays resulting in biomass loss were for $H$. wrightii $(43.0 \pm 7.1 \%)$ and S. filiforme $(30.3 \pm 6.3 \%)$ in Summer 2009; all other assays at this site showed biomass increase.

Seagrass elemental content

$\mathrm{C}: \mathrm{N}$ and $\mathrm{C}: \mathrm{P}$ ratios from Pelican Shoal donor seagrasses varied significantly with time, and $\mathrm{C}: \mathrm{N}$ ratios also varied significantly with seagrass species (Table 3, Figure 4). C:N ratios were significantly different in the Spring 2009, Summer 2009, Fall 2009, and Winter 2010, respectively ( $p<0.000$, Table 3), and were lowest in Winter $2010(16.8 \pm$ $0.46)$ and highest in Summer $2009(22.5 \pm 2.4)$. Thalassia testudinum had the lowest average C:N ratio $(16.5 \pm 0.6)$, followed by $H$. wrightii $(18.8 \pm 0.2)$ and S. filiforme $(23.2 \pm$ 1.7), respectively, and differences among species were significant $(p<0.001$, Table 3$)$. C:P ratios in Fall $2009(940.9 \pm 31.3)$ were significantly higher $(p<0.001$, Table 3$)$ than in Spring 2009 (672.8 \pm 46.0), Summer 2009 (686.5 \pm 51.0$)$, or Winter 2010 (641.6 \pm 
36.4), respectively. The lowest $\mathrm{C}: \mathrm{N}$ ratios in each species occurred in Winter 2010: $T$. testudinum $(14.0 \pm 0.1), H$. wrightii $(16.4 \pm 0.3)$ and $S$. filiforme $(17.0 \pm 0.3$, Figure 4).

The difference between $\mathrm{C}: \mathrm{N}$ and $\mathrm{C}: \mathrm{P}$ ratios from Pelican Shoal donor seagrasses and the ambient seagrasses at each assay varied as a function of species, time, and site (Table S2, Figure 5). In T. testudinum, donor C:N ratios were lower than ambient ratios in $44 \%$ of assays, not different in $44 \%$ of assays, and higher than ( $12 \%$ of assays) than ambient ratios (Table S2, Figure 5). Syringodium filiforme was present in the surrounding seagrass community at five of the sixteen assays; donor $\mathrm{C}: \mathrm{N}$ ratios were lower than ambient ratios in $40 \%$ of those assays, not different in $20 \%$ of assays, and higher in $40 \%$ of assays. Halodule wrightii was present in the surrounding seagrass community at six of the sixteen assays; donor $\mathrm{C}: \mathrm{N}$ ratios were lower than ambient ratios in $83 \%$ of and higher in $17 \%$ of assays.

No significant relationships were detected between seagrass biomass loss and $C: N$ and $C: P$ ratios for each seagrass species (linear regression, $\alpha=0.05$, all $p>0.11$; Figure 6), or between seagrass biomass loss and herbivorous fish abundance (linear regression, $\alpha=0.05, p=0.06$; Figure 7). Herbivorous fish formed a substantial component of the fish community during most fish surveys, and biomass loss was observed only when herbivorous fish were present, despite the absence of a statistically significant linear relationship between biomass loss and herbivore abundance (Figure 7).

\section{Discussion}

We established fish herbivores are capable of removing substantial quantities of seagrass biomass in our study system, and this pressure varied significantly across sites, seagrass species, and times of the year, though with lack of consistent patterns. Herbivore exclusion cages were effective in protecting our planting units from herbivory; 
across all species, sites, and events, seagrass biomass loss in full cages was $-3.1 \pm$ $0.3 \%$, vs. $12.3 \pm 1.3 \%$ in partial and full cages. Caging restoration sites has been suggested as a means to enhance planting unit success in restoration projects (Fonseca et al. 1998). However, we feel that caging on the scale of a seagrass restoration site is not a practical solution given tidal currents, maintenance requirements, and a desire to minimize the use of artificial structures in the marine environment.

We were unable to link seagrass biomass removal to abundance patterns of herbivorous fish. More robust and repeated fish surveys may provide the data necessary to establish this link. However, fish are transient across the landscape at the small scale of our assay sites, and it is possible for roving schools to pass through a restoration area, grazing as they move, resulting in episodic grazing events unrelated to local abundance. Our herbivory assays were deployed for a period of 72 hours, a relatively short period of time. If our PUs were subject to episodic grazing, and not detected by herbivorous fish in some assays, this could explain the observed variability in biomass loss among assays. Thus our results may underestimate herbivory pressure over longer temporal scales.

Herbivores may preferentially graze on enriched seagrasses (Williams 1988; McGlathery 1995; Heck \& Valentine 2006) or on faster growing, more palatable plants (Cebrián \& Duarte 1998). Goecker et al. (2005) observed selective feeding based on seagrass nitrogen content by the bucktooth parrotfish (Sparisoma radians). In contrast, other studies have shown that leaf nutrient concentration may not be a reliable indicator of nutritional quality (Cebrián \& Duarte 1998; Kirsch et al. 2002; White et al. 2011). We were unable to link seagrass biomass removal to $\mathrm{C}: \mathrm{N}$ or $\mathrm{C}: \mathrm{P}$ ratios in our study. This may indicate that the amount of variation in nutritional quality represented by our measured range of nutrient content was inconsequential to influence grazing rates. 
Another consideration is that $\mathrm{C}: \mathrm{N}$ and $\mathrm{C}: \mathrm{P}$ ratios are generally lower during winter months and peak in the summer and fall. The same seasonal patterns can be found for fish densities (which may be a good reason to limit studies of relationships between of nutrient content and herbivory to warmer months). Localized herbivory pressure may be driven more by fish grazer abundance than by plant nutrient content.

While this study was not explicitly designed to test herbivore feeding preferences, our results suggest that factors other than palatability play a role in seagrass herbivory. Fish herbivores may be using other cues to select plant resources, or responding to other selective pressures (e.g., predation risk). Overall, S. filiforme and $H$. wrightii had higher C:N ratios, but were grazed more heavily than T. testudinum (Table 3). Grazing on S. filiforme and $H$. wrightii was greater where these species were sparse or absent in the local seagrass community (i.e. Biscayne Channel, East Featherbed Bank, and Cutter Bank) than at No Name Shoal, where these two species are present in greater abundance. During several assays, the donor plant material had lower C:N ratios relative to the ambient seagrasses at that site, yet it was not consumed in substantial quantities. Conversely, there were some events where the planting units had higher C:N ratios than the ambient seagrasses, when substantial herbivory was observed (Figure 5). Our study intentionally placed PUs in clearings in order to simulate the conditions of an actual restoration project. Open space could be viewed as a higher risk microhabitat to small herbivorous fish (Orth et al. 1984b), but the attraction of new accessible and palatable food source, potentially of higher nutrient value, may positively influence foraging behavior in these areas.

Nutrient content in south Florida seagrasses can vary spatially over relatively small scales in response to environmental gradients, terrestrial or oceanic inputs, or other point sources (Fourqurean et al. 1992a; Caccia \& Boyer 2005; Campbell \& 
Fourqurean 2009). Donor sites for restoration projects are often distinct from the actual restoration site. Depending on the donor source and species, herbivores at a restoration site may be presented with seagrass transplants that are of higher nutrient value and/or a more palatable species that the ambient seagrasses at that site. Therefore spatial patterns of both nutrient enrichment and seagrass community structure may be important to understand in order to minimize herbivory pressure on transplants.

Despite the near absence of herbivory on $T$. testudinum that we observed, herbivory on this species is well documented (e.g. Kirsch et al. 2002, Goecker et al. 2005), and we did observe one of the most important seagrass herbivores, juvenile parrotfish species, in our fish surveys. Overall, herbivory pressure on T. testudinum was absent or very low in our study with the exception of the Spring 2009 assay at East Featherbed Bank, when $81.3 \pm 1.2 \%$ of seagrass biomass was removed from PU. The highest overall levels of herbivory were at East Featherbed Bank, which is close to major tidal cuts that provide access for fish using coral reefs to the east. The oceanic input at this site is also evident from the coarse sediment and abundance of small stony and soft corals. The lack of a strong herbivory signal for $T$. testudinum in the other three study sites may be due to the location of the sites within southern Biscayne Bay - several kilometers west from the coral reefs which are the likely source of herbivores. Herbivory pressure seemed consistently low at Cutter Bank, which was close to a mangrove shoreline.

Herbivory during our Winter 2009 pilot assays was low or absent (data not shown), so we incorporated a time factor into our experimental design. Winter 2010 fish surveys revealed dramatic differences in fish abundance from the Fall 2009 surveys. It is important to note that the Winter 2010 assay followed a rare extreme cold event in south Florida during January 2010. The average water temperature in January and 
February at this location ranges between $20^{\circ}$ and $21^{\circ} \mathrm{C}$ (Biscayne National Park, unpublished data). During the cold snap, water temperatures remained below $15^{\circ} \mathrm{C}$ for the 12-day period between 4-16 January 2010, and reached a low of $9.2^{\circ} \mathrm{C}$ on 11 January 2010. Water temperatures during the Winter 2010 herbivory assays ranged from $17.6^{\circ} \mathrm{C}$ to $19.5^{\circ} \mathrm{C}$. Fish abundance may have been abnormally low due to this cold event which was accompanied by fish kills in the area (personal observation) and others (Adams et al. 2012). However, even during more typical winter conditions, fish abundance is expected to be lower. In south Florida, abundance of some species is correlated with water temperature (Serafy et al. 2003, Tremaine \& Adams 1995), since tropical species are at the edges of their ranges in Florida. Because our study was not replicated seasonally, we cannot predict if the herbivory patterns we saw are representative through longer time frames, and our results should be interpreted accordingly. However, our results strongly suggest that transplanting activities in southern Biscayne Bay may be at lower risk from herbivory if conducted during winter months.

In some of our herbivory assays, a large proportion of the seagrass biomass in the planting units was removed (up to $81.9 \pm 1.2 \%$ ). Entire leaves were removed more often than bite marks in the leaves. In considering the herbivory pressure that we observed, herbivory impact on the scale of a seagrass landscape may be less extreme than on the scale of a restoration project. In highly productive ecosystems, absolute consumption of seagrass by herbivores may be small relative to primary production (Cebrián \& Latrigue 2004). Because of the rhizophytic morphology and clonal life history strategy of seagrasses, seagrass clones are able to tolerate herbivory, at least to a degree, and acute removal of leaves or shoots is not likely to cause the clone to perish. Of the three species used in our study, $S$. filiforme and $H$. wrightii have relatively rapid 
rhizome elongation rates (Marba \& Duarte 1998), and resources can be translocated among ramets along rhizomes (Marba et al. 2006a). The availability of stored carbon and nutrient reserves can influence a plant's ability to replace leaves lost to herbivores (Vergés \& Pérez 2008, Christianen et al 2011); and it may be the exhaustion of these reserves that lead to plant mortality following chronic, repeated grazing leaf loss (Fourqurean et al. 2010).

In restoration projects, seagrasses are usually transplanted as plugs or sods that are obtained with a coring device or shovel, or as bundles of bare rhizomes that contain a few shoots per rhizome (Fonseca et al. 1998). Some degree of transplant shock is expected, so newly transplanted seagrasses may be in a compromised condition. Subsequent removal of leaves or shoots in a planting unit through grazing has far more serious implications to a clone that may already be stressed and may have few photosynthetic shoots and low nutrient and carbohydrate reserves to grow and colonize the restoration area.

\section{Conclusions}

Leaf loss to herbivores may be a spatially variable but critically important determinant of seagrass restoration success. Given the highly variable nature of herbivory across sites, time, and species, we recommend that future restoration projects be designed with a priori knowledge of site-specific herbivory pressure. Site-specific herbivory assays with the range of species of interest, along with fish surveys, can provide a relatively fast, low-technology way to learn about herbivory pressure during the planning phase. This knowledge can be used to evaluate the potential risk of herbivory to seagrass transplants and inform decisions on donor species selection, planting unit 
type and density, project success criteria, and the potential need for future corrective actions.

Emerging management considerations for restoration planning in our system include limiting transplanting efforts to $T$. testudinum, and refraining from transplanting efforts on the Featherbed Banks. An additional conservative recommendation is to limit transplanting to the winter months, when overall herbivory risk appears to be the lowest. In some systems, winter planting may be undesirable due to slow growth or die-offs. In subtropical environments, this is less likely to be a relevant consideration (Fonseca et al. 1998), though success of winter plantings remains to be documented. It should be reiterated here that our winter assays followed an extreme cold event, and that herbivory levels during a typical winter may be higher that we observed. We acknowledge that it is a commonly held belief that "seagrass restoration projects" must involve the transplanting of seagrasses. However, given our results, the most conservative approach we can recommend is to refrain from seagrass transplanting all together in areas subject to high herbivory pressure. We extend this recommendation to potential projects in areas closer to coral reefs with more abundant parrotfish species, known to feed heavily on seagrasses (Kirsch et al. 2002; Maciá \& Robinson 2005; Armitage \& Fourqurean 2006), where the risk of heavy herbivory is expected. 
Table 1. Median, range, and sample size (number of quadrats) of Braun-Blanquet scores of the undisturbed seagrass community at each herbivory assay site. Species codes: $\mathrm{TT}=$ Thalassia testudinum, $\mathrm{SF}=\mathrm{S}$. filiforme, $\mathrm{HW}=$ Halodule wrightii. Scale interpretation: $0=$ not present in quadrat, $0.1=$ single occurrence, $0.5=$ few occurrences, $1=<5 \%$ cover, $2=5-25 \%$ cover, $3=25-50 \%$ cover, $4=50-75 \%$ cover, $5=$ 75-100\% cover (Fourqurean et al. 2001).

\begin{tabular}{lllllllllllll}
\hline & \multicolumn{3}{c}{ Biscayne } & \multicolumn{4}{c}{ No Name } & \multicolumn{4}{c}{ East Featherbed } & \multicolumn{3}{c}{ Cutter Bank } \\
Statistic & TT & SF & HW & TT & SF & HW & TT & SF & HW & TT & SF & HW \\
\hline Median & 5.0 & 0.0 & 0.0 & 3.0 & 0.5 & 0.5 & 5.0 & 0.0 & 0.0 & 5.0 & 0.0 & 0.0 \\
Range & 4.5 & 0.0 & 0.0 & 5.0 & 2.0 & 4.0 & 5.0 & 3.0 & 0.0 & 5.0 & 0.0 & 3.0 \\
$\mathrm{~N}$ & 71 & 71 & 71 & 111 & 111 & 111 & 400 & 400 & 400 & 1070 & 1070 & 1070 \\
\hline
\end{tabular}


Table 2. Results from Kruskal-Wallis tests of differences in planting unit biomass loss among three seagrass species within site-time pairs. Biomass loss data from the full cage treatment are excluded and data from open and partial cage treatments are pooled.

\begin{tabular}{lllll}
\hline Site & Time & $d f$ & $K$ & $P$ \\
\hline \multirow{4}{*}{ Biscayne Channel } & Spring & 2 & 8.9 & 0.012 \\
& Summer & 2 & 23.5 & 0.000 \\
& Fall & 2 & 14.4 & 0.001 \\
& Winter & 2 & 15.4 & 0.000 \\
\hline \multirow{4}{*}{ No Name Shoal } & Spring & 2 & 13.9 & 0.001 \\
& Summer & 2 & 29.6 & 0.000 \\
& Fall & 2 & 23.2 & 0.000 \\
& Winter & 2 & 6.5 & 0.038 \\
\hline \multirow{5}{*}{ East Featherbed Bank } & Spring & 2 & 45.8 & 0.000 \\
& Summer & 2 & 42.0 & 0.000 \\
& Fall & 2 & 17.6 & 0.000 \\
& Winter & 2 & 36.9 & 0.000 \\
\hline \multirow{3}{*}{ Cutter Bank } & Spring & 2 & 11.5 & 0.003 \\
& Summer & 2 & 12.4 & 0.002 \\
& Fall & 2 & 24.9 & 0.000 \\
& Winter & 2 & 6.5 & 0.039 \\
\hline
\end{tabular}


Table 3. Results from two-way ANOVA and Bonferroni tests $(\alpha=0.05)$ of Time and Species on carbon:nitrogen (C:N, rank-transformed) and carbon:phosphorus (C:P, untransformed) molar ratios in seagrasses from Pelican Shoal, the donor site for herbivory assays.

\begin{tabular}{|c|c|c|c|c|}
\hline \multirow{2}{*}{\multicolumn{5}{|c|}{$\begin{array}{l}\text { Source } \\
\text { Donor Site C:N Ratios }\end{array}$}} \\
\hline & & & & \\
\hline \multicolumn{5}{|l|}{ Time } \\
\hline Species & 2 & 913.6 & 102.8 & 0.000 \\
\hline Time * Species & 6 & 115.8 & 13.0 & 0.000 \\
\hline Error & 24 & 8. 9 & & \\
\hline \multicolumn{5}{|l|}{ Bonferroni Tests } \\
\hline \multicolumn{5}{|c|}{ Time $(\alpha=0.008)$ : } \\
\hline \multicolumn{5}{|l|}{ Spr09, Sum09 } \\
\hline \multicolumn{5}{|l|}{ Spr09, Fall09 } \\
\hline \multicolumn{5}{|l|}{ Spr09, Win10 } \\
\hline \multicolumn{5}{|l|}{ Sum09, Fall09 } \\
\hline \multicolumn{5}{|l|}{ Sum09, Win10 } \\
\hline \multicolumn{5}{|l|}{ Fall09, Win10 } \\
\hline \multicolumn{5}{|c|}{ Species $(\alpha=0.017)$ : } \\
\hline \multicolumn{3}{|c|}{ T. testudinum, H. wrightii } & & 0.000 \\
\hline \multicolumn{3}{|c|}{ T. testudinum, S. filiforme } & & 0.000 \\
\hline \multicolumn{3}{|c|}{ S. filiforme, H. wrightii } & & 0.000 \\
\hline \multicolumn{5}{|c|}{ Donor Site C:P Ratios } \\
\hline Time & 3 & 171995.0 & 36.6 & 0.000 \\
\hline Species & 2 & 15775.5 & 3.4 & 0.052 \\
\hline Time * Species & 6 & 60136.6 & 12.8 & 0.000 \\
\hline Error & 24 & 4704.2 & & \\
\hline \multicolumn{5}{|l|}{ Bonferroni Tests } \\
\hline \multicolumn{5}{|c|}{ Time $(\alpha=0.008)$ : } \\
\hline \multicolumn{3}{|l|}{ Spr09, Sum09 } & & 1.000 \\
\hline \multicolumn{3}{|l|}{ Spr09, Fall09 } & & 0.000 \\
\hline \multicolumn{3}{|l|}{ Spr09, Win10 } & & 1.000 \\
\hline \multicolumn{3}{|l|}{ Sum09, Fall09 } & & 0.000 \\
\hline \multicolumn{3}{|l|}{ Sum09, Win10 } & & 1.000 \\
\hline \multicolumn{3}{|l|}{ Fall09, Win10 } & & 0.000 \\
\hline
\end{tabular}


Table S1. Summary of fish community abundance at the four study sites: BC=Biscayne Channel, NN=No Name Shoal, EF=East Featherbed Bank, CB=Cutter Bank.

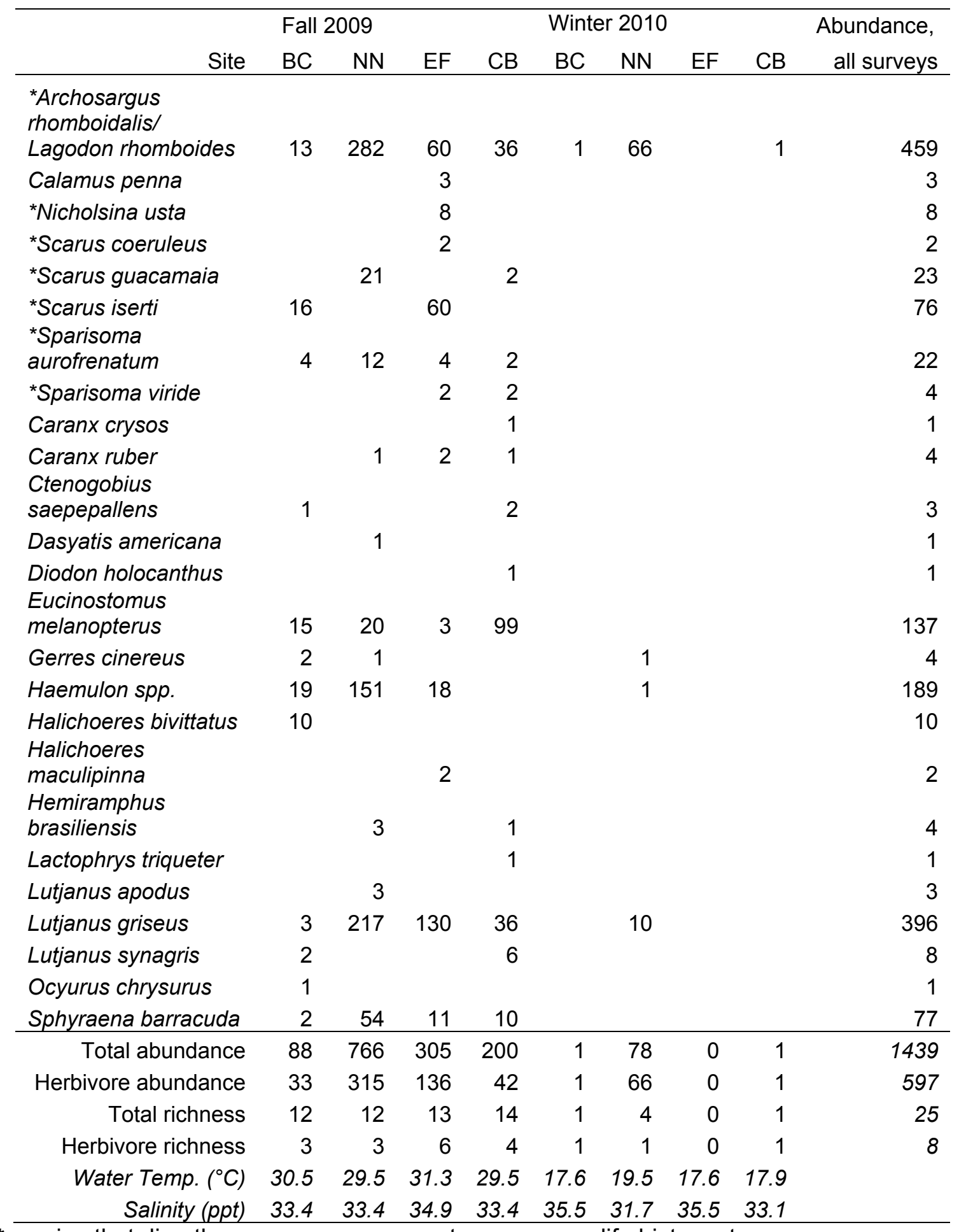

*species that directly consume seagrass at one or more life history stages 
Table S2. Results of independent $t$-tests of carbon:nitrogen (C:N) and carbon:phosphorus $(\mathrm{C}: \mathrm{P})$ molar ratios in seagrass leaves from the donor site (Pelican Shoal) vs. each herbivory assay site $(B C=$ Biscayne Channel, $C B=$ Cutter Bank, EF = East Featherbed Bank, NN = No Name Shoal) for each species/time pair.

\begin{tabular}{|c|c|c|c|c|c|c|c|c|}
\hline \multirow[b]{2}{*}{ Species } & \multirow[b]{2}{*}{ Time } & \multirow[b]{2}{*}{ Site } & \multicolumn{2}{|c|}{ C:N Ratio } & \multicolumn{4}{|c|}{ C:P Ratio } \\
\hline & & & $t$ & $\mathrm{df}$ & $P$ & $t$ & $\mathrm{df}$ & $P$ \\
\hline \multirow{16}{*}{$\begin{array}{l}\text { Thalassia } \\
\text { testudinum }\end{array}$} & Spr09 & $\mathrm{BC}$ & -0.6 & 4 & 0.594 & -0.6 & 4 & 0.583 \\
\hline & & $\mathrm{CB}$ & 4.4 & 4 & 0.012 & -18.0 & 4 & 0.000 \\
\hline & & $E F$ & 2.8 & 4 & 0.051 & -6.3 & 4 & 0.003 \\
\hline & & NN & 3.1 & 4 & 0.037 & -8.4 & 4 & 0.001 \\
\hline & Sum09 & $\mathrm{BC}$ & -11.8 & 4 & 0.000 & -2.7 & 4 & 0.054 \\
\hline & & $\mathrm{CB}$ & 0.1 & 4 & 0.935 & -5.0 & 4 & 0.007 \\
\hline & & $\mathrm{EF}$ & -4.0 & 4 & 0.017 & -10.3 & 4 & 0.000 \\
\hline & & NN & 2.3 & 4 & 0.085 & -7.0 & 4 & 0.002 \\
\hline & Fall09 & $\mathrm{BC}$ & -20.9 & 4 & 0.000 & 5.5 & 4 & 0.005 \\
\hline & & CB & -1.7 & 4 & 0.157 & 4.7 & 4 & 0.009 \\
\hline & & $\mathrm{EF}$ & -4.6 & 4 & 0.010 & 1.8 & 4 & 0.146 \\
\hline & & NN & -8.2 & 4 & 0.001 & 3.3 & 4 & 0.029 \\
\hline & Win10 & $\mathrm{BC}$ & -6.7 & 4 & 0.003 & 4.7 & 4 & 0.009 \\
\hline & & CB & 4.4 & 4 & 0.011 & 0.3 & 4 & 0.793 \\
\hline & & $\mathrm{EF}$ & -5.1 & 4 & 0.007 & 2.3 & 4 & 0.083 \\
\hline & & NN & 0.9 & 4 & 0.400 & 3.9 & 4 & 0.017 \\
\hline \multirow{5}{*}{$\begin{array}{l}\text { Syringodium } \\
\text { filiforme }\end{array}$} & Spr09 & NN & -0.4 & 4 & 0.732 & 2.1 & 4 & 0.101 \\
\hline & Sum09 & $\mathrm{BC}$ & 12.6 & 4 & 0.000 & 0.0 & 4 & 0.995 \\
\hline & & NN & 15.4 & 4 & 0.000 & -0.2 & 4 & 0.870 \\
\hline & Fall09 & NN & -3.3 & 4 & 0.031 & 9.1 & 4 & 0.001 \\
\hline & Win10 & NN & -8.5 & 4 & 0.001 & 1.6 & 4 & 0.193 \\
\hline \multirow{6}{*}{$\begin{array}{l}\text { Halodule } \\
\text { wrightii }\end{array}$} & Spr09 & NN & -7.6 & 4 & 0.002 & -1.3 & 4 & 0.265 \\
\hline & Sum09 & $\mathrm{BC}$ & -4.9 & 4 & 0.008 & -3.1 & 4 & 0.037 \\
\hline & & NN & -3.0 & 4 & 0.039 & -1.3 & 4 & 0.251 \\
\hline & Fall09 & NN & -18.6 & 4 & 0.000 & 10.0 & 4 & 0.001 \\
\hline & Win10 & $\mathrm{BC}$ & -8.4 & 4 & 0.001 & 0.7 & 4 & 0.534 \\
\hline & & NN & 3.3 & 4 & 0.030 & 5.3 & 4 & 0.006 \\
\hline
\end{tabular}


Figure 1. Location of study sites in southern Biscayne Bay, Biscayne National Park, Florida, USA.

Figure 2. Main effects of (a) time, (b) seagrass species, (c) exclusion treatment, and (d) site on mean ( \pm se) percent seagrass biomass loss in herbivory assays. All main effects were significant $(p<0.001)$ in a 4-way ANOVA on rank-transformed biomass loss data. For (c) lower case letters indicate Bonferroni-corrected significance at $p<0.017$. Species codes: TT=Thalassia testudinum, $\mathrm{SF}=$ Syringodium filiforme, $\mathrm{HW}=$ Halodule wrightii. Site codes: BC=Biscayne Channel, NN=No Name Shoal, EF=East Featherbed Bank, CB=Cutter Bank.

Figure 3. Mean ( \pm se) percent seagrass biomass loss through time by species within each assay site. Seagrass biomass data from the uncaged and partial herbivore exclusion treatments are pooled. Lowercase letters indicate statistical significance among species within each site:time pair (see Table 2). Species codes: TT=Thalassia testudinum, $\mathrm{SF}=$ Syringodium filiforme, $\mathrm{HW}=$ Halodule wrightii.

Figure 4. Mean ( \pm se) carbon:nitrogen $(C: N)$ and carbon:phosphorus $(C: P)$ molar ratios in seagrass leaves from the donor site, Pelican Shoal, by species and time. Lowercase letters indicate statistical significance among times within each species at $p<0.05$ as determined through 2-way ANOVAS followed by bonferroni pairwise comparisons. Species codes: HW=Halodule wrightii, SF=Syringodium filiforme, TT=Thalassia testudinum.

Figure 5. Mean ( \pm se) carbon:nitrogen $(\mathrm{C}: \mathrm{N}$, top row) and carbon:phosphorus (C:P, bottom row) molar ratios in seagrass leaves through time by site within species. Absence of a bar in a site/time group indicates that that species was not present for collection. Asterisks indicate differences from donor site values at $p<0.05$. Site codes: 
$\mathrm{PS}=$ Pelican Shoal, BC=Biscayne Channel, NN=No Name Shoal, EF=East Featherbed Bank, CB=Cutter Bank.

Figure 6. Mean ( \pm se) percent seagrass biomass loss vs. mean ( \pm se) carbon:nitrogen (C:N, left column) and mean ( \pm se) carbon:phosphorus (C:P, right column) molar ratios in donor site seagrass leaves, displayed by time for each seagrass species. Error bars are displayed to show variance in the observations, but regression analyses assumed that mean values for each point were the independent units of observation. No regressions were significant (all $p>0.11$ ). Seagrass biomass data from the uncaged and partial herbivore exclusion treatments are pooled.

Figure 7. Fish abundance (left axes) and biomass loss (mean \pm se, right axes) at the assay sites in Fall 2009 (left panel) and Winter 2010 (right panel). The stacked bars divide abundance into two feeding guilds: herbivorous fish (grey bars) vs. other fish (white bars). Percent biomass loss data from the uncaged and partial cage treatments are pooled, and presented by seagrass species (Thalassia testudinum, squares; Syringodium filiforme, triangles; Halodule wrightii, circles). Site codes: BC=Biscayne Channel, NN=No Name Shoal, EF=East Featherbed Bank, CB=Cutter Bank. 


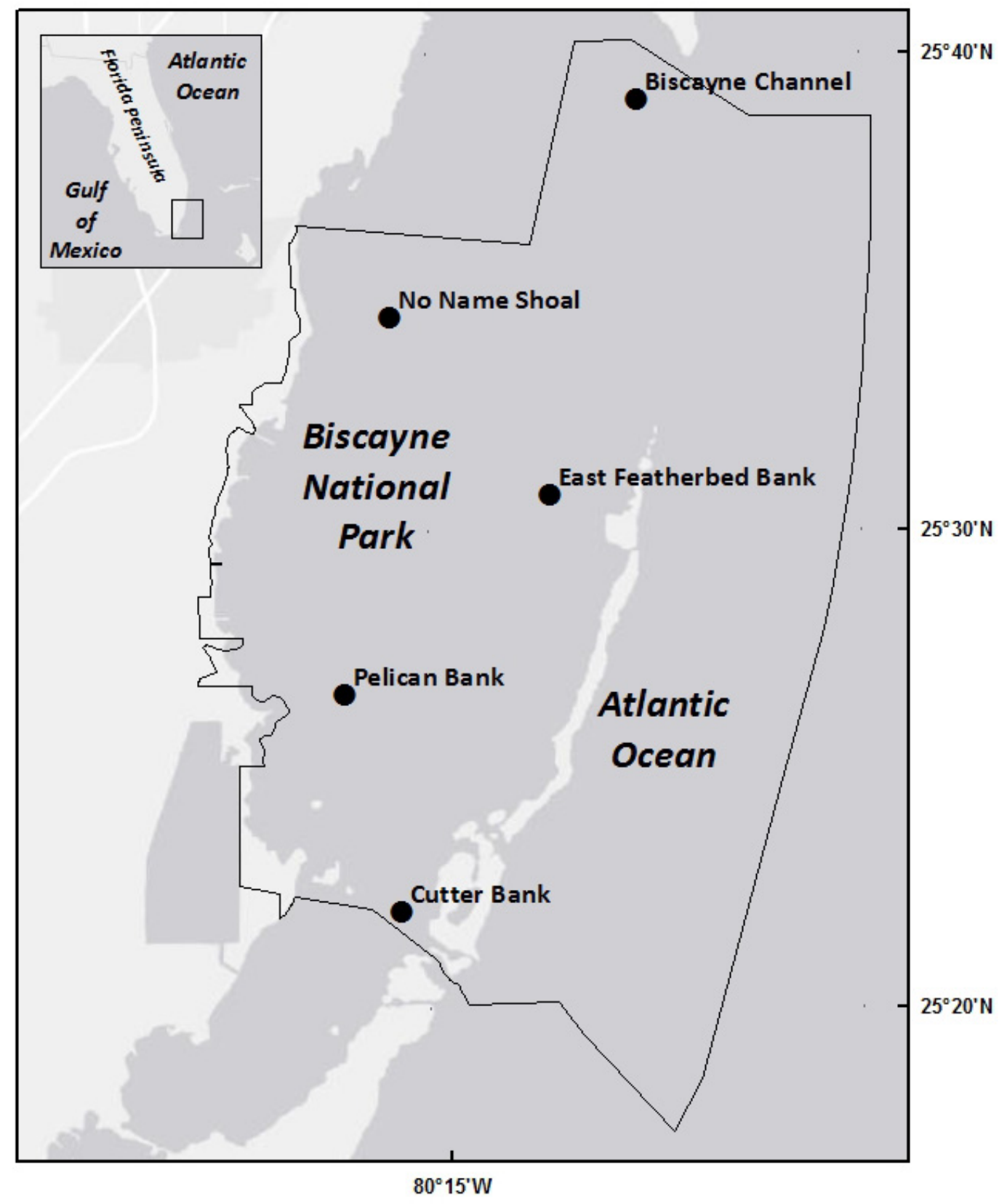



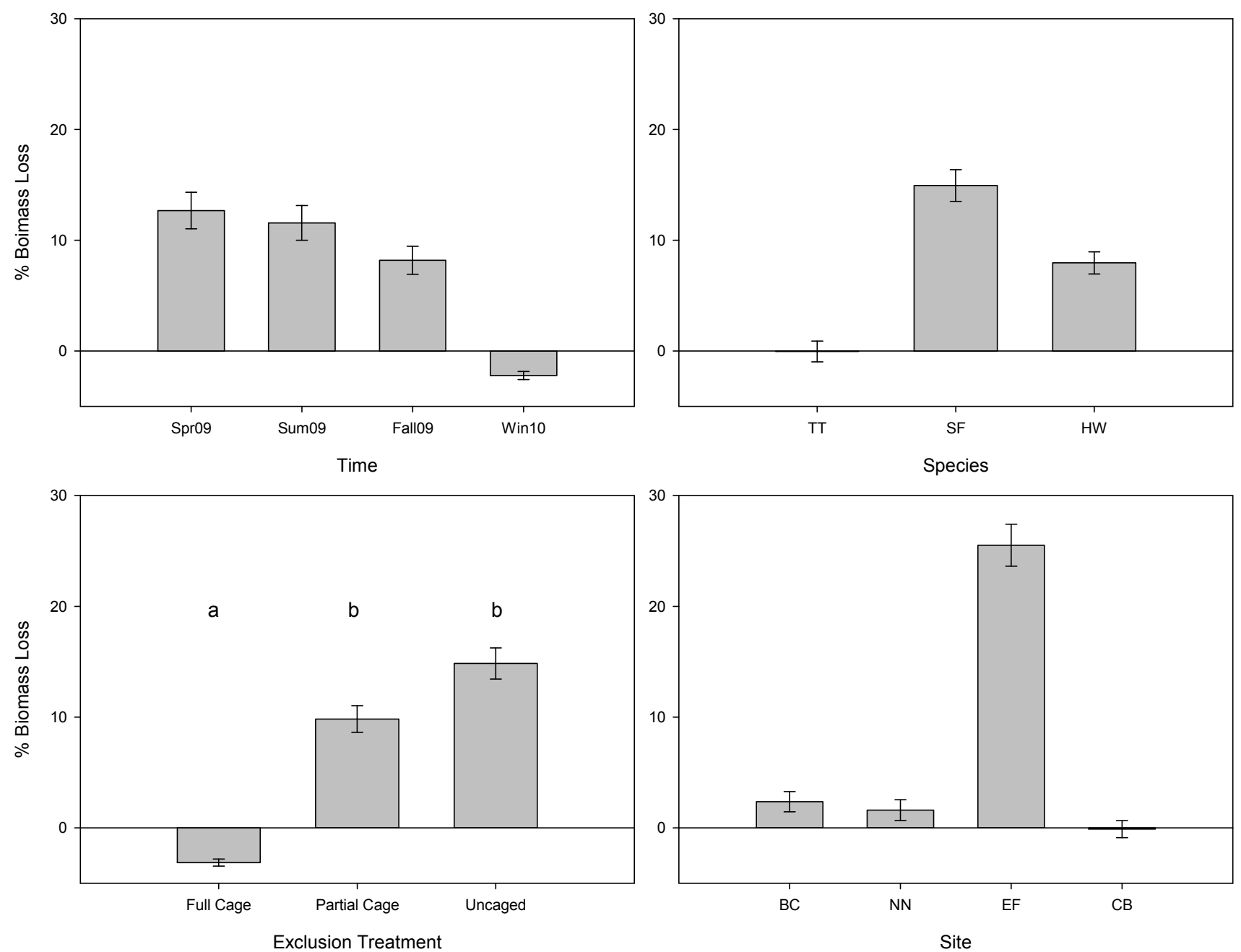


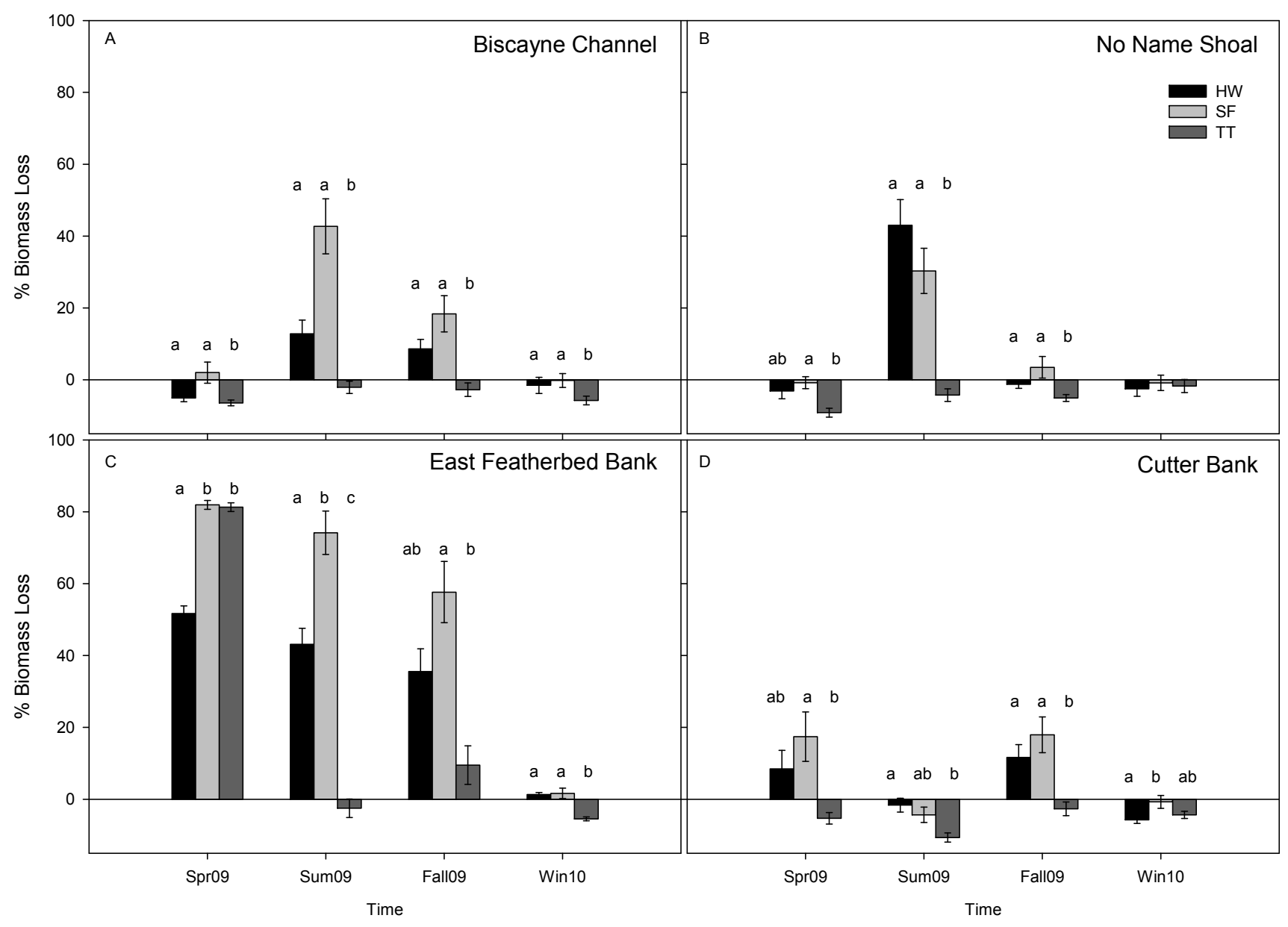



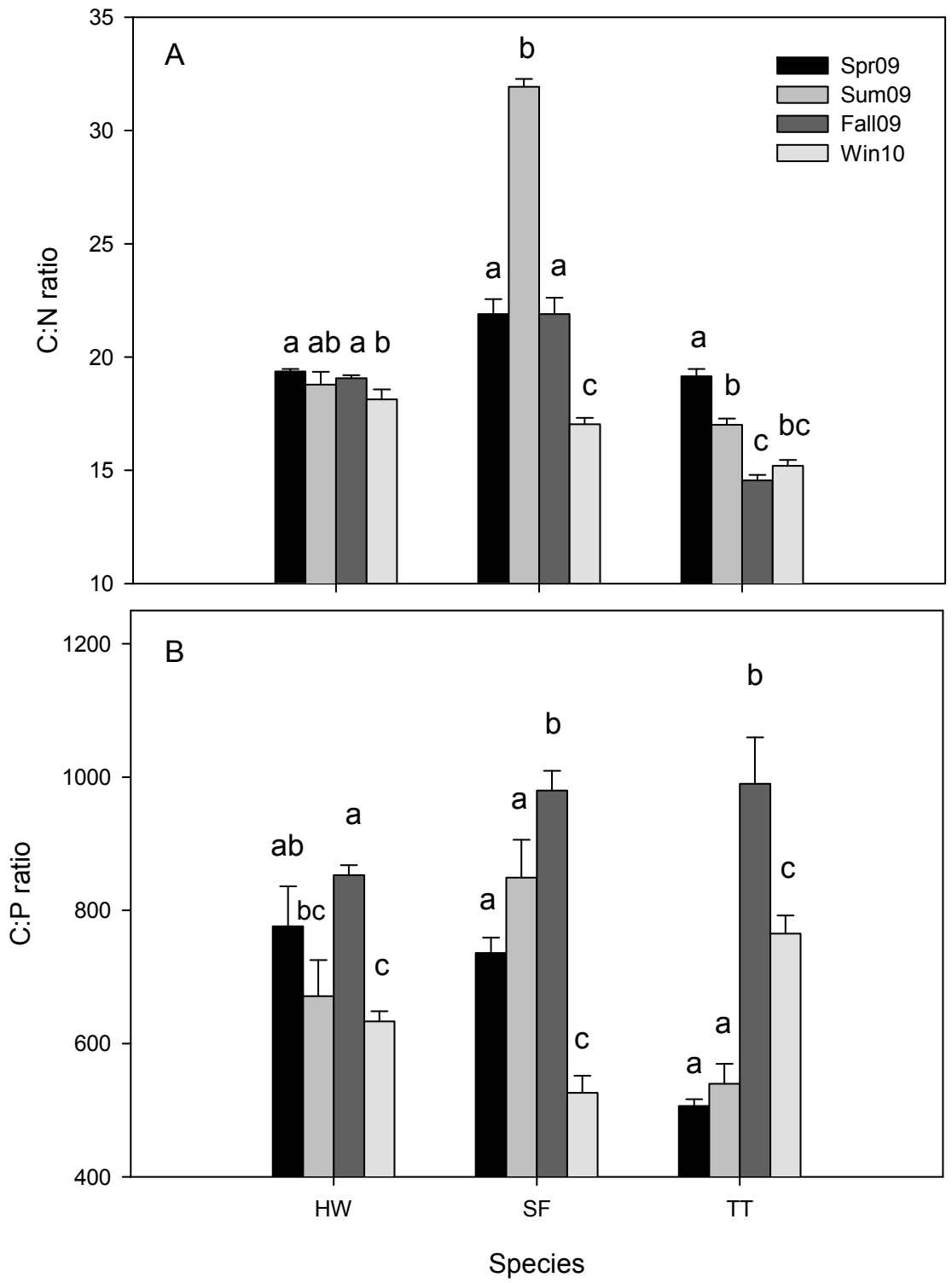


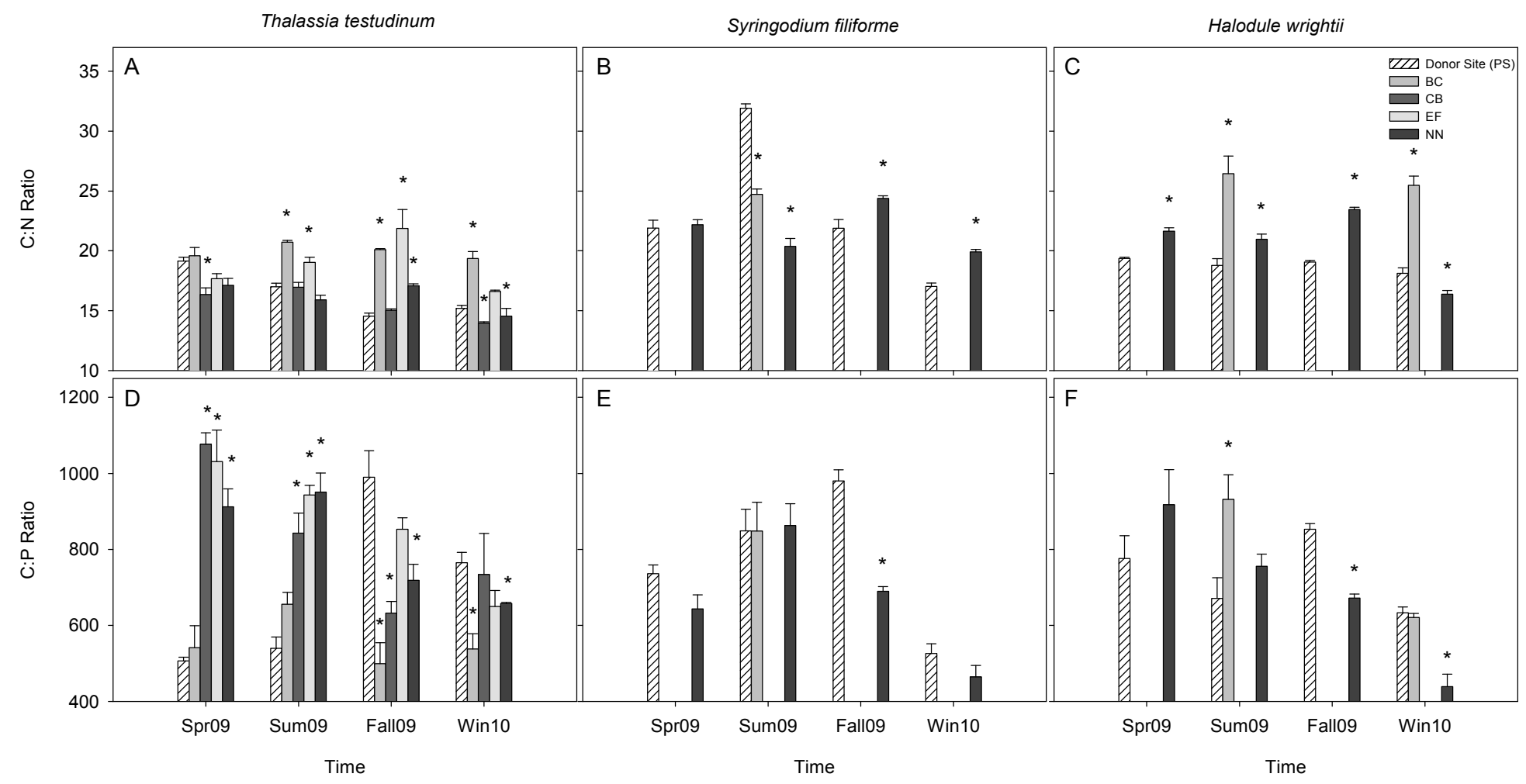




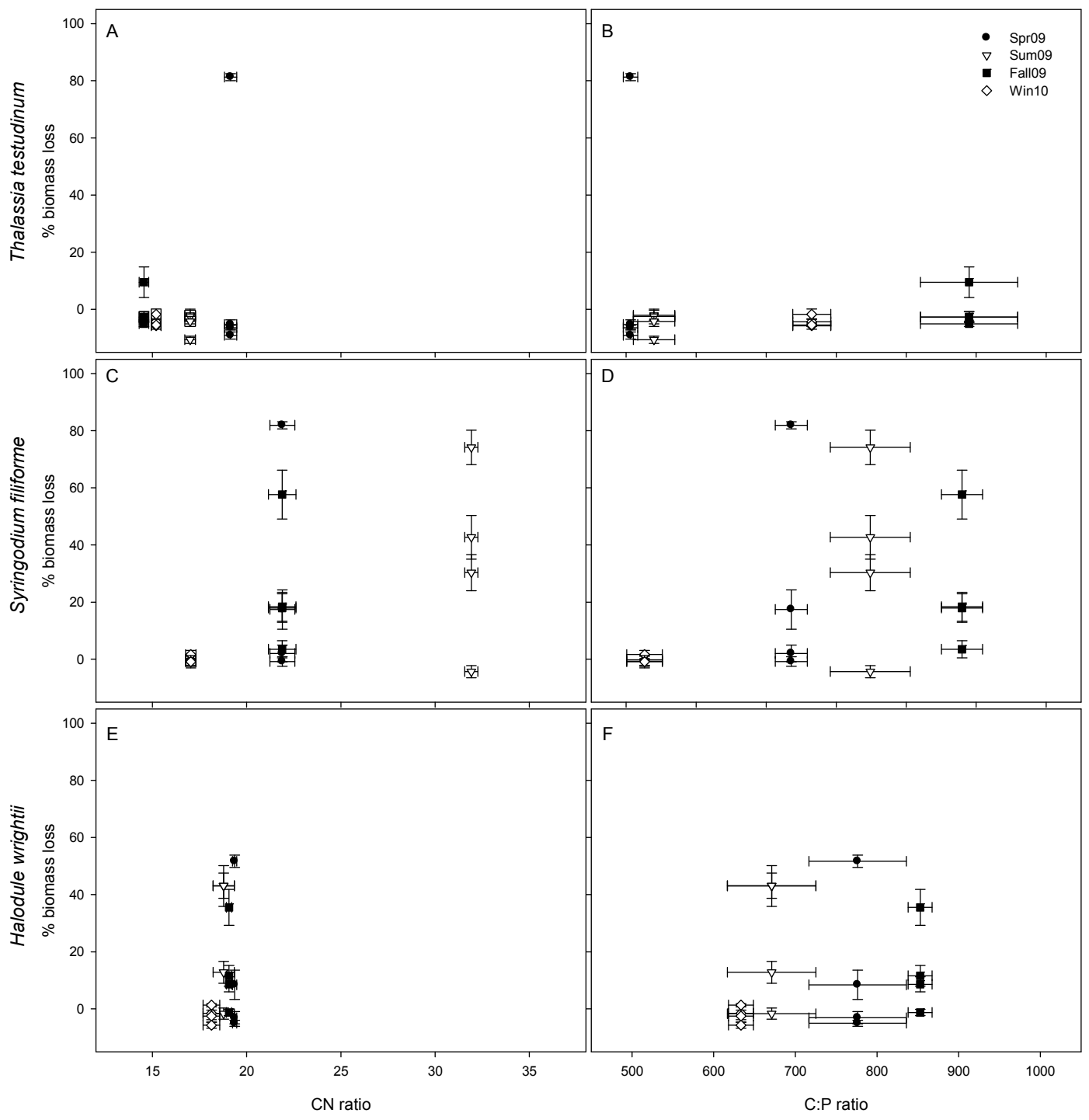




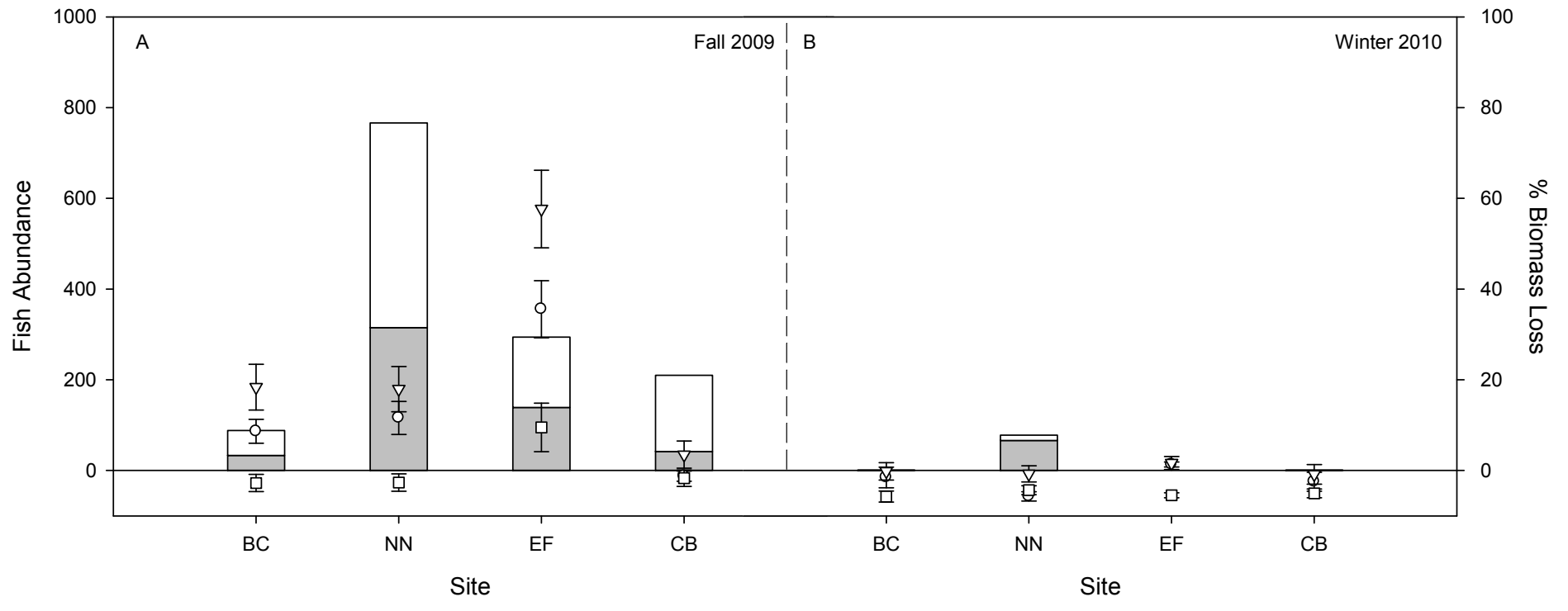


CHAPTER VII: Conclusion

This dissertation research evaluated the loss and recovery of ecosystem structure in disturbed seagrass meadows, as well as the efficacy of common seagrass restoration methods in accelerating recovery. Vessel grounding disturbances in seagrass meadows resulted not only in loss of seagrass community structure, but also altered other aspects of ecosystem structure including reducing benthic microalgae and macroalgae abundance, elemental stocks buried in seagrass sediment, porewater nutrient pools, and invertebrate community abundance and diversity. These impacts persisted in study sites that were up to five years in age since disturbance. Given the extensive vessel grounding injuries to seagrass meadows in south Florida, the potential cumulative impacts of these disturbance effects is of great concern to resource managers. Accordingly, seagrass restoration actions are implemented at vessel grounding disturbances with increasing frequency.

Seagrass restoration methods including filling excavations and delivering nutrients via bird roosting stakes had varying effects, some unexpected, on the recovery process. Filling excavations with quarried sand resulted in changes to seagrass ecosystem structure of greater magnitude than was caused by the initial disturbance. For example, ecosystem structure at filled sites was altered relative to both unrestored grounding disturbances and to the undisturbed seagrass ecosystem. Filling vessel grounding injuries initially altered seagrass ecosystem structure by creating a sediment matrix with different physical properties, low organic matter content and nutrient pools, reduced primary producer abundance, and altered microbial and invertebrate communities relative to the undisturbed ecosystem. Relative to reference seagrass meadows, restoration sites that received fill were characterized after 3-3.5 years by low macrophyte cover; reduced infaunal abundance and diversity; and coarse sediments 
with low sediment and porewater nutrient pools. Fertilization of restoration sites via placement of bird stakes was effective in increasing macroalgae cover, infaunal invertebrate abundance, and $\mathrm{N}$ and $\mathrm{P}$ availability in the sediments. However, concurrent enhancement of seagrass production was not detected over the time frames studied.

While I did not detect evidence of substantial convergence with the intact seagrass ecosystem in the restoration sites studied, some indicators of ecosystem development related to primary production and nutrient accumulation were evident. These results suggest that early stages of ecosystem development have begun at these sites. However, relatively little is known about the recovery of ecosystem structure in following restoration, and I suggest that the study sites were still in early phases of the recovery trajectory. Longer time frames will be needed to identify ecosystem recovery trajectories following both disturbance and restoration in this system.

Vessel grounding excavations have the potential to become larger because of erosion (Whitfield et al. 2002), and larger excavations have slower recovery rates (Di Carlo \& Kenworthy 2008; Uhrin et al. 2011) than less severe disturbances. Filling excavations achieves the important objective of site stabilization. Filled sites are characterized by coarse texture, low organic matter content, and slow recovery of seagrass communities, but it would be difficult to fill excavations with fine organic muds similar to sediments found in the undisturbed seagrass meadows.

Planting seagrasses is a restoration approach intended to result in accelerated colonization of restoration sites (Lewis 1987), and seagrasses transplanted to aid in restoration site recovery have some documented successes (e.g. Farrer 2010; Hall et al. 2012b). However, I found that seagrasses do not thrive in the modified environment of filled restoration sites, as was evident by low colonization of study sites over the time frame of the study. Further, top-down control may inhibit the success of planting efforts. 
In my analysis of herbivory pressure on experimental seagrass planting units, I confirmed that seagrass herbivores are capable of removing substantial seagrass biomass via direct grazing in southern Biscayne Bay. The observed herbivory pressure varied across seagrass species, location, and time. More biomass was lost during the spring and summer assays than in fall and winter assays. Biomass loss was greatest in S. filiforme and $H$. wrightii, and negligent in $T$. testudinum. The assay site closest to tidal cuts leading to nearby coral reefs experienced the highest average levels of herbivory. My research indicates that leaf loss to seagrass herbivores appears to be a spatially variable but critically important determinant of seagrass transplanting success. To maximize the potential for transplanting success and best utilize limited resources available for restoration, local knowledge of herbivory pressure, as well as seasonal dynamics of herbivore populations and physical location of restoration sites should be considered during restoration planning.

This collective body of work provides an enhanced perspective regarding impacts of physical disturbance to components of seagrass ecosystem structure beyond loss of seagrass biomass. Disturbance led to loss of organic matter and stored nutrients, and altered microbial and infaunal communities. These findings suggest that vessel grounding disturbances create more complex and persistent resource losses than previously understood by resource managers. Insight is also provided on the impacts of restoration actions themselves on seagrass ecosystem structure, and on the slow sequence of ecosystem development that occurs during the post-restoration recovery process. However, the disturbance effects caused by filling excavations may be unavoidable for practical reasons when site stabilization is a primary restoration objective, and because of ecological processes such as herbivory. 
In summary, resource managers should not underestimate the extent of resource injuries that are caused by vessel groundings in seagrass habitat, or the natural recovery time of such injuries. This recommendation is especially applicable to injuries involving sediment excavation. While the mechanics of implementing common seagrass restoration actions have been successfully worked through by the restoration community, the expectation of consistent recovery trajectories following use of these methods remains elusive. Rigorous restoration monitoring is strongly encouraged, for all methods and at all locations. A one-size-fits-all approach to seagrass restoration will not likely be appropriate, nor may recovery trajectories be consistent among methods and locations. 


\section{REFERENCES}

Abdo, Z., Schüette, U., Bent, S., Williams, C., Forney, L. \& Joyce, P. (2006). Statistical methods for characterizing diversity of microbial communities by analysis of terminal restriction fragment length polymorphisms of 16S rRNA genes.

Environmental Microbiology, 8, 929-938.

Adams, A., Hill, J., Kurth, B. \& Barbour, A. (2012). Effects of a severe cold event on the subtropical, estuarine-dependent common snook, Centropomus undecimalis. Gulf and Caribbean Research, 35, 13-21.

Admirall, W. (1984). The ecology of sediment-inhabiting diatoms. Progress on Phycological Research, 3, 269-322.

Akaike, H. (1973). Information theory and an extension of the maximum likelihood principle. In: Second international symposium on information theory. Springer Verlag, pp. 267-281.

Alcoverro, T. \& Mariani, S. (2004). Patterns of fish and sea urchin grazing on tropical Indo-Pacific seagrass beds. Ecography, 27, 361-365.

Allgeier, J.E., Rosemond, A.D., Mehring, A.S. \& Layman, C.A. (2010). Synergistic nutrient colimitation across a gradient of ecosystem fragmentation in subtropical mangrove-dominated wetlands. Limnology and Oceanography, 55, 2660-2668.

Anderson, M. \& Millar, R. (2004). Spatial variation and effects of habitat on temperate reef fish assemblages in northeastern New Zealand. Journal of Experimental Marine Biology and Ecology, 305, 191-221.

Anderson, M., Gorley, R. \& Clarke, K. (2008). PERMANOVA+ for PRIMER: guide to software and statistical methods. Primer-e, Plymouth, UK.

Armitage, A., Frankovich, T. \& Fourqurean, J.W. (2006). Variable responses within epiphytic and benthic microalgal communities to nutrient enrichment. Hydrobiologia, $569,423-435$.

Armitage, A., Frankovich, T., Heck KI, J. \& Fourqurean, J. (2005). Experimental nutrient enrichment causes complex changes in seagrass, microalgae, and macroalgae community structure in Florida Bay. Estuaries and Coasts, 28, 422-434.

Armitage, A.R. \& Fourqurean, J.W. (2006). The short-term influence of herbivory near patch reefs varies between seagrass species. Journal of Experimental Marine Biology and Ecology, 339, 65-74.

Barrón, C., Marba, N. \& Terrados, J. (2004). Community metabolism and carbon budget along a gradient of seagrass (Cymodocea nodosa) colonization. Limnology and Oceanography, 49, 1642-1651. 
Bell, S., Brooks, R.A., Robbins, B.D., Fonseca, M.S. \& Hall, M.O. (2001). Faunal response to fragmentation in seagrass habitats: implications for seagrass conservation. Biological Conservation, 100, 115-123.

Bell, S., Clements, L. \& Kurdziel, J. (1993). Production in natural and restored seagrasses: A case study of a macrobenthic polychaete. Ecological Applications, 3 , 610-621.

Bell, S., Hall, M., Soffian, S. \& Madley, K. (2002). Assessing the impact of boat propeller scars on fish and shrimp utilizing seagrass beds. Ecological Applications, 12, 206217.

Blum, L.K., Roberts, M.S., Garland, J.L. \& Mills, A.L. (2004). Distribution of microbial communities associated with the dominant high marsh plants and sediments of the United States East Coast. Microbial Ecology, 48, 375-88.

Bologna, P.A.X. \& Heck, K.L. (1999). Macrofaunal associations with seagrass epiphytes: Relative importance of trophic and structural characteristics. Journal of Experimental Marine Biology and Ecology, 242, 21-39.

Bucolo, P., Sullivan, M.J. \& Zimba, P.V. (2008). Effects of Nutrient Enrichment on Primary Production and Biomass of Sediment Microalgae in a Subtropical Seagrass Bed 1. Journal of Phycology, 44, 874-881.

Burdige, D. \& Zimmerman, R. (2002). Impact of sea grass density on carbonate dissolution in Bahamian sediments. Limnology and Oceanography, 47, 1751-1763.

Burnham, K. \& Anderson, D. (2002). Model selection and multimodel inference: a practical information-theoretic approach. 2nd edn. Springer, New York.

Caccia, V.G. \& Boyer, J.N. (2005). Spatial patterning of water quality in Biscayne Bay, Florida as a function of land use and water management. Marine Pollution Bulletin, 50, 1416-29.

Campbell, J.E. \& Fourqurean, J.W. (2009). Interspecific variation in the elemental and stable isotope content of seagrasses in South Florida. Marine Ecology Progress Series, 387, 109-123.

Canfield, D.E., Wollast, R., Mackenzie, F.T. \& Chou, L. (1993). Organic matter oxidation in marine sediments. In: Interactions of $C, N, P$, and $S$ Biogeochemical Cycles. (eds. Wollast, R., Chou, L. \& Mackenzie, F.T.). Springer, Berlin, pp. 333-363.

Capone, D. \& Taylor, B. (1980). Microbial nitrogen cycling in a seagrass community. In: Estuarine Perspectives (ed. Kennedy, V.). Academic Press, New York, pp. 153-162.

Di Carlo, G. \& Kenworthy, W.J. (2008). Evaluation of aboveground and belowground biomass recovery in physically disturbed seagrass beds. Oecologia, 158, 285-98. 
Cebrián, J. \& Duarte, C. (1994). The dependence of herbivory on growth rate in natural plant communities. Functional Ecology, 8, 518-525.

Cebrián, J. \& Duarte, C.M. (1998). Patterns in leaf herbivory on seagrasses. Aquatic Botany, 60, 67-82.

Cebrián, J. \& Latrigue, J. (2004). Patterns of herbivory and decomposition in aquatic and terrestrial ecosystems. Ecological Monographs, 74, 237-259.

Cebrián, J. \& Pedersen, M. (2000). Fate of production of the seagrass Cymodocea nodosa in different stages of meadow formation. Marine Ecology Progress Series, 204, 119-130.

Chau, J., Bagtzoglou, A. \& Willig, M. (2011). The Effect of Soil Texture on Richness and Diversity of Bacterial Communities. Environmental Forensics, 12, 333-341.

Clarke, K. \& Gorley, R. (2006). PRIMER v6. Primer v6. User manual/tutorial. Primer-E, Plymouth, UK, $192 \mathrm{pp}$.

Collie, J. \& Hall, S. (2000). A quantitative analysis of fishing impacts on shelfsea benthos. Journal of Animal Ecology, 69, 785-798.

Connell, E.L., Colmer, T.D. \& Walker, D.I. (1999). Radial oxygen loss from intact roots of Halophila ovalis as a function of distance behind the root tip and shoot illumination. Aquatic Botany, 63, 219-228.

Connell, J. (1978). Diversity in tropical rainforests and coral reefs. American Naturalist, 199, 1302-1310.

Connell, J.H. \& Slayter, R.O. (1977). Mechanisms of Succession in Natural Communities and Their Role in Community Stability and Organization. The American Naturalist, $111,1119-1144$.

Culman, S., Bukowski, R., Gauch, H., Caillo-Quiroz, H. \& Buckley, D. (2009). T-REX: software for the processing and analysis of T-RFLP data. BMC Bioinformatics, 10, $1-10$.

Danovaro, R. \& Fabiano, M. (1995). Seasonal and inter-annual variation of bacteria in a seagrass bed of the Mediterranean Sea: relationship with labile organic compounds and other environmental factors. Aquatic Microbial Ecology, 9, 17-26.

Dawes, C., Andorfer, J., Rose, C., Uranowski, C. \& Ehringer, N. (1997). Regrowth of the seagrass Thalassia testudinum into propeller scars. Aquatic Botany, 59, 139-155.

Dernie, K. (2003). Recovery rates of benthic communities following physical disturbance. Journal of Animal Ecology, 72, 1043-1056. 
Dobbs, F. \& Vozarik, J. (1983). Immediate effects of a storm on coastal infauna. Marine Ecology Progress Series, 11, 273-279.

Duarte, C. (1990). Seagrass nutrient content. Marine Ecology Progress Series, 67, $201-$ 207.

Duarte, C. \& Chiscano, C. (1999). Seagrass biomass and production: a reassessment. Aquatic Botany, 65, 159-174.

Duarte, C., Marbà, N., Gacia, E., Fourqurean, J.W., Beggins, J., Barrón, C., et al. (2010). Seagrass community metabolism: Assessing the carbon sink capacity of seagrass meadows. Global Biogeochemical Cycles, 24, GB4032.

Dunton, K. \& Schonberg, S. (2002). Assessment of propeller scarring in seagrass beds of the south Texas coast. Journal of Coastal Research, SI37, 100-110.

Durako, M. \& Moffler, M. (1984). Qualitative assessment of five artificial growth media on growth and survival of Thalassia testudinum (Hydrocharitaceae) seedlings. In: Proceedings of the Eleventh Annual Converence on Wetlands Restoration and Creation (ed. Webb, F.J.). Hillsborough Community College, Tampa FL, pp. 73-92.

Durako, M., Hall, M., Sargent, F. \& Peck, S. (1992). Propeller scars in seagrass beds: an assessment and experimental study of recolonization in Weedon Island State Preserve, Florida. In: Proceedings of the Nineteenth Annual Conference on Weltands Restoration and Creation. (ed. Webb Jr, F.). Tampa: Hillsborough Community College, pp. 42-53.

Durako, M.J. \& Moffler, M.D. (1985). Observations on the reproductive ecology of Thalassia testudinum (Hydrocharitaceae). III. Spatial and temporal variations in reproductive patterns within a seagrass bed. Aquatic Botany, 22, 265-276.

Engebretson, J.J. \& Moyer, C.L. (2003). Fidelity of Select Restriction Endonucleases in Determining Microbial Diversity by Terminal-Restriction Fragment Length Polymorphism. Applied and Environmental Microbiology, 69, 4823-4829.

Enríquez, S., Marbà, N., Duarte, C., Van Tussenbroek, B. \& Reyes-Zavala, G. (2001). Effects of seagrass Thalassia testudinum on sediment redox. Marine Ecology Progress Series, 219, 149-158.

Erftemeijer, P. \& Middelburg, J. (1993). Sediment-nutrient interactions in tropical seagrass beds: a comparison between a terrigenous and a carbonate sedimentary environment in South Sulawesi. Marine Ecology Progress Series, 102, 187-198.

Evans, N. \& Short, F. (2005). Functional Trajectory Models for Assessment of Transplanted Eelgrass, Zostera marina L., in the Great Bay Estuary, New Hampshire. Estuaries, 28, 936-947. 
Farrer, A. (2010). N-Control Seagrass Restoration Monitoring Report, Monitoring Events 2003-2008I Florida Keys National Marine Sanctuary, Monroe County, Florida.

Ferreira, C. \& Floeter, S. (2004). Trophic structure patterns of Brazilian reef fishes: a latitudinal comparison. Journal of Biogeography, 31, 1093-1106.

Fierer, N. \& Jackson, R. (2006). The diversity and biogeography of soil bacterial communities. Proceedings of the National Academy of Science USA, 103, 626-631.

Floeter, S. (2004). Latitudinal gradients in Atlantic reef fish communities: trophic structure and spatial use patterns. Journal of Fish Biology, 64, 1680-1699.

Folk, R. (1974). Petrology of Sedimentary Rocks. Co., 182p. Hemphill, Austin.

Fonseca, M. (2011). Addy Revisited: What Has Changed with Seagrass Restoration in 64 Years? Ecological Restoration, 29, 73-81.

Fonseca, M., Kenworthy, W. \& Courtney, F. (1996a). Development of planted seagrass beds in Tampa Bay, Florida, USA. I. Plant components. Marine Ecology Progress Series, 132, 127-139.

Fonseca, M., Kenworthy, W. \& Thayer, G.W. (1998). Guidelines for the conservation and restoration of seagrasses in the United States and adjacent waters. NOAA Coastal Ocean Program Decision Analysis Series No. 12. Silver Spring, MD. 222pp.

Fonseca, M., Kenworthy, W., Colby, D.R., Rittmaster, K. \& Thayer, G.W. (1990). Comparisons of fauna among natural and transplanted eelgrass Zostera marina meadows: criteria for mitigation. Marine Ecology Progress Series, 65, 251-264.

Fonseca, M., Meyer, D. \& Hall, M. (1996b). Development of planted seagrass beds in Tampa Bay, Florida, USA. II. Faunal components. Marine Ecology Progress Series, $132,141-156$.

Fonseca, M.S., Whitfield, P.E., Judson Kenworthy, W., Colby, D.R. \& Julius, B.E. (2004). Use of two spatially explicit models to determine the effect of injury geometry on natural resource recovery. Aquatic Conservation: Marine and Freshwater Ecosystems, 14, 281-298.

Fourqurean, J., Duarte, C., Kennedy, H., Marba, N., Holmer, M., Mateo, M.A., et al. (2012a). Seagrass ecosystems as a globally significant carbon stock. Nature Geoscience, 5, 505-509.

Fourqurean, J., Manuel, S., Coates, K., Kenworthy, W. \& Smith, S. (2010). Effects of excluding sea turtle herbivores from a seagrass bed: Overgrazing may have led to loss of seagrass meadows in Bermuda. Marine Ecology Progress Series, 419, 223232. 
Fourqurean, J.W., Kendrick, G. \& Chambers, R. (2012b). Carbon, nitrogen and phosphorus storage in subtropical seagrass meadows: examples from Florida Bay and Shark Bay. Marine and Freshwater Research, In Press.

Fourqurean, J.W., Powell, G.V.N., Kenworthy, W.J. \& Zieman, J.C. (1995). The effects of long-term manipulation of nutrient supply on competition between the seagrasses Thalassia testudinum and Halodule wrightii in Florida Bay. Oikos, 72, 349-358.

Fourqurean, J.W., Willsie, A., Rose, C.D. \& Rutten, L. (2001). Spatial and temporal pattern in seagrass community composition and productivity in south Florida. Marine Biology, 138, 341-354.

Fourqurean, J.W., Zieman, J.C. \& Powell, G. (1992a). Phosphorus limitation of primary production in Florida Bay: evidence from $\mathrm{C}$ : $\mathrm{N}$ : $\mathrm{P}$ ratios of the dominant seagrass Thalassia testudinum. Limnology and Oceanography, 37, 162-171.

Fourqurean, J.W., Zieman, J.C. \& Powell, G. (1992b). Relationships between porewater nutrients and seagrasses in a subtropical carbonate environment. Marine Biology, $114,57-65-65$.

Fraser, L.H. \& Madson, E.B. (2008). The interacting effects of herbivore exclosures and seed addition in a wet meadow. Oikos, 117, 1057-1063.

García-Martínez, M., López-López, A., Calleja, M.L., Marbà, N. \& Duarte, C.M. (2008). Bacterial Community Dynamics in a Seagrass (Posidonia oceanica) Meadow Sediment. Estuaries and Coasts, 32, 276-286.

Girvan, M.S., Bullimore, J., Pretty, J.N., Osborn, A.M. \& Ball, A.S. (2003). Soil Type Is the Primary Determinant of the Composition of the Total and Active Bacterial Communities in Arable Soils. Applied and Environmental Microbiology, 69, 18001809.

Goecker, M., Heck, K. \& Valentine, J. (2005). Effects of nitrogen concentrations in turtlegrass Thalassia testudinum on consumption by the bucktooth parrotfish Sparisoma radians. Marine Ecology Progress Series, 286, 239-248.

Granéli, E. \& Sundbäck, K. (1985). The response of planktonic and microbenthic algal assemblages to nutrient enrichment in shallow coastal waters, southwest Sweden. Journal of Experimental Marine Biology and Ecology, 85, 253-268.

Grech, A., Chartrand-Miller, K., Erftemeijer, P., Fonseca, M., McKenzie, L., Rasheed, M., et al. (2012). A comparison of threats, vulnerabilities and management approaches in global seagrass bioregions. Environmental Research Letters, 7, 024006.

Grime, J. (1973). Control of species density in herbaceous vegetation. Journal of Environmental Management, 1, 151-167. 
Gross, M. (1971). Carbon determination. . RE Carver. In: Procedures in sedimentary petrology (ed. Carver, R.). Wiley, New York, p. 653.

Hall, A.R., Miller, A.D., Leggett, H.C., Roxburgh, S.H., Buckling, A. \& Shea, K. (2012a). Diversity-disturbance relationships: frequency and intensity interact. Biology Letters, 8, 768-771.

Hall, E., Maixner, F., Franklin, O., Daims, H., Richter, A. \& Battin, T. (2011). Linking microbial and ecosystem ecology using ecological stoichiometry: a synthesis of conceptual and empirical approaches. Ecosystems, 14, 261-273.

Hall, M., Kenworthy, W. \& Merrello, M. (2012b). Experimental evaluation of techniques to restore severe boat damage in south Florida seagrass habitats. Final Report to Florida's State Wildlife Grant Program, Florida Fish and Wildlife Conservation Commission.

Hall, S. (1994). Physical disturbance and marine benthic communities: life in unconsolidated sediments. Oceanography and Marine Biology: an annual review, 32, 179-239.

Hammerstrom, K.K., Kenworthy, W.J., Whitfield, P.E. \& Merello, M.F. (2007). Response and recovery dynamics of seagrasses Thalassia testudinum and Syringodium filiforme and macroalgae in experimental motor vessel disturbances. Marine Ecology Progress Series, 345, 83-92.

Harris, J. (2003). Measurements of the soil microbial community for estimating the success of restoration. European Journal of Soil Science, 54, 801-808.

Hartman, W., Richardson, C., Vilgalys, R. \& Bruland, G. (2008). Environmental and anthropogenic controls over bacterial communities in wetland soils. Proceedings of the National Academy of Sciences USA, 105, 17842-17847.

Hay, M.E. (1981). Spatial patterns of grazing intensity on a Caribbean barrier reef: herbivory and algal distribution. Aquatic Botany, 11, 97-109.

Heck, K. \& Valentine, J. (2006). Plant-herbivore interactions in seagrass meadows. Journal of Experimental Marine Biology and Ecology, 330, 420-436.

Hemminga, M.A. \& Duarte, C.M. (2000). Seagrass Ecology. Water. Cambridge University Press, Cambridge.

Heneghan, L., Miller, S., Baer, S., Callaham Jr., M., Montgomery, J., Pavae-Zuckerman, M., et al. (2008). Integrating soil ecological knowledge into restoration management. Restoration Ecology, 16, 608-617.

Herbert, D. a. \& Fourqurean, J.W. (2008). Ecosystem Structure and Function Still Altered Two Decades After Short-Term Fertilization of a Seagrass Meadow. Ecosystems, 11, 688-700. 
Higgs, E. (1997). What is good ecological restoration? Conservation Biology, 11, 338348.

Hobbs, R. \& Norton, D. (1996). Towards a conceptual framework for restoration ecology. Restoration Ecology, 4, 93-110.

Holmer, M. \& Duarte, C.M. (2003). Sulfur cycling and seagrass (Posidonia oceanica) status in carbonate sediments. Biogeochemistry, 66, 223-239.

Holmer, M., Andersen, F., Nielsen, S. \& Boschker, H. (2001). The importance of mineralization based on sulfate reduction for nutrient regeneration in tropical seagrass sediments. Aquatic Botany, 71, 1-17.

Howarth, R. (1988). Nutrient limitation of net primary production in marine ecosystems. Annual Review of Ecology and Systematics, 19, 89-110.

Howe, H.F. \& Lane, D. (2004). Vole-Driven Succession in Experimental Wet-Prairie Restorations. Ecological Applications, 14, 1295-1305.

Ingram, R. (1971). Sieve analysis. In: Procedures in sedimentary petrology (ed. Carver, R.). Interscience, New York, pp. 69-94.

Isaksen, M. \& Finster, K. (1996). Sulphate reduction in the root zone of the seagrass Zostera noltii on the intertidal flats of a coastal lagoon (Arcachon, France). Marine Ecology Progress Series, 137, 187-194.

James, J.B., Sherman, T.D. \& Devereux, R. (2006). Analysis of bacterial communities in seagrass bed sediments by double-gradient denaturing gradient gel electrophoresis of PCR-amplified 16S rRNA genes. Microbial Ecology, 52, 655-61.

Jensen, H., McGlathery, K., Marino, R. \& Howarth, R. (1998). Forms and availability of sediment phosphorus in carbonate sand of Bermuda seagrass beds. Limnology and Oceanography, 43, 799-810.

Jensen, S.I., Kühl, M. \& Priemé, A. (2007). Different bacterial communities associated with the roots and bulk sediment of the seagrass Zostera marina. FEMS Microbiology Ecology, 62, 108-17.

Kaiser, M., Clarke, K. \& Hinz, H. (2006). Global analysis of response and recovery of benthic biota to fishing. Marine Ecology Progress Series, 311, 1-14.

Kenworthy, W. (1981). The interrelationship between seagrasses, Zostera marina and Halodule wrightii, and the physical and chemical properties of sediments in a midAtlantic coastal plain estuary near Beaufort, North Carolina (USA).

Kenworthy, W., Fonseca, M., Whitfield, P. \& Hammerstrom, K. (2000). A comparison of two methods for enhancing recovery of seagrasses into propeller scars: mechanical 
injection of a nutrient and growth hormone solution vs. defecation by roosting seabirds. Final report to the Florida Keys Restoration Trust Fund, Tavernier, FL.

Kenworthy, W., Fonseca, M., Whitfield, P. \& Hammerstrom, K. (2002). Analysis of seagrass recovery in experimental excavations and propeller-scar disturbances in the Florida Keys National Marine Sanctuary. Journal of Coastal Research, 37, 7585.

Kirsch, K., Barry, K. \& Fonseca, M. (2005). The Mini-312 Program-An Expedited Damage Assessment and Restoration Process for Seagrasses in the Florida Keys National Marine Sanctuary. Journal of Coastal Research.

Kirsch, K., Valentine, J. \& Heck, K. (2002). Parrotfish grazing on turtlegrass Thalassia testudinum: evidence for the importance of seagrass consumption in food web dynamics of the Florida Keys National Marine Sanctuary. Marine Ecology Progress Series, 227, 71-85.

Kopp, R. \& Smith, V. (1993). Valuing natural assets: the economics of natural resource damage assessment. Resources for the Future, Washington D.C.

Kristensen, E., Andersen, F.O., Holmboe, N., Holmer, M. \& Thongtham, N. (2000). Carbon and nitrogen mineralization in sediments of the Bangrong mangrove area, Phuket, Thailand. Aquatic Microbial Ecology, 22, 199-213.

Lal, A., Arthur, R., Marbà, N., Lill, A.W.T. \& Alcoverro, T. (2010). Implications of conserving an ecosystem modifier: Increasing green turtle (Chelonia mydas) densities substantially alters seagrass meadows. Biological Conservation, 143, 2730-2738.

Larson, F. \& Sundback, K. (2008). Role of microphytobenthos in recovery of functions in a shallow-water sediment system after hypoxic events. Marine Ecology Progress Series, 357, 1-16.

Legendre, P. \& Anderson, M. (1999). Distance-based redundancy analysis: testing multispecies responses in multifactorial ecological experiments. Ecological Monographs, 69, 1-24.

Leloup, J., Fossing, H., Kohls, K., Holmkvist, L., Borowski, C. \& Joergensen, B.B. (2009). Sulfate-reducing bacteria in marine sediment (Aarhus Bay, Denmark): abundance and diversity related to geochemical zonation. Environmental Microbiology, 11, 1278-1291.

Lewis, R. (1987). The Restoration and Creation of Seagrass Meadows in the Southeast United States. In: Proceedings of the Symposium on Subtropical-Tropical Seagrasses of the Southeastern United States. Florida Marine Research Publication. pp. 153-173. 
Liu, W., Marsh, T., Cheng, H. \& Forney, L. (1997). Characterization of microbial diversity by determining terminal restriction fragment length polymorphisms of genes encoding 16S rRNA. Applied and Environmental Microbiology, 78, 4516-4522.

Lohrer, A., Thrush, S. \& Gibbs, M. (2004). Bioturbators enhance ecosystem function through complex biogeochemical interactions. Nature, 431, 1092-1095.

Lopez, N.I., Duarte, C.M., Vallespinos, F., Romero, J. \& Alcoverro, T. (1998). The effect of nutrient additions on bacterial activity in seagrass (Posidonia oceanica) sediments. Journal of Experimental Marine Biology and Ecology, 224, 155-166.

Luczkovich, J. \& Stellwa. (1993). Isolation of cellulolytic microbes from the intestinal tract of the pinfish, Lagodon rhomboides: size-related changes in diet and microbial abundance. Marine Biology, 116, 381-388.

Maciá, S. \& Robinson, M.P. (2005). Effects of habitat heterogeneity in seagrass beds on grazing patterns of parrotfishes. Marine Ecology Progress Series, 303, 113-121.

Marba, N. \& Duarte, C.M. (1998). Rhizome elongation and seagrass clonal growth. Marine Ecology Progress Series, 174, 269-280.

Marba, N., Hemminga, M. \& Duarte, C. (2006a). Resource translocation within seagrass clones: allometric scaling to plant size and productivity. Oecologia, 150, 362-372.

Marba, N., Holmer, M., Gacia, E. \& Barron, C. (2006b). Seagrass Beds and Coastal Biogeochemistry. In: Seagrasses: biology, ecology, and conservation (eds. Larkum, A.W.D., Orth, R.J. \& Duarte, C.M.). Springer, pp. 135-157.

Marbà, N. \& Duarte, C. (2001). Growth and sediment space occupation by seagrass Cymodocea nodosa roots. Marine Ecology Progress Series, 224, 291-298.

Marquez, T., Price, R. \& Jolicoeur, J. (2008). Phosphorus content of the Biscayne Aquifer limestone. In: Florida Coastal Everglades LTER All Scientists Meeting. Coral Galbes, FL.

Mateo, M.A., Cebrian, J., Dunton, K., Mutchler, T., Larkum, A.W.D., Orth, R.J., et al. (2006). Carbon flux in seagrass ecosystems. In: Seagrasses Biology Ecology and Conservation (eds. Larkum, A.W.D., Orth, R.J. \& Duarte, C.M.). Springer, pp. 159192.

Mattson, W. (1980). Herbivory in relation to plant nitrogen content. Annual Review of Ecology and Systematics, 11, 119-161.

McArdle, B. \& Anderson, M. (2001). Fitting multivariate models to community data: a comment on distance-based redundancy analysis. Ecology, 82, 290-297.

McGlathery, K. (1995). Nutrient and grazing influences on a subtropical seagrass community. Marine Ecology Progress Series, 122, 239-252. 
McGlathery, K., Reynolds, L. \& Cole, L. (2012). Recovery trajectories during state change from bare sediment to eelgrass dominance. Marine Ecology Progress Series, 448, 209-221.

McLaughlin, P.A., Treat, S.-A.F., Thorhaug, A. \& Lemaitre, R. (1983). A Restored Seagrass (Thalassia) Bed and Its Animal Community. Environmental Conservation, 10, 247-254.

McMillan, C. \& Phillips, R. (1979). Differentiation in habitat response among populations of New World seagrass. Aquatic Botany, 7, 185-196.

McNeese, P., Kruer, C., Kenworthy, W., Schwartzschild, A., Wells, P. \& Hobbs, J. (2006). Topographic restoration of boat grounding damage at the Lignumvitae Submerged Land Management Area. In: Seagrass restoration: success, failure, and the cost of both. March 11, 2003. Sarasota, Florida. (eds. Treat, S. \& Lewis, R.). Velrico, FL.

Micheli, F., Bishop, M., Oeterson, C. \& Rivera, J. (2008). Alteration of seagrass species composition and function over two decades. Ecological Monographs, 78, 225-244.

Milbrandt, E.C., Greenawalt-Boswell, J. \& Sokoloff, P.D. (2008). Short-term indicators of seagrass transplant stress in response to sediment bacterial community disruption. Botanica Marina, 51, 103-111.

Milchunas, D., Sala, O. \& Lauenroth, W. (1988). A generalized model of the effects of grazing by large herbivores on grassland community structure. American Naturalist, 132, 87-106.

Miller, M. \& Dick, R. (1995). Dynamics of soil C and microbial biomass in whole soil and aggregates in two cropping systems. Applied Soil Ecology, 2, 253-361.

Moncreiff, C. \& Sullivan, M. (2001). Trophic importance of epiphytic algae in subtropical seagrass beds: evidence from multiple stable isotope analyses. Marine Ecology Progress Series, 215, 93-106.

Moncreiff, C.A., Sullivan, M. \& Daehnick, A.E. (1992). Primary production dynamics in seagrass beds of Mississippi Sound: the contributions of seagrass, epiphytic algae, sand microflora, and phytoplankton. Marine Ecology Progress Series, 87, 161-171.

Montserrat, F. \& Colen, C. (2008). Benthic community-mediated sediment dynamics. Marine Ecology Progress Series, 372, 43-59.

Montserrat, F., Van Colen, C., Degraer, S., Ysebaert, T. \& Herman, P. (2008). Benthic community-mediated sediment dynamics. Marine Ecology Progress Series, 372, 43-59.

Moriarty, D. \& Boon, P. (1985). Microbial biomass and productivity in seagrass beds. Geomicrobiology Journal, 4, 21-51. 
Murray, B., Pendleton, L., Jenkins, W. \& Sifleet, S. (2011). Green payments for blue carbon: economic incentives for protecting threatened coastal habitats. Nichols Institute Report 11-04. Nichols Institute for Environmental Policy Solutions ( No. 1104).

Nacke, H., Thürmer, A., Wollherr, A., Will, C., Hodac, L., Herold, N., et al. (2011). Pyrosequencing-based assessment of bacterial community structure along different management types in German forest and grassland soils. PLoS One, 6, e17000.

Neckles, H.A., Short, F.T., Barker, S. \& Kopp, B.S. (2005). Disturbance of eelgrass Zostera marina by commercial mussel Mytilus edulis harvesting in Maine: Dragging impacts and habitat recovery. Marine Ecology Progress Series, 285, 57-73.

Nocker, A., Burr, M. \& Camper, A.K. (2007). Genotypic microbial community profiling: a critical technical review. Microbial Ecology, 54, 276-89.

Norkko, A., Hewitt, J., Thrush, S. \& Funnell, G. (2001). Benthic-pelagic coupling and suspension-feeding bivalves: Linking site-specific sediment flux and biodeposition to benthic community structure. Limnology and Oceanography, 46, 2067-2072.

Orth, R., Carruthers, T. \& Dennison, W. (2006). A global crisis for seagrass ecosystems. BioScience, 56, 987-996.

Orth, R., Heck, K. \& Montfrans, J.V. (1984a). Faunal communities in seagrass beds: a review of the influence of plant structure and prey characteristics on predator-prey relationships. Estuaries and Coasts, 7, 339-350.

Orth, R.J., Heck, K.L. \& van Montfrans, J. (1984b). Faunal Communities in Seagrass Beds: A Review of the Influence of Plant Structure and Prey Characteristics on Predator: Prey Relationships. Estuaries, 7, 339-350.

Paine, R. (1971). A short-term experimental investigation of resource partitioning in a New Zealand rocky intertidal habitat. Ecology, 52, 1096-1106.

Paling, E., Fonseca, M., van Katwijk, M. \& van Keuling, M. (2009). Seagrass restoration. In: Coastal wetlands: an integrated ecosystem approach (eds. Perillo, G., Wolanski, E., Cahoon, D. \& Brinson, M.). Elsevier, Amsterdam, pp. 689-714.

Palmer, M., Ambrose, R. \& Poff, N. (1997). Ecological theory and community restoration ecology. Restoration Ecology, 5, 291-300.

Parker, J., Burkepile, D. \& Hay, M. (2006). Opposing effects of native and exotic herbivores on plant invasions. Science, 311, 1459-1461.

Patriquin, D. \& Knowles, R. (1972). Nitrogen fixation in the rhizosphere of marine angiosperms. Marine Biology, 16, 49-58. 
Pedersen, M., Duarte, C. \& Cebrián, J. (1997). Rate of changes in organic matter and nutrient stocks during seagrass Cymodocea nodosa colonization and stand development. Marine Ecology Progress Series, 159, 29-36.

Pedersen, O., Borum, J., Duarte, C. \& Fortes, M. (1998). Oxygen dynamics in the rhizosphere of Cymodocea rotundata. Marine Ecology Progress Series, 169, 283288.

Peterson, B., Stubler, A., Wall, C. \& Gobler, C. (2012). Nitrogen-rich groundwater intrusion affects productivity, but not herbivory, of the tropical seagrass Thalassia testudinum. Marine Ecology Progress Series, 15, 1-9.

Pollard, P. \& Kogure, K. (1993). The role of epiphytic and epibenthic algal productivity in a tropical seagrass, Syringodium isoetifolium (Aschers.) Dandy, community. Marine and Freshwater Research, 44, 141-154.

Posey, M. \& Lindberg, W. (1996). Influence of storm disturbance on an offshore benthic community. Bulletin of Marine Science, 59, 523-529.

Posey, M.H., Alphin, T.D., Cahoon, L.B., Lindquist, D.G., Mallin, M.A. \& Nevers, M.B. (2002). Top-down versus bottom-up limitation in benthic infaunal communities: Direct and indirect effects. Estuaries and Coasts, 25, 999-1014.

Powell, G.V.N., Kenworthy, W.J. \& Fourqurean, J.W. (1989). Experimental evidence for nutrient limitation of seagrass growth in a tropical estuary with restricted circulation. Bulletin of Marine Science, 44, 324-340.

Prado, P. \& Heck, K. (2011). Seagrass selection by omnivorous and herbivorous consumers: determining factors. Marine Ecology Progress Series, 429, 45-55.

Prado, P., Romero, J. \& Alcoverro, T. (2010). Nutrient status, plant availability and seasonal forcing mediate fish herbivory in temperate seagrass beds. Marine Ecology Progress Series, 409, 229-239.

Ramirez, K., Lauber, C. \& Knight, R. (2010). Consistent effects of nitrogen fertilization on soil bacterial communities in contrasting systems. Ecology, 91, 3463-3470.

Randall, J. (1965). Grazing effect on sea grasses by herbivorous reef fishes in the West Indies. Ecology, 43, 255-260.

Rasheed, M. (1999). Recovery of experimentally created gaps within a tropical Zostera capricorni (Aschers.) seagrass meadow, Queensland Australia. Journal of Experimental Marine Biology and Ecology, 235, 183-200.

Roessler, M. (1971). Environmental changes associated with a Florida power plant. Marine Pollution Bulletin, 2, 87-90. 
Rollon, R., De Ruyter Van Steveninck, E., Van Vierssen, W. \& Fortes, M. (1999). Contrasting recolonization strategies in multi-species seagrass meadows. Marine Pollution Bulletin, 37, 8-12.

Rose, C., Sharp, W., Kenworthy, W., Hunt, J., Lyons, W., Prager, E., et al. (1999). Overgrazing of a large seagrass bed by the sea urchin Lytechinus variegatus in Outer Florida Bay. Marine Ecology Progress Series, 190, 211-222.

Ruiz-Halpern, S., Macko, S. a. \& Fourqurean, J.W. (2008). The effects of manipulation of sedimentary iron and organic matter on sediment biogeochemistry and seagrasses in a subtropical carbonate environment. Biogeochemistry, 87, 113-126.

SER. (2004). The SER International Primer on Ecological Restoration. T.

SFNRC. (2008). Patterns of Propeller Scarred Seagrass in Florida Bay: Associations with Physical and Visitor Use Factors and Implications for Natural Resource Management.

Santos, S. \& Simon, J. (1980). Response of soft-bottom benthos to annual catastrophic disturbance in a south Florida estuary. Marine Ecology Progress Series, 3, 347-355.

Sargent, F., Leary, T., Crewz, D. \& Kruer, C. (1995). Scarring of Florida's seagrasses: assessment and management options. Florida Marine Research Institute Technical Report TR-1. Florida Department of Environmental Protection ( No. TR-1).

Savidge, W.B. \& Taghon, G.L. (1988). Passive and active components of colonization following two types of disturbance on intertidal sandflat. Journal of Experimental Marine Biology and Ecology, 115, 137-155.

Schaffner, L. (2010). and rates of recovery of macrobenthic communities in a polyhaline temperate estuary following sediment disturbance: effects of disturbance severity and potential. Estuaries and Coasts, 33, 1300-1313.

Schütte, U.M.E., Abdo, Z., Bent, S.J., Shyu, C., Williams, C.J., Pierson, J.D., et al. (2008). Advances in the use of terminal restriction fragment length polymorphism (T-RFLP) analysis of 16S rRNA genes to characterize microbial communities. Applied Microbiology and Biotechnology, 80, 365-80.

Sessitsch, A., Weilharter, A., Gerzabek, M.H., Kirchmann, H. \& Kandeler, E. (2001). Microbial population structures in soil particle size fractions of a long-term fertilizer field experiment. Applied and Environmental Microbiology, 67, 4215-4224.

Sheridan, P. (2004a). Recovery of floral and faunal communities after placement of dredged material on seagrasses in Laguna Madre, Texas. Estuarine, Coastal and Shelf Science, 59, 441-458.

Sheridan, P. (2004b). Comparison of restored and natural seagrass beds near Corpus Christi, Texas. Estuaries and Coasts, 27, 781-792. 
Sheridan, P., Henderson, C. \& McMahan, G. (2003). Fauna of natural seagrass and transplanted Halodule wrightii (shoalgrass) beds in Galveston Bay, Texas.

Restoration Ecology, 11, 139-154.

Short, F. (1987). Effects of sediment nutrients on seagrasses: literature review and mesocosm experiment. Aquatic Botany, 27, 41-57.

Short, F.T. \& Wyllie-Echeverria, S. (1996). Natural and human-induced disturbance of seagrasses. Environmental Conservation, 23, 17-27.

Skilleter, G., Cameron, B. \& Zharikov, Y. (2006). Effects of physical disturbance on infaunal and epifaunal assemblages in subtropical, intertidal seagrass beds. Marine Ecology Progress Series, 308, 61-78.

Smith, C., Danilowicz, B., Clear, A., Costello, F., Wilson, B. \& Meijer, W. (2005). T-Align, a web-based tool for comparison of multiple terminal restriction fragment length polymorphism profiles. FEMS Microbiology Ecology, 54, 375-380.

Spalding, M., Taylor, M., Martins, S., Green, E. \& Edwards, M. (2001). The global distribution and status of seagrass ecosystems. Discussion paper prepared for th eUNEP-WCMC Global Seagrass Workhsop.

Stoner, A. (1980). The role of seagrass biomass in the organization of benthic macrofaunal assemblages. Bulletin of Marine Science, 30, 537-551.

Stoner, A. \& Livingston, R. (1984). Ontogenetic patterns in diet and feeding morphology in sympatric sparid fishes from seagrass meadows. Copeia, 1, 174-187.

Strickland, J. \& Parsons, T. (1972). Determination of particulate carbon. A practical handbook of seawater analysis.

Summerson, H. \& Peterson, C. (1984). Role of predation in organizing benthic communities of a temperate-zone seagrass bed. Marine Ecology Progress Series, 15, 63-77.

Sørensen, K., Glazer, B., Hannides, A. \& Gaidos, E. (2007). Spatial structure of the microbial community in sandy carbonate sediment. Marine Ecology Progress Series, 346, 61-74.

Terrados, J. \& Duarte, C.M. (2000). Experimental evidence of reduced particle resuspension within a seagrass (Posidonia oceanica L. Journal of Experimental Marine Biology and Ecology, 243, 45-53.

Terrados, J., Duarte, C.M., Kamp-Nielsen, L., Agawin, N., Gacia, E., Lacap, D., et al. (1999). Are seagrass growth and survival constrained by the reducing conditions of the sediment? Aquatic Botany, 65, 175-197. 
Thorhaug, A. (1981). Biology and Management of Seagrass in the Caribbean. Ambio, 10, 295-298.

Tilman, D. (1985). The Resource-Ratio Hypothesis of Plant Succession. The American Naturalist, 125, 827 - 852.

Torsvik, V. \& Øvreås, L. (2002). Microbial diversity and function in soil: from genes to ecosystems. Current Opinion in Microbiology, 5, 240-245.

Treat, S. \& Lewis, R. (Eds.). (2006). Seagrass restoration: Success, failure, and the costs of both. March 11, 2003. Sarasota, Florida.

Tribble, G. (1981). Reef-basel herbivores and the distribution of two seagrasses (Syringodium filiforme and Thalassia testudinum) in the San Blas Islands (Western Caribbean). Marine Biology, 65, 277-281.

Tripathi, B., Kim, M., Singh, D., Lee-Cruz, L., Lai-Hoe, A., Ainuddin, A., et al. (2012). Tropical Soil Bacterial Communities in Malaysia: pH Dominates in the Equatorial Tropics Too. Microbial Ecology, 64, 474-484.

Uhrin, A. \& Holmquist, J. (2003). Effects of propeller scarring on macrofaunal use of the seagrass Thalassia testudinum. Marine Ecology Progress Series, 250, 61-70.

Uhrin, A., Kenworthy, W. \& Fonseca, M. (2011). Understanding uncertainty in seagrass injury recovery: an information-theoretic approach. Ecological Applications, 21, 1365-1379.

Valentine, J. \& Duffy, J.E. (2006). The central role of grazing in seagrass ecology. In: Seagrasses: Biology, ecology and conservation (eds. Larkum, A.W.D., Orth, R.J. \& Duarte, C.M.). Springer, pp. 463-501.

Valentine, J. \& Heck, K. (1999). Seagrass herbivory: evidence for the continued grazing of marine grasses. Marine Ecology Progress Series, 176, 291-302.

Vergés, A. \& Pérez, M. (2008). Compensation and resistance to herbivory in seagrasses: induced responses to simulated consumption by fish. Oecologia, 155, 751-760.

Virnstein, R., Mikkelsen, P., Cairns, K. \& Capone, M. (1983). Seagrass beds versus sand bottoms: the trophic importance of their associated benthic invertebrates. Florida Scientist., 46, 363-381.

Waycott, M., Duarte, C.M., Carruthers, T., Dennison, W., Olyarnik, S., Calladine, A., et al. (2009). Accelerating loss of seagrasses across the globe threatens coastal ecosystems. Proceedings of the National Academy of Sciences, 106, 12377-12381.

White, K.S., Westera, M.B. \& Kendrick, G.A. (2011). Spatial patterns in fish herbivory in a temperate Australian seagrass meadow. Estuarine, Coastal and Shelf Science, 93, 366-374. 
Whitfield, P.E., Kenworthy, W.J., Durako, M.J., Hammerstrom, K.K. \& Merello, M.F. (2004). Recruitment of Thalassia testudinum seedlings into physically disturbed seagrass beds. Marine Ecology Progress Series, 267, 121-131.

Whitfield, P.E., Kenworthy, W.J., Hammerstrom, K.K. \& Fonseca, M.S. (2002). The role of a hurricane in the expansion of disturbances initiated by motor vessels on seagrass banks. Journal of Coastal Research, 37SI, 86-99.

Whomersley, P. \& Huxham, M. (2010). Response of intertidal macrofauna to multiple disturbance types and intensities-An experimental approach. Marine Environmental Research, 69, 297-308.

Williams, S. (1988). Thalassia testudinum productivity and grazing by green turtles in a highly disturbed seagrass bed. Marine Biology, 98, 447-455.

Williams, S.L. (1990). Experimental Studies of Caribbean Seagrass Bed Development. Ecological Monographs, 60, 449-469.

Young, T.P., Petersen, D. a. \& Clary, J.J. (2005). The ecology of restoration: historical links, emerging issues and unexplored realms. Ecology Letters, 8, 662-673.

Zajac, R. \& Whitlatch, R. (1982). Responses of estuarine infauna to disturbance. I. Spatial and temporal variation of initial recolonization. Marine Ecology Progress Series, 10, 1-14.

Zajac, R., Whitlatch, R. \& Thrush, S. (1998). Recolonization and succession in softsediment infaunal communities: the spatial scale of controlling factors.

Hydrobiologia, 375-376, 227-240.

Zak, D., Blackwood, C. \& Waldrop, M. (2006). A molecular dawn for biogeochemistry. Trends in Ecology \& Evolution, 21, 288-295.

Zedler, J. \& Callaway, J. (1999). Tracking wetland restoration: do mitigation sites follow desired trajectories? Restoration Ecology, 7, 69-73.

Zhang, P., Zheng, J., Pan, G., Zhang, X., Li, L. \& Tippkotter, R. (2007). microbial community structure and function within particle size fractions of a paddy soil under different long-term fertilization treatments from the Tai Lake region, China. Colloids and Surfaces B: Biointerfaces, 58, 264-270.

Zieman, J. (1976). The ecological effects of physical damage from motor boats on turtle grass beds in southern Florida. Aquatic Botany, 2, 127-139.

Zieman, J. (1982). The ecology of the seagrasses of south Florida: a community profile. US Fish and Wildlife Service, Office of Biological Services, Washington, FWS/OBS82. 
VITA

\section{AMANDA SARAH BOURQUE}

BORN

Ellsworth, Maine

EDUCATION

1989-1993

B.A., Biology

Bates College

Lewiston, Maine

$1997-2001$

A.L.M., Biology

Harvard University

Cambridge, Massachusetts

2005-2012

Doctoral Candidate, Biological Sciences

Florida International University

Miami, Florida

EMPLOYMENT

2010-present

Supervisory Ecologist. Biscayne National Park. Homestead FL.

2003-2010

Biologist. Biscayne National Park. Homestead FL.

$2001-2003$

Research Scientist. Battelle Memorial Institute. Waltham MA, West Palm Beach FL.

2001

Project Scientist. Metcalf \& Eddy. Wakefield MA.

2000-2001

Research Associate. National Marine Fisheries Service. Miami FL.

$1999-2000$

Permit Specialist/Marine Biologist. Coastal Systems International, Inc. Coral Gables FL.

2006, 2007

Adjunct Faculty. Florida International University. Miami FL.

1996-1999

Administrative Assistant. Massachusetts Institute of Technology. Cambridge MA.

1997

Course Assistant. Harvard University. Cambridge MA.

1994-1996

Research Analyst. Cambridge Public Schools. Cambridge MA. 


\section{PRESENTATIONS AND PUBLICATIONS}

McGrath EM, Bourque AS, Gilliam D. 2012. Feasibility of rubble binding sponge propagation for use in reef restoration. Oral presentation at the $41^{\text {st }}$ Benthic Ecology Meeting, Norfolk, VA. March 2012.

Bourque AS, Fourqurean JW. 2011. Effects of Restoration on Ecosystem Structure in Tropical Seagrass Meadows. Oral presentation at the $21^{\text {st }}$ Biennial Conference of the Coastal and Estuarine Research Federation, Daytona Beach, FL. November 2011.

Lirman DL, Schopmeyer S, Manzello D, Gramer L, Precht W, Muller-Karger F, Banks K, Barnes B, Bartels E, Bourque A, Byrne J, Donahue S, Duquesnel J, Fisher L, Gilliam D, Hendee J, Johnson M, Maxwell K, McDevitt E, Monty J, Rueda D, Ruzicka R, Thanner S. 2011. Severe 2010 Cold-Water Event Caused Unprecedented Mortality to Corals of the Florida Reef Tract and Reversed Previous Survivorship Patterns. PLoS ONE 6(8): e23047.

Bourque AS, Tongue ML, Fourqurean JW. 2010. Herbivory in subtropical seagrass ecosystems and implications for seagrass restoration. Oral presentation at the $39^{\text {th }}$ Benthic Ecology Meeting, Wilmington, NC. March 2010.

Bourque AS. 2008. Natural Resource Damage Assessment and Restoration in the National Park Service: Coral Reef Vessel Grounding Case Studies in Biscayne National Park. Oral presentation at the International Coral Reef Symposium, Fort Lauderdale, FL. July 2008.

Miller MW, Bourque AS, Bohnsack J. 2002. Decline in Acroporid corals at Looe Key, FL, 1983-2000. Coral Reefs 21: 179-182.

Bourque AS. 2001. Biological and chemical analyses of Boston Harbor confined aquatic disposal (CAD) cells. A thesis in the field of Biology submitted for the degree of Master of Liberal Arts in Extension Studies, Harvard University, Cambridge, MA. 58 pages.

Bourque AS, Pederson J, Shine J. 2000. Biological and Chemical Analyses of Boston Harbor Confined Aquatic Disposal Cells. Poster presentation at the Conference on Dredged Material Management: Options and Environmental Considerations, Cambridge, MA. December 2000. 